NBER WORKING PAPER SERIES

\title{
QUANTIFYING INTERNATIONAL PRODUCTION SHARING AT THE BILATERAL AND SECTOR LEVELS
}

\author{
Zhi Wang \\ Shang-Jin Wei \\ Kunfu Zhu \\ Working Paper 19677 \\ http://www.nber.org/papers/w19677 \\ NATIONAL BUREAU OF ECONOMIC RESEARCH \\ 1050 Massachusetts Avenue \\ Cambridge, MA 02138
}

November 2013, Revised February 2018

The views in the paper are those of the authors and may not reflect the views of the USITC and its Commissioners, the National Bureau of Economic Research, or any other organization that the authors are affiliated with. We thank Peter Dixon for constructive discussions and Ellen Lan Lin and Nikhil Patel for editorial assistance.

NBER working papers are circulated for discussion and comment purposes. They have not been peer-reviewed or been subject to the review by the NBER Board of Directors that accompanies official NBER publications.

(C) 2013 by Zhi Wang, Shang-Jin Wei, and Kunfu Zhu. All rights reserved. Short sections of text, not to exceed two paragraphs, may be quoted without explicit permission provided that full credit, including $\odot$ notice, is given to the source. 
Quantifying International Production Sharing at the Bilateral and Sector Levels

Zhi Wang, Shang-Jin Wei, and Kunfu Zhu

NBER Working Paper No. 19677

November 2013, Revised February 2018

JEL No. F1,F15

\title{
ABSTRACT
}

This paper generalizes the gross exports accounting framework, initially proposed by Koopman, Wang, and Wei (2014) for a country's aggregate exports, to one at the sector, bilateral, and bilateral-sector levels. Such a generalization requires a conceptual distinction between value added exports by forward and backward industrial linkages, and a non-trivial way to allocate bilateral intermediate trade flows into their final destinations of absorption. We present the disaggregated decomposition results among 40 trading nations in 35 sectors from 1995 to 2011 based on the World Input-Output Database and show how they help us to better understand the patterns of cross-country production sharing.

\author{
Zhi Wang \\ Schar School of Policy and Government \\ George Mason Universty \\ 3351 Fairfax Drive, MS 3B1, \\ Alington, VA 22201 \\ zwang36@gmu.edu \\ Shang-Jin Wei \\ Graduate School of Business \\ Columbia University \\ Uris Hall 619 \\ 3022 Broadway \\ New York, NY 10027-6902 \\ and NBER \\ shangjin.wei@columbia.edu
}

\author{
Kunfu Zhu \\ University of International Business and Economics \\ Beijing 100029, CHINA \\ zhukunfu@163.com
}




\section{Introduction}

This paper aims to develop a disaggregated accounting framework that consistently decomposes gross trade at the sector, bilateral, or bilateral-sector level, into the sum of various value added and double counted components. For example, gross exports from a particular country-sector can be decomposed into the sum of value added contributions from its own sector, other sectors from the exporting country, sectors from all other countries, and double counted items.

A common approach in the existing literature is to decompose final demand or value-added (GDP) by industry using standard Leontief methods that extracts value added from gross outputs (exports). However, there is additional information about the structure of domestic value added and double counting in gross trade flows that cannot be captured by the standard Leontief decomposition. As we will show, these value added and double counted items each have different economic meanings and their relative importance represents different types of cross-country production sharing arrangements.

Estimating value added exports or domestic value added in a country's gross exports alone can be accomplished by directly applying the standard Leontief (1936) decomposition, which does not require decomposing international intermediate trade flows. However, uncovering the value added structure of gross trade at a disaggregated level requires finding a way to decompose intermediate trade into value added and double counted parts, which cannot be achieved by simply multiplying the Leontief inverse and final demand.

To solve the problem, we propose a method to decompose all bilateral intermediate trade flows into major final demand groups according to their final destination of absorption and express gross output in all stages of production as related countries' final demand. This key technical step enable us to decompose gross trade flows in any given year ex post into final products thus laid out the foundation to interpret gross trade in value-added terms in our accounting framework.

Koopman, Wang, and Wei (2014), KWW hereafter, have made a first effort in this direction by providing a unified framework to decompose a country's total gross exports into nine value added and double counted components. Conceptually, the nine components can be grouped into four buckets: (1) domestic value-added in exports that is absorbed abroad, similar to "value 
added exports" as defined by Johnson and Noguera (2012); (2) domestic value added that is initially exported but eventually returned home. While it is not part of a country's "value added exports," it is part of the exporting country's GDP; (3) foreign value added that is used in the production of a country's exports and eventually absorbed by other countries; and (4) what KWW call "pure double counted terms," arising from intermediate goods trade that cross borders multiple times. Other measures of international production sharing in the earlier literature such as VS (vertical specialization) and its variants, VS1 and VS1*, and the VAX ratio (the ratio of value added exports to gross exports) are shown to be some linear combinations of the terms in KWW's decomposition formula. While the method of KWW (2014) is valid only for a country's aggregate exports, our new framework is able to consistently decompose gross trade flows at any level of disaggregation into the above four buckets. It in fact allows one to further decompose each of the four buckets above into finer components representing different types of cross-country production sharing arrangements. For example, we can decompose exports of domestic value added by different demand channels and trade routes, further identifying whether they are embedded in final exports, intermediate exports that are absorbed in the direct importing countries, or intermediate exports that are re-exported and absorbed in home or third countries.

The main contribution of this paper is to provide such a consistent accounting framework for gross trade at either the sector, bilateral, or bilateral-sector level. It bridges the standard of System of National Account (SNA) and trade statistics, laid out the methodology foundation to interpret official trade data in value-added terms. In addition, it produces a series of decomposition results to illustrate how such a structural decomposition can help us to better understand the pattern of international production sharing and discover global value chains-related information masked by official trade data.

In order to do the decomposition at such a disaggregated level, we have to make an important distinction between backward and forward industrial linkages, which enables us to decompose gross intermediate trade flows based on their final destination of absorption at the bilateral-sector level. It turns out that separating value added by backward versus forward industrial linkages is a conceptual breakthrough that allows one to trace the structure of international production sharing at a disaggregated level. To the best of our knowledge, the literature has not previously made a clear distinction between them to separate various trade in value-added measures. While KWW (2014) made a distinction between domestic value added embedded in gross exports versus value 
added exports, they do so only at the country aggregate. More importantly, they do not distinguish backward versus forward industrial linkages - such a distinction is not important at the country aggregate level, but is crucial at a disaggregated level. In particular, value added via backward linkages is a crucial measure for many important indicators related to intermediate goods trade at the sector, bilateral, or bilateral-sector levels.

By applying our disaggregated decomposition framework to bilateral-sector gross trade flows in the World Input Output Database (WIOD) (Timmer et al. (2012)), we produce a sequence of large panel data sets that reveal the value added structure of 35 sectors' gross bilateral trade flows among 40 economies over 17 years ${ }^{1}$. While the paper does not directly investigate the causes or consequences of patterns of international production sharing, the disaggregated accounting framework that we developed and the panel data sets that are derived from the framework can be used by other researchers to enrich the set of possible future research on these topics.

Because the full decomposition results take up several gigabytes of space, we illustrate potential usefulness of the resulting data by a series of examples that utilize different subsets of the overall decomposition output. For example, we show how we may trace structural changes in a widely used measure of vertical specialization, initially proposed by Hummels, Ishii, and Yi (2001), to better understand global production sharing pattern changes over time. We distinguish two types of "trade in value added" measures and two types of domestic value added embedded in gross exports based on forward and backward industrial linkages at the country-sector or bilateral-sector levels and quantify their relationships. These represent significant new progress relative to KWW (2014). ${ }^{2}$

This paper is organized as follows: Section 2 presents our methodological framework and discusses the relationships among the various value-added trade measures at disaggregate levels as well as economic properties of various double counted components in gross trade flows. Section 3 reports selected empirical decomposition results based on the WIOD. Section 4

1 The country and industry classification of WIOD is listed in the online Appendix H.

2 The calculation of domestic value added that is ultimately absorbed abroad based on forward industrial linkages has been done at the bilateral and sector level. Indeed, some examples are given in KWW (2014). However, KWW did not separately compute the measures of trade in value added associated with gross trade flows. In addition, the computations of the other two components (foreign value-added and pure double counting) that could sum to $100 \%$ of gross trade flows are only done at the country aggregate level, not at the sector, bilateral, or bilateral-sector level in KWW. 
provides some concluding remarks.

\section{Concepts and Methodology}

\subsection{The Standard Leontief decomposition and its limitations}

All the decomposition methods in the recent vertical specialization and trade in value added literatures are rooted in Leontief (1936), who demonstrated that the amount and type of intermediate inputs needed in the production of one unit of output can be estimated based on input-output (IO) structures across countries and industries. Using the linkages across industries and countries, gross output in all stages of production that is needed to produce one unit of final product can be traced. When the gross output flows (labeled as "endogenous" in a standard IO model) associated with a particular level of final demand (labeled as "exogenous" in a standard IO model) are known, value added production and trade can be derived simply by multiplying these flows with the value added to gross output ratio in each country/industry.

To better understand how the standard Leontief decomposition works, let us assume a two-country (home and foreign) world, in which each country produces products in $\mathrm{N}$ differentiated tradable industries. Products in each sector can be consumed directly or used as intermediate inputs, and each country exports both intermediate and final goods and services.

All gross output produced by Country s must be used as either an intermediate or a final product at home or abroad, or

$$
X^{s}=A^{s s} X^{s}+Y^{s s}+A^{s r} X^{r}+Y^{s r} \quad r, s=1,2
$$

where $X^{s}$ is the $\mathrm{N} \times 1$ gross output vector of Country $s, Y^{s r}$ is the $\mathrm{N} \times 1$ final demand vector that gives demand in Country $\mathrm{r}$ for final products produced in $\mathrm{s}$, and $\mathrm{A}^{\mathrm{sr}}$ is the $\mathrm{N} \times \mathrm{N}$ IO coefficient matrix, giving intermediate use in $r$ of goods and services produced in s. The two-country production and trade system can be written as an ICIO model in block matrix notation

$$
\left[\begin{array}{l}
X^{s} \\
X^{r}
\end{array}\right]=\left[\begin{array}{ll}
A^{s s} & A^{s r} \\
A^{r s} & A^{r r}
\end{array}\right]\left[\begin{array}{l}
X^{s} \\
X^{r}
\end{array}\right]+\left[\begin{array}{l}
Y^{s s}+Y^{s r} \\
Y^{r s}+Y^{r r}
\end{array}\right]
$$

After rearranging terms, we have

$$
\left[\begin{array}{l}
X^{s} \\
X^{r}
\end{array}\right]=\left[\begin{array}{cc}
I-A^{s s} & -A^{s r} \\
-A^{r s} & I-A^{r r}
\end{array}\right]^{-1}\left[\begin{array}{c}
Y^{s s}+Y^{s r} \\
Y^{r s}+Y^{r r}
\end{array}\right]=\left[\begin{array}{ll}
B^{s s} & B^{s r} \\
B^{r s} & B^{r r}
\end{array}\right]\left[\begin{array}{l}
Y^{s} \\
Y^{r}
\end{array}\right]
$$

where $\mathrm{B}^{\text {sr }}$ denotes the $\mathrm{N} \times \mathrm{N}$ block matrix, commonly known as a Leontief inverse, which is the 
total requirement matrix that gives the amount of gross output required by Country $\mathrm{s}$ in producing a one-unit increase of final demand in Country r. $\mathrm{Y}^{\mathrm{s}}$ is an $\mathrm{N} \times 1$ vector that gives global use of Country s's final products, including domestic final sales $\mathrm{Y}^{\text {ss }}$ and exports of final products $Y^{\text {sr }}$. The relationship expressed in (3) reflects the standard Leontief insight. The intuition behind the expression is as follows: when $\$ 1$ of export is produced, a first round of value added is generated (denoted as V). This is the direct domestic value added induced by the $\$ 1$ export. To produce that export, intermediate inputs have to be used. The production of these intermediate inputs also generates value added. This is the second round or indirect domestic value added induced by the $\$ 1$ export. Such a process to generate indirect value added continues and can be traced to additional rounds of production throughout the economy, as intermediate inputs are used to produce other intermediate inputs. The total domestic value added induced by the $\$ 1$ export thus is equal to the sum of the direct and all rounds of indirect domestic value added generated from the $\$ 1$ of the export production process. Expressing this process mathematically using the terms defined above, we have

$$
\text { TV } \text { share }=V+V A+V A A+V A A A+\ldots=V\left(I+A+A^{2}+A^{3}+\ldots\right)=V(I-A)^{-1}=V B
$$

It can be shown that the power series of matrices is convergent and the inverse matrix exists as long as A is in full rank (Miller and Blair, 2009). It is easy to prove that each element of the final VB vector equals unity. ${ }^{3}$ The two-country total value added coefficient $(V B)$ matrix as named in the input-output literature can be written as:

$$
V B=\left[\begin{array}{ll}
V^{s} & V^{r}
\end{array}\left[\begin{array}{ll}
B^{s s} & B^{s r} \\
B^{r s} & B^{r r}
\end{array}\right]=\left[\begin{array}{ll}
V^{s} B^{s s}+V^{r} B^{r s} & V^{s} B^{s r}+V^{r} B^{r r}
\end{array}\right]\right.
$$

The decomposition of the country-sector level value added and final products production as a direct application of the standard Leontief decomposition can be expressed as follows:

$$
\hat{V} B \hat{Y}=\left[\begin{array}{cc}
\hat{V}^{s} & 0 \\
0 & \hat{V}^{r}
\end{array}\right]\left[\begin{array}{cc}
B^{s s} & B^{s r} \\
B^{r s} & B^{r r}
\end{array}\right]\left[\begin{array}{cc}
\hat{Y}^{s} & 0 \\
0 & \hat{Y}^{r}
\end{array}\right]=\left[\begin{array}{cc}
\hat{V}^{s} B^{s s} \hat{Y}^{s} & \hat{V}^{s} B^{s r} \hat{Y}^{r} \\
\hat{V}^{r} B^{r s} \hat{Y}^{s} & \hat{V}^{r} B^{r r} \hat{Y}^{r}
\end{array}\right]
$$

For $\mathrm{N}=2$, Equations (6) can be re-written by element as:

$3 \quad V B=V(I-A)^{-1}=(u-u A)(I-A)^{-1}=u(I-A)(I-A)^{-1}=u$ 


$$
\begin{aligned}
& \hat{V} B \hat{Y}=\left[\begin{array}{cccc}
v_{1}^{s} & 0 & 0 & 0 \\
0 & v_{2}^{s} & 0 & 0 \\
0 & 0 & v_{1}^{r} & 0 \\
0 & 0 & 0 & v_{2}^{r}
\end{array}\right]\left[\begin{array}{llll}
b_{11}^{s s} & b_{12}^{s s} & b_{11}^{s r} & b_{12}^{s r} \\
b_{21}^{s s} & b_{22}^{s s} & b_{21}^{s r} & b_{22}^{s r} \\
b_{11}^{r s} & b_{12}^{r s} & b_{11}^{r r} & b_{12}^{r r} \\
b_{21}^{r s} & b_{22}^{r s} & b_{21}^{r r} & b_{22}^{r r}
\end{array}\right]\left[\begin{array}{cccc}
y_{1}^{s} & 0 & 0 & 0 \\
0 & y_{2}^{s} & 0 & 0 \\
0 & 0 & y_{1}^{r r} & 0 \\
0 & 0 & 0 & y_{2}^{r}
\end{array}\right] \\
& =\left[\begin{array}{llll}
v_{1}^{s} b_{11}^{s s} y_{1}^{s s} & v_{1}^{s} b_{12}^{s s} y_{2}^{s} & v_{1}^{s} b_{11}^{s r} y_{1}^{r r} & v_{1}^{s} b_{12}^{s r} y_{2}^{r} \\
v_{2}^{s} b_{21}^{s s} y_{1}^{s} & v_{2}^{s} b_{22}^{s s} y_{2}^{s} & v_{2}^{s} b_{21}^{s r} y_{1}^{r r} & v_{2}^{s} b_{22}^{s r} y_{2}^{r} \\
v_{1}^{r} b_{11}^{r s} y_{1}^{s} & v_{1}^{r} b_{12}^{r s} y_{2}^{s} & v_{1}^{r} b_{11}^{r r} y_{1}^{r r} & v_{1}^{r} b_{12}^{r r} y_{2}^{r} \\
v_{2}^{r} b_{21}^{r s} y_{1}^{s} & v_{2}^{r} b_{22}^{r s} y_{2}^{s} & v_{2}^{r} b_{21}^{r r} y_{1}^{r} & v_{2}^{r} b_{22}^{r r} y_{2}^{r}
\end{array}\right]
\end{aligned}
$$

This matrix gives the estimates of sector and country sources of value added in each country's final goods production. Each element in the matrix represents the value added from a source sector of a source country directly or indirectly used in the production of final goods (absorbed in both the domestic and foreign markets) in the source country. Looking at the matrix along the row yields the distribution of value added created from one country-sector used across all countries-sectors. For example, the first element of the first row, $v_{1}^{s} b_{11}^{s s}\left(y_{1}^{s s}+y_{1}^{s r}\right)$ is value added from sector 1 of Country s to produce the final products of sector 1 for domestic sales and exports. The second element, $v_{1}^{s} b_{12}^{s s}\left(y_{2}^{s s}+y_{2}^{s r}\right)$, is value added of sector 1 in Country s from production of intermediates used as inputs to produce the final products of sector 2 . The third and fourth elements, $v_{1}^{s} b_{11}^{s r}\left(y_{1}^{r s}+y_{1}^{r r}\right)$ and $v_{1}^{s} b_{12}^{s r}\left(y_{2}^{r s}+y_{2}^{r r}\right)$, are value added of sector 1 in Country $\mathrm{s}$ from the production of intermediate inputs to produce final products in sectors 1 and 2 in Country $r$, respectively. Therefore, summing up the first row of the matrix, we obtain the total value added created by production factors employed in sector 1 of Country s. In other words, it equals GDP by industry of sector 1 in Country s. Expressing this mathematically,

$$
\begin{aligned}
& v a_{1}^{s} \text { or } G D P_{1}^{s}=v_{1}^{s} x_{1}^{s}=v_{1}^{s}\left(b_{11}^{s s} y_{1}^{s}+b_{12}^{s s} y_{2}^{s}+b_{11}^{s r} y_{1}^{r}+b_{12}^{s r} y_{2}^{r}\right) \\
& =\left[v_{1}^{s} b_{11}^{s s}\left(y_{1}^{s s}+y_{1}^{s r}\right)+v_{1}^{s} b_{12}^{s s}\left(y_{2}^{s s}+y_{2}^{s r}\right)\right]+\left[v_{1}^{s} b_{11}^{s r}\left(y_{1}^{r s}+y_{1}^{r r}\right)+v_{1}^{s s} b_{12}^{s r}\left(y_{2}^{r s}+y_{2}^{r r}\right)\right]
\end{aligned}
$$

Looking at the $\hat{V B} \hat{Y}$ matrix down a column yields the contributions of value added from all countries-sectors to the final goods produced by a particular country-sector. For example, the second element in the first column, $v_{2}^{s} b_{21}^{s s}\left(y_{1}^{s s}+y_{1}^{s r}\right)$, is value added created from sector 2 in Country $\mathrm{s}$ in its production of intermediate inputs used by sector 1 in Country $\mathrm{s}$ to produce its final products, and the third and fourth elements, $v_{1}^{r} b_{11}^{r s}\left(y_{1}^{s s}+y_{1}^{s r}\right)$ and $v_{2}^{r} b_{21}^{r s}\left(y_{1}^{s s}+y_{1}^{s r}\right)$ are value added from sectors 1 and 2 of (foreign) Country $r$ to produce intermediate inputs used by sector 1 
in Country s in the production of its final products, respectively. Adding up all elements in the first column equals the value of final products of sector 1 produced in Country s, i.e:

$$
\begin{aligned}
& v_{1}^{s} b_{11}^{s s}\left(y_{1}^{s s}+y_{1}^{s r}\right)+v_{2}^{s} b_{21}^{s s}\left(y_{1}^{s s}+y_{1}^{s r}\right)+v_{1}^{r} b_{11}^{r s}\left(y_{1}^{s s}+y_{1}^{s r}\right)+v_{2}^{r} b_{21}^{r s}\left(y_{1}^{s s}+y_{1}^{s r}\right) \\
& =\left(v_{1}^{s} b_{11}^{s s}+v_{2}^{s} b_{21}^{s s}+v_{1}^{r} b_{11}^{r s}+v_{2}^{r} b_{21}^{r s}\right) y_{1}^{s s}=y_{1}^{s}
\end{aligned}
$$

In summary, the sum of the $\hat{V} B \hat{Y}$ matrix along a row accounts for how each country's domestic value added originating in a particular sector is used by the sector itself and all its downstream countries-sectors. It traces forward industrial linkages across all downstream countries-industries from a producer's perspective. The sum of the $\hat{V} B \hat{Y}$ matrix down a column accounts for all upstream countries-sectors' value added contributions to a specific country-sector's final products; it traces backward industrial linkages across upstream countries/industries (as different stages of production) from a user's perspective. Based on the identity given by equation (5), all these sources should sum to $100 \%$ of the value of the final products for any given country-sector.

Therefore, the producer-side perspective (summing elements in a row) decomposes how each country's GDP by industry is used, directly and indirectly to satisfy domestic and foreign final demand, while the user-side perspective (summing elements in a column) decomposes a country-sector's final goods and services production into its original country-sector sources. As an example, in the electronics sector, the producer-side perspective includes the value added created by production factors employed at the electronics sector and incorporated into the final goods exports of electronics itself (direct domestic value added exports), as well as in the final goods exports of computers, consumer appliances, and automobiles (indirect domestic value added exports). In other words, it decomposes GDP (domestic value added) by industry according to where (i.e., which sector-country) it is used. Such a forward linkage perspective is consistent with the literature on factor content of trade. On the other hand, decomposition from a user's perspective includes all upstream country-sector's contributions to value added in a specific country-sector's final goods exports. In the electronics sector, it includes value added in the electronics sector itself as well as value added in inputs from all other upstream country-sectors (such as glass from country A, rubber from country B, and transportation and design from the home country) used to produce electronics for exports by the home country (direct/indirect domestic value added and foreign value added in final goods exports). Such a backward industrial linkage based perspective aligns well with case studies of supply chains of 
specific sectors and products, as the iPod or iPhone examples frequently cited in the literature.

These two different ways to decompose value added and final goods production each have their own economic interpretations and thus different roles in economic analysis. The GDP by industry decomposition can address questions such as "who is the final consumer of value-added generated from the Japanese electronics industry?" while the final products decomposition is able to answer questions such as "what is the difference in the value added source structure between a car exported from Germany and that from China?" While they are equivalent in the aggregate since global value added production equals global final demand, they are not equal to each other at the sector, or bilateral-sector level.

There are several attempts to estimate trade in value added and to decompose value added and final goods production based on the standard Leontief decomposition and ICIO database in recent years. Timmer et al. $(2013,2014)$ decompose manufacturing final goods production based on backward industrial linkages. For example, their method provides estimates on how much contribution an unskilled worker employed in the Chinese steel industry makes to cars produced in Germany, or how much contribution a skilled US worker in the electronics industry makes to a computer consumed by Chinese households.

Johnson and Noguera (2012) and Johnson (2014) estimate value added exports based on forward industrial linkages. However, they only measure sector value added absorbed by foreign countries, i.e., part of GDP by industry statistics that are driven by foreign final demand. Defining the VAX ratio by such a forward linkage method would yield a measure that is not well behaved at the sector or bilateral level, because domestic value added from other domestic sectors is not reflected in the forward linkage based calculations, but is quantitatively important for a typical country-sector. Indeed, the VAX ratio as defined this way could be infinite for sectors that do not directly export. We will suggest an alternative way to define such a summary index based on backward industrial linkages which is consistently bounded by zero and one at any level of disaggregation later in this paper.

In any case, if one is only interested in computing domestic value added embedded in a country-sector's gross exports that is ultimately absorbed abroad, applying the standard Leontief decomposition is sufficient. However, as pointed out in the introduction, to better understand different types of cross-country production sharing arrangements, one needs to quantify the structure of domestic value added and other components of gross exports at the sector, bilateral, 
and bilateral-sector levels. In such circumstances, the standard Leontief decomposition is not sufficient since it does not provide a way to decompose intermediate trade flows across countries into various value added terms according to their final absorption as it does to sector-level value added and final goods production illustrated by equation (7).

In Leontief's time from the 1930s to the1960s, intermediate goods trade is relatively unimportant. Today, it is more than half of world gross trade. Most of such trade is two-way trade in intermediate goods. For example, US exports parts of machineries to China which are used in the machineries to produce car parts for the US and Germany's auto industries. So being able to decompose intermediate goods trade has become crucial in generating a complete value added accounting of gross trade flows. KWW has made a useful step to perform such decomposition at the country aggregate level, but as we pointed out earlier, there is no need to keep track of forward and backward linkages across countries and industries separately at that level, which makes the job easier. However, one has to confront such technical challenges in decomposing gross trade flows at the sector, bilateral, or bilateral-sector level, which has to go beyond a simple application of the standard Leontief decomposition, as we will demonstrate in detail below.

\subsection{Decomposing intermediate and gross trade flows ${ }^{4}$}

The gross exports of Country s to Country r, $E^{s r}$, can be decomposed into two parts: final goods exports and intermediate goods exports based on the following accounting identity:

$$
E^{s r}=Y^{s r}+A^{s r} X^{r}
$$

As shown in the previous section, final goods exports can be easily decomposed into domestic and foreign value added by directly applying the standard Leontief decomposition. However, the decomposition of intermediate goods exports is more complex. It cannot be achieved by simply multiplying the Leontief inverse with gross intermediate exports (which leads to double counting) because the latter has to be solved from the ICIO models first for any given level of final demand. To overcome this problem, all intermediate goods trade needs to be

\footnotetext{
4 To help readers understand the derivation of our gross trade decomposition equation, we also extend the two-country, two-sector ICIO model specified in section 2.1 into a 3-country, 2-sector model as an example in Appendix A to show how a country's gross exports can be decomposed into the sum of components that include both the country's domestic value added in exports and various double-counted components at the bilateral-sector level.
} 
expressed as different countries' final demand according to where they are absorbed before they can be consistently decomposed. This is what we are going to do next.

Extending equation (3) to a G country setting, and inserting it into the last term of equation (10), we can decompose Country s's gross intermediate goods exports to Country $r$ according to where they are absorbed as:

$$
\begin{aligned}
& A^{s r} X^{r}=A^{s r} B^{r r} Y^{r r}+A^{s r} \sum_{t \neq s, r}^{G} B^{r t} Y^{t t}+A^{s r} B^{r r} \sum_{t \neq s, r}^{G} Y^{r t}+A^{s r} \sum_{t \neq s, r}^{G} B^{r t} \sum_{u \neq s, t}^{G} Y^{t u} \\
& +A^{s r} B^{r r} Y^{r s}+A^{s r} \sum_{t \neq s, r}^{G} B^{r t} Y^{t s}+A^{s r} B^{r s} Y^{s s}+A^{s r} B^{r s} \sum_{t \neq s}^{G} Y^{s t}
\end{aligned}
$$

These eight terms ${ }^{5}$ on the right side of equation (11) collectively decompose Country s's intermediate exports to Country $\mathrm{r}$ completely according to where they are finally absorbed. It will be used later to decompose the domestic originated value of a country's bilateral gross exports into different value added and double counted components.

From equation (2), the gross output production and use balance conditions, we know

$$
\begin{aligned}
& X^{r}=A^{r r} X^{r}+\sum_{t \neq r}^{G} A^{r t} X^{t}+Y^{r r}+\sum_{t \neq r}^{G} Y^{r t} \\
& =A^{r r} X^{r}+Y^{r r}+\sum_{t \neq r}^{G} E^{r t}=A^{r r} X^{r}+Y^{r r}+E^{r^{*}}
\end{aligned}
$$

Re-arranging terms:

$$
X^{r}=\left(I-A^{r r}\right)^{-1} Y^{r r}+\left(I-A^{r r}\right)^{-1} E^{r^{*}}=L^{r r} Y^{r r}+L^{r r} E^{r^{*}}
$$

where $L^{r r}=\left(I-A^{r r}\right)^{-1}$ is the local Leontief inverse.

Inserting equation (13) into the last term of equation (10), Country s's intermediate goods exports to Country $\mathrm{r}$ can also be decomposed into the following two components according to where it is used (domestic sales and exports), similar to a single country IO model:

$$
A^{s r} X^{r}=A^{s r} L^{r r} Y^{r r}+A^{s r} L^{r r} E^{r^{*}}
$$

It will be used later to decompose the foreign originated value of a country's bilateral gross exports into different value added and double counted components. ${ }^{6}$

Equations (11) and (14), each completely decomposing Country s's intermediate exports to Country $\mathrm{r}$ according to where they are finally absorbed, are the key technical steps to fully

A detailed interpretation of each term in equation (11) is in Appendix B.

6 By doing so, we significantly simplify our core decomposition equation (18). 
decomposing gross bilateral trade flows, since they convert gross output (and gross exports), usually endogenous variables in standard ICIO models, to exogenous variables in the gross trade accounting framework we developed in this paper. Together with the adding-up condition for the global value added multiplier defined in equation (5) and the local value added multipliers defined below, they are the major stepping stones for deriving our gross exports decomposition formula.

Extending equation (5) to a G country setting, we can obtain Country s's domestic and foreign value added (represented by partner Country $r$ and third Country $t$ ) multipliers as follows:

$$
V^{s} B^{s s}+V^{r} B^{r s}+\sum_{t \neq s, r}^{G} V^{t} B^{t s}=u
$$

Defining "\#” as an element-wise matrix multiplication operation, ${ }^{7}$ Country s's final goods exports to Country $\mathrm{r}$ can be easily decomposed into domestic and foreign value added at the sector level by applying the standard Leontief decomposition directly:

$$
Y^{s r}=\left(V^{s} B^{s s}\right)^{T} \# Y^{s r}+\left(V^{r} B^{r s}\right)^{T} \# Y^{s r}+\left(\sum_{i \neq s, r}^{G} V^{t} B^{t s}\right)^{T} \# Y^{s r}
$$

Similarly, the value of Country s's gross intermediate exports to Country $r$ at sector the level can be expressed as

$$
\begin{aligned}
& A^{s r} X^{r}=\left(V^{s} B^{s s}\right)^{T} \#\left(A^{s r} X^{r}\right)+\left(V^{r} B^{r s}\right)^{T} \#\left(A^{s r} X^{r}\right)+\left(\sum_{t \neq s, r}^{G} V^{t} B^{t s}\right)^{T} \#\left(A^{s r} X^{r}\right) \\
& =\left(V^{s} L^{s s}\right)^{T} \#\left(A^{s r} X^{r}\right)+\left(V^{s} B^{s s}-V^{s} L^{s s}\right)^{T} \#\left(A^{s r} X^{r}\right) \\
& +\left(V^{r} B^{r s}\right)^{T} \#\left(A^{s r} X^{r}\right)+\left(\sum_{t \neq s, r}^{G} V^{t} B^{t s}\right)^{T} \#\left(A^{s r} X^{r}\right)
\end{aligned}
$$

where $V^{s} L^{s s}$ is the domestic value added multiplier similar to a single country IO model.

Inserting equation (11) into the first term of equation (17) and equation (14) into the last two terms of equation (17) respectively, then combining equations (16) and (17), we obtain the decomposition equation of Country s's gross exports to Country $r$ as follows ${ }^{8}$ :

\footnotetext{
7 For example, when a matrix is multiplied by an $n \times 1$ column vector, each row of the matrix is multiplied by the corresponding row element of the vector.

${ }^{8}$ Using equations (10)-(12), one can further decompose $A^{s r} X^{r}$ in DDC (category 5) and $E^{r *}$ in FDC (category 8) according to final demand, i.e., where they are finally absorbed. We chose to express these two double counting terms in the current format and use equation (14) to decompose the foreign originated value in order to simplify our final decomposition formula. The further decomposition of DDC and FDC according to their final absorption is reported in Appendix C (equation C8 and C9).
} 


$$
\begin{aligned}
& E^{s r}=\underbrace{\left(V^{s} B^{s s}\right)^{T} \# Y^{s r}}_{(1)-D V A_{-} F I N}+\underbrace{\left(V^{s} L^{s s}\right)^{T} \#\left(A^{s r} B^{r r} Y^{r r}\right)}_{(2)-D V A_{-} I N T} \\
& +\underbrace{\left(V^{s} L^{s s}\right)^{T} \#\left[A^{s r} \sum_{t \neq s, r}^{G} B^{r t} Y^{t t}+A^{s r} B^{r r} \sum_{t \neq s, r}^{G} Y^{r t}+A^{s r} \sum_{t \neq s, r}^{G} B^{r t} \sum_{u \neq s, t}^{G} Y^{t u}\right]}_{(3)-D V A_{-} I N T r e x} \\
& +\underbrace{\left(V^{s} L^{s s}\right)^{T} \#\left[A^{s r} B^{r r} Y^{r s}+A^{s r} \sum_{t \neq s, r}^{G} B^{r t} Y^{t s}+A^{s r} B^{r s} Y^{s s}\right]}_{(4)-R D V_{-} G} \\
& +\underbrace{\left[\left(V^{s} L^{s s}\right)^{T} \#\left(A^{s r} B^{r s} \sum_{t \neq s}^{G} Y^{s t}\right)+\left(V^{s} L^{s s} \sum_{t \neq s}^{G} A^{s t} B^{t s}\right)^{T} \#\left(A^{s r} X^{r}\right)\right]}_{(5)-D D C} \\
& +\underbrace{\left[\left(V^{r} B^{r s}\right)^{T} \# Y^{s r}+\left(\sum_{t \neq s, r}^{G} V^{t} B^{t s}\right)^{T} \# Y^{s r}\right]}_{(6)-F V A_{-} F I N} \\
& +\underbrace{\left[\left(V^{r} B^{r s}\right)^{T} \#\left(A^{s r} L^{r r} Y^{r r}\right)+\left(\sum_{t \neq s, r}^{G} V^{t} B^{t s}\right)^{T} \#\left(A^{s r} L^{r r} Y^{r r}\right)\right]}_{(7)-F V A \text { INT }} \\
& +\underbrace{\left[\left(V^{r} B^{r s}\right)^{T} \#\left(A^{s r} L^{r r} E^{r^{*}}\right)+\left(\sum_{t \neq s, r}^{G} V^{t} B^{t s}\right)^{T} \#\left(A^{s r} L^{r r} E^{r^{*}}\right)\right]}_{(8)-F D C}
\end{aligned}
$$

where $V^{s} L^{s s} \sum_{t \neq s}^{G} A^{s t} B^{t s}=V^{s} B^{s s}-V^{s} L^{s s}$. Equation (18) indicates that the gross exports from Country s to Country $\mathrm{r}$ at sector levels can be completely decomposed into the sum of 16 detailed terms in 8 major categories. To better understand each category in this accounting equation, we provide the following economic interpretations:

The $1^{\text {st }}$ category, $\left(V^{s} B^{s s}\right)^{T} \# Y^{s r}$, is domestic value added (DVA for short) embodied in final goods exports. We label it as DVA_FIN for short.

The $2^{\text {nd }}$ category, $\left(V^{s} L^{s s}\right)^{T} \#\left(A^{s r} B^{r r} Y^{r r}\right)$, is DVA in intermediate exports used by direct importer (r) to produce local final goods consumed in $\mathrm{r}$. We label it as DVA_INT for short. ${ }^{9}$

\footnotetext{
9 Note that the first and second terms in equation (18) include both domestic value-added directly and indirectly absorbed by the importing country. Domestic value added of the exporting country that is directly absorbed by the partner country can be measured as $\left(V^{s} L^{s s}\right)^{T} \# Y^{s r}$ (final goods), which is a portion of the $1^{\text {st }}$ term, and $\left(V^{s} L^{s s}\right)^{T} \#\left(A^{s r} L^{r r} Y^{r r}\right)$ (intermediate goods), which is a portion of the $2^{\text {nd }}$ term. These two portions are called "Ricardian Trade" by Borin and Mancini (2015), which do not involve any additional production activity in third countries. The domestic value-added in exports indirectly absorbed by the partner country is measured by $\left[V^{s}\left(B^{s s}-L^{s s}\right)\right]^{T} \# Y^{s r}$ and $\left(V^{s} L^{s s}\right)^{T} \#\left(A^{s r}\left(B^{r r}-L^{r r}\right) Y^{r r}\right)$ respectively, which involve production activities in third countries before the value-added in exports is finally absorbed in the partner country. In Appendix D, we provide an alternative decomposition formula that accounts for traditional or direct and GVC trade separately. Equation (18) shows clearly which part in gross bilateral trade flow can be decomposed by applying the standard Leontief decomposition directly (final goods trade), which part cannot (intermediate goods trade), while the alternative equation we provide in Appendix D shows clearly which part of domestic value-added of the exporting
} 
The $3^{\text {rd }}$ category is DVA in intermediate exports used by the direct importer (r) to produce exports ultimately consumed by other countries except s. We name them as DVA_INTrex for short. It includes three detailed terms: $\left(V^{s} L^{s s}\right)^{T} \#\left(A^{s r} \sum_{t \neq s, r}^{G} B^{r t} Y^{t t}\right)$ is DVA in intermediate exports that are used by Country $r$ to produce intermediates that it re-exports to third Country $t$ for production of local final goods; $\left(V^{s} L^{s s}\right)^{T} \#\left(A^{s r} B^{r r} \sum_{t \neq s, r}^{G} Y^{r t}\right)$, is DVA in intermediate exports used by Country $r$ to produce final goods that it re-exports to third Country t; $\left(V^{s} L^{s s}\right)^{T} \#\left(A^{s r} \sum_{t \neq s, r}^{G} B^{r t} \sum_{u \neq s, t}^{G} Y^{t u}\right)$ is DVA in intermediate exports used by Country $\mathrm{r}$ to produce intermediates that it re-exports to third Country $t$ for production of final goods exports that are shipped to other countries (including the direct importer, Country r) except Country s.

The first three categories are all DVA embodied in Country s's gross exports to Country $r$ and ultimately absorbed abroad, which are value-added exports (labeled as VAX by Johnson and Noguera (2012)) associated with gross export flows based on backward industrial linkages. We name them collectively as VAX_G for short.

The $4^{\text {th }}$ category is DVA in intermediate exports that are returned to Country s and consumed at home. We name them as RDV_G for short. It also includes three detailed terms: $\left(V^{s} L^{s s}\right)^{T} \#\left(A^{s r} B^{r r} Y^{r s}\right)$ is DVA that returns home via its final imports from the direct importer (r); $\left(V^{s} L^{s s}\right)^{T} \#\left(A^{s r} \sum_{t \neq s, r}^{G} B^{r t} Y^{t s}\right)$ is DVA that returns home via final imports from third countries; and $\left(V^{s} L^{s s}\right)^{T} \#\left(A^{s r} B^{r s} Y^{s s}\right)$ is DVA that returns home via its intermediate imports and used to produce domestic final products. Summing across all sectors and trading partners, the first two terms equal the $4^{\text {th }}$ term, and the last term equals the $5^{\text {th }}$ term in equation (36) of KWW. ${ }^{10}$

The first four categories are DVA embodied in Country s's sector level gross exports to

country is absorbed by its partner country directly and indirectly, and which part of domestic value-added of the exporting country is absorbed in third countries. Both decompositions are useful depending on one's particular analytical needs.

10 Equation (36) of KWW:

$u E^{s^{*}}=V^{s} B^{s s} \sum_{r \neq s}^{G} Y^{s r}+V^{s} \sum_{r \neq s}^{G} B^{s r} Y^{r r}+V^{s} \sum_{r \neq s}^{G} B^{s r} \sum_{t \neq s, r}^{G} Y^{r t}+V^{s} \sum_{r \neq s}^{G} B^{s r} Y^{r s}+V^{s} \sum_{r \neq s}^{G} B^{s r} A^{r s} L^{s s} Y^{s s}+V^{s} \sum_{r \neq s}^{G} B^{s r} A^{r s} L^{s s} E^{s^{*}}$

$+\sum_{i \neq s}^{G} V^{t} B^{t s} \sum_{r \neq s}^{G} Y^{s r}+\sum_{t \neq s}^{G} V^{t} B^{t s} \sum_{r \neq s}^{G} A^{s r} L^{r r} Y^{r r}+\sum_{l \neq s}^{G} V^{t} B^{t s} \sum_{r \neq s}^{G} A^{s r} L^{r r} E^{r *}$ 
Country $\mathrm{r}$, which include value added created from all sectors in Country s. We name their sum as DVA_G for short. At the country aggregate, it reduces to equation (37) of KWW. ${ }^{11}$ As we will show by selected decomposition examples based on WIOD in the next section, these DVA terms represent different types of cross country production sharing arrangements and can be used to gauge the role and position of a country in various global value chains.

The $5^{\text {th }}$ category has two terms. The first term, $\left(V^{s} L^{s s}\right)^{T} \#\left(A^{s r} B^{r s} \sum_{t \neq s}^{G} Y^{s t}\right)$, is DVA embodied in its intermediate exports to Country $\mathrm{r}$ but return home as its intermediate imports, and used for production of its final exports, which are parts of DVA in Country s's final exports and are already counted once in the first category of equation (18). For this reason, they are a portion of domestic double counted terms caused by the back and forth intermediate goods trade in order to produce exports of final products in Country s. The second term, $\left(V^{s} L^{s s} \sum_{t \neq s}^{G} A^{s t} B^{t s}\right)^{T} \#\left(A^{s r} X^{r}\right)$, is DVA in intermediate exports to Country $r$ that returns home as intermediate imports and used for production of its intermediate exports. It is also a domestic double counted portion caused by the back and forth intermediate trade to produce intermediate exports in Country s (repeat counting of Country s's intermediate goods exports). ${ }^{12}$ We name them as DDC for short. Summing these two terms across all sectors and country pairs equals the $6^{\text {th }}$ term in equation (36) of KWW.

The $6^{\text {th }}$ category includes two terms: the first term $\left(V^{r} B^{r s}\right)^{T} \# Y^{s r}$, is foreign value added (FVA) from the importer (r) embodied in final exports; the second term, $\left(\sum_{t \neq s, r}^{G} V^{t} B^{t s}\right)^{T} \# Y^{s r}$, is FVA from other Countries (t) embodied in final exports. We label them as FVA_FIN for short. Summing them across all sectors and country pairs equals the $7^{\text {th }}$ term in equation (36) of KWW.

Adding up the $1^{\text {st }}$ (DVA from source Country s), and the $6^{\text {th }}$ (FVA from Country $r$ and Country t) categories accounts for $100 \%$ of the value of the sector level final exports from Country s to Country r.

The $7^{\text {th }}$ category also includes two terms: the first term $\left(V^{r} B^{r s}\right)^{T} \#\left(A^{s r} L^{r r} Y^{r r}\right)$, is FVA from

\footnotetext{
11 Equation (37) of KWW:

$D V^{s}=V^{s}\left(I-A^{s s}\right)^{-1} E^{s^{*}}=V T^{s^{*}}+V^{s} \sum_{r \neq s}^{G} B^{s r} Y^{r s}+V^{s} \sum_{r \neq s}^{G} B^{s r} A^{r s}\left(I-A^{s s}\right)^{-1} Y^{s s} \geq V T^{s^{*}}=V^{s} B^{s s} \sum_{r \neq s}^{G} Y^{s r}+V^{s} \sum_{r \neq s}^{G} B^{s r} Y^{r r}+V^{s} \sum_{r \neq s}^{G} B^{s r} \sum_{i \neq s, r}^{G} Y^{r t}$

$12\left(V^{s} B^{s s}-V^{s} L^{s s}\right)^{T} \#\left(A^{s r} X^{r}\right)=\left(V^{s} L^{s s} \sum_{t \neq s}^{G} A^{s t} B^{t s}\right) \#\left(A^{s r} X^{r}\right)$.
} 
the importer ( $\mathrm{r}$ ) embodied in intermediate exports, which are then used by $\mathrm{r}$ to produce its domestic final goods. The second term, $\left(\sum_{t \neq s, r}^{G} V^{t} B^{t s}\right)^{T} \#\left(A^{s r} L^{r r} Y^{r r}\right)$, is FVA from third Country $\mathrm{t}$ embodied in intermediate exports, which are then used by Country $r$ to produce its local final goods. We name them as FVA_INT for short. Summing them across all sectors and country pairs equals the $8^{\text {th }}$ term in equation (36) of $\mathrm{KWW} .^{13}$

Summing the $6^{\text {th }}$ and $7^{\text {th }}$ categories yield the total foreign value added embodied in Country s's sector level gross exports to Country r. We name them as FVA for short.

The last category is double counted terms in Country s's gross exports originating from foreign countries. Similar to categories 6 and 7, it also includes two terms: the first term, $\left(V^{r} B^{r s}\right)^{T} \#\left(A^{s r} L^{r r} E^{r^{*}}\right)$, is FVA from the importer (r) embodied in intermediate exports to produce its exports, which is a pure double counted term of r's value added in s's exports. The second term, $\left(\sum_{t \neq s, r}^{G} V^{t} B^{t s}\right)^{T} \#\left(A^{s r} L^{r r} E^{r^{*}}\right)$, is FVA from third Country t embodied in intermediate exports to produce its exports to the world. We label them as FDC for short.

The $5^{\text {th }}$ and last categories are both pure double counted terms in Country s's gross exports but originating from home country and foreign countries respectively. We name their sum as PDC for short.

The sum of the last four categories can be seen as an extension of the vertical specialization (VS) measure proposed by Hummels, Ishii, and Yi (2001) in a multi-country setting with more than one country engaging in intermediate goods trade. ${ }^{14}$ As we will show by examples in the next section, these different components within the total VS also represent different types of cross-country production sharing arrangements and are useful to study the upstream value-added structures of a country's gross exports in various global value chains.

13 The $6^{\text {th }}$ and $7^{\text {th }}$ categories can be grouped differently in decomposing bilateral gross trade flows. Summing up the first terms of these two categories yields total value added from the direct importer (Country r) used in the production of gross exports of Country s. We can label them as MVA for short. Summing up the second terms of these two categories yields total value added from other countries ( $\mathrm{t}$ ) used in the production of gross exports of Country s. We can label them as OVA for short.

14 KWW (2014) split the PDC terms into domestic and foreign content based on the origins of the double counted terms, and allocate a portion of the PDC to the VS measure. In this paper, we allocate the entire PDC term (DDC and FDC) to the VS measure so as to keep the notion of "domestic value added embedded in gross exports" as a "net" concept, and is then consistent with the one country model that the original Hummels, Ishii, and Yi (2001) measure is based on. It avoids additional layer in the decomposition and intuitively appealing. Note that the VS measure is not a "net" concept and always contains double counted terms no matter how the PDC term is allocated. Both ways to allocate the DDC term seems reasonable, which one to use is subject to what the issue to be investigated. 
The 16 detailed terms in the 8 categories discussed above completely decompose bilateral gross exports from Country s to Country $\mathrm{r}$ into different value added and double counted components, and their sum equals $100 \%$ of bilateral trade flows at the sector level. The disaggregated accounting framework made by equation (18) is also diagrammed in Figure 1.

\section{Figure 1 Gross trade accounting: Conceptual framework}

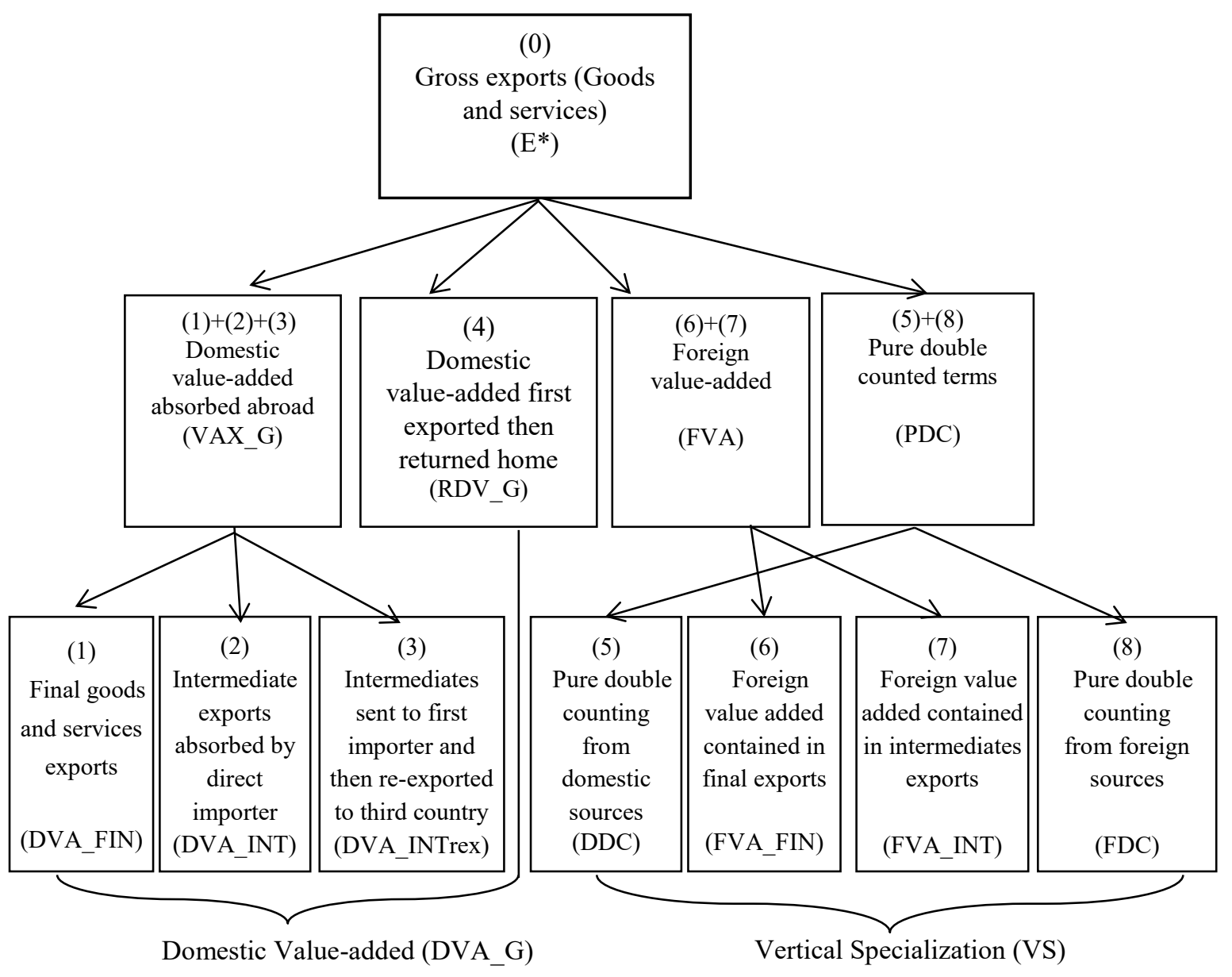

Note: $E^{*}$ can be at country-sector, country aggregate, bilateral-sector, or bilateral aggregate levels; both VAX_G and RDV_G are based on backward industrial linkages.

Summing up equation (18) across the $\mathrm{G}-1$ trading partners and $\mathrm{N}$ sectors, we obtain a decomposition equation for total gross exports of Country s, which can be verified to be identical to equation (36) in KWW (2014). Detailed proof is given in Appendix E. This formally shows that our formula generalizes the one in KWW from country aggregate to country-sector and bilateral-sector level.

Summing up equation (18) to all s and $r$, the direct importer's value added in exports (sum of the first term in categories (6) and (7), we label it as MVA for short) equals to RDV_G, and the 
third countries' value added in exports (sum of the second term in categories (6) and (7), we label it as OVA for short) equals to DVA_INTrex in world total exports. This indicates that FVA exactly double counts RDV_G and DVA_INTrex in measuring value-added in global exports. The intuition of such equivalence is simple: when RDV_G and DVA_INTrex cross borders from the source country to the direct importer for the first time, they are both counted as part of the source country's domestic value added in its gross exports. When they cross national borders for the second time either from the direct importer back to the source country or are re-exported to a third country, they are counted another time as MVA or OVA in gross exports of the direct importing country. Therefore, FVA is value-added that crosses national borders at least twice.

DDC and FDC only occur when there are back and forth intermediate trade flows among countries. Their values are measured by the back and forth movement of intermediate trade flows that cross national borders at least 3 times but through different routes: (1) as intermediate exports from the home country, (2) returned from the direct importer or re-exported by these direct importing countries to third countries as intermediate exports, and (3) exported by a third country again to other countries including the home country as intermediate or final products. Those intermediate trade transactions are not part of any country's GDP or final demand (beyond what has already been counted in categories $1-4,6$, and 7 in equation (18)), similar to domestic inter-industry transactions that use one type of intermediate input to produce another type of intermediate inputs. Because all cross-country trade transactions are recorded by each country's customs authority, they show up in official trade statistics. In comparison, domestic intermediate input transactions are deducted from total gross output when official GDP by industry statistics is accounted for. Therefore, PDC is not a value added concept, and has different economic and mathematical properties compared to RDV_G and FVA, although the three of them all represent double counted terms in a country's gross exports. This intuition also helps readers to understand why both DDC and FDC should be considered as part of the vertical specialization (VS) measure. In Appendix C, we present a detailed concordance, in a three-country setting, between each of the domestic value added measures and these double counted terms.

\subsection{Relationships among various trade in value-added measures}

With the bilateral-sector gross exports decomposition equation (18) in hand, we are ready to formally define two related "trade in value added" measures and the two notions of "domestic 
value added embedded in gross exports" at the bilateral-sector level. We also reflect on how the value added trade to gross trade ratio and a summary statistic of double counting can be defined properly at the country-sector and bilateral-sector level. ${ }^{15}$

a) We have defined domestic value added in bilateral exports from Country $s$ to Country $r$ that is ultimately absorbed by other countries as the sum of the first three categories in equation (18) in our earlier discussion:

$$
\begin{aligned}
& V A X_{-} G^{s r}=\left(V^{s} B^{s s}\right)^{T} \# Y^{s r}+\left(V^{s} L^{s s}\right)^{T} \#\left(A^{s r} B^{r r} Y^{r r}\right) \\
& +\left(V^{s} L^{s s}\right)^{T} \#\left(A^{s r} \sum_{t \neq s, r}^{G} B^{r t} Y^{t t}\right)+\left(V^{s} L^{s s}\right)^{T} \#\left(A^{s r} B^{r r} \sum_{t \neq s, r}^{G} Y^{r t}\right) \\
& +\left(V^{s} L^{s s}\right)^{T} \#\left(A^{s r} \sum_{t \neq s, r}^{G} B^{r t} \sum_{u \neq s, t}^{G} Y^{t u}\right)
\end{aligned}
$$

It measures the amount of all domestic value added exported via a particular sector (e.g., US electronics), including value added originating from any domestic sector (e.g., including US plastics, chemicals, and automobiles) via backward industrial linkages, and is ultimately absorbed abroad (in direct importing country or third countries). There are three key features to take into account. The first is that the measure focuses on the identity of the last sector through which domestic value added from all domestic sectors is exported. The second is the phrase "ultimately absorbed abroad", that is, the measure excludes the part of domestic value added that eventually returns home. The third is it is always a part of gross export flows in a particular trading route thus its value is always bounded by the value of the corresponding gross trade flows.

b) We have also defined domestic value added embodied in gross exports from Country s to Country $r$ based on backward industrial linkages as the sum of the first four categories in equation (18) as follows and label the last term in equation (20) as $R D V{ }_{-} G^{s r}$, which measures returned domestic value added based on backward industrial linkages from Country s to Country $\mathrm{r}$ that is first exported but ultimately returned and absorbed at home:

$$
D V A_{-} G^{s r}=V A X_{-} G^{s r}+R D V_{-} G^{s r}
$$

c) From equation (30) of KWW, we can define domestic value added exports of a particular

15 In KWW, only the forward linkage based value added trade measure is defined in equation (30), which is similar to Equation (21) of this paper. Equations (19), (20), and (23) are all new and necessary to trace value added exports and domestic value added embedded in gross exports beyond the country aggregate level. 
sector from Country s to Country $r$ based on forward industrial linkages as:

$$
V A X_{-} F^{s r}=\hat{V}^{s} B^{s s} Y^{s r}+\hat{V}^{s} B^{s r} Y^{r r}+\hat{V}^{s} \sum_{t \neq s, r}^{G} B^{s t} Y^{t r}
$$

Where $\hat{V}^{s}$ is a $\mathrm{N}$ by $\mathrm{N}$ diagonal matrix with direct value added coefficients of Country s, $V^{s}$, along the diagonal. It measures the amount of domestic value added originating from a specific sector (e.g., from the US electronics sector), via all sectors' gross exports from the source country (i.e., including gross exports from the US automobile and machinery sectors in addition to the US electronics sector), and ultimately absorbed in a particular destination country. It has been the most widely used trade in value-added measure in the literature since it has been proposed by Johnson and Noguera (2012). There are also three key features here. Using the example of value added exports from the US electronics sector, the first key is that some of the value added from that sector can be exported indirectly via other US sectors such as automobiles, because some of the US electronics products are used as intermediate inputs in the production of automobile exports. So this measure includes indirectly exported value added from the electronics sector via forward industrial linkages. The second key is the phrase "ultimately absorbed in a particular destination country." The part of value added that eventually returns and is consumed at home is also not part of the value added exports. Finally, it always deviates from gross trade flows because it includes indirect value-added contributed to other sectors' gross exports and indirect trade via third countries.

It is interesting to note that equations (19) and (21) clearly show that $V A X X_{-} F^{s r}$ requires that DVA from Country $\mathrm{s}$ has to be absorbed by a particular destination country r, while $V A X \_G^{s r}$ includes domestic value added absorbed not only by direct importing Country r, but also by third countries $\mathrm{t}$ or $\mathrm{u}$. It demonstrates analytically why we claim that $V A X_{-} G^{s r}$ is the trade in value added measure which is fully consistent and bounded by gross bilateral trade flows and $V A X_{-} F^{s r}$ is not due to indirect trade through third countries. At the country aggregate, these two measures are the same, but at the sector, bilateral or bilateral-sector level, they are different except by coincidence.

d) Similar to VAX_F, we define RDV_F as the amount of DVA from a specific sector embodied in the source country's intermediate gross exports to Country r, but eventually return to, via all possible routines through third countries and other sectoral linkages, and is absorbed in 
source Country s.

$$
R D V_{-} F^{s r}=\hat{V}^{s} L^{s s} A^{s r} \sum_{t}^{G} B^{r t} Y^{t s}=\hat{V}^{s} L^{s s}\left[A^{s r} B^{r r} Y^{r s}+A^{s r} B^{r s} Y^{s s}+A^{s r} \sum_{t \neq s, r}^{G} B^{r t} Y^{t s}\right]
$$

e) Similar to $D V A_{-} G^{S r}$, we define $D V A_{-} F^{s r}$ as the measure of DVA from a particular sector of the source Country s that is embodied in Country s's gross exports via forward industrial linkages.

$$
D V A_{-} F^{s r}=V A X_{-} F^{s r}+R D V_{-} F^{s r}
$$

Summing up equation (23) across all trading partners, we obtain:

$$
\sum_{r \neq s}^{G} D V A_{-} F^{s r}=\sum_{r \neq s}^{G}\left(V A X_{-} F^{s r}+R D V_{-} F^{s r}\right)=\hat{V}^{s} L^{s s} \sum_{r \neq s}^{G} E^{s r}=\hat{V}^{s} L^{s s} E^{s^{*}}
$$

It measures how much a sector's domestic value added can be generated from the production of gross exports in Country s, regardless of whether this value added is finally absorbed by the home country or other countries. We can show that, at the bilateral-sector level, $\hat{V}^{s} L^{s s} E^{s r} \neq V A X_{-} F^{s r}+R D V_{-} F^{s r}$ due to $\hat{V}^{s} L^{s s} E^{s r}$ only trace where the domestic value-added is produced, while $D V A_{-} F^{s r}$ also requires these value-added have to be absorbed by a particular partner country r. This implies that the first part of equation (37) in KWW (2014) can only be extended to the country-sector level but not to the bilateral-sector level due to country s's domestic value added embodied in $\hat{V}^{s} L^{s s} E^{s r}$ could be absorbed by a third country t. Detailed proof of equations (24) is given in Appendix G.

Our main analytical results can be summarized by the following statements: ${ }^{17}$

- In a world of three or more countries, VAX_G and VAX_F, are, in general, not equal to each other at the disaggregate level, though they are the same at the country aggregate level. DVA_G and DVA_F are also only the same at country aggregate level. These relationships can be summarized by Table 1 below: At any disaggregate level, VAX_G is always less than or equal to gross exports, thus the ratio of VAX_G to gross exports has an upper bound of one. Therefore, 1-VAX_G ratio is conceptually meaningful when gross exports are positive

\footnotetext{
16 To help readers understand the derivation of the two types of value added trade and two types of GDP in gross exports measures defined in equations (19) to (23), we use the three-country, two sector ICIO model as an example in Appendix F to show the relationship among these forward/backward linkage based measures.

17 Due to space limitation, we leave the derivation of equations (19) to (23), mathematical proofs of Propositions $\mathrm{A}-\mathrm{C}$ that correspond to the four statements, and a more detailed discussion on the relationship among these measures to Appendix F.
} 
and can be used as summary statistic for the extent of double counting in trade statistics at any level of disaggregation. Such a measure is always bounded by zero and 1. (The conventional VAX_F ratio is identical to this measure at the country aggregate level, but only at this level.)

- At the country-sector level, VAX_F $\leq$ DVA_F (=VAX_F+RDV_F) $\leq$ sector-level value added production. Therefore, the ratios of VAX_F and DVA_F to GDP by industry both have an upper bound of one. These ratios can be used as summary statistics for cross-country production sharing.

- Because both RDV_F and RDV_G are non-negative, therefore, both DVA_F and DVA_G are always greater than or equal to the two trade in value-added measures (VAX_F and VAX_G) by definition.

\section{Table 1 Relationship among different trade in value added related measures}

\begin{tabular}{|c|c|c|c|c|c|c|}
\hline \multicolumn{2}{|c|}{ Aggregation level } & \multirow{2}{*}{$\begin{array}{c}\begin{array}{c}\text { VAX_G } \\
\& \\
\text { VAX_F }\end{array} \\
\Rightarrow\end{array}$} & \multirow{2}{*}{$\begin{array}{c}\begin{array}{c}\text { RDV_G } \\
\& \\
\text { RDV_F }\end{array} \\
\neq\end{array}$} & \multirow{2}{*}{$\begin{array}{c}\text { DVA_G } \\
\text { \& } \\
\text { DVA_F } \\
\neq\end{array}$} & \multirow{2}{*}{$\begin{array}{c}\underset{\mathbf{Q}}{\text { DV_F }} \\
\hat{V}^{s} L^{s s} E^{s^{*}} \\
\neq\end{array}$} & \multirow{2}{*}{$\begin{array}{c}\text { DVA_G } \\
\text { \& } \\
\left(V^{s} L^{s s}\right)^{T} \# E^{s r} \\
\neq\end{array}$} \\
\hline$e_{i}^{s r}$ & Bilateral-Sector & & & & & \\
\hline$\sum_{i=1}^{N} e_{i}^{s r}$ & $\begin{array}{l}\text { Bilateral } \\
\text { Aggregate }\end{array}$ & $\neq$ & $=$ & $\neq$ & $\neq$ & $\neq$ \\
\hline$\sum_{r \neq s}^{G} e_{i}^{s r}$ & Country-Sector & $\neq$ & $\neq$ & $\neq$ & $=$ & $\neq$ \\
\hline$\sum_{r \neq s i=1}^{G} \sum_{i}^{N} e_{i}^{s r}$ & $\begin{array}{l}\text { Country } \\
\text { Aggregate }\end{array}$ & $=$ & $=$ & $=$ & $=$ & $=$ \\
\hline
\end{tabular}

The intuition behind these statements is simple: since direct value added exports at the sector level are the same for the two "trade in value added" measures, only indirect value added trade may differ. The indirect value added exports in the forward-linkage-based measure are the sector's value added embodied in other (downstream) sectors' gross exports, which has no relation to the gross exports from that sector. Therefore, the ratio of value added exports to gross exports at the sector level cannot be properly defined based on forward industrial linkage. It is in fact common in the data for some sectors to have very little or no gross exports (e.g., service sectors), but their output is used by other domestic industries as intermediate inputs, and thus they can have a large amount of indirect value added exports through other sectors. In such cases, the forward linkage based VAX ratio can become large and even infinite. Similarly, at the 
bilateral level, due to indirect value added trade via third countries, two countries can have a large volume of value added trade with little or no gross trade. Therefore, the ratio of value added exports to gross exports as defined in the literature is not upper bounded by one. However, because such indirect value added exports are part of the total value added created by the same sector, the forward-linkage-based value added exports and domestic value added embedded in the gross exports to GDP ratio can be properly defined at the sector level.

\section{Applications: Decomposition Results for 40 Economies during 1995-2011}

We apply our disaggregated accounting framework to the World Input-Output Database (WIOD). The WIOD, developed by a consortium of eleven European research institutions funded by the European Commission, provides a time series of inter-country input-output (ICIO) tables from 1995 to 2011, covering 40 economies including all major industrialized countries and major emerging trading nations. Timmer et al. (2012) provide a detailed description of this database.

Our disaggregated accounting framework produces a series of panel data sets, consisting of many GN (1435) by G (41) and GN by GN matrices each year, collectively taking up more than 20 gigabytes of storage space when the decomposition is computed at the most detailed level. To illustrate how the estimation outcomes can help us to better understand cross country production sharing patterns in a manageable manner, we provide a series of examples, which are selected and processed from subsets of the detailed results.

\subsection{Decomposing bilateral-sector level gross trade}

As stated, Equation (18) is a key result of the paper. To illustrate what it can achieve, we use the US-China bilateral trade in electrical and optical equipment as an example. Among all bilateral-sector level trade flows in recent years, this is the single biggest product group measured by the volume of gross trade, with the sum of two-way flows reaching $\$ 212$ billion in 2011. By gross statistics, presented in column 1 of Table 2, the trade is highly imbalanced, with Chinese exports to the US ( $\$ 176.9$ billion in 2011) being five times that of US exports to China ( $\$ 35.1$ billion in 2011). If we separate exports of final goods versus that of intermediate goods (reported in columns $2 \mathrm{a}$ and $2 \mathrm{~b}$ of Table 2), we see that most of the Chinese exports consist of final goods, whereas most of the US exports consist of intermediate goods. 
We provide a decomposition of the bilateral trade flows for selected years $(1995,2005$, and 2011) in columns (3)-(7) of Table 2. More precisely, Column $(1)=(3)+(4)+(5)+(6)+(7)$, where column (3), VAX_G, represents the exporter's domestic value added that is ultimately absorbed by other countries, including by both the direct importing country and other foreign countries; column (4), RDV_G, is the part of domestic value added initially exported but ultimately returned home and is absorbed at home; column (5), MVA, is the part of the FVA that comes from the direct importing country; column (6), OVA, is the part of the FVA that comes from third countries; and finally, column (7) is the pure double counted items.

Column $(3)=(3 a)+(3 b)+(3 c)$, that is, the VAX_G part is further decomposed into DVA in final goods, DVA in intermediate goods directly and indirectly absorbed by trading partners, and DVA in intermediate goods re-exported from the direct importing country and ultimately absorbed in third countries.

The decomposition results show that US and Chinese exports have very different value added structures. First, the VAX_G as a share of gross exports is much higher for US exports (81\% in 2011) than for Chinese exports (about 70\% in 2011). ${ }^{18}$ Second, correspondingly, the FVA share (MVA+OVA) is higher for Chinese exports than for US exports. This is especially true for the OVA share in China. In other words, US exports rely overwhelmingly on their own value added (only $2.1 \%$ from China and 5.8\% from other countries in 2011), whereas Chinese exports use more foreign value added, especially value added from third countries (with $3.2 \%$ from the United States and 23.1\% from Japan, Korea, and all other countries). Third, whereas the RDV_G share is trivial for China, it is non-negligible for the United States (7.0\% in 2011). This again reflects the different positions the two countries occupy in the global production chain. As the United States produces and exports parts and components, it is on the upstream of the chain; part of its value added in its exports returns home as embedded in imports from other countries. In comparison, China is on the downstream of the chain; very little of its value added comes back home as intermediate goods in other countries' exports. This is also evidenced by China having a much higher proportion of FVA used in producing its final goods exports to the US, while the US has a higher share of FVA in producing its intermediate goods exports to China.

The decomposition of VAX_G into (3a), (3b), and (3c) also reveals differences between the

18 Because WIOD does not distinguish processing and normal trade, the domestic value added share for China is likely to be overestimated. For a method to correct this, see Koopman, Wang, and Wei (2012). 
two exporters. In particular, the VAX_G in Chinese exports to the United States is dominated by DVA in final goods, whereas the VAX_G in US exports is dominated by DVA in intermediate goods that is absorbed by China and other countries.

As a consequence of these differences in the structure of value added composition, China-US trade balance in this sector looks much smaller when computed in terms of domestic value added than in terms of gross trade. In column (8), we report forward-linkage based value added exports, or VAX_F. Because this measure captures value added originating in that sector in all downstream sectors of exports from the exporting country but excludes contributions of value added from other (upstream) domestic sectors to the electrical and optical equipment sector, it is generally not the same as VAX_G at the bilateral-sector level, and in our application, VAX_F is smaller than VAX_G (this is generally true for downstream sectors).

We report the US-China bilateral balance of trade in electrical and optical equipment sector by gross and various value-added components in the bottom section of table 2 .

It is important to bear in mind that at the bilateral-sector level, VAX_G is always a part of gross trade flows, while VAX_F always deviates from gross trade flows due to indirect exports via other sectors and third counties. While VAX_G is a measure of "trade in value added" that is bounded by the bilateral gross trade flows, it is not a proper measure of bilateral value added trade flows, because it also includes a portion of value added that is absorbed by third countries, unlike VAX_F, which is absorbed by a particular partner country only.

The results reported in the bottom section of table 2 not only reveal the misleading nature of balance of trade computed from gross trade statistics but also the sources of the error. For instance, based on the value added method, in 2011, US-China bilateral balance of electric and optical equipment is only about two thirds of what is indicated by the gross trade data. Domestic value-added absorbed by other countries only took $66.9 \%$ (column 3 ) of the total gross imbalance; the rest of it came from third country transfer and double counting: $27.4 \%$ due to Chinese exports to the US using more value-added from third countries than that in US exports to China (column 6); 3.4\% due to Chinese exports to the US including more US value added than Chinese value-added embodied in US exports to China (column 5); and another 3.1\% due to more pure double counting in China's exports to the US than that in US exports to China (column 7), indicating Chinese value-added has more border crossing than US value-added before they reach their final consumers. 
Table 2: US-China Trade in Electrical and Optical Equipment (WIOD C14)

Unit: millions USD

\begin{tabular}{|c|c|c|c|c|c|c|c|c|c|c|c|c|c|}
\hline \multirow{2}{*}{\multicolumn{2}{|c|}{ Year }} & TEXP & TEXPF & TEXPI & VAX_G & DVA_FIN & DVA_INT & DVA_Intrex & RDV_G & MVA & OVA & PDC & VAX_F \\
\hline & & $\begin{aligned} & (1) \\
= & 2 a+2 b\end{aligned}$ & (2a) & (2b) & $\begin{array}{c}(3) \\
=3 a+3 b+3 c\end{array}$ & (3a) & (3b) & (3c) & (4) & (5) & (6) & (7) & (8) \\
\hline \multicolumn{14}{|c|}{ China exports to the United States } \\
\hline \multirow[t]{2}{*}{1995} & Value & 10,998 & 7,634 & 3,364 & 8,544 & 5,947 & 2,046 & 552 & 16 & 314 & 1,948 & 176 & 3,922 \\
\hline & Share & 100 & 69.4 & 30.6 & 77.7 & 54.1 & 18.6 & 5.0 & 0.1 & 2.9 & 17.7 & 1.6 & 35.7 \\
\hline \multirow[t]{2}{*}{2005} & Value & 87,608 & 53,492 & 34,116 & 53,784 & 33,399 & 16,329 & 4,056 & 341 & 3,665 & 26,332 & 3,485 & 25,682 \\
\hline & Share & 100 & 61.1 & 38.9 & 61.4 & 38.1 & 18.6 & 4.6 & 0.4 & 4.2 & 30.1 & 4.0 & 29.3 \\
\hline \multirow[t]{2}{*}{2011} & Value & 176,924 & 104,156 & 72,769 & 123,187 & 74,043 & 39,801 & 9,344 & 1,296 & 5,581 & 40,915 & 5,946 & 53,078 \\
\hline & Share & 100 & 58.9 & 41.1 & 69.6 & 41.8 & 22.5 & 5.3 & 0.7 & 3.2 & 23.1 & 3.4 & 30.0 \\
\hline \multicolumn{14}{|c|}{ US exports to China } \\
\hline \multirow[t]{2}{*}{1995} & Value & 3,400 & 1,284 & 2,116 & 2,691 & 1,097 & 1,215 & 379 & 182 & 13 & 383 & 130 & 1,746 \\
\hline & Share & 100 & 37.8 & 62.2 & 79.2 & 32.3 & 35.7 & 11.2 & 5.4 & 0.4 & 11.3 & 3.8 & 51.4 \\
\hline \multirow[t]{2}{*}{2005} & Value & 16,402 & 3,845 & 12,556 & 11,926 & 3,264 & 5,072 & 3,591 & 1,777 & 231 & 1,251 & 1,216 & 8,748 \\
\hline & Share & 100 & 23.4 & 76.6 & 72.7 & 19.9 & 30.9 & 21.9 & 10.8 & 1.4 & 7.6 & 7.4 & 53.3 \\
\hline \multirow[t]{2}{*}{2011} & Value & 35,059 & 10,584 & 24,475 & 28,314 & 9,377 & 12,195 & 6,742 & 2,470 & 718 & 2,044 & 1,513 & 23,754 \\
\hline & Share & 100 & 30.2 & 69.8 & 80.8 & 26.7 & 34.8 & 19.2 & 7.0 & 2.1 & 5.8 & 4.3 & 67.8 \\
\hline \multicolumn{14}{|c|}{ US-China trade balance } \\
\hline \multirow[t]{2}{*}{1995} & Value & $-7,598$ & $-6,350$ & $-1,248$ & $-5,853$ & $-4,850$ & -831 & -173 & 166 & -301 & $-1,565$ & -46 & $-2,716$ \\
\hline & Share & 100 & 83.6 & 16.4 & 77.0 & 63.8 & 10.9 & 2.3 & -2.2 & 4.0 & 20.6 & 0.6 & 35.7 \\
\hline \multirow[t]{2}{*}{2005} & Value & $-71,206$ & $-49,647$ & $-21,560$ & $-41,858$ & $-30,135$ & $-11,257$ & -465 & 1,436 & $-3,434$ & $-25,081$ & $-2,269$ & $-16,934$ \\
\hline & Share & 100 & 69.7 & 30.3 & 58.8 & 42.3 & 15.8 & 0.7 & -2.0 & 4.8 & 35.2 & 3.2 & 23.8 \\
\hline \multirow[t]{2}{*}{2011} & Value & $-141,865$ & $-93,572$ & $-48,294$ & $-94,873$ & $-64,666$ & $-27,606$ & $-2,602$ & 1,174 & $-4,863$ & $-38,871$ & $-4,433$ & $-29,342$ \\
\hline & Share & 100 & 66.0 & 34.0 & 66.9 & 45.6 & 19.5 & 1.8 & -0.8 & 3.4 & 27.4 & 3.1 & 20.7 \\
\hline
\end{tabular}

Note: TEXP is the value of total export goods, TEXPF and TEXPI are the values of total final export goods and total intermediate export goods, respectively, in million US\$ (3a) and (3b) equal Term 1 and Term 2, (3c) equals the sum of Term 3 to Term 5, (4) equals the sum of Term 6 to Term 8, (5) equals Term $11+$ Term 13, (6) equals Term 12 + Term 14 and (7) equals the sum of Term 9, Term 10, Term 15, and Term 16 in equation (18) of this paper. Therefore (1)=(3)+(4)+(5)+(6)+(7); MVA is the sum of MVA_FIN and MVA_INT, OVA is the sum of OVA_FIN and OVA_INT. 


\subsection{Identifying a country's role in global value chains by the structure of domestic value added embodied in its exports}

As shown by equation (18) and Figure 1, different components within a country's domestic value added in its sector's gross exports represent different types of cross-country production sharing arrangements. In other words, different structures of these components

contain useful information about the nature of cross country production sharing. For example, two countries may have very similar shares of domestic value added in their gross exports but very different value added structures due to their different roles in global value chains. We had given a hypothetical example to make such a point in the introduction; we now report a real world example based on data from the WIOD.

When comparing textile exports by the United States and India, if we only pay attention to the shares of domestic value added in the sector's gross exports (DVA) for the two countries, reported in Columns (3) and (9) of Table 3, respectively, they look very similar during 19952011. In fact, the shares were almost identical in 2005. Do US and Indian textile sectors truly participate in the global textile production chains in the same way? To gain insight, it is useful to make use of our more detailed decomposition formula, with the results reported in Columns (4)-(7) for the United States and Columns (10)-(13) for India, respectively. Once we lift this veil, we see remarkable differences. For textile exports, the DVA_FIN share is about $80 \%$ for India (Column 10), but only 50\% for the United States (Column 4). On the other hand, the DVA_INT share is about 10\% for India's textile exports (Column 11) but close to 30\% for that of the United States (Column 5). Furthermore, US textile gross exports embed about 10\% or more domestic value added that will eventually return home after being used as intermediate inputs in other countries' exports (Column 7). In contrast, Indian textile gross exports contain virtually no domestic value added that eventually returns home (Column 13). These differences suggest that the textile sector in these two countries occupy different positions in global textile production chains. In particular, India is likely at the bottom of the chain, while the US is at a more upstream position. 
Table 3: Structure of domestic value added in gross exports of the textile industry (WIOD sector 04), USA and India, 1995-2011

\begin{tabular}{|c|c|c|c|c|c|c|c|c|c|c|c|c|}
\hline \multirow[b]{3}{*}{ Year } & \multicolumn{6}{|c|}{ USA } & \multicolumn{6}{|c|}{ India } \\
\hline & \multirow[b]{2}{*}{$\begin{array}{c}\text { Gross } \\
\text { Exports }\end{array}$} & \multirow[b]{2}{*}{$\begin{array}{c}\text { \% of } \\
\text { DVA_G } \\
\text { in } \\
\text { Exports }\end{array}$} & \multicolumn{4}{|c|}{ \% of DVA_G } & \multicolumn{6}{|c|}{ \% of DVA_G } \\
\hline & & & $\begin{array}{c}\text { DVA_ } \\
\text { FIN }\end{array}$ & $\begin{array}{c}\text { DVA_ } \\
\text { INT }\end{array}$ & $\begin{array}{c}\text { DVA } \\
\text { INTrex }\end{array}$ & $\begin{array}{c}\text { RDV }_{-} \\
\mathbf{G}\end{array}$ & $\begin{array}{c}\text { Gross } \\
\text { Exports }\end{array}$ & $\begin{array}{c}\% \text { of } \\
\text { DVA_G } \\
\text { in } \\
\text { Exports }\end{array}$ & $\begin{array}{c}\text { DVA_ } \\
\text { FIN }\end{array}$ & $\begin{array}{c}\text { DVA_ } \\
\text { INT }\end{array}$ & $\begin{array}{c}\text { DVA } \\
\text { INTrex }\end{array}$ & $\begin{array}{c}\text { RDV } \\
\text { G }\end{array}$ \\
\hline (1) & (2) & (3) & (4) & (5) & (6) & (7) & (8) & (9) & (10) & (11) & (12) & (13) \\
\hline 1995 & 13,070 & 89.3 & 58.6 & 24.3 & 8.3 & 8.9 & 8,933 & 91.7 & 73.6 & 17.8 & 8.6 & 0.1 \\
\hline 2000 & 17,125 & 87.5 & 55.8 & 21.6 & 6.5 & 16.2 & 14,806 & 89.4 & 74.1 & 13.6 & 12.2 & 0.1 \\
\hline 2005 & 17,060 & 84.4 & 47.3 & 26.3 & 10.6 & 15.9 & 19,506 & 83.9 & 82.7 & 9.3 & 7.9 & 0.1 \\
\hline 2007 & 15,663 & 85.0 & 47.6 & 27.8 & 11.7 & 12.9 & 22,747 & 82.4 & 84.6 & 8.5 & 6.8 & 0.1 \\
\hline 2009 & 13,694 & 86.2 & 51.9 & 25.7 & 12.3 & 10.1 & 19,156 & 84.4 & 86.4 & 7.7 & 5.8 & 0.1 \\
\hline 2010 & 14,479 & 81.5 & 51.0 & 26.5 & 12.8 & 9.8 & 23,364 & 83.3 & 78.8 & 13.0 & 8.1 & 0.2 \\
\hline 2011 & 16,185 & 80.6 & 51.8 & 26.0 & 12.8 & 9.3 & 25,879 & 84.1 & 81.1 & 11.8 & 7.0 & 0.1 \\
\hline
\end{tabular}

\subsection{Tracing structures of Vertical Specialization across countries and over time}

Vertical specialization or VS, is a summary statistic to measure international production sharing widely used in the literature (e.g., Hummels, Ishii, and Yi (2001), and Antras (2013)). However, as shown by our equation (18) and Figure 1, there are different components within VS, and each has a different economic meaning and represents different types of cross-country production sharing arrangement. For example, a large share of foreign value added in a country's final goods exports (FVA_FIN) may indicate that the country mainly engages in final assembling activities based on imported components and just participates in cross-country production sharing on the low end of a global value chain, while an increasing foreign value added share in a country's intermediate exports (FVA_INT) may imply the country is upgrading its industry to start producing intermediate goods for other countries, especially when more and more of these goods are exported to third countries for final goods production. The latter is a sign that the country is no longer at the bottom of the GVCs.

Pure double counting terms in a country's exports (PDC) can only occur when there is back and forth trade of intermediate products. An increasing weight of PDC share in VS 
indicates the deepening of cross-country production sharing. Intermediate goods have to cross national borders multiple times before they are used in final goods production. Therefore, knowing the relative importance of these components and their changing trend over time in a country's total VS can help us to gauge the depth and pattern of cross-country production sharing and discover the major drivers of the general increase of VS in a country's gross exports during the last two decades.

As shown in Table 4, across all countries and all sectors, the total VS sourced from manufacturing and services sectors used in world manufacturing goods production has increased by 8.6 percentage points (from $22.9 \%$ in 1995 to $31.5 \%$ in 2011, column 3). Interestingly, the VS structure information reported in the last three columns indicates that this net increase is mainly driven by an increase of PDC. This suggests that the international production chain is getting longer; over time, a rising portion of trade reflects intermediate goods made and exported by one country, used in the production of the next-stage intermediate goods and exported by another country to be used by the next country to produce yet another intermediate good. This progressively increasing trade of intermediate goods that cross national borders multiple times is what gives the rising share of PDC.

Table 4: Average VS Structure of World Manufacturing Industries

\begin{tabular}{cccccc}
\hline \multirow{2}{*}{ Year } & \multirow{2}{*}{$\begin{array}{c}\text { Gross exports } \\
\text { (Billions USD) }\end{array}$} & \multirow{2}{*}{$\begin{array}{c}\text { VS share in } \\
\text { gross exports }\end{array}$} & FVA_FIN & FVA_INT & PDC \\
\cline { 4 - 6 } & 4020.2 & 22.9 & 44.6 & 34.2 & 21.1 \\
\hline $\mathbf{1 9 9 5}$ & 4916.6 & 27.1 & 44.7 & 31.5 & 23.9 \\
$\mathbf{2 0 0 0}$ & 7850.6 & 30.7 & 41.3 & 31.7 & 27.0 \\
$\mathbf{2 0 0 5}$ & 10472.4 & 32.5 & 39.7 & 31.5 & 28.8 \\
$\mathbf{2 0 0 7}$ & 9093.7 & 29.1 & 42.4 & 32.7 & 24.9 \\
$\mathbf{2 0 0 9}$ & 10878.7 & 31.0 & 40.7 & 32.8 & 26.5 \\
$\mathbf{2 0 1 0}$ & 12458.3 & 31.5 & 39.7 & 33.7 & 26.7 \\
\hline $\mathbf{2 0 1 1}$ & & & & & \\
\hline
\end{tabular}

Note: VS is sourced from manufacturing and services sectors only.

Because the share of foreign value added in final goods exports in total VS has declined by about 5 percentage points during the same period (from $44.6 \%$ in 1995 to 39.7 in 2011), and because the share of foreign value added in intermediate goods exports in total VS stayed almost 
constant, the increase of VS share in world manufacturing exports is driven mainly by an increase in PDC share (from 21.1\% in 1995 to $26.7 \%$ in 2011). If this trend continues, the PDC share may reach the level of the FVA share and become an important feature of cross-country production sharing. If we add the shares of FVA_INT and PDC, these two components involving intermediate goods trade have already accounted for more than $60 \%$ of the total manufacturing VS in 2011.

Of course, there is heterogeneity in the VS structure both across countries and across sectors, especially between industrialized and developing economies. Table 5 reports total VS and its structure in electrical and optical equipment exports for six Asian economies: Japan; Korea; Taiwan; China; India; and Indonesia. The three industrialized Asian economies are reported in the right panel. Despite their difference in the level of total VS shares, their VS structure is very similar: lower and declining in FVA_FIN, relatively stable in FVA_INT, and rapidly expanding in PDC. Taiwan's VS structure is an informative example (presented in the right bottom 5 rows in Table 5). Taiwan is an important supplier of parts and components, and crucially, as Taiwan often occupies several different positions in the global production chain (since it produces both inputs into chip making, memory chips themselves, and components that embed the chips), the collective shares of PDC and FVA_INT has reached about $80 \%$ of its total VS (or $40 \%$ of its gross exports) since 2005.

Table 5: VS Structure of Electrical and Optical Equipment Exports for Selected Asian Economies

\begin{tabular}{|c|c|c|c|c|c|c|c|c|c|c|}
\hline \multirow[b]{2}{*}{ Year } & \multirow{2}{*}{$\begin{array}{c}\text { Gross } \\
\text { Exports } \\
\text { (Millions } \\
\text { USD) }\end{array}$} & \multirow{2}{*}{$\begin{array}{c}\text { VS } \\
\text { share in } \\
\text { Gross } \\
\text { Exports }\end{array}$} & \multicolumn{3}{|c|}{$\%$ of VS } & \multirow{2}{*}{$\begin{array}{c}\text { Gross } \\
\text { Exports } \\
\text { (Millions } \\
\text { USD) }\end{array}$} & \multirow{2}{*}{$\begin{array}{c}\text { VS } \\
\text { share in } \\
\text { Gross } \\
\text { Exports }\end{array}$} & \multicolumn{3}{|c|}{$\%$ of VS } \\
\hline & & & $\begin{array}{l}\text { FVA } \\
\text { _FIN }\end{array}$ & $\begin{array}{r}\text { FVA } \\
\text { _INT }\end{array}$ & PDC & & & $\begin{array}{l}\text { FVA } \\
\text { _FIN }\end{array}$ & $\begin{array}{l}\text { FVA } \\
\text { INT }\end{array}$ & PDC \\
\hline & \multicolumn{5}{|c|}{ China } & \multicolumn{5}{|c|}{ Japan } \\
\hline 1995 & 34,032 & 22.2 & 56.6 & 27.3 & 16.1 & 124,265 & 6.9 & 43.0 & 33.5 & 23.6 \\
\hline 2000 & 68,998 & 26.2 & 53.4 & 23.6 & 23.0 & 136,123 & 10.0 & 41.6 & 28.2 & 30.2 \\
\hline 2005 & 296,936 & 38.8 & 50.6 & 23.6 & 25.7 & 143,324 & 12.3 & 34.1 & 30.1 & 35.7 \\
\hline 2010 & 638,982 & 30.7 & 48.1 & 25.8 & 26.1 & 162,861 & 15.3 & 33.1 & 34.2 & 32.8 \\
\hline 2011 & 721,417 & 30.2 & 48.1 & 26.5 & 25.5 & 166,935 & 16.4 & 32.3 & 36.7 & 31.0 \\
\hline
\end{tabular}




\begin{tabular}{lccccc|rcccc}
\hline \multicolumn{9}{c}{} & \multicolumn{3}{c}{ India } & \multicolumn{5}{c}{ Korea } \\
$\mathbf{1 9 9 5}$ & 1,260 & 10.9 & 38.1 & 40.2 & 21.7 & 40,639 & 28.1 & 29.7 & 43.3 & 26.9 \\
$\mathbf{2 0 0 0}$ & 1,927 & 17.8 & 41.6 & 32.2 & 26.2 & 60,434 & 35.5 & 39.9 & 30.6 & 29.5 \\
$\mathbf{2 0 0 5}$ & 5,962 & 20.2 & 42.1 & 30.1 & 27.9 & 102,595 & 35.2 & 30.4 & 30.7 & 38.9 \\
$\mathbf{2 0 1 0}$ & 23,994 & 19.1 & 53.9 & 23.9 & 22.3 & 147,823 & 37.4 & 24.4 & 38.7 & 36.9 \\
$\mathbf{2 0 1 1}$ & 29,470 & 19.5 & 52.4 & 25.2 & 22.4 & 159,191 & 37.3 & 26.1 & 40.0 & 33.9 \\
\hline & & \multicolumn{2}{c}{ Indonesia } & & & & Taiwan & & \\
$\mathbf{1 9 9 5}$ & 2,831 & 28.7 & 70.1 & 19.0 & 10.8 & 41,818 & 44.0 & 40.0 & 38.9 & 21.1 \\
$\mathbf{2 0 0 0}$ & 7,637 & 30.6 & 53.5 & 23.3 & 23.3 & 77,861 & 45.3 & 40.5 & 30.9 & 28.5 \\
$\mathbf{2 0 0 5}$ & 8,387 & 29.8 & 43.5 & 26.7 & 29.8 & 100,957 & 49.8 & 21.8 & 32.3 & 45.9 \\
\hline $\mathbf{2 0 1 0}$ & 11,666 & 29.1 & 46.4 & 28.0 & 25.6 & 142,943 & 49.8 & 15.6 & 39.6 & 44.8 \\
$\mathbf{2 0 1 1}$ & 12,558 & 30.8 & 47.9 & 29.0 & 23.1 & 147,646 & 48.7 & 17.2 & 41.2 & 41.6 \\
\hline
\end{tabular}

Note: VS reported here is sourced from manufacturing and services sector only.

In comparison, for other developing Asian countries such as China, India, and Indonesia (presented in the left panel of Table 5), the share of FVA_FIN still accounts for about 50\% of their total VS until 2011. However, there are also interesting differences among the three emerging Asian giants: the VS structure change during the 17 years for China was mainly driven by the decline of FVA_FIN and increase of PDC, while FVA_INT stayed relatively stable. For Indonesia, it was driven by the rapid expansion of both FVA_INT and PDC, which increased by at least 10 percentage points during this period, indicating that there was rapid upgrading of Indonesia's electrical and optical equipment industries during this period. For India, the late-comer in the Asian global production network of electrical and optical equipment, the share of FVA_FIN rose (from $38.1 \%$ in 1995 to $52.4 \%$ in 2011) and the FVA_INT share continued to decline (from $40.2 \%$ in 1995 to $25.2 \%$ in 2011), while the PDC share stayed relatively stable in the last 17 years. This may be the result of a strategic shift from import substitution to export oriented development; it is also consistent with a move from the upper stream portion of the production chain to a more downstream position as China and Indonesia did decades ago. This empirical evidence indicates that the structure of VS in addition to its total sums offer additional information about each country's respective position in the global value chain. 


\section{Concluding Remarks}

This paper developed a disaggregated accounting framework of gross trade flows at either the sector, bilateral, or bilateral-sector level. It provides a transparent framework to completely decompose gross exports into its various components, including exports of value-added, domestic value-added that returns home, foreign value-added, and double-counted intermediate trade. These conceptually different components sum up to $100 \%$ of the gross trade flows at any level of disaggregation. By identifying which parts of the official data are double counted and the sources of the double counting, it bridges gross trade statistics and national accounts in consistence with the System of National Accounts standard. More importantly, it goes beyond simply extracting value-added trade from gross trade, and recovers additional useful information about the structure of international production sharing at a disaggregated level that is masked by gross trade data.

In principle, when new countries or years are added to the WIOD database, or an alternative inter-country input-output table becomes available, our accounting framework can be applied as well. So the accounting framework developed in this paper is not inherently tied to the WIOD database and can be a stand-alone tool to help us extract useful information from official trade statistics. It is our hope that this gross trade accounting method and the datasets generated by applying the method could provide a useful tool and additional data source for other researchers in the international trade community to study a variety of issues that relate to cross-country production sharing and global value chains.

\section{References}

Antras, Pol. 2013. Firms, Contracts, and Global Production. CREI Lectures in Macroeconomics. Manuscript on the author's website.

Borin, Alessandro, and Michele Mancini. 2015. "Follow the value added: Bilateral gross exports accounting." Working paper of Banca D'Italia. No. 1026. Economic Research and International Relations Area. 
Hummels, David, Jun Ishii, and Kei-Mu Yi. 2001. "The Nature and Growth of Vertical Specialization in World Trade.” Journal of International Economics 54(1): 75-96.

Johnson, Robert C. 2014. "Five Facts about Value Added Exports and Implications for Macroeconomics and Trade Research.” Journal of Economic Perspectives 28(2): 119-142.

Johnson, Robert C., and Guillermo Noguera. 2012. "Accounting for Intermediates: Production Sharing and Trade in Value added." Journal of International Economics 86(2): 224-236.

Koopman, Robert, Zhi Wang, and Shang-Jin Wei. 2012. "Estimating domestic content in exports when processing trade is pervasive." Journal of Development Economics 99(1): 178189.

Koopman, Robert, Zhi Wang, and Shang-Jin Wei. 2014. "Tracing Value added and Double Counting in Gross Exports." American Economic Review 104(2): 459-494. Also available as NBER Working Paper No. 18579.

Leontief, Wassily W. 1936. "Quantitative Input and Output Relations in the Economic System of the United States." Review of Economics and Statistics 18: 105-125.

Miller, Ronald E., and Peter D. Blair. 2009. Input-output Analysis: Foundations and Extensions. Cambridge: Cambridge University Press.

Timmer, Marcel P., Abdul A. Erumban, Bart Los, Robert Stehrer, and Gaaitzen J. De Vries. 2014. "Slicing Up Global Value Chains.” Journal of Economic Perspectives 28(2): 99-118.

Timmer, Marcel P., Bart Los, Robert Stehrer, Gaaitzen J. de Vries. 2013. "Fragmentation, incomes and jobs: an analysis of European competitiveness.” Economic Policy 28(76): 613661.

Timmer, Marcel, Abdul A. Erumban, Joseph Francois, Valeria Andreoni Aurélien Genty, Reitze Gouma, Bart Los, Frederik Neuwahl, Olga Pindyuk, Johannes Poeschl, José M. Rueda-Cantuche, Robert Stehrer, Gerhard Streicher, Umed Temurshoev, Alejandro Villanueva, Gaaitzen J. de Vries. 2012. "The World Input-Output Database (WIOD): Contents, Sources and Methods." WIOD Background document available at www.wiod.org. 
Table A1 Definition of different measures of value-added in trade

\begin{tabular}{|c|c|c|c|}
\hline Label & Definition in words & Key characters & Equation \# \\
\hline $\mathbf{V A X} \mathbf{F}$ & $\begin{array}{l}\text { Value-added exports, } \\
\text { forward-linkage-based }\end{array}$ & \multirow{2}{*}{$\begin{array}{l}\text { 1. DVA generated in producing goods and services that } \\
\text { satisfy foreign final demand } \\
\text { 2. Including indirect value-added exports } \\
\text { 3. Excluding DVA associated with intermediate } \\
\text { exports that are returned and absorbed at home } \\
\text { 4. Trade in value-added concepts, produced in one } \\
\text { country, consumed by others. }\end{array}$} & 21 \\
\hline VAX_G & $\begin{array}{l}\text { Value-added exports } \\
\text { associated with gross } \\
\text { bilateral trade flows } \\
\text { backward-linkage-based }\end{array}$ & & 19 \\
\hline RDV_F & $\begin{array}{l}\text { DVA returned home, } \\
\text { forward-linkage-based }\end{array}$ & \multirow{2}{*}{$\begin{array}{l}\text { DVA generated by producing intermediate inputs } \\
\text { exported to other countries, which eventually returns } \\
\text { home via imports to satisfy domestic final demand }\end{array}$} & 22 \\
\hline RDV_G & $\begin{array}{l}\text { DVA returned home, } \\
\text { backward-linkage-based }\end{array}$ & & 20 \\
\hline DVA_F & $\begin{array}{l}\text { DVA embodied in a } \\
\text { country's gross exports, } \\
\text { forward-linkage-based }\end{array}$ & \multirow{2}{*}{$\begin{array}{l}\text { 1. Production side concept, consistent with GDP by } \\
\text { industry statistics } \\
\text { 2. Focuses only on where the DVA is produced } \\
\text { 3. Includes the part of DVA that is generated by } \\
\text { producing intermediate inputs for other countries but } \\
\text { eventually re-imported and consumed at home. }\end{array}$} & 23 \\
\hline DVA_G & $\begin{array}{l}\text { DVA embodied in a } \\
\text { country's gross exports, } \\
\text { backward-linkage-based }\end{array}$ & & 20 \\
\hline
\end{tabular}


Table A2 Decomposition of gross exports from country s to country $r$

\begin{tabular}{|c|c|c|c|c|}
\hline Category & Label & Terms & Math & Description \\
\hline 1 & DVA_FIN & 1 & $\left(V^{s} B^{s s}\right)^{T} \# Y^{s r}$ & DVA embodied in final exports \\
\hline 2 & DVA_INT & 2 & $\left(V^{s} L^{s s}\right)^{T} \#\left(A^{s r} B^{r r} Y^{r r}\right)$ & $\begin{array}{l}\text { DVA in intermediate exports used by direct importer }(r) \text { to produce } \\
\text { local final products }\end{array}$ \\
\hline \multirow{3}{*}{3} & \multirow{3}{*}{ DVA_INTrex } & 3 & $\left(V^{s} L^{s s}\right)^{T} \#\left(A^{s r} \sum_{t \neq s, r}^{G} B^{r t} Y^{t t}\right)$ & $\begin{array}{l}\text { DVA in intermediate exports used to produce intermediates that are } \\
\text { re-exported to third countries for production of local final products }\end{array}$ \\
\hline & & 4 & $\left(V^{s} L^{s s}\right)^{T} \#\left(A^{s r} B^{r r} \sum_{t \neq s, r}^{G} Y^{r t}\right)$ & $\begin{array}{l}\text { DVA in intermediate exports used by } r \text { to produce final products } \\
\text { that are re-exported to third countries }\end{array}$ \\
\hline & & 5 & $\left(V^{s} L^{s s}\right)^{T} \#\left(A^{s r} \sum_{t \neq s, r}^{G} B^{r t} \sum_{u \neq s, t}^{G} Y^{t u}\right)$ & $\begin{array}{l}\text { DVA in intermediate exports used by } r \text { to produce intermediates that } \\
\text { are re-exported to } t \text { for the latter's production of final exports that } \\
\text { are shipped to other countries except Country s }\end{array}$ \\
\hline \multirow{3}{*}{4} & \multirow{3}{*}{ RDV_G } & 6 & $\left(V^{s} L^{s s}\right)^{T} \#\left(A^{s r} B^{r r} Y^{r s}\right)$ & DVA that returns home via its final imports from $r$ \\
\hline & & 7 & $\left(V^{s} L^{s s}\right)^{T} \#\left(A^{s r} \sum_{t \neq s, r}^{G} B^{r t} Y^{t s}\right)$ & DVA that returns home via final imports from third countries \\
\hline & & 8 & $\left(V^{s} L^{s s}\right)^{T} \#\left(A^{s r} B^{r s} Y^{s s}\right)$ & $\begin{array}{l}\text { DVA that returns home via its intermediate imports and used to } \\
\text { produce domestic final products }\end{array}$ \\
\hline \multirow{2}{*}{5} & \multirow{2}{*}{ DDC } & 9 & $\left(V^{s} L^{s s}\right)^{T} \#\left(A^{s r} B^{r s} \sum_{t \neq s}^{G} Y^{s t}\right)$ & $\begin{array}{l}\text { DVA embodied in its intermediate exports to Country } r \text { but returns } \\
\text { home as its intermediate imports, and used for production of its } \\
\text { final exports }\end{array}$ \\
\hline & & 10 & $\left(V^{s} L^{s s} \sum_{t \neq s}^{G} A^{s t} B^{t s}\right)^{T} \#\left(A^{s r} X^{r}\right)$ & $\begin{array}{l}\text { DVA in intermediate exports to Country } r \text { that returns home as } \\
\text { intermediate imports and used for production of its intermediate } \\
\text { exports }\end{array}$ \\
\hline \multirow[b]{2}{*}{6} & \multirow[b]{2}{*}{ FVA_FIN } & 11 & $\left(V^{r} B^{r s}\right)^{T} \# Y^{s r}$ & FVA from the importer ( $r$ ) embodied in final exports \\
\hline & & 12 & $\left(\sum_{t \neq s}^{G} V^{t} B\right.$ & FVA from other Countries ( $\mathrm{t}$ ) embodied in final exports \\
\hline \multirow{2}{*}{7} & \multirow{2}{*}{ FVA_INT } & 13 & $\left(V^{r} B^{r s}\right)^{T} \#\left(A^{s r} L^{r r} Y^{r r}\right)$ & $\begin{array}{l}\text { FVA from the importer (r) embodied in intermediate exports, which } \\
\text { are then used by } r \text { to produce its domestic final goods }\end{array}$ \\
\hline & & 14 & $\left(\sum_{t \neq s, r}^{G} V^{t} B^{t s}\right)^{T} \#\left(A^{s r} L^{r r} Y^{r r}\right)$ & $\begin{array}{l}\text { FVA from third Country } t \text { embodied in intermediate exports, which } \\
\text { are then used by Country } r \text { to produce its local final goods }\end{array}$ \\
\hline \multirow{2}{*}{8} & \multirow{2}{*}{ FDC } & 15 & $\left(V^{r} B^{r s}\right)^{T} \#\left(A^{s r} L^{r r} E^{r^{*}}\right)$ & $\begin{array}{l}\text { FVA from the importer (r) embodied in intermediate exports to } \\
\text { produce its exports }\end{array}$ \\
\hline & & 16 & $\left(\sum_{t \neq s, r}^{G} V^{t} B^{t s}\right)^{T} \#\left(A^{s r} L^{r r} E^{r^{*}}\right)$ & $\begin{array}{l}\text { FVA from third Country t embodied in intermediate exports to } \\
\text { produce its exports to the world }\end{array}$ \\
\hline
\end{tabular}

Note: VAX_G $=$ DVA_FIN + DVA_INT + DVA_INTrex, FVA $=$ FVA_FIN + FVA_INT,

$\mathrm{PDC}=\mathrm{DDC}+\mathrm{FDC}, \mathrm{DVA} \_\mathrm{G}=\mathrm{VAX} \_\mathrm{G}+\mathrm{RDV} \_\mathrm{G}, \mathrm{VS}=\mathrm{FVA}+\mathrm{PDC} ; \mathrm{MVA}=$ Term $11+$ Term 13,

OVA $=$ Term $12+$ Term 14 , Total Value of Final exports $=$ DVA_FIN + FVA_FIN,

Total Value of intermediate exports = DVA_INT+DVA_INTrex+RDV_G+ DDC+ FVA_INT +FDC. 


\title{
Online Appendixes (not for publication)
}

\section{Quantifying International Production Sharing at the Bilateral and Sector Levels}

\author{
Zhi Wang, Shang-Jin Wei, and Kunfu Zhu
}

\section{Appendix A: Decompose intermediate and gross trade: 2-country 2-sector and 3-country}

\section{2-sector Cases}

In the 2-country 2-sector ICIO model mentioned in section 2.1, the gross exports of Country s can be decomposed into two parts: final goods exports and intermediate goods exports based on following accounting identity:

$$
E^{s r}=\left[\begin{array}{l}
e_{1}^{s r} \\
e_{2}^{s r}
\end{array}\right]=\left[\begin{array}{l}
y_{1}^{s r} \\
y_{2}^{s r}
\end{array}\right]+\left[\begin{array}{ll}
a_{11}^{s r} & a_{12}^{s r} \\
a_{21}^{s r} & a_{22}^{s r}
\end{array}\right]\left[\begin{array}{l}
x_{1}^{r} \\
x_{2}^{r}
\end{array}\right]
$$

Based on equation (3) in main text, the gross output of Country $r$ can be decomposed into the following four components according to where they are finally absorbed:

$$
\begin{aligned}
& X^{r}=\left[\begin{array}{l}
x_{1}^{r} \\
x_{2}^{r}
\end{array}\right]=\left[\begin{array}{ll}
b_{11}^{r s} & b_{12}^{r s} \\
b_{21}^{r s} & b_{22}^{r s}
\end{array}\right]\left[\begin{array}{l}
y_{1}^{s s}+y_{1}^{s r} \\
y_{2}^{s s}+y_{2}^{s r}
\end{array}\right]+\left[\begin{array}{ll}
b_{11}^{r r} & b_{12}^{r r} \\
b_{21}^{r r} & b_{22}^{r r}
\end{array}\right]\left[\begin{array}{l}
y_{1}^{r r}+y_{1}^{r s} \\
y_{2}^{r r}+y_{2}^{r s}
\end{array}\right] \\
& =\left[\begin{array}{ll}
b_{11}^{r r} & b_{12}^{r r} \\
b_{21}^{r r} & b_{22}^{r r}
\end{array}\right]\left[\begin{array}{l}
y_{1}^{r r} \\
y_{2}^{r r}
\end{array}\right]+\left[\begin{array}{ll}
b_{11}^{r r} & b_{12}^{r r} \\
b_{21}^{r r} & b_{22}^{r r}
\end{array}\right]\left[\begin{array}{l}
y_{1}^{r s} \\
y_{2}^{r s}
\end{array}\right]+\left[\begin{array}{ll}
b_{11}^{r s} & b_{12}^{r s} \\
b_{21}^{r s} & b_{22}^{r s}
\end{array}\right]\left[\begin{array}{l}
y_{1}^{s s} \\
y_{2}^{s s}
\end{array}\right]+\left[\begin{array}{ll}
b_{11}^{r s} & b_{12}^{r s} \\
b_{21}^{r s} & b_{22}^{r s}
\end{array}\right]\left[\begin{array}{l}
y_{1}^{s r} \\
y_{2}^{s r}
\end{array}\right]
\end{aligned}
$$

Insert equation (A2) into the last term of equation (A1), we can decompose Country s' gross intermediate goods exports according to where they are absorbed as:

$$
\begin{aligned}
& A^{s r} X^{r}=\left[\begin{array}{ll}
a_{11}^{s r} & a_{12}^{s r} \\
a_{21}^{s r} & a_{22}^{s r}
\end{array}\right]\left[\begin{array}{l}
x_{1}^{r} \\
x_{2}^{r}
\end{array}\right]=\left[\begin{array}{ll}
a_{11}^{s r} & a_{12}^{s r} \\
a_{21}^{s r} & a_{22}^{s r}
\end{array}\right]\left[\begin{array}{ll}
b_{11}^{r r} & b_{12}^{r r} \\
b_{21}^{r r} & b_{22}^{r r}
\end{array}\right]\left[\begin{array}{l}
y_{1}^{r r} \\
y_{2}^{r r}
\end{array}\right]+\left[\begin{array}{ll}
a_{11}^{s r} & a_{12}^{s r} \\
a_{21}^{s r} & a_{22}^{s r}
\end{array}\right]\left[\begin{array}{ll}
b_{11}^{r r} & b_{12}^{r r} \\
b_{21}^{r r} & b_{22}^{r r}
\end{array}\right]\left[\begin{array}{l}
y_{1}^{r s} \\
y_{2}^{r s}
\end{array}\right] \\
& +\left[\begin{array}{ll}
a_{11}^{s r} & a_{12}^{s r} \\
a_{21}^{s r} & a_{22}^{s r}
\end{array}\right]\left[\begin{array}{ll}
b_{11}^{r s} & b_{12}^{r s} \\
b_{21}^{r s} & b_{22}^{r s}
\end{array}\right]\left[\begin{array}{l}
y_{1}^{s s} \\
y_{2}^{s s}
\end{array}\right]+\left[\begin{array}{ll}
a_{11}^{s r} & a_{12}^{s r} \\
a_{21}^{s r} & a_{22}^{s r}
\end{array}\right]\left[\begin{array}{ll}
b_{11}^{r s} & b_{12}^{r s} \\
b_{21}^{r s} & b_{22}^{r s}
\end{array}\right]\left[\begin{array}{l}
y_{1}^{s r} \\
y_{2}^{s r}
\end{array}\right]
\end{aligned}
$$

The first term in the last right side of equation (A3) is the part of Country s' intermediate goods exports used by Country $r$ to produce domestic final goods and consumed in Country r; the second term is the part of country s' intermediate goods exports used by Country $r$ to produce final goods exports that are shipped back to Country s; the third term is the part of Country s' intermediate goods exports that are used by Country $r$ to produce intermediate exports, shipped back to Country s and used by Country s to produce its domestic consumed 
final goods; the last term is the part of country s' intermediate goods exports used by Country $r$ to produce intermediate goods exports that are shipped back to Country s to produce final goods exports to Country r. These four terms completely decompose Country s' intermediate exports according to where they are finally absorbed.

From the gross output production and use balance conditions, we know

$$
\begin{aligned}
& {\left[\begin{array}{l}
x_{1}^{r} \\
x_{2}^{r}
\end{array}\right]=\left[\begin{array}{ll}
a_{11}^{r r} & a_{12}^{r r} \\
a_{21}^{r r} & a_{22}^{r r}
\end{array}\right]\left[\begin{array}{l}
x_{1}^{r} \\
x_{2}^{r}
\end{array}\right]+\left[\begin{array}{ll}
a_{11}^{r s} & a_{12}^{r s} \\
a_{21}^{r s} & a_{22}^{r s}
\end{array}\right]\left[\begin{array}{l}
x_{1}^{s} \\
x_{2}^{s}
\end{array}\right]+\left[\begin{array}{l}
y_{1}^{r s} \\
y_{2}^{r s}
\end{array}\right]+\left[\begin{array}{l}
y_{1}^{r r} \\
y_{2}^{r r}
\end{array}\right]} \\
& =\left[\begin{array}{ll}
a_{11}^{r r} & a_{12}^{r r} \\
a_{21}^{r r} & a_{22}^{r r}
\end{array}\right]\left[\begin{array}{l}
x_{1}^{r} \\
x_{2}^{r}
\end{array}\right]+\left[\begin{array}{l}
y_{1}^{r r} \\
y_{2}^{r r}
\end{array}\right]+\left[\begin{array}{l}
e_{1}^{r s} \\
e_{2}^{r s}
\end{array}\right]
\end{aligned}
$$

Re-arranging:

$$
\left[\begin{array}{l}
x_{1}^{r} \\
x_{2}^{r}
\end{array}\right]=\left[\begin{array}{cc}
1-a_{11}^{r r} & -a_{12}^{r r} \\
-a_{21}^{r r} & 1-a_{22}^{r r}
\end{array}\right]^{-1}\left[\begin{array}{c}
y_{1}^{r r} \\
y_{2}^{r r}
\end{array}\right]+\left[\begin{array}{cc}
1-a_{11}^{r r} & -a_{12}^{r r} \\
-a_{21}^{r r} & 1-a_{22}^{r r}
\end{array}\right]^{-1}\left[\begin{array}{c}
e_{1}^{r s} \\
e_{2}^{r s}
\end{array}\right]
$$

Define:

$$
L^{r r}=\left[\begin{array}{ll}
l_{11}^{r r} & l_{12}^{r r} \\
l_{21}^{r r} & l_{22}^{r r}
\end{array}\right]=\left[\begin{array}{cc}
1-a_{11}^{r r} & -a_{12}^{r r} \\
-a_{21}^{r r} & 1-a_{22}^{r r}
\end{array}\right]^{-1} \text { as local Leontief inverse matrix, then equation (A5) }
$$

can be Re-written as

$$
\left[\begin{array}{l}
x_{1}^{r} \\
x_{2}^{r}
\end{array}\right]=\left[\begin{array}{ll}
l_{11}^{r r} & l_{12}^{r r} \\
l_{21}^{r r} & l_{22}^{r r}
\end{array}\right]\left[\begin{array}{l}
y_{1}^{r r} \\
y_{2}^{r r}
\end{array}\right]+\left[\begin{array}{ll}
l_{11}^{r r} & l_{12}^{r r} \\
l_{21}^{r r} & l_{22}^{r r}
\end{array}\right]\left[\begin{array}{c}
e_{1}^{r s} \\
e_{2}^{r s}
\end{array}\right]
$$

Insert equation (A6) into last term in equation (A1), the intermediate goods exports by Country s can also be decomposed into following two components according to where it is used similar to a single country IO model:

$$
A^{s r} X^{r}=\left[\begin{array}{ll}
a_{11}^{s r} & a_{12}^{s r} \\
a_{21}^{s r} & a_{22}^{s r}
\end{array}\right]\left[\begin{array}{l}
x_{1}^{r r} \\
x_{2}^{r r}
\end{array}\right]=\left[\begin{array}{ll}
a_{11}^{s r} & a_{12}^{s r} \\
a_{21}^{s r} & a_{22}^{s r}
\end{array}\right]\left[\begin{array}{ll}
l_{11}^{r r} & l_{12}^{r r} \\
l_{21}^{r r} & l_{22}^{r r}
\end{array}\right]\left[\begin{array}{l}
y_{1}^{r r} \\
y_{2}^{r r}
\end{array}\right]+\left[\begin{array}{ll}
a_{11}^{s r} & a_{12}^{s r} \\
a_{21}^{s r} & a_{22}^{s r}
\end{array}\right]\left[\begin{array}{ll}
l_{11}^{r r} & l_{12}^{r r} \\
l_{21}^{r r} & l_{22}^{r r}
\end{array}\right]\left[\begin{array}{c}
e_{1}^{r s} \\
e_{2}^{r s}
\end{array}\right]
$$

Equations (A3) and (A7), both of them completely decompose Country s' intermediate exports, are the key technical step to fully decompose gross trade flows, since they transfer gross output (and gross exports), usually endogenous variables in standard ICIO models, to exogenous variables in the gross trade accounting framework we proposed. Together with the global 
value-added multiplier adding-up condition defined in equation (5) in main text and the local value-added multipliers defined below, they are the major step stones in deriving our gross exports decomposition formula.

From equation (5) in main text, we can obtain Country s' domestic and foreign value-added multipliers as follows:

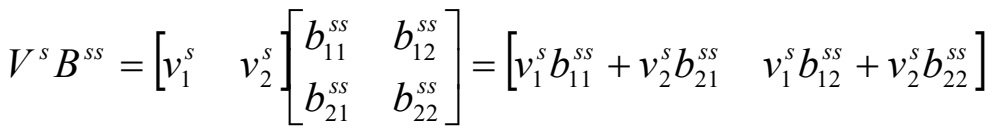

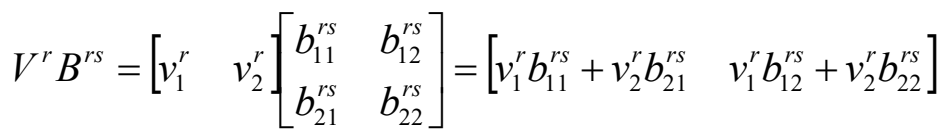

Also from equation (5) in main text we know that the sum of equations (A8) and (A9) equals unity. In a single country IO model, domestic value-added multiplier can be calculated as

$$
V^{s}\left(I-A^{s s}\right)^{-1}=V^{s} L^{s s}=\left[\begin{array}{ll}
v_{1}^{s} & v_{2}^{s}
\end{array}\left[\begin{array}{ll}
l_{11}^{s s} & l_{12}^{s s} \\
l_{21}^{s s} & l_{22}^{s s}
\end{array}\right]=\left[\begin{array}{ll}
v_{1}^{s} l_{11}^{s s}+v_{2}^{s} l_{21}^{s s} & v_{1}^{s} l_{12}^{s s}+v_{2}^{s} l_{22}^{s s}
\end{array}\right]\right.
$$

Using equation (A10), the property of the sum of equations (A8) and (A9) equals to unity, and define “\#” as element-wise matrix multiplication operation ${ }^{19}$, the value of Country s' gross intermediate exports can be decomposed as

$$
\begin{aligned}
& A^{s r} X^{r}=\left[\begin{array}{ll}
a_{11}^{s r} & a_{12}^{s r} \\
a_{21}^{s r} & a_{22}^{s r}
\end{array}\right]\left[\begin{array}{l}
x_{1}^{r} \\
x_{2}^{r}
\end{array}\right]=\left[\begin{array}{l}
v_{1}^{s} l_{11}^{s s}+v_{2}^{s} l_{21}^{s s} \\
v_{1}^{s} l_{12}^{s s}+v_{2}^{s} l_{22}^{s s}
\end{array}\right] \#\left\{\left[\begin{array}{ll}
a_{11}^{s r} & a_{12}^{s r} \\
a_{21}^{s r} & a_{22}^{s r}
\end{array}\right]\left[\begin{array}{l}
x_{1}^{r} \\
x_{2}^{r}
\end{array}\right]\right\} \\
& +\left\{\left[\begin{array}{l}
v_{1}^{s} b_{11}^{s s}+v_{2}^{s} b_{21}^{s s} \\
v_{1}^{s} b_{12}^{s s}+v_{2}^{s} b_{22}^{s s}
\end{array}\right]-\left[\begin{array}{l}
v_{1}^{s} l_{11}^{s s}+v_{2}^{s} l_{21}^{s s} \\
v_{1}^{s} l_{12}^{s s}+v_{2}^{s} l_{22}^{s s}
\end{array}\right]\right\} \#\left\{\left[\begin{array}{ll}
a_{11}^{s r} & a_{12}^{s r} \\
a_{21}^{s r} & a_{22}^{s r}
\end{array}\right]\left[\begin{array}{l}
x_{1}^{r} \\
x_{2}^{r}
\end{array}\right]\right\} \\
& +\left[\begin{array}{l}
v_{1}^{r} b_{11}^{r s}+v_{2}^{r} b_{21}^{r s} \\
v_{1}^{r} b_{11}^{r s}+v_{2}^{r} b_{21}^{r s}
\end{array}\right] \#\left\{\left[\begin{array}{ll}
a_{11}^{s r} & a_{12}^{s r} \\
a_{21}^{s r} & a_{22}^{s r}
\end{array}\right]\left[\begin{array}{c}
x_{1}^{r} \\
x_{2}^{r}
\end{array}\right]\right\}
\end{aligned}
$$

Finally, based on the standard Leontief decomposition, Country s' final goods exports can be decomposed into domestic and foreign value-added as follows:

\footnotetext{
19 For example, when a matrix is multiplied by $n \quad n \times 1$ column vector, each row of the matrix is multiplied by the corresponding row of the vector.
} 


$$
\left[\begin{array}{l}
y_{1}^{s r} \\
y_{2}^{s r}
\end{array}\right]=\left[\begin{array}{l}
v_{1}^{s} b_{11}^{s s}+v_{2}^{s} b_{21}^{s s} \\
v_{1}^{s} b_{12}^{s s}+v_{2}^{s} b_{22}^{s s}
\end{array}\right] \#\left[\begin{array}{l}
y_{1}^{s r} \\
y_{2}^{s r}
\end{array}\right]+\left[\begin{array}{l}
v_{1}^{r} b_{11}^{r s}+v_{2}^{r} b_{21}^{r s} \\
v_{1}^{r} b_{11}^{r s}+v_{2}^{r} b_{21}^{r s}
\end{array}\right] \#\left[\begin{array}{l}
y_{1}^{s r} \\
y_{2}^{s r}
\end{array}\right]
$$

Inserting equations (A3) and (A7) into equation (A11), and combining equations (A11) and (A12), we obtain Country s' gross exports decomposition equation as:

$$
\begin{aligned}
& E^{s r}=\left[\begin{array}{l}
e_{1}^{s r} \\
e_{2}^{s r}
\end{array}\right]=\left[\begin{array}{l}
y_{1}^{s r} \\
y_{2}^{s r}
\end{array}\right]+\left[\begin{array}{ll}
a_{11}^{s r} & a_{12}^{s r} \\
a_{21}^{s r} & a_{22}^{s r}
\end{array}\right]\left[\begin{array}{l}
x_{1}^{r} \\
x_{2}^{r}
\end{array}\right] \\
& =\left[\begin{array}{l}
v_{1}^{s} b_{11}^{s s}+v_{2}^{s} b_{21}^{s s} \\
v_{1}^{s} b_{12}^{s s}+v_{2}^{s} b_{22}^{s s}
\end{array}\right] \#\left[\begin{array}{l}
y_{1}^{s r} \\
y_{2}^{s r}
\end{array}\right]+\left[\begin{array}{l}
v_{1}^{s} l_{11}^{s s}+v_{2}^{s s} l_{21}^{s s} \\
v_{1}^{s} l_{12}^{s s}+v_{2}^{s} l_{22}^{s s}
\end{array}\right] \#\left\{\left[\begin{array}{ll}
a_{11}^{s r} & a_{12}^{s r} \\
a_{21}^{s r} & a_{22}^{s r}
\end{array}\right]\left[\begin{array}{ll}
b_{11}^{r r} & b_{12}^{r r} \\
b_{21}^{r r} & b_{22}^{r r}
\end{array}\right]\left[\begin{array}{l}
y_{1}^{r r} \\
y_{2}^{r r}
\end{array}\right]\right\} \\
& +\left[\begin{array}{l}
v_{1}^{s} l_{11}^{s s}+v_{2}^{s} l_{21}^{s s} \\
v_{1}^{s} l_{12}^{s s}+v_{2}^{s} l_{22}^{s s}
\end{array}\right] \#\left\{\left[\begin{array}{ll}
a_{11}^{s r} & a_{12}^{s r} \\
a_{21}^{s r} & a_{22}^{s r}
\end{array}\right]\left[\begin{array}{ll}
b_{11}^{r r} & b_{12}^{r r} \\
b_{21}^{r r} & b_{22}^{r r}
\end{array}\right]\left[\begin{array}{l}
y_{1}^{r s} \\
y_{2}^{r s}
\end{array}\right]\right\}+\left[\begin{array}{ll}
v_{1}^{s} l_{11}^{s s}+v_{2}^{s s} l_{21}^{s s} \\
v_{1}^{s} l_{12}^{s s}+v_{2}^{s} l_{22}^{s s}
\end{array}\right] \#\left\{\left[\begin{array}{ll}
a_{11}^{s r} & a_{12}^{s r} \\
a_{21}^{s r} & a_{22}^{s r}
\end{array}\right]\left[\begin{array}{ll}
b_{11}^{r s} & b_{12}^{r s} \\
b_{21}^{r s} & b_{22}^{r s}
\end{array}\right]\left[\begin{array}{l}
y_{1}^{s s} \\
y_{2}^{s s}
\end{array}\right]\right\} \\
& +\left[\begin{array}{l}
v_{1}^{s} l_{11}^{s s}+v_{2}^{s s} l_{21}^{s s} \\
v_{1}^{s} l_{12}^{s s}+v_{2}^{s} l_{22}^{s s}
\end{array}\right] \#\left\{\left[\begin{array}{ll}
a_{11}^{s r} & a_{12}^{s r} \\
a_{21}^{s r} & a_{22}^{s r}
\end{array}\right]\left[\begin{array}{ll}
b_{11}^{r s} & b_{12}^{r s} \\
b_{21}^{r s} & b_{22}^{r s}
\end{array}\right]\left[\begin{array}{l}
y_{1}^{s r} \\
y_{2}^{s r}
\end{array}\right]\right\} \\
& \left.+\left\{\left[\begin{array}{ll}
v_{1}^{s} b_{11}^{s s}+v_{2}^{s} b_{21}^{s s} \\
v_{1}^{s s} b_{12}^{s s}+v_{2}^{s} b_{22}^{s s}
\end{array}\right]-\left[\begin{array}{ll}
v_{1}^{s} l_{11}^{s s}+v_{2}^{s} l_{21}^{s s} \\
v_{1}^{s} l_{12}^{s s}+v_{2}^{s} l_{22}^{s s}
\end{array}\right]\right\} \#\left\{\begin{array}{ll}
a_{11}^{s r} & a_{12}^{s r} \\
a_{21}^{s r} & a_{22}^{s r}
\end{array}\right]\left[\begin{array}{l}
x_{1}^{r} \\
x_{2}^{r}
\end{array}\right]\right\} \\
& +\left[\begin{array}{l}
v_{1}^{r} b_{11}^{r s}+v_{2}^{r} b_{21}^{r s} \\
v_{1}^{r} b_{11}^{r s}+v_{2}^{r} b_{21}^{r s}
\end{array}\right] \#\left[\begin{array}{l}
y_{1}^{s r} \\
y_{2}^{s r}
\end{array}\right]+\left[\begin{array}{ll}
v_{1}^{r} b_{11}^{r s}+v_{2}^{r r} b_{21}^{r s} \\
v_{1}^{r} b_{11}^{r s}+v_{2}^{r} b_{21}^{r s}
\end{array}\right] \#\left\{\left[\begin{array}{ll}
a_{11}^{s r} & a_{12}^{s r} \\
a_{21}^{s r} & a_{22}^{s r}
\end{array}\right]\left[\begin{array}{ll}
l_{11}^{r r} & l_{12}^{r r} \\
l_{21}^{r r} & l_{22}^{r r}
\end{array}\right]\left[\begin{array}{l}
y_{1}^{r r} \\
y_{2}^{r r}
\end{array}\right]\right\} \\
& +\left[\begin{array}{l}
v_{1}^{r} b_{11}^{r s}+v_{2}^{r} b_{21}^{r s} \\
v_{1}^{r} b_{11}^{r s}+v_{2}^{r} b_{21}^{r s}
\end{array}\right] \#\left\{\left[\begin{array}{ll}
a_{11}^{s r} & a_{12}^{s r} \\
a_{21}^{s r} & a_{22}^{s r}
\end{array}\right]\left[\begin{array}{ll}
l_{11}^{r r} & l_{12}^{r r} \\
l_{21}^{r r} & l_{22}^{r r}
\end{array}\right]\left[\begin{array}{l}
e_{1}^{r s} \\
e_{2}^{r s}
\end{array}\right]\right\}
\end{aligned}
$$

Equation (A13) indicates that the gross exports of a country can be completely decomposed into the sum of nine terms. It is an extension of equation (13) in KWW; with the domestic pure double counting term being further split by production related to final and intermediate goods exports respectively. To better understand each term in this accounting equation, we provide the following economic interpretations:

The first term is domestic value added embodied in the final exports of the $1^{\text {st }}$ and $2^{\text {nd }}$ sectors of Country s. Each of them has two parts: domestic value added created by the sector itself and domestic value added created by the other sector embodied in the sector's final exports.

The second term is domestic value added embodied in Country s' $1^{\text {st }}$ and $2^{\text {nd }}$ sector's intermediate exports which are used by Country $r$ to produce final goods, $y_{1}^{r r}$ and $y_{2}^{r r}$, and are 
consumed in $r$.

These two terms are domestic value added embodied in Country s' gross exports which are ultimately absorbed by Country r. They are value added exports of Country s.

The third term is domestic value added embodied in Country s' $1^{\text {st }}$ and $2^{\text {nd }}$ sector's intermediate exports used to produce Country r's final exports, i.e. country s' imports of final goods from $r$.

The fourth term is domestic value added embodied in Country s' $1^{\text {st }}$ and $2^{\text {nd }}$ sector's intermediate exports that are used by Country $\mathrm{r}$ to produce intermediate exports and return to Country s via its intermediate imports to produce its domestic final goods.

These two terms are domestic value added embodied in the $1^{\text {st }}$ and $2^{\text {nd }}$ sector's gross exports which returned home and are finally consumed in Country s.

The first four terms are the domestic value added (GDP) embodied in the $1^{\text {st }}$ and $2^{\text {nd }}$ sectors' gross exports of Country s, which include value added created from all sectors in Country s.

The fifth term is domestic value added of Country $s^{\prime} 1^{\text {st }}$ and $2^{\text {nd }}$ sector's intermediate exports which return home as its $1^{\text {st }}$ and/or $2^{\text {nd }}$ sector's intermediate imports and are used for production of Country s' both sector's final exports and are finally consumed in Country r. They are part of the value-added in Country s' final exports and already counted once by the first term of equation (A13), therefore it is a domestic double counted portion caused by the back and forth intermediate goods trade in order to produce final goods exports in Country s.

The sixth term is domestic value added of Country $s^{\prime} 1^{\text {st }}$ and $2^{\text {nd }}$ sector's intermediate exports that return home as intermediate imports and are used for production of Country s' intermediate exports to Country r. It is also a domestic double counted portion caused by the back and forth intermediate goods trade in order to produce intermediate goods exports in Country s.

Sum of the first to the sixth terms equals domestic content of the $1^{\text {st }}$ and $2^{\text {nd }}$ sector's gross 
exports, $\sum_{i}^{2} v_{i}^{s} b_{i 1}^{s s} e_{1}^{s r}$ and $\sum_{i}^{2} v_{i}^{s} b_{i 2}^{s s} e_{2}^{s r}$

The seventh term is foreign value added used in Country $s^{\prime} 1^{\text {st }}$ and $2^{\text {nd }}$ sector's final goods exports. Each of them also has two parts: foreign value-added from the sector itself and the other sector used to produce final exports from Country s. Adding up the first and the seventh terms accounts $100 \%$ of the value of the final exports in Country s by sector.

The eighth term is foreign value added used to produce the $1^{\text {st }}$ and $2^{\text {nd }}$ sector intermediate exports of Country s, which are then used by Country $r$ to produce its domestic final goods. Summing the seventh and eighth terms, the two elements in the resulted vector are total foreign value added embodied in the $1^{\text {st }}$ and $2^{\text {nd }}$ sectors' gross exports of Country s, respectively.

The ninth term is foreign value added embodied in the $1^{\text {st }}$ and $2^{\text {nd }}$ sector's intermediate exports used by Country $r$ to produce its final and intermediate exports, which is the foreign double counted term of Country s' exports. Adding up the eighth and ninth term yields the foreign content of the $1^{\text {st }}$ and $2^{\text {nd }}$ sector's intermediate exports.

Therefore, sum the seventh to the ninth terms equals the foreign content of the $1^{\text {st }}$ and $2^{\text {nd }}$ sector's gross exports of Country s, $\sum_{i}^{2} v_{i}^{r} b_{i 1}^{r s} e_{1}^{s r}$ and $\sum_{i}^{2} v_{i}^{r} b_{i 2}^{r s} e_{2}^{s r}$.

It is easy to show that the aggregation of the two sectors in equation (A13) results in equation (13) in KWW. A detailed proof is given as follow: 
$u E^{s r}=\left[\begin{array}{ll}v_{1}^{s} & v_{2}^{s}\end{array}\left[\begin{array}{ll}b_{11}^{s s} & b_{12}^{s s} \\ b_{21}^{s s} & b_{22}^{s s}\end{array}\right]\left[\begin{array}{l}y_{1}^{s r} \\ y_{2}^{s r}\end{array}\right]+\left[\begin{array}{ll}v_{1}^{s} & v_{2}^{s}\end{array}\right]\left[\begin{array}{ll}l_{11}^{s s} & l_{12}^{s s} \\ l_{21}^{s s} & l_{22}^{s s}\end{array}\right]\left[\begin{array}{ll}a_{11}^{s r} & a_{12}^{s r} \\ a_{21}^{s r} & a_{22}^{s r}\end{array}\right]\left[\begin{array}{ll}b_{11}^{r r} & b_{12}^{r r} \\ b_{21}^{r r} & b_{22}^{r r}\end{array}\right]\left[\begin{array}{l}y_{1}^{r r} \\ y_{2}^{r r}\end{array}\right]\right.$

$+\left[\begin{array}{ll}v_{1}^{s} & v_{2}^{s}\end{array}\left[\begin{array}{ll}l_{11}^{s s} & l_{12}^{s s} \\ l_{21}^{s s} & l_{22}^{s s}\end{array}\right]\left[\begin{array}{ll}a_{11}^{s r} & a_{12}^{s r} \\ a_{21}^{s r} & a_{22}^{s r}\end{array}\right]\left[\begin{array}{ll}b_{11}^{r r} & b_{12}^{r r} \\ b_{21}^{r r} & b_{22}^{r r}\end{array}\right]\left[\begin{array}{l}y_{1}^{r s} \\ y_{2}^{r s}\end{array}\right]+\left[\begin{array}{ll}v_{1}^{s} & v_{2}^{s}\end{array}\right]\left[\begin{array}{ll}l_{11}^{s s} & l_{12}^{s s} \\ l_{21}^{s s} & l_{22}^{s s}\end{array}\right]\left[\begin{array}{ll}a_{11}^{s r} & a_{12}^{s r} \\ a_{21}^{s r} & a_{22}^{s r}\end{array}\right]\left[\begin{array}{ll}b_{11}^{r s} & b_{12}^{r s} \\ b_{21}^{r s} & b_{22}^{r s}\end{array}\right]\left[\begin{array}{l}y_{1}^{s s} \\ y_{2}^{s s}\end{array}\right]\right.$

$+\left[\begin{array}{ll}v_{1}^{s} & v_{2}^{s}\end{array}\right]\left[\begin{array}{ll}l_{11}^{s s} & l_{12}^{s s} \\ l_{21}^{s s} & l_{22}^{s s}\end{array}\right]\left[\begin{array}{ll}a_{11}^{s r} & a_{12}^{s r} \\ a_{21}^{s r} & a_{22}^{s r}\end{array}\right]\left[\begin{array}{ll}b_{11}^{r s} & b_{12}^{r s} \\ b_{21}^{r s} & b_{22}^{r s}\end{array}\right]\left[\begin{array}{l}y_{1}^{s r} \\ y_{2}^{s r}\end{array}\right]+\left[\begin{array}{ll}v_{1}^{s} & v_{2}^{s}\end{array}\right]\left\{\left[\begin{array}{ll}b_{11}^{s s} & b_{12}^{s s} \\ b_{21}^{s s} & b_{22}^{s s}\end{array}\right]-\left[\begin{array}{ll}l_{11}^{s s} & l_{12}^{s s} \\ l_{21}^{s s} & l_{22}^{s s}\end{array}\right]\right)\left[\begin{array}{ll}a_{11}^{s r} & a_{12}^{s r} \\ a_{21}^{s r} & a_{22}^{s r}\end{array}\right]\left[\begin{array}{l}x_{1}^{r} \\ x_{2}^{r}\end{array}\right]$

$+\left[\begin{array}{ll}v_{1}^{s} & v_{2}^{s}\end{array}\right]\left[\begin{array}{ll}b_{11}^{r s} & b_{12}^{r s} \\ b_{21}^{r s} & b_{22}^{r s}\end{array}\right]\left[\begin{array}{l}y_{1}^{s r} \\ y_{2}^{s r}\end{array}\right]+\left[\begin{array}{ll}v_{1}^{s} & v_{2}^{s}\end{array}\right]\left[\begin{array}{ll}b_{11}^{r s} & b_{12}^{r s} \\ b_{21}^{r s} & b_{22}^{r s}\end{array}\right]\left[\begin{array}{ll}a_{11}^{s r} & a_{12}^{s r} \\ a_{21}^{s r} & a_{22}^{s r}\end{array}\right]\left[\begin{array}{ll}l_{11}^{r r} & l_{12}^{r r} \\ l_{21}^{r r} & l_{22}^{r r}\end{array}\right]\left[\begin{array}{l}y_{1}^{r r} \\ y_{2}^{r r}\end{array}\right]$

$+\left[\begin{array}{ll}v_{1}^{s} & v_{2}^{s}\end{array}\right]\left[\begin{array}{ll}b_{11}^{r s} & b_{12}^{r s} \\ b_{21}^{r s} & b_{22}^{r s}\end{array}\right]\left[\begin{array}{ll}a_{11}^{s r} & a_{12}^{s r} \\ a_{21}^{s r} & a_{22}^{s r}\end{array}\right]\left[\begin{array}{ll}l_{11}^{r r} & l_{12}^{r r} \\ l_{21}^{r r} & l_{22}^{r r}\end{array}\right]\left[\begin{array}{c}e_{1}^{r s} \\ e_{2}^{r s}\end{array}\right]$

$=V^{s} B^{s s} Y^{s r}+V^{s} L^{s s} A^{s r} B^{r r} Y^{r r}+V^{s} L^{s s} A^{s r} B^{r r} Y^{r s}+V^{s} L^{s s} A^{s r} B^{r s} Y^{s s}+V^{s} L^{s s} A^{s r} B^{r s} Y^{s r}$

$+V^{s}\left(B^{s s}-L^{s s}\right) A^{s r} X^{r}+V^{r} B^{r s} Y^{s r}+V^{r} B^{r s} A^{s r} L^{r r} Y^{r r}+V^{r} B^{r s} A^{s r} L^{r r} E^{r s}$

$=V^{s} B^{s s} Y^{s r}+V^{s} B^{s r} Y^{r r}+V^{s} B^{s r} Y^{r s}+V^{s} L^{s s} A^{s r} B^{r s} Y^{s s}+V^{s} L^{s s} A^{s r} B^{r s} E^{s r}$

$+V^{r} B^{r s} Y^{s r}+V^{r} B^{r s} A^{s r} L^{r r} Y^{r r}+V^{r} B^{r s} A^{s r} L^{r r} E^{r s}$

Based on property of Leontief inverse matrix, we have:

$$
\begin{aligned}
& B^{s r}=\left[\begin{array}{ll}
b_{11}^{s r} & b_{12}^{s r} \\
b_{21}^{s r} & b_{22}^{s r}
\end{array}\right]=\left[\begin{array}{cc}
1-a_{11}^{s s} & -a_{12}^{s s} \\
-a_{21}^{s s} & 1-a_{22}^{s s}
\end{array}\right]^{-1}\left[\begin{array}{ll}
a_{11}^{s r} & a_{12}^{s r} \\
a_{21}^{s r} & a_{22}^{s r}
\end{array}\right]\left[\begin{array}{ll}
b_{11}^{r r} & b_{12}^{r r} \\
b_{21}^{r r} & b_{22}^{r r}
\end{array}\right]=L^{s s} A^{s r} B^{r r} \\
& B^{s s}-L^{s s}=\left[\begin{array}{ll}
b_{11}^{s s} & b_{12}^{s s} \\
b_{21}^{s s} & b_{22}^{s s}
\end{array}\right]-\left[\begin{array}{cc}
1-a_{11}^{s s} & -a_{12}^{s s} \\
-a_{21}^{s s} & 1-a_{22}^{s s}
\end{array}\right]^{-1} \\
& =\left[\begin{array}{cc}
1-a_{11}^{s s} & -a_{12}^{s s} \\
-a_{21}^{s s} & 1-a_{22}^{s s}
\end{array}\right]^{-1}\left[\begin{array}{ll}
a_{11}^{s r} & a_{12}^{s r} \\
a_{21}^{s r} & a_{22}^{s r}
\end{array}\right]\left[\begin{array}{ll}
b_{11}^{r s} & b_{12}^{r r} \\
b_{21}^{r s} & b_{22}^{r s}
\end{array}\right]=L^{s s} A^{s r} B^{r s}
\end{aligned}
$$

Similarly, the Country r' gross exports can be decomposed as: 


$$
\begin{aligned}
& {\left[\begin{array}{l}
e_{1}^{r s} \\
e_{2}^{r s}
\end{array}\right]=\left[\begin{array}{l}
v_{1}^{r} b_{11}^{r r}+v_{2}^{r} b_{21}^{r r} \\
v_{1}^{r} b_{12}^{r r}+v_{2}^{r} b_{22}^{r r}
\end{array}\right] \#\left[\begin{array}{l}
y_{1}^{r s} \\
y_{2}^{r s}
\end{array}\right]+\left[\begin{array}{l}
v_{1}^{r} l_{11}^{r r}+v_{2}^{r} l_{21}^{r r} \\
v_{1}^{r} l_{12}^{r r}+v_{2}^{r} l_{22}^{r r}
\end{array}\right] \#\left[\begin{array}{ll}
a_{11}^{r s} & a_{12}^{r s} \\
a_{21}^{r s} & a_{22}^{r s}
\end{array}\right]\left[\begin{array}{ll}
b_{11}^{s s} & b_{12}^{s s} \\
b_{21}^{s s} & b_{22}^{s s}
\end{array}\right]\left[\begin{array}{l}
y_{1}^{s s} \\
y_{2}^{s s}
\end{array}\right]} \\
& +\left[\begin{array}{l}
v_{1}^{r} l_{11}^{r r}+v_{2}^{r} l_{21}^{r r} \\
v_{1}^{r} l_{12}^{r r}+v_{2}^{r} l_{22}^{r r}
\end{array}\right] \#\left[\begin{array}{ll}
a_{11}^{r s} & a_{12}^{r s} \\
a_{21}^{r s} & a_{22}^{r s}
\end{array}\right]\left[\begin{array}{ll}
b_{11}^{s s} & b_{12}^{s s} \\
b_{21}^{s s} & b_{22}^{s s}
\end{array}\right]\left[\begin{array}{l}
y_{1}^{s r} \\
y_{2}^{s r}
\end{array}\right] \\
& +\left[\begin{array}{l}
v_{1}^{r} l_{11}^{r r}+v_{2}^{r} l_{21}^{r r} \\
v_{1}^{r} l_{12}^{r r}+v_{2}^{r} l_{22}^{r r}
\end{array}\right] \#\left[\begin{array}{ll}
a_{11}^{r s} & a_{12}^{r s} \\
a_{21}^{r s} & a_{22}^{r s}
\end{array}\right]\left[\begin{array}{ll}
b_{11}^{s r} & b_{12}^{s r} \\
b_{21}^{s r} & b_{22}^{s r}
\end{array}\right]\left[\begin{array}{l}
y_{1}^{r r} \\
y_{2}^{r r}
\end{array}\right] \\
& +\left[\begin{array}{l}
v_{1}^{r} l_{11}^{r r}+v_{2}^{r} l_{21}^{r r} \\
v_{1}^{r} l_{12}^{r r}+v_{2}^{r} l_{22}^{r r}
\end{array}\right] \#\left[\begin{array}{ll}
a_{11}^{r s} & a_{12}^{r s} \\
a_{21}^{r s} & a_{22}^{r s}
\end{array}\right]\left[\begin{array}{ll}
b_{11}^{s r} & b_{12}^{s r} \\
b_{21}^{s r} & b_{22}^{s r}
\end{array}\right]\left[\begin{array}{l}
y_{1}^{r s} \\
y_{2}^{r s}
\end{array}\right] \\
& +\left\{\left[\begin{array}{l}
v_{1}^{r} b_{11}^{r r}+v_{2}^{r} b_{21}^{r r} \\
v_{1}^{r} b_{12}^{r r}+v_{2}^{r} b_{22}^{r r}
\end{array}\right]-\left[\begin{array}{l}
v_{1}^{r} l_{11}^{r r}+v_{2}^{r} l_{21}^{r r} \\
v_{1}^{r} l_{12}^{r r}+v_{2}^{r} l_{22}^{r r}
\end{array}\right]\right\} \#\left\{\left[\begin{array}{ll}
a_{11}^{r s} & a_{12}^{r s} \\
a_{21}^{r s} & a_{22}^{r s}
\end{array}\right]\left[\begin{array}{l}
x_{1}^{s} \\
x_{2}^{s}
\end{array}\right]\right\} \\
& +\left[\begin{array}{l}
v_{1}^{s} b_{11}^{s r}+v_{2}^{s} b_{21}^{s r} \\
v_{1}^{s} b_{12}^{s r}+v_{2}^{s} b_{22}^{s r}
\end{array}\right] \#\left[\begin{array}{l}
y_{1}^{r s} \\
y_{2}^{r s}
\end{array}\right]+\left[\begin{array}{l}
v_{1}^{s} b_{11}^{s r}+v_{2}^{s} b_{21}^{s r} \\
v_{1}^{s} b_{12}^{s r}+v_{2}^{s} b_{22}^{s r}
\end{array}\right] \#\left[\begin{array}{ll}
a_{11}^{r s} & a_{12}^{r s} \\
a_{21}^{r s} & a_{22}^{r s}
\end{array}\right]\left[\begin{array}{ll}
l_{11}^{s s} & l_{12}^{s s} \\
l_{21}^{s s} & l_{22}^{s s}
\end{array}\right]\left[\begin{array}{l}
y_{1}^{s s} \\
y_{2}^{s s}
\end{array}\right] \\
& +\left[\begin{array}{l}
v_{1}^{s} b_{11}^{s r}+v_{2}^{s} b_{21}^{s r} \\
v_{1}^{s} b_{12}^{s r}+v_{2}^{s} b_{22}^{s r}
\end{array}\right] \#\left[\begin{array}{ll}
a_{11}^{r s} & a_{12}^{r s} \\
a_{21}^{r s} & a_{22}^{r s}
\end{array}\right]\left[\begin{array}{ll}
l_{11}^{s s} & l_{12}^{s s} \\
l_{21}^{s s} & l_{22}^{s s}
\end{array}\right]\left[\begin{array}{l}
e_{1}^{s r} \\
e_{2}^{s r}
\end{array}\right]
\end{aligned}
$$

In a 3-country, 2-sector model, the gross output of Country $r$ can be decomposed into the following four components according to where they are finally absorbed:

$$
\begin{aligned}
& X^{r}=\left[\begin{array}{l}
x_{1}^{r} \\
x_{2}^{r}
\end{array}\right]=\left[\begin{array}{ll}
b_{11}^{r s} & b_{12}^{r s} \\
b_{21}^{r s} & b_{22}^{r s}
\end{array}\right]\left[\begin{array}{l}
y_{1}^{s s}+y_{1}^{s r}+y_{1}^{s t} \\
y_{2}^{s s}+y_{2}^{s r}+y_{2}^{s t}
\end{array}\right]+\left[\begin{array}{ll}
b_{11}^{r r} & b_{12}^{r r} \\
b_{21}^{r r} & b_{22}^{r r}
\end{array}\right]\left[\begin{array}{l}
y_{1}^{r r}+y_{1}^{r t}+y_{1}^{r s} \\
y_{2}^{r r}+y_{2}^{r t}+y_{2}^{r s}
\end{array}\right] \\
& =\left[\begin{array}{ll}
b_{11}^{r r} & b_{12}^{r r} \\
b_{21}^{r r} & b_{22}^{r r}
\end{array}\right]\left[\begin{array}{l}
y_{1}^{r r} \\
y_{2}^{r r}
\end{array}\right]+\left[\begin{array}{ll}
b_{11}^{r r} & b_{12}^{r r} \\
b_{21}^{r r} & b_{22}^{r r}
\end{array}\right]\left[\begin{array}{l}
y_{1}^{r t} \\
y_{2}^{r t}
\end{array}\right]+\left[\begin{array}{ll}
b_{11}^{r r} & b_{12}^{r r} \\
b_{21}^{r r} & b_{22}^{r r}
\end{array}\right]\left[\begin{array}{l}
y_{1}^{r s} \\
y_{2}^{r s}
\end{array}\right] \\
& +\left[\begin{array}{ll}
b_{11}^{r s} & b_{12}^{r s} \\
b_{21}^{r s} & b_{22}^{r s}
\end{array}\right]\left[\begin{array}{l}
y_{1}^{s s} \\
y_{2}^{s s}
\end{array}\right]+\left[\begin{array}{ll}
b_{11}^{r s} & b_{12}^{r s} \\
b_{21}^{r s} & b_{22}^{r s}
\end{array}\right]\left[\begin{array}{l}
y_{1}^{s r} \\
y_{2}^{s r}
\end{array}\right]+\left[\begin{array}{ll}
b_{11}^{r s} & b_{12}^{r s} \\
b_{21}^{r s} & b_{22}^{r s}
\end{array}\right]\left[\begin{array}{l}
y_{1}^{s t} \\
y_{2}^{s t}
\end{array}\right]
\end{aligned}
$$

Insert equation (A18) into the last term of equation (A1), we can decompose Country s' gross intermediate goods exports to Country $\mathrm{r}$ according to where they are absorbed as:

$$
\begin{aligned}
& A^{s r} X^{r}=\left[\begin{array}{ll}
a_{11}^{s r} & a_{12}^{s r} \\
a_{21}^{s r} & a_{22}^{s r}
\end{array}\right]\left[\begin{array}{l}
x_{1}^{r r} \\
x_{2}^{r}
\end{array}\right] \\
& =\left[\begin{array}{ll}
a_{11}^{s r} & a_{12}^{s r} \\
a_{21}^{s r} & a_{22}^{s r}
\end{array}\right]\left[\begin{array}{ll}
b_{11}^{r r} & b_{12}^{r r} \\
b_{21}^{r r} & b_{22}^{r r}
\end{array}\right]\left[\begin{array}{l}
y_{1}^{r r} \\
y_{2}^{r r}
\end{array}\right]+\left[\begin{array}{ll}
a_{11}^{s r} & a_{12}^{s r} \\
a_{21}^{s r} & a_{22}^{s r}
\end{array}\right]\left[\begin{array}{ll}
b_{11}^{r r} & b_{12}^{r r} \\
b_{21}^{r r} & b_{22}^{r r}
\end{array}\right]\left[\begin{array}{l}
y_{1}^{r t} \\
y_{2}^{r t}
\end{array}\right]+\left[\begin{array}{ll}
a_{11}^{s r} & a_{12}^{s r} \\
a_{21}^{s r} & a_{22}^{s r}
\end{array}\right]\left[\begin{array}{ll}
b_{11}^{r r} & b_{12}^{r r} \\
b_{21}^{r r} & b_{22}^{r r}
\end{array}\right]\left[\begin{array}{l}
y_{1}^{r s} \\
y_{2}^{r s}
\end{array}\right] \\
& +\left[\begin{array}{ll}
a_{11}^{s r} & a_{12}^{s r} \\
a_{21}^{s r} & a_{22}^{s r}
\end{array}\right]\left[\begin{array}{ll}
b_{11}^{r s} & b_{12}^{r s} \\
b_{21}^{r s} & b_{22}^{r s}
\end{array}\right]\left[\begin{array}{l}
y_{1}^{s s} \\
y_{2}^{s s}
\end{array}\right]+\left[\begin{array}{ll}
a_{11}^{s r} & a_{12}^{s r} \\
a_{21}^{s r} & a_{22}^{s r}
\end{array}\right]\left[\begin{array}{ll}
b_{11}^{r s} & b_{12}^{r s} \\
b_{21}^{r s} & b_{22}^{r s}
\end{array}\right]\left[\begin{array}{l}
y_{1}^{s r} \\
y_{2}^{s r}
\end{array}\right]+\left[\begin{array}{ll}
a_{11}^{s r} & a_{12}^{s r} \\
a_{21}^{s r} & a_{22}^{s r}
\end{array}\right]\left[\begin{array}{ll}
b_{11}^{r s} & b_{12}^{r s} \\
b_{21}^{r s} & b_{22}^{r s}
\end{array}\right]\left[\begin{array}{l}
y_{1}^{s t} \\
y_{2}^{s t}
\end{array}\right]
\end{aligned}
$$

(A19)

From the gross output production and use balance conditions, we know 


$$
\begin{aligned}
& {\left[\begin{array}{l}
x_{1}^{r} \\
x_{2}^{r}
\end{array}\right]=\left[\begin{array}{ll}
a_{11}^{r r} & a_{12}^{r r} \\
a_{21}^{r r} & a_{22}^{r r}
\end{array}\right]\left[\begin{array}{l}
x_{1}^{r} \\
x_{2}^{r}
\end{array}\right]+\left[\begin{array}{ll}
a_{11}^{r t} & a_{12}^{r t} \\
a_{21}^{r t} & a_{22}^{r t}
\end{array}\right]\left[\begin{array}{l}
x_{1}^{t} \\
x_{2}^{t}
\end{array}\right]+\left[\begin{array}{ll}
a_{11}^{r s} & a_{12}^{r s} \\
a_{21}^{r s} & a_{22}^{r s}
\end{array}\right]\left[\begin{array}{l}
x_{1}^{s} \\
x_{2}^{s}
\end{array}\right]+\left[\begin{array}{l}
y_{1}^{r s} \\
y_{2}^{r s}
\end{array}\right]+\left[\begin{array}{l}
y_{1}^{r r} \\
y_{2}^{r r}
\end{array}\right]+\left[\begin{array}{l}
y_{1}^{r t} \\
y_{2}^{r t}
\end{array}\right]} \\
& =\left[\begin{array}{ll}
a_{11}^{r r} & a_{12}^{r r} \\
a_{21}^{r r} & a_{22}^{r r}
\end{array}\right]\left[\begin{array}{l}
x_{1}^{r} \\
x_{2}^{r}
\end{array}\right]+\left[\begin{array}{l}
y_{1}^{r r} \\
y_{2}^{r r}
\end{array}\right]+\left[\begin{array}{l}
e_{1}^{r s} \\
e_{2}^{r s}
\end{array}\right]+\left[\begin{array}{l}
e_{1}^{r t} \\
e_{2}^{r t}
\end{array}\right]=\left[\begin{array}{ll}
a_{11}^{r r} & a_{12}^{r r} \\
a_{21}^{r r} & a_{22}^{r r}
\end{array}\right]\left[\begin{array}{l}
x_{1}^{r} \\
x_{2}^{r}
\end{array}\right]+\left[\begin{array}{l}
y_{1}^{r r} \\
y_{2}^{r r}
\end{array}\right]+\left[\begin{array}{l}
e_{1}^{r *} \\
e_{2}^{r *}
\end{array}\right]
\end{aligned}
$$

Re-arranging:

$$
\begin{aligned}
{\left[\begin{array}{l}
x_{1}^{r} \\
x_{2}^{r}
\end{array}\right] } & =\left[\begin{array}{cc}
1-a_{11}^{r r} & -a_{12}^{r r} \\
-a_{21}^{r r} & 1-a_{22}^{r r}
\end{array}\right]^{-1}\left[\begin{array}{c}
y_{1}^{r r} \\
y_{2}^{r r}
\end{array}\right]+\left[\begin{array}{cc}
1-a_{11}^{r r} & -a_{12}^{r r} \\
-a_{21}^{r r} & 1-a_{22}^{r r}
\end{array}\right]^{-1}\left[\begin{array}{c}
e_{1}^{r^{*}} \\
e_{2}^{r^{*}}
\end{array}\right] \\
& =\left[\begin{array}{ll}
l_{11}^{r r} & l_{12}^{r r} \\
l_{21}^{r r} & l_{22}^{r r}
\end{array}\right]\left[\begin{array}{l}
y_{1}^{r r} \\
y_{2}^{r r}
\end{array}\right]+\left[\begin{array}{ll}
r r & l_{12}^{r r} \\
l_{21}^{r r} & l_{22}^{r r}
\end{array}\right]\left[\begin{array}{c}
e_{1}^{r *} \\
e_{2}^{r *}
\end{array}\right]
\end{aligned}
$$

Insert equation (A21) into last term in equation (A1), the intermediate goods exports by Country s can also be decomposed into following two components according to where it is used similar to a single country IO model:

$$
A^{s r} X^{r}=\left[\begin{array}{ll}
a_{11}^{s r} & a_{12}^{s r} \\
a_{21}^{s r} & a_{22}^{s r}
\end{array}\right]\left[\begin{array}{l}
x_{1}^{r} \\
x_{2}^{r}
\end{array}\right]=\left[\begin{array}{ll}
a_{11}^{s r} & a_{12}^{s r} \\
a_{21}^{s r} & a_{22}^{s r}
\end{array}\right]\left[\begin{array}{ll}
l_{11}^{r r} & l_{12}^{r r} \\
l_{21}^{r r} & l_{22}^{r r}
\end{array}\right]\left[\begin{array}{l}
y_{1}^{r r} \\
y_{2}^{r r}
\end{array}\right]+\left[\begin{array}{ll}
a_{11}^{s r} & a_{12}^{s r} \\
a_{21}^{s r} & a_{22}^{s r}
\end{array}\right]\left[\begin{array}{ll}
l_{11}^{r r} & l_{12}^{r r} \\
l_{21}^{r r} & l_{22}^{r r}
\end{array}\right]\left[\begin{array}{l}
e_{1}^{r^{*}} \\
e_{2}^{r *}
\end{array}\right]
$$

Follow the logic of equation (5) in the main text, we can obtain Country s' domestic and foreign value-added multipliers as follows:

$$
\begin{aligned}
& V^{s} B^{s s}=\left[\begin{array}{ll}
v_{1}^{s} & v_{2}^{s}
\end{array}\left[\begin{array}{ll}
b_{11}^{s s} & b_{12}^{s s} \\
b_{21}^{s s} & b_{22}^{s s}
\end{array}\right]=\left[\begin{array}{ll}
v_{1}^{s} b_{11}^{s s}+v_{2}^{s} b_{21}^{s s} & v_{1}^{s} b_{12}^{s s}+v_{2}^{s} b_{22}^{s s}
\end{array}\right]\right. \\
& V^{r} B^{r s}=\left[\begin{array}{ll}
v_{1}^{r} & v_{2}^{r}
\end{array}\left[\begin{array}{ll}
b_{11}^{r s} & b_{12}^{r s} \\
b_{21}^{r s} & b_{22}^{r s}
\end{array}\right]=\left[\begin{array}{ll}
v_{1}^{r} b_{11}^{r s}+v_{2}^{r} b_{21}^{r s} & v_{1}^{r} b_{12}^{r s}+v_{2}^{r} b_{22}^{r s}
\end{array}\right]\right.
\end{aligned}
$$

$$
V^{t} B^{t s}=\left[\begin{array}{ll}
v_{1}^{t} & v_{2}^{t}
\end{array}\left[\begin{array}{ll}
b_{11}^{t s} & b_{12}^{t s} \\
b_{21}^{t s} & b_{22}^{t s}
\end{array}\right]=\left[\begin{array}{lll}
v_{1}^{t} b_{11}^{t s}+v_{2}^{t} b_{21}^{t s} & v_{1}^{t} b_{12}^{t s}+v_{2}^{t} b_{22}^{t s}
\end{array}\right]\right.
$$

And we know that the sum of equations (A23), (A24) and (A25) equals unity.

Using equation (A19), the property of the sum of equations (A23), (A24) and (A25) equals to unity, and define "\#” as element-wise matrix multiplication operation, the value of Country s' bilateral intermediate exports to Country $r$ can be decomposed as 


$$
\begin{aligned}
& A^{s r} X^{r}=\left[\begin{array}{ll}
a_{11}^{s r} & a_{12}^{s r} \\
a_{21}^{s r} & a_{22}^{s r}
\end{array}\right]\left[\begin{array}{l}
x_{1}^{r} \\
x_{2}^{r}
\end{array}\right]=\left[\begin{array}{l}
v_{1}^{s} l_{11}^{s s}+v_{2}^{s} l_{21}^{s s} \\
v_{1}^{s} l_{12}^{s s}+v_{2}^{s} l_{22}^{s s}
\end{array}\right] \#\left\{\left[\begin{array}{ll}
a_{11}^{s r} & a_{12}^{s r} \\
a_{21}^{s r} & a_{22}^{s r}
\end{array}\right]\left[\begin{array}{l}
x_{1}^{r} \\
x_{2}^{r}
\end{array}\right]\right\} \\
& +\left\{\left[\begin{array}{l}
v_{1}^{s} b_{11}^{s s}+v_{2}^{s} b_{21}^{s s} \\
v_{1}^{s} b_{12}^{s s}+v_{2}^{s} b_{22}^{s s}
\end{array}\right]-\left[\begin{array}{l}
v_{1}^{s} l_{11}^{s s}+v_{2}^{s} l_{21}^{s s} \\
v_{1}^{s} l_{12}^{s s}+v_{2}^{s} l_{22}^{s s}
\end{array}\right]\right\} \#\left\{\left[\begin{array}{ll}
a_{11}^{s r} & a_{12}^{s r} \\
a_{21}^{s r} & a_{22}^{s r}
\end{array}\right]\left[\begin{array}{l}
x_{1}^{r} \\
x_{2}^{r}
\end{array}\right]\right\} \\
& +\left[\begin{array}{l}
v_{1}^{r} b_{11}^{r s}+v_{2}^{r} b_{21}^{r s} \\
v_{1}^{r} b_{11}^{r s}+v_{2}^{r} b_{21}^{r s}
\end{array}\right] \#\left\{\left[\begin{array}{ll}
a_{11}^{s r} & a_{12}^{s r} \\
a_{21}^{s r} & a_{22}^{s r}
\end{array}\right]\left[\begin{array}{l}
x_{1}^{r} \\
x_{2}^{r}
\end{array}\right]\right\}+\left[\begin{array}{l}
v_{1}^{t} b_{11}^{t s}+v_{2}^{t} b_{21}^{t s} \\
v_{1}^{t} b_{12}^{t s}+v_{2}^{t} b_{22}^{t s}
\end{array}\right] \#\left\{\left[\begin{array}{ll}
a_{11}^{s r} & a_{12}^{s r} \\
a_{21}^{s r} & a_{22}^{s r}
\end{array}\right]\left[\begin{array}{l}
x_{1}^{r} \\
x_{2}^{r}
\end{array}\right]\right\}
\end{aligned}
$$

Finally, based on the standard Leontief decomposition, Country s' final goods exports to Country r can be decomposed into domestic and foreign value-added as follows:

$$
\left[\begin{array}{l}
y_{1}^{s r} \\
y_{2}^{s r}
\end{array}\right]=\left[\begin{array}{l}
v_{1}^{s} b_{11}^{s s}+v_{2}^{s} b_{21}^{s s} \\
v_{1}^{s} b_{12}^{s s}+v_{2}^{s} b_{22}^{s s}
\end{array}\right] \#\left[\begin{array}{l}
y_{1}^{s r} \\
y_{2}^{s r}
\end{array}\right]+\left[\begin{array}{l}
v_{1}^{r} b_{11}^{r s}+v_{2}^{r} b_{21}^{r s} \\
v_{1}^{r} b_{11}^{r s}+v_{2}^{r} b_{21}^{r s}
\end{array}\right] \#\left[\begin{array}{l}
y_{1}^{s r} \\
y_{2}^{s r}
\end{array}\right]+\left[\begin{array}{c}
v_{1}^{t} b_{11}^{t s}+v_{2}^{t} b_{21}^{t s} \\
v_{1}^{t} b_{12}^{t s}+v_{2}^{t} b_{22}^{t s}
\end{array}\right] \#\left[\begin{array}{c}
y_{1}^{s r} \\
y_{2}^{s r}
\end{array}\right]
$$

Inserting equations (A19) and (A22) into equation (A26):

$$
\begin{aligned}
& {\left[\begin{array}{ll}
a_{11}^{s r} & a_{12}^{s r} \\
a_{21}^{s r} & a_{22}^{s r}
\end{array}\right]\left[\begin{array}{l}
x_{1}^{r} \\
x_{2}^{r}
\end{array}\right]=\left[\begin{array}{l}
v_{1}^{s} l_{11}^{s s}+v_{2}^{s} l_{21}^{s s} \\
v_{1}^{s} l_{12}^{s s}+v_{2}^{s} l_{22}^{s s}
\end{array}\right] \#\left\{\left[\begin{array}{ll}
a_{11}^{s r} & a_{12}^{s r} \\
a_{21}^{s r} & a_{22}^{s r}
\end{array}\right]\left[\begin{array}{ll}
b_{11}^{r r} & b_{12}^{r r} \\
b_{21}^{r r} & b_{22}^{r r}
\end{array}\right]\left[\begin{array}{c}
y_{1}^{r r} \\
y_{2}^{r r}
\end{array}\right]\right\}} \\
& +\left[\begin{array}{l}
v_{1}^{s} l_{11}^{s s}+v_{2}^{s} l_{21}^{s s} \\
v_{1}^{s} l_{12}^{s s}+v_{2}^{s} l_{22}^{s s}
\end{array}\right] \#\left\{\left[\begin{array}{ll}
a_{11}^{s r} & a_{12}^{s r} \\
a_{21}^{s r} & a_{22}^{s r}
\end{array}\right]\left[\begin{array}{ll}
b_{11}^{r t} & b_{12}^{r t} \\
b_{21}^{r t} & b_{22}^{r t}
\end{array}\right]\left[\begin{array}{l}
y_{1}^{t t} \\
y_{2}^{t t}
\end{array}\right]\right\}+\left[\begin{array}{l}
v_{1}^{s} l_{11}^{s s}+v_{2}^{s} l_{21}^{s s} \\
v_{1}^{s} l_{12}^{s s}+v_{2}^{s} l_{22}^{s s}
\end{array}\right] \#\left\{\left[\begin{array}{ll}
a_{11}^{s r} & a_{12}^{s r} \\
a_{21}^{s r} & a_{22}^{s r}
\end{array}\right]\left[\begin{array}{ll}
b_{11}^{r r} & b_{12}^{r r} \\
b_{21}^{r r} & b_{22}^{r r}
\end{array}\right]\left[\begin{array}{l}
y_{1}^{r t} \\
y_{2}^{r t}
\end{array}\right]\right\} \\
& +\left[\begin{array}{l}
v_{1}^{s} l_{11}^{s s}+v_{2}^{s} l_{21}^{s s} \\
v_{1}^{s} l_{12}^{s s}+v_{2}^{s} l_{22}^{s s}
\end{array}\right] \#\left\{\left[\begin{array}{ll}
a_{11}^{s r} & a_{12}^{s r} \\
a_{21}^{s r} & a_{22}^{s r}
\end{array}\right]\left[\begin{array}{ll}
b_{11}^{r t} & b_{12}^{r t} \\
b_{21}^{r t} & b_{22}^{r t}
\end{array}\right]\left[\begin{array}{l}
y_{1}^{t r} \\
y_{2}^{t r}
\end{array}\right]\right\}+\left[\begin{array}{l}
v_{1}^{s} l_{11}^{s s}+v_{2}^{s} l_{21}^{s s} \\
v_{1}^{s} l_{12}^{s s}+v_{2}^{s} l_{22}^{s s}
\end{array}\right] \#\left\{\left[\begin{array}{ll}
a_{11}^{s r} & a_{12}^{s r} \\
a_{21}^{s r} & a_{22}^{s r}
\end{array}\right]\left[\begin{array}{ll}
b_{11}^{r r} & b_{12}^{r r} \\
b_{21}^{r r} & b_{22}^{r r}
\end{array}\right]\left[\begin{array}{l}
y_{1}^{r s} \\
y_{2}^{r s}
\end{array}\right]\right\} \\
& +\left[\begin{array}{l}
v_{1}^{s} l_{11}^{s s}+v_{2}^{s} l_{21}^{s s} \\
v_{1}^{s} l_{12}^{s s}+v_{2}^{s} l_{22}^{s s}
\end{array}\right] \#\left\{\left[\begin{array}{ll}
a_{11}^{s r} & a_{12}^{s r} \\
a_{21}^{s r} & a_{22}^{s r}
\end{array}\right]\left[\begin{array}{ll}
b_{11}^{r t} & b_{12}^{r t} \\
b_{21}^{r t} & b_{22}^{r t}
\end{array}\right]\left[\begin{array}{l}
y_{1}^{t s} \\
y_{2}^{t s}
\end{array}\right]\right\}+\left[\begin{array}{l}
v_{1}^{s} l_{11}^{s s}+v_{2}^{s} l_{21}^{s s} \\
v_{1}^{s} l_{12}^{s s}+v_{2}^{s} l_{22}^{s s}
\end{array}\right] \#\left\{\left[\begin{array}{ll}
a_{11}^{s r} & a_{12}^{s r} \\
a_{21}^{s r} & a_{22}^{s r}
\end{array}\right]\left[\begin{array}{ll}
b_{11}^{r s} & b_{12}^{r s} \\
b_{21}^{r s} & b_{22}^{r s}
\end{array}\right]\left[\begin{array}{l}
y_{1}^{s s} \\
y_{2}^{s s}
\end{array}\right]\right\} \\
& +\left[\begin{array}{l}
v_{1}^{s} l_{11}^{s s}+v_{2}^{s} l_{21}^{s s} \\
v_{1}^{s} l_{12}^{s s}+v_{2}^{s} l_{22}^{s s}
\end{array}\right] \#\left\{\left[\begin{array}{ll}
a_{11}^{s r} & a_{12}^{s r} \\
a_{21}^{s r} & a_{22}^{s r}
\end{array}\right]\left[\begin{array}{cc}
b_{11}^{r s} & b_{12}^{r s} \\
b_{21}^{r s} & b_{22}^{r s}
\end{array}\right]\left[\begin{array}{l}
y_{1}^{s r} \\
y_{2}^{s r}
\end{array}\right]\right\}+\left\{\left[\begin{array}{l}
v_{1}^{s} b_{11}^{s s}+v_{2}^{s} b_{21}^{s s} \\
v_{1}^{s} b_{12}^{s s}+v_{2}^{s} b_{22}^{s s}
\end{array}\right]-\left[\begin{array}{l}
v_{1}^{s} l_{11}^{s s}+v_{2}^{s} l_{21}^{s s} \\
v_{1}^{s} l_{12}^{s s}+v_{2}^{s s} l_{22}^{s s}
\end{array}\right]\right\} \#\left\{\left\{\begin{array}{ll}
a_{11}^{s r} & a_{12}^{s r} \\
a_{21}^{s r} & a_{22}^{s r}
\end{array}\right]\left[\begin{array}{l}
x_{1}^{r} \\
x_{2}^{r}
\end{array}\right]\right\} \\
& +\left[\begin{array}{l}
v_{1}^{r} b_{11}^{r s}+v_{2}^{r} b_{21}^{r s} \\
v_{1}^{r} b_{12}^{r s}+v_{2}^{r} b_{22}^{r s}
\end{array}\right] \#\left\{\left[\begin{array}{ll}
a_{11}^{s r} & a_{12}^{s r} \\
a_{21}^{s r} & a_{22}^{s r}
\end{array}\right]\left[\begin{array}{ll}
l_{11}^{r r} & l_{12}^{r r} \\
l_{21}^{r r} & l_{22}^{r r}
\end{array}\right]\left[\begin{array}{l}
y_{1}^{r r} \\
y_{2}^{r r}
\end{array}\right]\right\}+\left[\begin{array}{l}
v_{1}^{r} b_{11}^{r s}+v_{2}^{r} b_{21}^{r s} \\
v_{1}^{r} b_{12}^{r s}+v_{2}^{r} b_{22}^{r s}
\end{array}\right] \#\left\{\left[\begin{array}{ll}
a_{11}^{s r} & a_{12}^{s r} \\
a_{21}^{s r} & a_{22}^{s r}
\end{array}\right]\left[\begin{array}{ll}
l_{11}^{r r} & l_{12}^{r r} \\
l_{21}^{r r} & l_{22}^{r r}
\end{array}\right]\left[\begin{array}{c}
e_{1}^{r^{*}} \\
e_{2}^{r^{*}}
\end{array}\right]\right\} \\
& +\left[\begin{array}{l}
v_{1}^{t} b_{11}^{t s}+v_{2}^{t} b_{21}^{t s} \\
v_{1}^{t} b_{12}^{t s}+v_{2}^{t} b_{22}^{t s}
\end{array}\right] \#\left\{\left[\begin{array}{ll}
a_{11}^{s r} & a_{12}^{s r} \\
a_{21}^{s r} & a_{22}^{s r}
\end{array}\right]\left[\begin{array}{ll}
l_{11}^{r r} & l_{12}^{r r} \\
l_{21}^{r r} & l_{22}^{r r}
\end{array}\right]\left[\begin{array}{l}
y_{1}^{r r} \\
y_{2}^{r r}
\end{array}\right]\right\}+\left[\begin{array}{l}
v_{1}^{t} b_{11}^{t s}+v_{2}^{t} b_{21}^{t s} \\
v_{1}^{t} b_{12}^{t s}+v_{2}^{t} b_{22}^{t s}
\end{array}\right] \#\left\{\left[\begin{array}{ll}
a_{11}^{s r} & a_{12}^{s r} \\
a_{21}^{s r} & a_{22}^{s r}
\end{array}\right]\left[\begin{array}{ll}
l_{11}^{r r} & l_{12}^{r r} \\
l_{21}^{r r} & l_{22}^{r r}
\end{array}\right]\left[\begin{array}{l}
e_{1}^{r^{*}} \\
e_{2}^{r^{*}}
\end{array}\right]\right\}
\end{aligned}
$$

Combining equations (A27) and (A28), we obtain decomposition equation of Country s' bilateral exports to Country r as: 


$$
\begin{aligned}
& E^{s r}=\left[\begin{array}{l}
e_{1}^{s r} \\
e_{2}^{s r}
\end{array}\right]=\left[\begin{array}{l}
v_{1}^{s} b_{11}^{s s}+v_{2}^{s} b_{21}^{s s} \\
v_{1}^{s} b_{12}^{s s}+v_{2}^{s} b_{22}^{s s}
\end{array}\right] \#\left[\begin{array}{l}
y_{1}^{s r} \\
y_{2}^{s r}
\end{array}\right]+\left[\begin{array}{l}
v_{1}^{s} l_{11}^{s s}+v_{2}^{s} l_{21}^{s s} \\
v_{1}^{s} l_{12}^{s s}+v_{2}^{s} l_{22}^{s s}
\end{array}\right] \#\left\{\left[\begin{array}{ll}
a_{11}^{s r} & a_{12}^{s r} \\
a_{21}^{s r} & a_{22}^{s r}
\end{array}\right]\left[\begin{array}{cc}
b_{11}^{r r} & b_{12}^{r r} \\
b_{21}^{r r} & b_{22}^{r r}
\end{array}\right]\left[\begin{array}{c}
y_{1}^{r r} \\
y_{2}^{r r}
\end{array}\right]\right\} \\
& +\left[\begin{array}{l}
v_{1}^{s} l_{11}^{s s}+v_{2}^{s} l_{21}^{s s} \\
v_{1}^{s} l_{12}^{s s}+v_{2}^{s} l_{22}^{s s}
\end{array}\right] \#\left\{\left\{\left[\begin{array}{ll}
a_{11}^{s r} & a_{12}^{s r} \\
a_{21}^{s r} & a_{22}^{s r}
\end{array}\right]\left[\begin{array}{ll}
b_{11}^{r t} & b_{12}^{r t} \\
b_{21}^{r t} & b_{22}^{r t}
\end{array}\right]\left[\begin{array}{l}
y_{1}^{t t} \\
y_{2}^{t t}
\end{array}\right]\right\}+\left[\begin{array}{l}
v_{1}^{s} l_{11}^{s s}+v_{2}^{s} l_{21}^{s s} \\
v_{1}^{s} l_{12}^{s s}+v_{2}^{s} l_{22}^{s s}
\end{array}\right] \#\left\{\left[\begin{array}{ll}
a_{11}^{s r} & a_{12}^{s r} \\
a_{21}^{s r} & a_{22}^{s r}
\end{array}\right]\left[\begin{array}{ll}
b_{11}^{r r} & b_{12}^{r r} \\
b_{21}^{r r} & b_{22}^{r r}
\end{array}\right]\left[\begin{array}{l}
y_{1}^{r t} \\
y_{2}^{r t}
\end{array}\right]\right\}\right. \\
& +\left[\begin{array}{l}
v_{1}^{s} l_{11}^{s s}+v_{2}^{s} l_{21}^{s s} \\
v_{1}^{s} l_{12}^{s s}+v_{2}^{s} l_{22}^{s s}
\end{array}\right] \#\left\{\left\{\left[\begin{array}{ll}
a_{11}^{s r} & a_{12}^{s r} \\
a_{21}^{s r} & a_{22}^{s r}
\end{array}\right]\left[\begin{array}{ll}
b_{11}^{r t} & b_{12}^{r t} \\
b_{21}^{r t} & b_{22}^{r t}
\end{array}\right]\left[\begin{array}{l}
y_{1}^{t r} \\
y_{2}^{t r}
\end{array}\right]\right\}+\left[\begin{array}{l}
v_{1}^{s} l_{11}^{s s}+v_{2}^{s} l_{21}^{s s} \\
v_{1}^{s} l_{12}^{s s}+v_{2}^{s s} l_{22}^{s s}
\end{array}\right] \#\left\{\left[\begin{array}{ll}
a_{11}^{s r} & a_{12}^{s r} \\
a_{21}^{s r} & a_{22}^{s r}
\end{array}\right]\left[\begin{array}{ll}
b_{11}^{r r} & b_{12}^{r r} \\
b_{21}^{r r} & b_{22}^{r r}
\end{array}\right]\left[\begin{array}{l}
y_{1}^{r s} \\
y_{2}^{r s}
\end{array}\right]\right\}\right. \\
& +\left[\begin{array}{l}
v_{1}^{s} l_{11}^{s s}+v_{2}^{s} l_{21}^{s s} \\
v_{1}^{s} l_{12}^{s s}+v_{2}^{s} l_{22}^{s s}
\end{array}\right] \#\left\{\left[\begin{array}{ll}
a_{11}^{s r} & a_{12}^{s r} \\
a_{21}^{s r} & a_{22}^{s r}
\end{array}\right]\left[\begin{array}{ll}
b_{11}^{r t} & b_{12}^{r t} \\
b_{21}^{r t} & b_{22}^{r t}
\end{array}\right]\left[\begin{array}{l}
y_{1}^{t s} \\
y_{2}^{t s}
\end{array}\right]\right\}+\left[\begin{array}{l}
v_{1}^{s} l_{11}^{s s}+v_{2}^{s} l_{21}^{s s} \\
v_{1}^{s} l_{12}^{s s}+v_{2}^{s} l_{22}^{s s}
\end{array}\right] \#\left\{\left[\begin{array}{ll}
a_{11}^{s r} & a_{12}^{s r} \\
a_{21}^{s r} & a_{22}^{s r}
\end{array}\right]\left[\begin{array}{ll}
b_{11}^{r s} & b_{12}^{r s} \\
b_{21}^{r s} & b_{22}^{r s}
\end{array}\right]\left[\begin{array}{l}
y_{1}^{s s} \\
y_{2}^{s s}
\end{array}\right]\right\} \\
& +\left[\begin{array}{l}
v_{1}^{s} l_{11}^{s s}+v_{2}^{s} l_{21}^{s s} \\
v_{1}^{s} l_{12}^{s s}+v_{2}^{s s} l_{22}^{s s}
\end{array}\right] \#\left\{\left[\begin{array}{ll}
a_{11}^{s r} & a_{12}^{s r} \\
a_{21}^{s r} & a_{22}^{s r}
\end{array}\right]\left[\begin{array}{ll}
b_{11}^{r s} & b_{12}^{r s} \\
b_{21}^{r s} & b_{22}^{r s}
\end{array}\right]\left[\begin{array}{c}
y_{1}^{s r}+y_{1}^{s t} \\
y_{2}^{s r}+y_{1}^{s t}
\end{array}\right]\right\} \\
& +\left\{\left[\begin{array}{l}
v_{1}^{s} b_{11}^{s s}+v_{2}^{s} b_{21}^{s s} \\
v_{1}^{s} b_{12}^{s s}+v_{2}^{s} b_{22}^{s s}
\end{array}\right]-\left[\begin{array}{l}
v_{1}^{s} l_{11}^{s s}+v_{2}^{s} l_{21}^{s s} \\
v_{1}^{s} l_{12}^{s s}+v_{2}^{s} l_{22}^{s s}
\end{array}\right]\right\} \#\left\{\left[\begin{array}{ll}
a_{11}^{s r} & a_{12}^{s r} \\
a_{21}^{s r} & a_{22}^{s r}
\end{array}\right]\left[\begin{array}{l}
x_{1}^{r} \\
x_{2}^{r}
\end{array}\right]\right\} \\
& +\left[\begin{array}{l}
v_{1}^{r} b_{11}^{r s}+v_{2}^{r} b_{21}^{r s} \\
v_{1}^{r} b_{11}^{r s}+v_{2}^{r} b_{21}^{r s}
\end{array}\right] \#\left[\begin{array}{l}
y_{1}^{s r} \\
y_{2}^{s r}
\end{array}\right]+\left[\begin{array}{l}
v_{1}^{r} b_{11}^{r s}+v_{2}^{r} b_{21}^{r s} \\
v_{1}^{r} b_{12}^{r s}+v_{2}^{r} b_{22}^{r s}
\end{array}\right] \#\left\{\left[\begin{array}{ll}
a_{11}^{s r} & a_{12}^{s r} \\
a_{21}^{s r} & a_{22}^{s r}
\end{array}\right]\left[\begin{array}{ll}
l_{11}^{r r} & l_{12}^{r r} \\
l_{21}^{r r} & l_{22}^{r r}
\end{array}\right]\left[\begin{array}{l}
y_{1}^{r r} \\
y_{2}^{r r}
\end{array}\right]\right\} \\
& +\left[\begin{array}{l}
v_{1}^{r} b_{11}^{r s}+v_{2}^{r} b_{21}^{r s} \\
v_{1}^{r} b_{12}^{r s}+v_{2}^{r} b_{22}^{r s}
\end{array}\right] \#\left\{\left[\begin{array}{ll}
a_{11}^{s r} & a_{12}^{s r} \\
a_{21}^{s r} & a_{22}^{s r}
\end{array}\right]\left[\begin{array}{ll}
l_{11}^{r r} & l_{12}^{r r} \\
l_{21}^{r r} & l_{22}^{r r}
\end{array}\right]\left[\begin{array}{c}
e_{1}^{r *} \\
e_{2}^{r *}
\end{array}\right]\right\} \\
& +\left[\begin{array}{l}
v_{1}^{t} b_{11}^{t s}+v_{2}^{t} b_{21}^{t s} \\
v_{1}^{t} b_{12}^{t s}+v_{2}^{t} b_{22}^{t s}
\end{array}\right] \#\left[\begin{array}{l}
y_{1}^{s r} \\
y_{2}^{s r}
\end{array}\right]+\left[\begin{array}{l}
v_{1}^{t} b_{11}^{t s}+v_{2}^{t} b_{21}^{t s} \\
v_{1}^{t} b_{12}^{t s}+v_{2}^{t} b_{22}^{t s}
\end{array}\right] \#\left\{\left[\begin{array}{ll}
a_{11}^{s r} & a_{12}^{s r} \\
a_{21}^{s r} & a_{22}^{s r}
\end{array}\right]\left[\begin{array}{ll}
l_{11}^{r r} & l_{12}^{r r} \\
l_{21}^{r r} & l_{22}^{r r}
\end{array}\right]\left[\begin{array}{l}
y_{1}^{r r} \\
y_{2}^{r r}
\end{array}\right]\right\} \\
& +\left[\begin{array}{l}
v_{1}^{t} b_{11}^{t s}+v_{2}^{t} b_{21}^{t s} \\
v_{1}^{t} b_{12}^{t s}+v_{2}^{t} b_{22}^{t s}
\end{array}\right] \#\left\{\left[\begin{array}{ll}
a_{11}^{s r} & a_{12}^{s r} \\
a_{21}^{s r} & a_{22}^{s r}
\end{array}\right]\left[\begin{array}{ll}
l_{11}^{r r} & l_{12}^{r r} \\
l_{21}^{r r} & l_{22}^{r r}
\end{array}\right]\left[\begin{array}{l}
e_{1}^{r^{*}} \\
e_{2}^{r^{*}}
\end{array}\right]\right\}
\end{aligned}
$$

Equation (A29) indicates that the exports at bilateral and sector level of a country can be completely decomposed into the sum of sixteen terms. To better understand each term in this accounting equation, we provide the following economic interpretations:

The first term is domestic value added embodied in the final exports of the $1^{\text {st }}$ and $2^{\text {nd }}$ sectors of Country s to Country r. Each of them has two parts: domestic value added created by the sector itself and domestic value added created by the other sector embodied in the sector's final exports of Country s to Country r.

The second term is domestic value added embodied in Country s' $1^{\text {st }}$ and $2^{\text {nd }}$ sector's intermediate exports of Country s to Country $r$ which are used by Country $r$ to produce its domestic final goods, $y_{1}^{r r}$ and $y_{2}^{r r}$, and are consumed in $\mathrm{r}$. 
The third term is domestic value added embodied in Country s' $1^{\text {st }}$ and $2^{\text {nd }}$ sector's bilateral intermediate exports used to produce Country r's intermediate exports to Country $\mathrm{t}$ and ultimately absorbed by Country t' domestic final goods, $y_{1}^{t t}$ and $y_{2}^{t t}$.

The fourth term is domestic value added embodied in Country s' $1^{\text {st }}$ and $2^{\text {nd }}$ sector's bilateral intermediate exports used to produce Country r's final exports to Country t, $y_{1}^{r t}$ and $y_{2}^{r t}$.

The fifth term is domestic value added embodied in Country s' $1^{\text {st }}$ and $2^{\text {nd }}$ sector's bilateral intermediate exports used to produce Country r's intermediate exports to Country $\mathrm{t}$ and ultimately absorbed by Country t' final exports to Country r, $y_{1}^{t r}$ and $y_{2}^{t r}$.

These five terms are domestic value added embodied in Country s' exports to Country r which are ultimately absorbed by Country r. They are value added exports of Country s via bilateral exports to Country $r$.

The sixth term is domestic value added embodied in Country s' $1^{\text {st }}$ and $2^{\text {nd }}$ sector's bilateral intermediate exports used to produce Country r's final exports back to Country s, i.e. country s' imports of final goods from $\mathrm{r}, y_{1}^{r s}$ and $y_{2}^{r s}$.

The seventh term is domestic value added embodied in Country s' $1^{\text {st }}$ and $2^{\text {nd }}$ sector's bilateral intermediate exports used to produce intermediate exports to Country t and ultimately absorbed by Country t' final exports to Country s, $y_{1}^{t s}$ and $y_{2}^{t s}$.

The eighth term is domestic value added embodied in Country s' $1^{\text {st }}$ and $2^{\text {nd }}$ sector's bilateral intermediate exports that are used by Country $r$ to produce intermediate exports and return to Country s via its intermediate imports to produce its domestic final goods.

These three terms are domestic value added embodied in the $1^{\text {st }}$ and $2^{\text {nd }}$ sector's bilateral exports which returned home and are finally consumed in Country s.

The first eight terms are the domestic value added (GDP) embodied in the $1^{\text {st }}$ and $2^{\text {nd }}$ sectors' bilateral exports of Country s, which include value added created from all sectors in 


\section{Country s' bilateral exports to Country r.}

The ninth term is domestic value added of Country $s^{\prime} 1^{\text {st }}$ and $2^{\text {nd }}$ sector's bilateral intermediate exports which return home as its $1^{\text {st }}$ and/or $2^{\text {nd }}$ sector's intermediate imports and are used for production of Country s' both sector's final exports and are finally consumed in Country r. They are part of the value-added in Country s' final exports and already counted once by the first terms of equation (A29) and the decomposition equation of Country s' exports to Country $r$, therefore it is a domestic double counted portion caused by the back and forth intermediate goods trade in order to produce final goods exports in Country s.

The tenth term is domestic value added of Country s' $1^{\text {st }}$ and $2^{\text {nd }}$ sector's intermediate exports that return home as intermediate imports and are used for production of Country s' intermediate exports to Country $r$. It is also a domestic double counted portion caused by the back and forth intermediate goods trade in order to produce intermediate goods exports in Country s.

Sum of the first to the sixth tenth equals domestic content of the $1^{\text {st }}$ and $2^{\text {nd }}$ sector's gross exports, $\sum_{i}^{2} v_{i}^{s} b_{i 1}^{s s} e_{1}^{s r}$ and $\sum_{i}^{2} v_{i}^{s s} b_{i 2}^{s s} e_{2}^{s r}$.

The $11^{\text {th }}$ term is Country r's value added used in Country s' $1^{\text {st }}$ and $2^{\text {nd }}$ sector's final exports to Country r. Each of them also has two parts: Country r's value-added from the sector itself and the other sector used to produce final exports from Country s.

The $12^{\text {th }}$ term is Country r's value added used to produce the $1^{\text {st }}$ and $2^{\text {nd }}$ sector intermediate exports of Country s to Country $r$, which are then used by Country $r$ to produce its domestic final goods.

The $13^{\text {th }}$ term is Country r's value added embodied in the $1^{\text {st }}$ and $2^{\text {nd }}$ sector's intermediate exports to Country $r$ and used by Country $r$ to produce its final and intermediate exports, which is the portion of foreign double counted term of Country s' exports to Country $r$.

Summing the $11^{\text {th }}$ to the $13^{\text {th }}$ terms equals the Country r's content of the $1^{\text {st }}$ and $2^{\text {nd }}$ sector's 
gross exports of Country s, $\sum_{i}^{2} v_{i}^{r} b_{i 1}^{r s} e_{1}^{s r}$ and $\sum_{i}^{2} v_{i}^{r} b_{i 2}^{r s} e_{2}^{s r}$.

The $14^{\text {th }}$ term is Country t's value added used in Country s' $1^{\text {st }}$ and $2^{\text {nd }}$ sector's final exports to Country r. Each of them also has two parts: Country t's value-added from the sector itself and the other sector used to produce final exports from Country s. Adding up the $1^{\text {st }}$, the $11^{\text {th }}$ and the $14^{\text {th }}$ terms accounts $100 \%$ of the value of the final exports in Country s to Country $r$ by sector.

The $15^{\text {th }}$ term is Country t's value added used to produce the $1^{\text {st }}$ and $2^{\text {nd }}$ sector intermediate exports of Country s to Country $r$, which are then used by Country $r$ to produce its domestic final goods. Summing the $11^{\text {th }}$, the $12^{\text {th }}$, the $14^{\text {th }}$ and $15^{\text {th }}$ terms, the four elements in the resulted vector are total foreign value added embodied in the $1^{\text {st }}$ and $2^{\text {nd }}$ sectors' gross exports of Country s to Country r, respectively.

The $16^{\text {th }}$ term is Country t's value added embodied in the $1^{\text {st }}$ and $2^{\text {nd }}$ sector's intermediate exports to Country $r$ and used by Country $r$ to produce its final and intermediate exports, which is the foreign double counted term of Country s' exports to Country r. Adding up the $13^{\text {th }}$ and the $16^{\text {th }}$ terms are the foreign double counted term of Country s' exports. Adding up the $10^{\text {th }}$, the $13^{\text {th }}$ and the $16^{\text {th }}$ terms are the double counting terms of gross exports of Country s to Country r.

\section{Appendix B: The Interpretation of Eight Terms in Equation (11)}

Equation (11) in main text decomposes Country s' gross intermediate goods exports to Country $r$ according to where they are absorbed as:

$$
\begin{aligned}
& A^{s r} X^{r}=A^{s r} B^{r r} Y^{r r}+A^{s r} \sum_{t \neq s, r}^{G} B^{r t} Y^{t t}+A^{s r} B^{r r} \sum_{t \neq s, r}^{G} Y^{r t}+A^{s r} \sum_{t \neq s, r}^{G} B^{r t} \sum_{u \neq s, t}^{G} Y^{t u} \\
& +A^{s r} B^{r r} Y^{r s}+A^{s r} \sum_{t \neq s, r}^{G} B^{r t} Y^{t s}+A^{s r} B^{r s} Y^{s s}+A^{s r} \sum_{t \neq s}^{G} B^{r s} Y^{s t}
\end{aligned}
$$

The $1^{\text {st }}$ term in equation (B1) is the part of Country s' intermediate goods exports used by Country $r$ to produce domestic final goods that are eventually consumed in Country $r$; the $2^{\text {nd }}$ term is the part of Country s' intermediate exports used by the direct importer, Country r, to 
produce intermediate goods that are exported to the third Country $t$ for production of final goods consumed in $\mathrm{t}$; the $3^{\text {rd }}$ term is the part of Country s' intermediate exports used by Country $r$ to produce final exports which are ultimately absorbed by third Country $t$; the $4^{\text {th }}$ term is the part of Country s' intermediate exports to Country $r$ used by $r$ to produce intermediate exports to the third Country $t$ for production of final exports absorbed by other countries (including the direct importer $r$ ) except source Country s; the $5^{\text {th }}$ term is the part of Country s' intermediate goods exports to Country $r$ that are embedded in Country r's final goods exports returned to Country s; the $6^{\text {th }}$ term is the part of Country s' intermediate exports used by the direct importer (r) to produce intermediate exports to the third Country t for its production of final exports that are shipped back to Country s; the $7^{\text {th }}$ term is the part of Country s' intermediate goods exports that are used by Country $r$ to produce intermediate exports that are shipped back to Country $s$ to produce its domestic consumed final goods; and the last term is the part of country s' intermediate goods exports used by Country $r$ to produce intermediate goods that are shipped back to Country s to produce final goods exports to all other countries. These eight terms collectively decompose Country s' intermediate exports to Country r completely according to where they are finally absorbed. It will be used later to decompose domestic originated value of a country's bilateral gross exports into different value added and double counted components.

\section{Appendix C: Different types of double counted terms in gross trade statistics}

KWW (2014) has identified three conceptually different types of double counted terms in a country's gross exports: (1) RDV represents the source country's domestic value-added that is initially exported but imported back and consumed at home. Because it is not domestic value that stays abroad, it is double counted in trade statistics. However, because it constitutes a part of the source country's GDP, it is not double counted in either the global or the source country's GDP. (2) FVA represents the foreign value added in the source country's gross exports that are ultimately absorbed in foreign countries. Since it is already counted in other countries' GDP, it is double counted in both trade statistics and global GDP. (3) PDC represents the value of intermediate products that is already captured by other terms in the gross exports decomposition 
equation. Because it represents repeat counting of the same value added terms at least three times and only occur when there is two way intermediates trade, KWW label it as "pure double-counted terms."

Although mathematical expressions of these double counted terms are included in their gross exports decomposition equation (36), KWW only illustrate the difference among them in a two country setting, and did not explicitly derive the relations among them and show how they repeat count other domestic value-added terms. This is what we will do in this appendix.

Summing up equation (18) over all sectors and trading partners, we obtain an equation exactly the same as equation (36) in KWW (2014), and rearranging it as

$$
\begin{aligned}
& u E^{s^{*}}=u \sum_{r \neq s}^{G} E^{s r}=\underbrace{V^{s} B^{s s} \sum_{r \neq s}^{G} Y^{s r}}_{(1)-D V A_{-} F I N}+\underbrace{V^{s} B^{s s} \sum_{r \neq s}^{G} A^{s r} L^{r r} Y^{r r}}_{(2)-D V A_{-} I N T} \\
& +\underbrace{V^{s} \sum_{r \neq s}^{G} \sum_{t \neq s, r}^{G} B^{s t} A^{t r} L^{r r} Y^{r r}+V^{s} \sum_{r \neq s}^{G} B^{s r} \sum_{t \neq s, r}^{G} Y^{r t}}_{(3)-D V A_{-} I N T r e x} \\
& +\underbrace{V_{r \neq s}^{s} \sum_{r \neq s}^{G} B^{s r} Y^{r s}+V^{s} \sum_{r \neq s}^{G} B^{s r} A^{r s} L^{s s} Y^{s s}}_{(6)-R D V_{-} B}+\underbrace{V^{s} \sum_{r \neq s}^{G} B^{s r} A^{r s} L^{s s} E^{s^{*}}}_{(5)-D D C} \\
& +\underbrace{\sum_{r \neq s}^{G} V^{r} B^{r s} Y^{s r}+\sum_{r \neq s}^{G} V^{r} B^{r s} A^{s r} L^{r r} Y^{r r}}_{(8)-O V A}+\underbrace{\sum_{r \neq s}^{G} V^{r} B^{r s} A^{s r} L^{r r} E^{r *}}_{(7)-M D C} \\
& +\underbrace{\sum_{t \neq s}^{G} V^{t} B^{t s} \sum_{r \neq s}^{G} Y^{s r}+\sum_{t \neq s, r}^{G} V^{t} B^{t s} \sum_{r \neq s}^{G} A^{s r} L^{r r} Y^{r r}+\sum_{t \neq s, r}^{G} V^{t} B^{t s} \sum_{r \neq s}^{G} A^{s r} L^{r r} E^{r *}}_{(7)-M, r}
\end{aligned}
$$

Where $\mathrm{E}^{\mathrm{s}^{*}}$ denotes gross exports of country s.

Based on Equations (13), (18), and (20) in the main text, the GDP of Country s can be expressed as

$$
\begin{aligned}
& G D P^{s}=V^{s} X^{s}=V^{s} L^{s s} Y^{s s}+V^{s} L^{s s} E^{s^{*}} \\
& =V^{s} L^{s s} Y^{s s}+D V A_{-} F I N^{s}+D V A_{-} I N T^{s}+D V A_{-} I N T r e x x^{s}+R D V^{s}
\end{aligned}
$$

Combining equations $(\mathrm{C} 1)$ and $(\mathrm{C} 2)$, we have 


$$
\begin{aligned}
& u E^{s^{*}}=D V A_{-} F I N^{s}+D V A_{-} I N T^{s}+D V A_{-} I N T r e x^{s}+R D V^{s} \\
& +D D C^{s}+M V A^{s}+M D C^{s}+O V A^{s}+O D C^{s} \\
& =G D P^{s}-V^{s} L^{s s} Y^{s s}+D D C^{s}+M V A^{s}+M D C^{s}+O V A^{s}+O D C^{s} \\
& =G D P^{s}-V^{s} L^{s s} Y^{s s}+D D C^{s}+F V A^{s}+F D C^{s}
\end{aligned}
$$

Summing up equation (C3) over all $\mathrm{G}$ countries and rearranging, we obtain

$$
\begin{aligned}
& u \sum_{s}^{G} E^{s^{*}}-\sum_{s}^{G} G D P^{s}=-\sum_{s}^{G} V^{s} L^{s s} Y^{s s}++\sum_{s}^{G} D D C^{s}+\sum_{s}^{G} F V A^{s}+\sum_{s}^{G} F D C^{s} \\
& =-\sum_{s}^{G} V^{s} L^{s s} Y^{s s}+\sum_{s}^{G} D D C^{s}+\sum_{s}^{G} M V A^{s}+\sum_{s}^{G} M D C+\sum_{s}^{G} O V A^{s}+\sum_{s}^{G} O D C
\end{aligned}
$$

As indicated by equation (C1), MVA is the direct importing country's value added embodied in the source country's exports and ultimately absorbed by the direct importer. OVA is value added from third countries that are embodied in the source country's gross exports.

We summarize the relationship among the major terms in equation (C1) by the following three propositions. Proposition C.1 reveals how the two components of FVA, MVA, and OVA, are related to other terms. Propositions C.2. and C.3 reveal how the two pure double counted terms, DDC and FDC, respectively, are related to other terms.

Proposition C.1: The FVA in a country's gross exports double counts the RDV_B in gross exports of direct importing countries and DVA_INTrex in gross exports of third countries.

Proof: Based on equation (C1), we can obtain

(1) Total RDV_B equals total MVA for the world:

$$
\begin{aligned}
& \sum_{s}^{G} M V A^{s}=\sum_{s}^{G} \sum_{r \neq s}^{G} V^{r} B^{r s} Y^{s r}+\sum_{s}^{G} \sum_{r \neq s}^{G} V^{r} B^{r s} A^{s r} L^{r r} Y^{r r} \\
& =\sum_{s}^{G} \sum_{r \neq s}^{G} V^{s} B^{s r} Y^{r s}+\sum_{s}^{G} \sum_{r \neq s}^{G} V^{s} B^{s r} A^{r s} L^{s s} Y^{s s}=\sum_{s}^{G} R D V^{s}
\end{aligned}
$$

(2) Total OVA equals total DVA_INTrex in the world: 


$$
\begin{aligned}
& \sum_{s}^{G} O V A^{s}=\sum_{s}^{G} \sum_{t \neq s, r}^{G} V^{t} B^{t s} \sum_{r \neq s}^{G} Y^{s r}+\sum_{s}^{G} \sum_{t \neq s, r}^{G} V^{t} B^{t s} \sum_{r \neq s}^{G} A^{s r} L^{r r} Y^{r r} \\
& =\sum_{s}^{G} \sum_{t \neq s, r}^{G} V^{s} B^{s t} \sum_{r \neq s}^{G} A^{t r} L^{r r} Y^{r r}+\sum_{s}^{G} \sum_{t \neq s, r}^{G} V^{s} B^{s t} \sum_{r \neq s}^{G} Y^{t r} \\
& =\sum_{s}^{G} \sum_{t \neq s, r}^{G} V^{s} B^{s t} \sum_{r \neq s}^{G} A^{t r} L^{r r} Y^{r r}+\sum_{s}^{G} \sum_{r \neq s}^{G} V^{s} B^{s r} \sum_{t \neq s, s}^{G} Y^{r t}=\sum_{s}^{G} D V A_{-} \text {INTrex }^{s}
\end{aligned}
$$

Since FVA = MVA + OVA, therefore,

$$
\sum_{s}^{G} F V A^{s}=\sum_{s}^{G} D V A_{-} \text {INTrex }{ }^{s}+\sum_{s}^{G} R D V^{s}
$$

This indicates that FVA exactly double counts RDV_B and DVA_INTrex in measuring value-added in global exports.

The intuition of this proposition is simple: when RDV_B and DVA_INTrex cross borders from the source country to the direct importer for the first time, they are both counted as part of the source country's domestic value added in its gross exports. When they cross national borders for the second time either from the direct importer back to the source country or are re-exported to a third country, they are counted another time as MVA or OVA in gross exports of the direct importing country. Therefore, FVA is value-added that crosses national borders at least twice.

Proposition C.2: The DDC in a country's gross exports repeatedly counts the value of the gross intermediate trade flows originating from the home country. The limit of the double counting coefficient equals $V^{s} \sum_{r \neq s}^{G} B^{s r} A^{r s}$.

\section{Proof:}

$$
\begin{aligned}
& D D C^{s}=V^{s} \sum_{r \neq s}^{G} B^{s r} A^{r s} L^{s s} E^{s^{*}}=V^{s} \sum_{r \neq s}^{G} B^{s r} A^{r s}\left(X^{s}-L^{s s} Y^{s s}\right) \\
& =V^{s} \sum_{r \neq s}^{G} B^{s r} A^{r s}\left(B^{s s} \sum_{t \neq s}^{G} Y^{s t}+\sum_{t \neq s}^{G} B^{s t} Y^{t t}+\sum_{t \neq s}^{G} B^{s t} \sum_{u \neq s, t}^{G} Y^{t u}+\sum_{t \neq s}^{G} B^{s t} Y^{t s}+\sum_{t \neq s}^{G} B^{s t} A^{t s} L^{s s} Y^{s s}\right)
\end{aligned}
$$

where the double counting coefficient is a 1 by $\mathrm{N}$ vector. The terms inside the parentheses are $\mathrm{N}$ 
by 1 vectors, representing different parts of gross output induced by the production of Country s's total gross exports (which sum to $X^{s}-L^{s s} Y^{s s}$ ). Their values are measured by the back and forth movement of intermediate trade flows originating from the home country, which crosses national borders at least 3 times: (1) as intermediate exports from the home country, (2) returned from the direct importer as intermediate imports, and (3) exported to other countries again as intermediate or final products. The process can continue and repeat further until the value is absorbed by a destination country.

Proposition C.3: The FDC in a country's gross exports repeatedly counts the value of gross intermediate exports originating from all other countries except the home country. The limit of the double counting coefficient for each country t equals $V^{t} \sum_{t \neq s}^{G} B^{t s} A^{s r}$.

\section{Proof:}

$$
\begin{aligned}
& F D C^{s}=\sum_{t \neq s}^{G} V^{t} B^{t s} \sum_{r \neq s}^{G} A^{s r} L^{r r} E^{r^{*}}=\sum_{t \neq s}^{G} V^{t} B^{t s} \sum_{r \neq s}^{G} A^{s r}\left(X^{r}-L^{r r} Y^{r r}\right) \\
& =\sum_{t \neq s}^{G} V^{t} B^{t s} \sum_{r \neq s}^{G} A^{s r}\left(B^{r r} \sum_{u \neq r}^{G} Y^{r u}+\sum_{u \neq r}^{G} B^{r u} Y^{u u}+\sum_{u \neq r}^{G} B^{r u} \sum_{v \neq u, r}^{G} Y^{u v}+\sum_{u \neq r}^{G} B^{r u} Y^{u r}+\sum_{u \neq r}^{G} B^{r u} A^{u r} L^{r r} Y^{r r}\right)
\end{aligned}
$$

where the double counting coefficient is a 1 by $\mathrm{N}$ vector. The terms inside the parentheses are $\mathrm{N}$ by 1 vectors, representing different parts of gross output induced by the production of other countries' total gross exports (this part of the output in each country sums to $X^{r}-L^{r r} Y^{r r}$ ). Their values are measured by the back and forth movement of intermediate trade flows originating from other (foreign) countries, which also cross national borders at least 3 times but through different routes: (1) as intermediate exports from the home country, (2) re-exported by direct importing countries to third countries as intermediate exports, and (3) exported by a third country again to other countries except the home country as intermediate or final products. The process can continue and repeat further until the value is absorbed by a destination country.

The intuition behind propositions C. 2 and C. 3 is also simple: positive values of DDC and FDC only occur when there are back and forth intermediate trade flows among countries. They repeatedly count intermediate trade flows that cross national borders. Those intermediate 
trade transactions are not part of any country's GDP or final demand (beyond what has already been counted), similar to domestic inter-industry transactions that use one type of intermediate input to produce another type of intermediate inputs. Because all cross-country trade transactions are recorded by two countries' customs authorities, they show up in trade statistics. In comparison, domestic intermediate input transactions are deducted from total gross output when official GDP by industry statistics is accounted for. Therefore, PDC is not a value added concept, and has different economic and mathematical properties compared to RDV_B and FVA, although all three represent double counted terms in a country's gross exports.

Based on equation (C3), the gross exports of Country s in 3 country case can be expressed as

$$
\begin{aligned}
& u E^{s^{*}}=\underbrace{\left[V^{s} B^{s s} Y^{s r}+V^{s} B^{s s} Y^{s t}\right]}_{S 1-D V A_{-} F I N}+\underbrace{\left[V^{s} B^{s s} A^{s r} L^{r r} Y^{r r}+V^{s} B^{s s} A^{s t} L^{t t} Y^{t t}\right]}_{S 2-D V A_{-} I N T} \\
& +\underbrace{\left[V^{s} B^{s r} A^{r t} L^{t t} Y^{t t}+V^{s} B^{s t} A^{t r} L^{r r} Y^{r r}+V^{s} B^{s r} Y^{r t}+V^{s} B^{s t} Y^{t r}\right]}_{S 4-R A_{-} I N T r e x}] \\
& +\underbrace{\left[V^{s} B^{s r} Y^{r s}+V^{s} B^{s t} Y^{t s}+V^{s} B^{s r} A^{r s} L^{s s} Y^{s s}+V^{s} B^{s t} A^{t s} L^{s s} Y^{s s}\right]}_{S 5-D D C}] \\
& +\underbrace{\left[V^{s} B^{s r} A^{r s} L^{s s} E^{s^{*}}+V^{s} B^{s t} A^{t s} L^{s s} E^{s^{*}}\right]}_{S 6-M D C}] \\
& +\underbrace{\left[V^{r} B^{r s} Y^{s r}+V^{t} B^{t s} Y^{s t}+V^{r} B^{r s} A^{s r} L^{r r} Y^{r r}+V^{t} B^{t s} A^{s t} L^{t t} Y^{t t}\right]}_{S 6-M V A}] \\
& +\underbrace{\left[V^{t s} Y^{s r}+V^{r} B^{r s} Y^{s t}+V^{t} B^{t s} A^{s r} L^{r r} Y^{r r}+V^{r} B^{r s} A^{s t} L^{t t} Y^{t t}\right]}_{\left.S V^{r s} A^{s r} L^{r r} E^{r *}+V^{t} B^{t s} A^{s t} L^{t t} E^{t^{*}}\right]} \\
& +\underbrace{\left[V^{t} B^{t s} A^{s r} L^{r r} E^{r *}+V^{r} B^{r s} A^{s t} L^{t t} E^{t^{*}}\right]}_{S 7-O V A_{-} F I N}
\end{aligned}
$$

Similarly, 


$$
\begin{aligned}
& u E^{r^{*}}=\left[V^{r} B^{r r} Y^{r t}+V^{r} B^{r r} Y^{r s}\right]+\left[V^{r} B^{r r} A^{r t} L^{t t} Y^{t t}+V^{r} B^{r r} A^{r s} L^{s s} Y^{s s}\right] \\
& +\left[V^{r} B^{r t} A^{t s} L^{s s} Y^{s s}+V^{r} B^{r s} A^{s t} L^{t t} Y^{t t}+V^{r} B^{r t} Y^{t s}+V^{r} B^{r s} Y^{s t}\right] \\
& +\left[V^{r} B^{r t} Y^{t r}+V^{r} B^{r s} Y^{s r}+V^{r} B^{r t} A^{t r} L^{r r} Y^{r r}+V^{r} B^{r s} A^{s r} L^{r r} Y^{r r}\right] \\
& +\left[V^{r} B^{r t} A^{t r} L^{r r} E^{r^{*}}+V^{r} B^{r s} A^{s r} L^{r r} E^{r *}\right] \\
& +\left[V^{s} B^{s r} Y^{r s}+V^{t} B^{t r} Y^{r t}+V^{s} B^{s r} A^{r s} L^{s s} Y^{s s}+V^{t} B^{t r} A^{r t} L^{t t} Y^{t t}\right] \\
& +\left[V^{s} B^{s r} A^{r s} L^{s s} E^{s^{*}}+V^{t} B^{t r} A^{r t} L^{t t} E^{t^{*}}\right] \\
& +\left[V^{s} B^{s r} Y^{r t}+V^{t} B^{t r} Y^{r s}+V^{s} B^{s r} A^{r t} L^{t t} Y^{t t}+V^{t} B^{t r} A^{r s} L^{s s} Y^{s s}\right] \\
& +\left[V^{s} B^{s r} A^{r t} L^{t t} E^{t^{*}}+V^{t} B^{t r} A^{r s} L^{s s} E^{s^{*}}\right] \\
& u E^{t^{*}}=\left[V^{t t} B^{t t} Y^{t s}+V^{t t} B^{t t} Y^{t r}\right]+\left[V^{t t} B^{t t} A^{t s} L^{s s} Y^{s s}+V^{t t} B^{t t} A^{t r} L^{r r} Y^{r r}\right] \\
& +\left[V^{t t} B^{t s} A^{s r} L^{r r} Y^{r r}+V^{t t} B^{t r} A^{r s} L^{s s} Y^{s s}+V^{t t} B^{t s} Y^{s r}+V^{t t} B^{t r} Y^{r s}\right] \\
& +\left[V^{t t} B^{t s} Y^{s t}+V^{t t} B^{t r} Y^{r t}+V^{t t} B^{t s} A^{s t} L^{t t} Y^{t t}+V^{t t} B^{t r} A^{r t} L^{t t} Y^{t t}\right] \\
& +\left[V^{t t} B^{t s} A^{s t} L^{t t} E^{t^{*}}+V^{t t} B^{t r} A^{r t} L^{t t} E^{t^{*}}\right] \\
& +\left[V^{s} B^{s t} Y^{t s}+V^{r} B^{r t} Y^{t r}+V^{s} B^{s t} A^{t s} L^{s s} Y^{s s}+V^{r} B^{r t} A^{t r} L^{r r} Y^{r r}\right] \\
& +\left[V^{s} B^{s t} A^{t s} L^{s s} E^{s^{*}}+V^{r} B^{r t} A^{t r} L^{r r} E^{r *}\right] \\
& +\left[V^{s} B^{s t} Y^{t r}+V^{r} B^{r t} Y^{t s}+V^{s} B^{s t} A^{t r} L^{r r} Y^{r r}+V^{r} B^{r t} A^{t s} L^{s s} Y^{s s}\right] \\
& +\left[V^{s} B^{s t} A^{t r} L^{r r} E^{r *}+V^{r} B^{r t} A^{t s} L^{s s} E^{s^{*}}\right]
\end{aligned}
$$


Comparing equation (C10), (C11) and (C12), the concordance of value added and double counted terms in gross exports for 3-country, N-sector case can be summaries in following tables:

Table C1. How value-added is double counted in gross exports: 3 country case

\begin{tabular}{|c|c|c|c|c|c|c|c|}
\hline Country & $\begin{array}{l}\text { Double counting } \\
\text { measures }\end{array}$ & DVA_INTrex & RDV_B & DDC & MVA & MDC & OVA \\
\hline \multirow{3}{*}{ Country S } & Term NO. & S3 & S4 & S5 & S6 & S7 & S8 \\
\hline & $\begin{array}{l}\text { Value-Added } \\
\text { measure in other } \\
\text { countries }\end{array}$ & $\begin{array}{c}\text { OVA of R and } \\
\mathrm{T}\end{array}$ & $\begin{array}{l}\text { MVA of } \\
\text { R and T }\end{array}$ & $\begin{array}{l}\text { MDC of } \\
\text { R and T }\end{array}$ & $\begin{array}{c}\text { RDV_B } \\
\text { of } \mathrm{R} \text { and } \\
\mathrm{T}\end{array}$ & $\begin{array}{l}\mathrm{DDC} \text { of } \\
\mathrm{R} \text { and } \mathrm{T}\end{array}$ & $\begin{array}{c}\text { DVA_INTrex } \\
\text { of R and T }\end{array}$ \\
\hline & $\begin{array}{l}\text { Term NO. in other } \\
\text { countries }\end{array}$ & $\mathrm{R} 8$ and $\mathrm{T} 8$ & $\begin{array}{c}\text { R6 and } \\
\text { T6 }\end{array}$ & $\begin{array}{c}\text { R7 and } \\
\text { T7 }\end{array}$ & $\mathrm{R} 4$ and $\mathrm{T} 4$ & $\begin{array}{c}\mathrm{R} 5 \text { and } \\
\mathrm{T} 5\end{array}$ & $\mathrm{R} 3$ and $\mathrm{T} 3$ \\
\hline \multirow{3}{*}{ Country R } & Term NO. & $\mathbf{R 3}$ & R4 & R5 & R6 & R7 & R8 \\
\hline & \begin{tabular}{|l} 
Value-Added \\
measure in other \\
countries
\end{tabular} & $\begin{array}{c}\text { OVA of } \mathrm{T} \text { and } \\
\mathrm{S}\end{array}$ & $\begin{array}{l}\text { MVA of } \\
\text { T and } S\end{array}$ & $\begin{array}{l}\text { MDC of } \\
\text { T and S }\end{array}$ & $\begin{array}{l}\text { RDV_B } \\
\text { of T and } S\end{array}$ & $\begin{array}{l}\text { DDC of } \\
T \text { and } S\end{array}$ & $\begin{array}{c}\text { DVA_INTrex } \\
\text { of T and S }\end{array}$ \\
\hline & $\begin{array}{l}\text { Term NO. in other } \\
\text { countries }\end{array}$ & $\mathrm{S} 8$ and $\mathrm{T} 8$ & $\begin{array}{c}\text { S6 and } \\
\text { T6 }\end{array}$ & $\begin{array}{c}\text { S7 and } \\
\text { T7 }\end{array}$ & S4 and T4 & $\begin{array}{c}\text { S5 and } \\
\text { T5 }\end{array}$ & $\mathrm{S} 3$ and $\mathrm{T} 3$ \\
\hline \multirow{3}{*}{ Country T } & Term NO. & T3 & T4 & T5 & T6 & $\mathbf{T} 7$ & T8 \\
\hline & $\begin{array}{l}\text { Value-Added } \\
\text { measure in other } \\
\text { countries }\end{array}$ & $\begin{array}{c}\text { OVA of S and } \\
\mathrm{R}\end{array}$ & $\begin{array}{l}\text { MVA of } \\
\text { S and R }\end{array}$ & $\begin{array}{l}\text { MDC of } \\
\text { S and R }\end{array}$ & $\begin{array}{l}\text { RDV_B } \\
\text { of S and R }\end{array}$ & $\begin{array}{l}\text { DDC of } \\
\text { S and R }\end{array}$ & $\begin{array}{c}\text { DVA_INTrex } \\
\text { of S and R }\end{array}$ \\
\hline & $\begin{array}{l}\text { Term NO. in other } \\
\text { countries }\end{array}$ & $\mathrm{R} 8$ and $\mathrm{S} 8$ & $\begin{array}{l}\text { R6 and } \\
\text { S6 }\end{array}$ & $\begin{array}{c}\text { R7 and } \\
\text { S7 }\end{array}$ & R4 and S4 & $\begin{array}{l}\text { R5 and } \\
\text { S5 }\end{array}$ & $\mathrm{R} 3$ and $\mathrm{S} 3$ \\
\hline
\end{tabular}


Table C2. The detailed concordance of value added and double counted terms in gross exports: 3 country case

\begin{tabular}{|c|c|c|c|c|c|c|c|c|c|}
\hline \multirow[b]{2}{*}{ Term Label } & \multicolumn{3}{|c|}{ Country S } & \multicolumn{3}{|c|}{ Country R } & \multicolumn{3}{|c|}{ Country T } \\
\hline & $\begin{array}{l}\text { Term } \\
\text { NO. }\end{array}$ & Equation & $\begin{array}{c}\text { Concordance } \\
\text { Term NO. }\end{array}$ & $\begin{array}{l}\text { Term } \\
\text { NO. }\end{array}$ & Equation & $\begin{array}{c}\text { Concordance } \\
\text { Term NO. }\end{array}$ & $\begin{array}{l}\text { Term } \\
\text { NO. }\end{array}$ & Equation & $\begin{array}{c}\text { Concordance } \\
\text { Term NO. }\end{array}$ \\
\hline DVA_INTrex1 & $S 3-1$ & $V^{s} B^{s r} A^{r t} L^{i t} Y^{t t}$ & $R 8-3$ & $R 3-1$ & $V^{r} B^{r t} A^{t s} L^{S S} Y^{s S}$ & $T 8-3$ & $T 3-1$ & $V^{t} B^{t s} A^{s r} L^{r r} Y^{r r}$ & $S 8-3$ \\
\hline DVA_INTrex2 & $S 3-2$ & $V^{s} B^{s t} A^{t r} L^{r r} Y^{r r}$ & $T 8-4$ & $R 3-2$ & $V^{r} B^{r s} A^{s t} L^{t t} Y^{t t}$ & $S 8-4$ & $T 3-2$ & $V^{t} B^{t r} A^{r s} L^{s s} Y^{s s}$ & $R 8-4$ \\
\hline DVA_INTrex3 & S3-3 & $V^{s} B^{s r} Y^{r t}$ & $R 8-1$ & $R 3-3$ & $V^{r} B^{r t} Y^{t s}$ & $T 8-1$ & T3-3 & $V^{t} B^{t s} Y^{s r}$ & $S 8-1$ \\
\hline DVA_INTrex4 & $S 3-4$ & $V^{s} B^{s t} Y^{t r}$ & $T 8-2$ & $R 3-4$ & $V^{r} B^{r s} Y^{s t}$ & $S 8-2$ & $T 3-4$ & $V^{t} B^{t r} Y^{r s}$ & $R 8-2$ \\
\hline RDV_B1 & S4-1 & $V^{s} B^{s r} Y^{r s}$ & $R 6-2$ & $\overline{R 4-1}$ & $V^{r} B^{r t} Y^{t r}$ & $T 6-2$ & T4-1 & $V^{t} B^{t s} Y^{s t}$ & $S 6-2$ \\
\hline RDV_B2 & $S 4-2$ & $V^{s} B^{s t} Y^{t s}$ & $T 6-1$ & $R 4-2$ & $V^{r} B^{r s} Y^{s r}$ & $S 6-1$ & $T 4-2$ & $V^{t} B^{t r} Y^{r t}$ & R6-1 \\
\hline RDV_B3 & $S 4-3$ & $V^{s} B^{s r} A^{r s} L^{s s} Y^{s s}$ & $R 6-4$ & $R 4-3$ & $V^{r} B^{r t} A^{t r} L^{r r} Y^{r r}$ & $T 6-4$ & T4-3 & $V^{t} B^{t s} A^{s t} L^{t t} Y^{t t}$ & $S 6-4$ \\
\hline RDV_B4 & $S 4-4$ & $V^{s} B^{s t} A^{t s} L^{s s} Y^{s s}$ & $T 6-3$ & $R 4-4$ & $V^{r} B^{r s} A^{s r} L^{r r} Y^{r r}$ & $S 6-3$ & $T 4-4$ & $V^{t} B^{t r} A^{r t} L^{t t} Y^{t t}$ & $R 6-3$ \\
\hline DDC1 & S5-1 & $V^{s} B^{s r} A^{r s} L^{s s} E^{s^{*}}$ & $R 7-2$ & $R 5-1$ & $V^{r} B^{r t} A^{t r} L^{r r} E^{r^{*}}$ & $T 7-2$ & $T 5-1$ & $V^{t} B^{t s} A^{s t} L^{t t} E^{t^{*}}$ & $S 7-2$ \\
\hline DDC2 & $S 5-2$ & $V^{s} B^{s t} A^{t s} L^{s s} E^{s^{n}}$ & $T 7-1$ & $R 5-2$ & $V^{r} B^{r s} A^{s r} L^{r r} E^{r^{r}}$ & $S 7-1$ & $T 5-2$ & $V^{t} B^{t r} A^{r t} L^{t t} E^{t^{*}}$ & $R 7-1$ \\
\hline MVA_FIN1 & S6-1 & $V^{r} B^{r s} Y^{s r}$ & $R 4-2$ & $R 6-1$ & $V^{t} B^{t r} Y^{r t}$ & $T 4-2$ & $T 6-1$ & $V^{s} B^{s t} Y^{t s}$ & $S 4-2$ \\
\hline MVA_FIN2 & $S 6-2$ & $V^{t} B^{t s} Y^{s t}$ & T4-1 & $R 6-2$ & $V^{s} B^{s r} Y^{r S}$ & $S 4-1$ & $T 6-2$ & $V^{r} B^{r t} Y^{t r}$ & $R 4-1$ \\
\hline MVA_INT1 & $S 6-3$ & $V^{r} B^{r s} A^{s r} L^{r r} Y^{r r}$ & $R 4-4$ & $R 6-3$ & $V^{t} B^{t r} A^{r t} L^{t t} Y^{t t}$ & $T 4-4$ & T6-3 & $V^{s} B^{s t} A^{t s} L^{S S} Y^{s S}$ & $S 4-4$ \\
\hline MVA_INT2 & $S 6-4$ & $V^{t} B^{t s} A^{s t} L^{t t} Y^{t t}$ & $T 4-3$ & $R 6-4$ & $V^{s} B^{s r} A^{r s} L^{s s} Y^{s s}$ & $S 4-3$ & $T 6-4$ & $V^{r} B^{r t} A^{t r} L^{r r} Y^{r r}$ & $R 4-3$ \\
\hline MDC1 & $S 7-1$ & $V^{r} B^{r s} A^{s r} L^{r r} E^{r^{r}}$ & $R 5-2$ & $R 7-1$ & $V^{t} B^{t r} A^{r t} L^{t t} E^{t^{*}}$ & $T 5-2$ & $T 7-1$ & $V^{s} B^{s t} A^{t s} L^{s s} E^{s^{*}}$ & $S 5-2$ \\
\hline MDC2 & $S 7-2$ & $V^{t} B^{t s} A^{s t} L^{t t} E^{t^{*}}$ & $T 5-1$ & $R 7-2$ & $V^{s} B^{s r} A^{r s} L^{s s} E^{s^{*}}$ & $S 5-1$ & $T 7-2$ & $V^{r} B^{r t} A^{t r} L^{r r} E^{r^{*}}$ & $R 5-1$ \\
\hline OVA_FIN1 & $S 8-1$ & $V^{t} B^{t s} Y^{s r}$ & $T 3-3$ & $R 8-1$ & $V^{s} B^{s r} Y^{r t}$ & $S 3-3$ & $T 8-1$ & $V^{r} B^{r t} Y^{t s}$ & $R 3-3$ \\
\hline OVA_FIN2 & $S 8-2$ & $V^{r} B^{r s} Y^{s t}$ & $R 3-4$ & $R 8-2$ & $V^{t} B^{t r} Y^{r s}$ & $T 3-4$ & $T 8-2$ & $V^{s} B^{s t} Y^{t r}$ & $S 3-4$ \\
\hline OVA_INT1 & $S 8-3$ & $V^{t} B^{t s} A^{s r} L^{r r} Y^{r r}$ & $T 3-1$ & $R 8-3$ & $V^{s} B^{s r} A^{r t} L^{t t} Y^{t t}$ & $S 3-1$ & $T 8-3$ & $V^{r} B^{r t} A^{t s} L^{S S} Y^{s S}$ & $R 3-1$ \\
\hline OVA_INT2 & $S 8-4$ & $V^{r} B^{r s} A^{s t} L^{t t} Y^{t t}$ & $R 3-2$ & $R 8-4$ & $V^{t} B^{t r} A^{r s} L^{s s} Y^{s s}$ & $T 3-2$ & $T 8-4$ & $V^{s} B^{s t} A^{t r} L^{r r} Y^{r r}$ & $S 3-2$ \\
\hline
\end{tabular}




\section{Appendix D: Decomposition of a country's bilateral exports into traditional and GVC trade}

In traditional trade, the domestic factor content embodied exports are directly absorbed by importers without involving re-exports or production activities in any third countries. The intermediate exports and final exports in traditional bilateral trade can be measured as $\left(V^{s} L^{s s}\right)^{T} \# Y^{s r}$ and $\left(V^{s} L^{s s}\right)^{T} \#\left(A^{s r} L^{r r} Y^{r r}\right)$, which are not involved re-exports and third countries. Therefore, equation (18) in main text can be further decomposed as:

$$
\begin{aligned}
& E^{s r}=\left[\left(V^{s} L^{s s}\right)^{T} \# Y^{s r}+\left(V^{s} L^{s s}\right)^{T} \#\left(A^{s r} L^{r r} Y^{r r}\right)\right] \\
& +\left[\left(V^{s} B^{s s}-V^{s} L^{s s}\right)^{T} \# Y^{s r}+\left(V^{s} L^{s s}\right)^{T} \#\left(A^{s r} B^{r r} Y^{r r}-A^{s r} L^{r r} Y^{r r}\right)\right] \\
& +\left(V^{s} L^{s s}\right)^{T} \#\left[A^{s r} \sum_{t \neq s, r}^{G} B^{r t} Y^{t t}+A^{s r} B^{r r} \sum_{t \neq s, r}^{G} Y^{r t}+A^{s r} \sum_{t \neq s, r}^{G} B^{r t} \sum_{u \neq s, t}^{G} Y^{t u}\right] \\
& +\left(V^{s} L^{s s}\right)^{T} \#\left[A^{s r} B^{r r} Y^{r s}+A^{s r} \sum_{t \neq s, r}^{G} B^{r t} Y^{t s}+A^{s r} B^{r s} Y^{s s}\right] \\
& +\left[\left(V^{s} L^{s s}\right)^{T} \#\left(A^{s r} \sum_{t \neq s}^{G} B^{r s} Y^{s t}\right)+\left(V^{s} L^{s s} \sum_{t \neq s}^{G} A^{s t} B^{t s}\right)^{T} \#\left(A^{s r} X^{r}\right)\right] \\
& +\left[\left(V^{r} B^{r s}\right)^{T} \# Y^{s r}+\left(\sum_{t \neq s, r}^{G} V^{t} B^{t s}\right)^{T} \# Y^{s r}\right]+\left[\left(V^{r} B^{r s}\right)^{T} \#\left(A^{s r} L^{r r} Y^{r r}\right)+\left(\sum_{t \neq s, r}^{G} V^{t} B^{t s}\right)^{T} \#\left(A^{s r} L^{r r} Y^{r r}\right)\right] \\
& +\left[\left(V^{r} B^{r s}\right)^{T} \#\left(A^{s r} L^{r r} E^{r *}\right)+\left(\sum_{t \neq s, r}^{G} V^{t} B^{t s}\right)^{T} \#\left(A^{s r} L^{r r} E^{r^{*}}\right)\right]
\end{aligned}
$$

Based on definition of Leontief inverse matrix, we can obtain

$$
\begin{aligned}
& V^{s} B^{s s}-V^{s} L^{s s}=V^{s}\left(B^{s s}-L^{s s}\right)=V^{s} L^{s s} \sum_{t \neq s}^{G} A^{s t} B^{t s} \\
& A^{s r} B^{r r} Y^{r r}-A^{s r} L^{r r} Y^{r r}=A^{s r}\left(B^{r r}-L^{r r}\right) Y^{r r}=A^{s r} \sum_{t \neq r}^{G} B^{r t} A^{t r} L^{r r} Y^{r r}
\end{aligned}
$$

And

$$
\begin{aligned}
& A^{s r} \sum_{t \neq s, r}^{G} B^{r t} Y^{t t}+A^{s r} B^{r r} \sum_{t \neq s, r}^{G} Y^{r t}+A^{s r} \sum_{t \neq s, r}^{G} B^{r t} \sum_{u \neq s, t}^{G} Y^{t u}=A^{s r} \sum_{t \neq s, r}^{G} B^{r t} Y^{t r}+A^{s r} \sum_{t \neq s}^{G} B^{r t} \sum_{u \neq s, r}^{G} Y^{t u} \\
& A^{s r} B^{r r} Y^{r s}+A^{s r} \sum_{t \neq s, r}^{G} B^{r t} Y^{t s}+A^{s r} B^{r s} Y^{s s}=A^{s r} \sum_{t}^{G} B^{r t} Y^{t s}
\end{aligned}
$$

Inserting equation D2-D5 into equation D1, the decomposition equation can be rearranged as 


$$
\begin{aligned}
& E^{s r}=\left[\left(V^{s} L^{s s}\right)^{T} \# Y^{s r}+\left(V^{s} L^{s s}\right)^{T} \#\left(A^{s r} L^{r r} Y^{r r}\right)\right] \\
& +\left[\left(V^{s} L^{s s} \sum_{t \neq s}^{G} A^{s t} B^{t s}\right)^{T} \# Y^{s r}+\left(V^{s} L^{s s}\right)^{T} \#\left(A^{s r} \sum_{t \neq r}^{G} B^{r t} A^{t r} L^{r r} Y^{r r}\right)+\left(V^{s} L^{s s}\right)^{T} \#\left(A^{s r} \sum_{t \neq s, r}^{G} B^{r t} Y^{t r}\right)\right] \\
& +\left[\left(V^{s} L^{s s}\right)^{T} \#\left(A^{s r} \sum_{t \neq s}^{G} B^{r t} \sum_{u \neq s, r}^{G} Y^{t u}\right)\right]+\left[\left(V^{s} L^{s s}\right)^{T} \#\left(A^{s r} \sum_{t}^{G} B^{r t} Y^{t s}\right)\right] \\
& +\left[\left(V^{s} L^{s s}\right)^{T} \#\left(A^{s r} \sum_{t \neq s}^{G} B^{r s} Y^{s t}\right)+\left(V^{s} L^{s s} \sum_{t \neq s}^{G} A^{s t} B^{t s}\right)^{T} \#\left(A^{s r} X^{r}\right)\right] \\
& +\left[\left(V^{r} B^{r s}\right)^{T} \# Y^{s r}+\left(\sum_{t \neq s, r}^{G} V^{t} B^{t s}\right)^{T} \# Y^{s r}\right]+\left[\left(V^{r} B^{r s}\right)^{T} \#\left(A^{s r} L^{r r} Y^{r r}\right)+\left(\sum_{t \neq s, r}^{G} V^{t} B^{t s}\right)^{T} \#\left(A^{s r} L^{r r} Y^{r r}\right)\right] \\
& +\left[\left(V^{r} B^{r s}\right)^{T} \#\left(A^{s r} L^{r r} E^{r^{* *}}\right)+\left(\sum_{t \neq s, r}^{G} V^{t} B^{t s}\right)^{T} \#\left(A^{s r} L^{r r} E^{r *}\right)\right]
\end{aligned}
$$

The $1^{\text {st }}$ category, $\left(V^{s} L^{s s}\right)^{T} \# Y^{s r}+\left(V^{s} L^{s s}\right)^{T} \#\left(A^{s r} L^{r r} Y^{r r}\right)$, is the domestic value added embodied in traditional exports, which directly absorbed by trade partner $\mathrm{r}$. The $2^{\text {nd }}$ category is country s's value added embodied in GVC exports and ultimately absorbed by trade partner $\mathrm{r}$. The $3^{\text {rd }}$ category is country s's domestic value-added in GVC exports and ultimately absorbed by the third country (other countries). The $4^{\text {th }}$ category is Country s's domestic value-added in its intermediate exports and ultimately absorbed by source Country s. the $2^{\text {nd }}$ to $4^{\text {th }}$ categories are the domestic value added embodied in GVC exports. Other categories are same to equation (18) in the main text.

\section{Appendix E: Decomposition of a country's gross exports in G-country N-sector case}

The economic interpretations for the 16 terms in equations (18) are listed in table E1. 
Table E1 Definition of the 16 Terms in Equation (18) of the Main Text

\begin{tabular}{|c|c|c|c|}
\hline Number & Label & Description & Categories \\
\hline T1 & DVA_FIN & Domestic Value Added in final goods exports & DVA_FIN \\
\hline $\mathbf{T 2}$ & DVA_INT & $\begin{array}{l}\text { Domestic Value Added in intermediate exports used by direct } \\
\text { importer to produce its domestic final goods and consumed there }\end{array}$ & DVA_INT \\
\hline T3 & DVA_INTrex1 & $\begin{array}{l}\text { Domestic Value Added in intermediate exports used by the } \\
\text { direct importer to produce intermediate exports for production of } \\
\text { domestic used final goods in third countries }\end{array}$ & DVA_INTrex \\
\hline T4 & DVA_INTrex2 & $\begin{array}{l}\text { Domestic Value Added in intermediate exports used by the } \\
\text { direct importer to produce final goods exports to third countries }\end{array}$ & DVA_INTrex \\
\hline T5 & DVA_INTrex3 & $\begin{array}{l}\text { Domestic Value Added in Intermediate exports used by the } \\
\text { direct importer to produce intermediate exports to third countries }\end{array}$ & DVA_INTrex \\
\hline T6 & RDV_FIN1 & $\begin{array}{l}\text { Returned Domestic Value Added in final goods imports -from } \\
\text { the direct importer }\end{array}$ & RDV_B \\
\hline T7 & RDV_FIN2 & $\begin{array}{l}\text { Returned Domestic Value Added in final goods imports -via } \\
\text { third countries }\end{array}$ & RDV_B \\
\hline T8 & RDV_INT & $\begin{array}{l}\text { Returned Domestic Value Added in intermediate imports used } \\
\text { produce final goods consumed at home }\end{array}$ & RDV_B \\
\hline T9 & DDC_FIN & $\begin{array}{l}\text { Double counted Domestic Value Added used to produce final } \\
\text { goods exports }\end{array}$ & DDC \\
\hline T10 & DDC_INT & $\begin{array}{l}\text { Double counted Domestic Value Added used to produce } \\
\text { intermediate exports }\end{array}$ & $\mathrm{DDC}$ \\
\hline T11 & MVA_FIN & $\begin{array}{l}\text { Direct importer's Value Added in exporting country's final } \\
\text { goods exports }\end{array}$ & $\begin{array}{l}\text { FVA_FIN or } \\
\text { MVA }\end{array}$ \\
\hline T12 & MVA_INT & $\begin{array}{l}\text { Direct importer's Value Added in exporting country's } \\
\text { intermediate goods exports }\end{array}$ & $\begin{array}{l}\text { FVA_INT or } \\
\text { MVA }\end{array}$ \\
\hline T13 & MDC & $\begin{array}{l}\text { Direct importer's Value Added double counted in home } \\
\text { country's exports production }\end{array}$ & FDC \\
\hline T14 & OVA_FIN & $\begin{array}{l}\text { Third countries' Value Added in exporting country's final goods } \\
\text { exports }\end{array}$ & $\begin{array}{l}\text { FVA_FIN or } \\
\text { OVA }\end{array}$ \\
\hline T15 & OVA_INT & $\begin{array}{l}\text { Third countries' Value Added in exporting country's } \\
\text { intermediate goods exports }\end{array}$ & $\begin{array}{l}\text { FVA_INT or } \\
\text { OVA }\end{array}$ \\
\hline T16 & ODC & $\begin{array}{l}\text { Third countries' Value Added double counted in home country's } \\
\text { exports production }\end{array}$ & FDC \\
\hline
\end{tabular}

Rearranging equation (18) in the main text as following nine groups: 


$$
\begin{aligned}
& E^{s r}=\left(V^{s} B^{s s}\right)^{T} \# Y^{s r}+\left[\left(V^{s} L^{s s}\right)^{T} \#\left(A^{s r} B^{r r} Y^{r r}\right)+\left(V^{s} L^{s s}\right)^{T} \#\left(A^{s r} \sum_{t \neq s, r}^{G} B^{r t} Y^{t t}\right)\right] \\
& +\left[\left(V^{s} L^{s s}\right)^{T} \#\left(A^{s r} B^{r r} \sum_{t \neq s, r}^{G} Y^{r t}\right)+\left(V^{s} L^{s s}\right)^{T} \#\left(A^{s r} \sum_{t \neq s, r}^{G} \sum_{u \neq s, t}^{G} B^{r t} Y^{t u}\right)\right] \\
& +\left[\left(V^{s} L^{s s}\right)^{T} \#\left(A^{s r} B^{r r} Y^{r s}\right)+\left(V^{s} L^{s s}\right)^{T} \#\left(A^{s r} \sum_{t \neq s, r}^{G} B^{r t} Y^{t s}\right)\right]+\left(V^{s} L^{s s}\right)^{T} \#\left(A^{s r} B^{r s} Y^{s s}\right) \\
& +\left[\left(V^{s} L^{s s}\right)^{T} \#\left(A^{s r} \sum_{t \neq s}^{G} B^{r s} Y^{s t}\right)+\left(V^{s} B^{s s}-V^{s} L^{s s}\right)^{T} \#\left(A^{s r} X^{r}\right)\right] \\
& +\left[\left(V^{r} B^{r s}\right)^{T} \# Y^{s r}+\left(\sum_{t \neq s, r}^{G} V^{t} B^{t s}\right)^{T} \# Y^{s r}\right] \\
& +\left[\left(V^{r} B^{r s}\right)^{T} \#\left(A^{s r} L^{r r} Y^{r r}\right)+\left(\sum_{t \neq s, r}^{G} V^{t} B^{t s}\right)^{T} \#\left(A^{s r} L^{r r} Y^{r r}\right)\right] \\
& +\left[\left(V^{r} B^{r s}\right)^{T} \#\left(A^{s r} L^{r r} E^{r^{* *}}\right)+\left(\sum_{t \neq s, r}^{G} V^{t} B^{t s}\right)^{T} \#\left(A^{s r} L^{r r} E^{r^{*}}\right)\right]
\end{aligned}
$$

Rearranging

$$
\begin{aligned}
& E^{s r}=\left(V^{s} B^{s s}\right)^{T} \# Y^{s r}+\left(V^{s} L^{s s}\right)^{T} \#\left(A^{s r} \sum_{t \neq s}^{G} B^{r t} Y^{t t}\right)+\left(V^{s} L^{s s}\right)^{T} \#\left(A^{s r} \sum_{t \neq s}^{G} \sum_{u \neq s, t}^{G} B^{r t} Y^{t u}\right) \\
& +\left(V^{s} L^{s s}\right)^{T} \#\left(A^{s r} \sum_{t \neq s}^{G} B^{r t} Y^{t s}\right)+\left(V^{s} L^{s s}\right)^{T} \#\left(A^{s r} B^{r s} Y^{s s}\right) \\
& +\left[\left(V^{s} L^{s s}\right)^{T} \#\left(A^{s r} \sum_{t \neq s}^{G} B^{r s} Y^{s t}\right)+\left(V^{s} B^{s s}-V^{s} L^{s s}\right)^{T} \#\left(A^{s r} X^{r}\right)\right] \\
& +\left(\sum_{t \neq s}^{G} V^{t} B^{t s}\right)^{T} \# Y^{s r}+\left(\sum_{t \neq s}^{G} V^{t} B^{t s}\right)^{T} \#\left(A^{s r} L^{r r} Y^{r r}\right)+\left(\sum_{t \neq s}^{G} V^{t} B^{t s}\right)^{T} \#\left(A^{s r} L^{r r} E^{r^{*}}\right)
\end{aligned}
$$

Summing up all the G-1 trading partners, we obtain the decomposition equation of Country s' gross exports to the world:

$$
\begin{aligned}
& E^{s^{*}}=\left(V^{s} B^{s s}\right)^{T} \# \sum_{r \neq s}^{G} Y^{s r}+\left(V^{s} L^{s s}\right)^{T} \#\left(\sum_{r \neq s}^{G} A^{s r} \sum_{t \neq s}^{G} B^{r t} Y^{t t}\right)+\left(V^{s} L^{s s}\right)^{T} \#\left(\sum_{r \neq s}^{G} A^{s r} \sum_{t \neq s}^{G} \sum_{u \neq s, t}^{G} B^{r t} Y^{t u}\right) \\
& +\left(V^{s} L^{s s}\right)^{T} \#\left(\sum_{r \neq s}^{G} A^{s r} \sum_{t \neq s}^{G} B^{r t} Y^{t s}\right)+\left(V^{s} L^{s s}\right)^{T} \#\left(\sum_{r \neq s}^{G} A^{s r} B^{r s} Y^{s s}\right) \\
& +\left[\left(V^{s} L^{s s}\right)^{T} \#\left(\sum_{r \neq s}^{G} A^{s r} \sum_{t \neq s}^{G} B^{r s} Y^{s t}\right)+\left(V^{s} B^{s s}-V^{s} L^{s s}\right)^{T} \#\left(\sum_{r \neq s}^{G} A^{s r} X^{r}\right)\right] \\
& +\left(\sum_{t \neq s}^{G} V^{t} B^{t s}\right)^{T} \# \sum_{r \neq s}^{G} Y^{s r}+\left(\sum_{t \neq s}^{G} V^{t} B^{t s}\right)^{T} \#\left(\sum_{r \neq s}^{G} A^{s r} L^{r r} Y^{r r}\right)+\left(\sum_{t \neq s}^{G} V^{t} B^{t s}\right)^{T} \#\left(\sum_{r \neq s}^{G} A^{s r} L^{r r} E^{r *}\right)
\end{aligned}
$$

As a sum of domestic value-added in gross exports to all other G-1 countries, and combine the $2^{\text {nd }}$ and the $3^{\text {rd }}$, the $4^{\text {th }}$ and the $5^{\text {th }}$, as well as the $6^{\text {th }}$ and the $7^{\text {th }}$ terms respectively, the first 10 terms that decompose Country s' domestic value-added in equation (18) of the main text reduce to 7 
terms without separation of direct importer and third countries. Similarly, the last 6 terms in equation (18) of the main text that decompose foreign value-added in bilateral gross exports are summed to three terms with no distinction between direct importing country and third countries.

Summing up equation (E2) over all sectors, we obtain following equation:

$$
\begin{aligned}
& u E^{s^{*}}=V^{s} B^{s s} \sum_{r \neq s}^{G} Y^{s r}+V^{s} L^{s s} \sum_{r \neq s}^{G} A^{s r} \sum_{t \neq s}^{G} B^{r t} Y^{t t}+V^{s} L^{s s} \sum_{r \neq s}^{G} A^{s r} \sum_{t \neq s}^{G} B^{r t} \sum_{u \neq s, t}^{G} Y^{t u} \\
& +V^{s} L^{s s} \sum_{r \neq s}^{G} A^{s r} \sum_{t \neq s}^{G} B^{r t} Y^{t s}+V^{s} L^{s s} \sum_{r \neq s}^{G} A^{s r} B^{r s} Y^{s s} \\
& +\left[V^{s} L^{s s} \sum_{r \neq s}^{G} A^{s r} \sum_{t \neq s}^{G} B^{r s} Y^{s t}+V^{s}\left(B^{s s}-L^{s s}\right) \sum_{r \neq s}^{G} A^{s r} X^{r}\right] \\
& +\sum_{t \neq s}^{G} V^{t} B^{t s} \sum_{r \neq s}^{G} Y^{s r}+\sum_{t \neq s}^{G} V^{t} B^{t s} \sum_{r \neq s}^{G} A^{s r} L^{r r} Y^{r r}+\sum_{t \neq s}^{G} V^{t} B^{t s} \sum_{r \neq s}^{G} A^{s r} L^{r r} E^{r^{*}}
\end{aligned}
$$

Because $\sum_{r \neq s}^{G} A^{s r} \sum_{t \neq s}^{G} B^{r t}=\sum_{t \neq s}^{G} A^{s t} \sum_{r \neq s}^{G} B^{t r}$

Therefore,

$$
\begin{aligned}
& V^{s} L^{s s} \sum_{r \neq s}^{G} A^{s r} \sum_{t \neq s}^{G} B^{r t} Y^{t t}=V^{s} L^{s s} \sum_{t \neq s}^{G} A^{s t} \sum_{r \neq s}^{G} B^{t r} Y^{r r} \\
& V^{s} L^{s s} \sum_{r \neq s}^{G} A^{s r} \sum_{t \neq s}^{G} B^{r t} \sum_{u \neq s, t}^{G} Y^{t u}=V^{s} L^{s s} \sum_{t \neq s}^{G} A^{s t} \sum_{r \neq s}^{G} B^{t r} \sum_{u \neq s, r}^{G} Y^{r u} \\
& V^{s} L^{s s} \sum_{r \neq s}^{G} A^{s r} \sum_{t \neq s}^{G} B^{r t} Y^{t s}=V^{s} L^{s s} \sum_{t \neq s}^{G} A^{s t} \sum_{r \neq s}^{G} B^{t r} Y^{r s}
\end{aligned}
$$

So, equation (E3) can be re-arranged as

$$
\begin{aligned}
& u E^{s^{*}}=V^{s} B^{s s} \sum_{r \neq s}^{G} Y^{s r}+V^{s} L^{s s} \sum_{t \neq s}^{G} A^{s t} \sum_{r \neq s}^{G} B^{t r} Y^{r r}+V^{s} L^{s s} \sum_{t \neq s}^{G} A^{s t} \sum_{r \neq s}^{G} B^{t r} \sum_{u \neq s, r}^{G} Y^{r u} \\
& +V^{s} L^{s s} \sum_{t \neq s}^{G} A^{s t} \sum_{r \neq s}^{G} B^{t r} Y^{r s}+V^{s} L^{s s} \sum_{r \neq s}^{G} A^{s r} B^{r s} Y^{s s} \\
& +\left[V^{s} L^{s s} \sum_{r \neq s}^{G} A^{s r} B^{r s} \sum_{t \neq s}^{G} Y^{s t}+V^{s}\left(B^{s s}-L^{s s}\right) \sum_{t \neq s}^{G} A^{s t} X^{t}\right] \\
& +\sum_{t \neq s}^{G} V^{t} B^{t s} \sum_{r \neq s}^{G} Y^{s r}+\sum_{t \neq s}^{G} V^{t} B^{t s} \sum_{r \neq s}^{G} A^{s r} L^{r r} Y^{r r}+\sum_{t \neq s}^{G} V^{t} B^{t s} \sum_{r \neq s}^{G} A^{s r} L^{r r} E^{r^{*}}
\end{aligned}
$$

Based on the definition of global Leontief Inverse matrix, following identity holds: 


$$
\begin{aligned}
& {\left[\begin{array}{cccc}
I-A^{11} & -A^{12} & \cdots & -A^{1 G} \\
-A^{21} & I-A^{22} & \cdots & -A^{2 G} \\
\vdots & \vdots & \ddots & \vdots \\
-A^{G 1} & -A^{G 2} & \cdots & I-A^{G G}
\end{array}\right]\left[\begin{array}{cccc}
B^{11} & B^{12} & \cdots & B^{1 G} \\
B^{21} & B^{22} & \cdots & B^{2 G} \\
\vdots & \vdots & \ddots & \vdots \\
B^{G 1} & B^{G 2} & \cdots & B^{G G}
\end{array}\right]=\left[\begin{array}{cccc}
I & 0 & \cdots & 0 \\
0 & I & \cdots & 0 \\
\vdots & \vdots & \ddots & \vdots \\
0 & 0 & \cdots & I
\end{array}\right]} \\
& =\left[\begin{array}{cccc}
B^{11} & B^{12} & \cdots & B^{1 G} \\
B^{21} & B^{22} & \cdots & B^{2 G} \\
\vdots & \vdots & \ddots & \vdots \\
B^{G 1} & B^{G 2} & \cdots & B^{G G}
\end{array}\right]\left[\begin{array}{cccc}
I-A^{11} & -A^{12} & \cdots & -A^{1 G} \\
-A^{21} & I-A^{22} & \cdots & -A^{2 G} \\
\vdots & \vdots & \ddots & \vdots \\
-A^{G 1} & -A^{G 2} & \cdots & I-A^{G G}
\end{array}\right]
\end{aligned}
$$

From (E5) we can obtain following two equations:

$$
\begin{aligned}
& \left(I-A^{s s}\right) B^{s r}-\sum_{t \neq s}^{G} A^{s t} B^{t r}=0 \\
& \left(I-A^{s s}\right) B^{s s}-\sum_{r \neq s}^{G} A^{s r} B^{r s}=I=B^{s s}\left(I-A^{s s}\right)-\sum_{r \neq s}^{G} B^{s r} A^{r s}
\end{aligned}
$$

Re-arrange equation (E6) and (E7)

$$
\begin{aligned}
& B^{s r}=\left(I-A^{s s}\right)^{-1} \sum_{r \neq s}^{G} A^{s t} B^{t r}=L^{s s} \sum_{r \neq s}^{G} A^{s t} B^{t r} \\
& L^{s s} \sum_{r \neq s}^{G} A^{s r} B^{r s}=B^{s s}-L^{s s}=\sum_{r \neq s}^{G} B^{s r} A^{r s} L^{s s}
\end{aligned}
$$

Because $L^{s s}, B^{s r}$ and $A^{r s} \geq 0$, Therefore $B^{s s}-L^{s s} \geq 0$.

Inserting equation (E8) and (E9) into equation (E4)

$$
\begin{aligned}
& u E^{s^{*}}=V^{s} B^{s s} \sum_{r \neq s}^{G} Y^{s r}+V^{s} \sum_{r \neq s}^{G} B^{s r} Y^{r r}+V^{s} \sum_{r \neq s}^{G} B^{s r} \sum_{u \neq s, r}^{G} Y^{r u}+V^{s} \sum_{r \neq s}^{G} B^{s r} Y^{r s} \\
& +V^{s} \sum_{r \neq s}^{G} B^{s r} A^{r s} L^{s s} Y^{s s}+\left[V^{s} \sum_{r \neq s}^{G} B^{s r} A^{r s} L^{s s} \sum_{t \neq s}^{G} Y^{s t}+V^{s} \sum_{r \neq s}^{G} B^{s r} A^{r s} L^{s s} \sum_{t \neq s}^{G} A^{s t} X^{t}\right] \\
& +\sum_{t \neq s}^{G} V^{t} B^{t s} \sum_{r \neq s}^{G} Y^{s r}+\sum_{t \neq s}^{G} V^{t} B^{t s} \sum_{r \neq s}^{G} A^{s r} L^{r r} Y^{r r}+\sum_{t \neq s}^{G} V^{t} B^{t s} \sum_{r \neq s}^{G} A^{s r} L^{r r} E^{r^{*}}
\end{aligned}
$$

Re-arrange

$$
\begin{aligned}
& u E^{s^{*}}=V^{s} B^{s s} \sum_{r \neq s}^{G} Y^{s r}+V^{s} \sum_{r \neq s}^{G} B^{s r} Y^{r r}+V^{s} \sum_{r \neq s}^{G} B^{s r} \sum_{u \neq s, r}^{G} Y^{r u}+V^{s} \sum_{r \neq s}^{G} B^{s r} Y^{r s} \\
& +V^{s} \sum_{r \neq s}^{G} B^{s r} A^{r s} L^{s s} Y^{s s}+V^{s} \sum_{r \neq s}^{G} B^{s r} A^{r s} L^{s s} E^{s^{*}} \\
& +\sum_{t \neq s}^{G} V^{t} B^{t s} \sum_{r \neq s}^{G} Y^{s r}+\sum_{t \neq s}^{G} V^{t} B^{t s} \sum_{r \neq s}^{G} A^{s r} L^{r r} Y^{r r}+\sum_{t \neq s}^{G} V^{t} B^{t s} \sum_{r \neq s}^{G} A^{s r} L^{r r} E^{r^{*}}
\end{aligned}
$$


It is exactly the same as equation (36) in KWW.

Table E2 Comparison of the 16 terms in Equation (21) and the 9 terms in Equation (36) of KWW.

\begin{tabular}{|c|c|c|}
\hline $\begin{array}{l}\text { WWZ } \\
\text { Equation } \\
21 \\
\end{array}$ & $\begin{array}{c}\text { KWW } \\
\text { Equation } \\
36\end{array}$ & Description \\
\hline T1 & T1 & Domestic Value Added exports in final goods exports \\
\hline $\mathbf{T 2}$ & \multirow[b]{2}{*}{$\mathbf{T 2}$} & \multirow{2}{*}{$\begin{array}{l}\text { Domestic Value Added in intermediate exports for } \\
\text { production of all other countries' domestic used final goods. } \\
\text { WWZ separates direct importer and third countries }\end{array}$} \\
\hline T3 & & \\
\hline T4 & \multirow[b]{2}{*}{ T3 } & \multirow{2}{*}{$\begin{array}{l}\text { Domestic Value Added in intermediate exports used by } \\
\text { producing final exports to the other countries. WWZ } \\
\text { separates final exports from the direct importer and third } \\
\text { countries. }\end{array}$} \\
\hline T5 & & \\
\hline T6 & \multirow[b]{2}{*}{ T4 } & \multirow{2}{*}{$\begin{array}{l}\text { Returned Domestic Value Added in final goods imports from } \\
\text { the other countries. WWZ separates final imports from the } \\
\text { direct importer and third countries. }\end{array}$} \\
\hline T7 & & \\
\hline T8 & 5 & Returned Domestic Value Added in intermediate imports \\
\hline T9 & \multirow[b]{2}{*}{ T6 } & \multirow{2}{*}{$\begin{array}{l}\text { Double counted Domestic Value Added in gross exports. } \\
\text { WWZ separates double counting due to final and intermediate } \\
\text { exports production. }\end{array}$} \\
\hline T10 & & \\
\hline T11 & \multirow[b]{2}{*}{ T7 } & \multirow{2}{*}{$\begin{array}{l}\text { Foreign Value Added in exporting country's final goods } \\
\text { exports. WWZ separates FVA from direct importer and from } \\
\text { third countries. }\end{array}$} \\
\hline T14 & & \\
\hline T12 & \multirow[b]{2}{*}{ T8 } & \multirow{2}{*}{$\begin{array}{l}\text { Foreign Value Added in exporting country's intermediate } \\
\text { goods exports. . WWZ separates FVA from direct importer } \\
\text { and from third countries. }\end{array}$} \\
\hline T15 & & \\
\hline T13 & \multirow[b]{2}{*}{ T9 } & \multirow{2}{*}{$\begin{array}{l}\text { Double counted Foreign Value Added in exporting country's } \\
\text { gross exports. WWZ separates FDC from direct importer and } \\
\text { from third countries. }\end{array}$} \\
\hline T16 & & \\
\hline
\end{tabular}

Appendix F: Relationship among forward and backward linkage based trade in value-added measures: 3-country, 2-sector case

Without loss of generality, define $v a x_{-} f_{1}^{s r}$ as value-added exports based on forward industrial linkage by the first sector of Country s (producer's perspective) to Country $r$, then 


$$
\begin{aligned}
& v a x_{-} f_{1}^{s r}=V_{1}^{s} B^{s s} Y^{s r}+V_{1}^{s} B^{s r} Y^{r r}+V_{1}^{s} B^{s t} Y^{t r} \\
& =\left[\begin{array}{ll}
v_{1}^{s} & 0
\end{array}\right]\left[\begin{array}{ll}
b_{11}^{s s} & b_{12}^{s s} \\
b_{21}^{s s} & b_{22}^{s s}
\end{array}\right]\left[\begin{array}{l}
y_{1}^{s r} \\
y_{2}^{s r}
\end{array}\right]+\left[\begin{array}{ll}
v_{1}^{s} & 0
\end{array}\right]\left[\begin{array}{ll}
b_{11}^{s r} & b_{12}^{s r} \\
b_{21}^{s r} & b_{22}^{s r}
\end{array}\right]\left[\begin{array}{l}
y_{1}^{r r} \\
y_{2}^{r r}
\end{array}\right]+\left[\begin{array}{ll}
v_{1}^{s} & 0
\end{array}\right]\left[\begin{array}{ll}
b_{11}^{s t} & b_{12}^{s t} \\
b_{21}^{s t} & b_{22}^{s t}
\end{array}\right]\left[\begin{array}{l}
y_{1}^{t r} \\
y_{2}^{t r}
\end{array}\right] \\
& =v_{1}^{s} \sum_{j}^{N} b_{1 j}^{s s} y_{j}^{s r}+v_{1}^{s} \sum_{j}^{N} b_{1 j}^{s r} y_{j}^{r r}+v_{1}^{s} \sum_{j}^{N} b_{1 j}^{s t} y_{j}^{t r}
\end{aligned}
$$

Where $V_{1}^{s}=\left[\begin{array}{ll}v_{1}^{s} & 0\end{array}\right]$. The three terms in equation $(\mathrm{F} 1)$ represent three different ways that value-added created from the $1^{\text {st }}$ sector of the source Country $\mathrm{s}$ is absorbed by the destination Country r: The first term is sector 1's value-added embodied in Country s' final goods exports (of both sectors) consumed by Country r, the second term is sector 1's value-added embodied in Country $s$ ' intermediate goods exports (of both sectors) used by Country $r$ to produce its domestic final goods and consumed there. The last term is sector 1's value-added embodied in Country s' intermediate goods exports (of both sectors) to third Country $t$ and used by t to produce final goods exports to Country r.

Denote $v a x_{-} g_{1}^{s r}$ as Country s' value-added from all sectors embodied in sector 1's gross exports to Country $r$, which is the sum of first five terms in equation (18) in the main text:

$$
\begin{aligned}
& v a x \_g_{1}^{s r}=u\left[\left(V^{s} B^{s s}\right) \# Y_{1}^{s r}\right]+u\left[\left(V^{s} L^{s s}\right) \#\left(A_{1}^{s r} B^{r r} Y^{r r}\right)\right]+u\left[\left(V^{s} L^{s s}\right) \#\left(A_{1}^{s r} B^{r t} Y^{t t}\right)\right] \\
& +u\left[\left(V^{s} L^{s s}\right) \#\left(A_{1}^{s r} B^{r r} Y^{r t}\right)\right]+u\left[\left(V^{s} L^{s s}\right) \#\left(A_{1}^{s r} B^{r t} Y^{t r}\right)\right] \\
& =\left[\begin{array}{ll}
v_{1}^{s} & v_{2}^{s}
\end{array}\left[\begin{array}{ll}
b_{11}^{s s} & b_{12}^{s s} \\
b_{21}^{s s} & b_{22}^{s s}
\end{array}\right]\left[\begin{array}{c}
y_{1}^{s r} \\
0
\end{array}\right]+\left[\begin{array}{ll}
v_{1}^{s} & v_{2}^{s}
\end{array}\right]\left[\begin{array}{cc}
l_{11}^{s s} & l_{12}^{s s} \\
l_{21}^{s s} & l_{22}^{s s}
\end{array}\right]\left[\begin{array}{cc}
a_{11}^{s r} & a_{12}^{s r} \\
0 & 0
\end{array}\right]\left[\begin{array}{ll}
b_{11}^{r r} & b_{12}^{r r} \\
b_{21}^{r r} & b_{22}^{r r}
\end{array}\right]\left\{\left[\begin{array}{l}
y_{1}^{r r} \\
y_{2}^{r r}
\end{array}\right]+\left[\begin{array}{l}
y_{1}^{r t} \\
y_{2}^{r t}
\end{array}\right]\right\}\right. \\
& +\left[\begin{array}{ll}
v_{1}^{s} & v_{2}^{s}
\end{array}\right]\left[\begin{array}{ll}
l_{11}^{s s} & l_{12}^{s s} \\
l_{21}^{s s} & l_{22}^{s s}
\end{array}\right]\left[\begin{array}{cc}
a_{11}^{s r} & a_{12}^{s r} \\
0 & 0
\end{array}\right]\left[\begin{array}{ll}
b_{11}^{r t} & b_{12}^{r t} \\
b_{21}^{r t} & b_{22}^{r t}
\end{array}\right]\left\{\left[\begin{array}{l}
y_{1}^{t t} \\
y_{2}^{t t}
\end{array}\right]+\left[\begin{array}{l}
y_{1}^{t r} \\
y_{2}^{t r}
\end{array}\right]\right\} \\
& =\left(v_{1}^{s} b_{11}^{s s}+v_{2}^{s} b_{21}^{s s}\right) y_{1}^{s r}+\left(v_{1}^{s} l_{11}^{s s}+v_{2}^{s} l_{21}^{s s}\right) \sum_{j}^{N} a_{1 j}^{s r} b_{i j}^{r r}\left(y_{j}^{r r}+y_{j}^{r t}\right)+\left(v_{1}^{s} l_{11}^{s s}+v_{2}^{s} l_{21}^{s s}\right) \sum_{j}^{N} a_{1 j}^{s r} b_{i j}^{r t}\left(y_{j}^{t r}+y_{j}^{t t}\right) \\
& \text { Where } Y_{1}^{s r}=\left[\begin{array}{c}
y_{1}^{s r} \\
0
\end{array}\right], A_{1}^{s r}=\left[\begin{array}{cc}
a_{11}^{s r} & a_{12}^{s r} \\
0 & 0
\end{array}\right] \text { and } A_{1}^{s t}=\left[\begin{array}{cc}
a_{11}^{s t} & a_{12}^{s t} \\
0 & 0
\end{array}\right] \text {. Equations (F2) is the only value-added }
\end{aligned}
$$

trade measure that is consistent to bilateral gross trade flows (forward linkage based value-added export measures divert from bilateral gross trade flows due to either indirect exports through other domestic sectors or indirect exports through third countries). The difference between 3-country model and 2-country model is obvious, since (F1) not only includes value-added exports from Country $\mathrm{s}$ embodied in its own gross exports to Country $\mathrm{r}$ (second term), but also include value-added exports by Country s embodied in its gross exports to third Country t, but finally 
absorbed by Country r(last term), while (F2) only concern value-added embodied in Country s' gross exports to country $r$ that will stay abroad, regardless these value-added is finally absorbed by Country $r$ or by other third countries.

Denote $r d v_{-} f_{1}^{s r}$ as the $1^{\text {st }}$ sector's domestic value-added in the Country s' exports to Country $\mathrm{r}$ that is retuned and absorbed in Country s ((producer's perspective, forward linkage based).

$$
\begin{aligned}
& r d v_{-} f_{1}^{s r}=V_{1}^{s} L^{s s} A^{s r} B^{r r} Y^{r s}+V_{1}^{s} L^{s s} A^{s r} B^{r t} Y^{t s}+V_{1}^{s} L^{s s} A^{s r} B^{r s} Y^{s s} \\
& =\left[\begin{array}{ll}
v_{1}^{s s} & 0
\end{array}\right]\left[\begin{array}{ll}
l_{11}^{s s} & l_{12}^{s s} \\
l_{21}^{s s} & l_{22}^{s s}
\end{array}\right]\left[\begin{array}{ll}
a_{11}^{s r} & a_{12}^{s r} \\
a_{21}^{s r} & a_{22}^{s r}
\end{array}\right]\left\{\left[\begin{array}{ll}
b_{11}^{r r} & b_{12}^{r r} \\
b_{21}^{r r} & b_{22}^{r r}
\end{array}\right]\left[\begin{array}{l}
y_{1}^{r s} \\
y_{2}^{r s}
\end{array}\right]+\left[\begin{array}{ll}
b_{11}^{r t} & b_{12}^{r t} \\
b_{21}^{r t} & b_{22}^{r t}
\end{array}\right]\left[\begin{array}{l}
y_{1}^{t s} \\
y_{2}^{t s}
\end{array}\right]+\left[\begin{array}{ll}
b_{11}^{r s} & b_{12}^{r s} \\
b_{21}^{r s} & b_{22}^{r s}
\end{array}\right]\left[\begin{array}{l}
y_{1}^{s s} \\
y_{2}^{s s}
\end{array}\right]\right\}
\end{aligned}
$$

And Denote $r d v_{-} g_{1}^{s r}$ as Country s' domestic value-added from all sectors in the $1^{\text {st }}$ sector's gross exports that is returned and absorbed in Country s (user perspective, backward linkage based).

$$
\begin{aligned}
& r d v_{-} g_{1}^{s r}=u\left[\left(V^{s} L^{s s}\right) \#\left(A_{1}^{s r} B^{r r} Y^{r s}\right)\right]+u\left[\left(V^{s} L^{s s}\right) \#\left(A_{1}^{s r} B^{r t} Y^{t s}\right)\right]+u\left[\left(V^{s} L^{s s}\right) \#\left(A_{1}^{s r} B^{r s} Y^{s s}\right)\right] \\
& =\left[\begin{array}{ll}
v_{1}^{s} & v_{2}^{s}
\end{array}\left[\begin{array}{ll}
l_{11}^{s s} & l_{12}^{s s} \\
l_{21}^{s s} & l_{22}^{s s}
\end{array}\right]\left[\begin{array}{cc}
a_{11}^{s r} & a_{12}^{s r} \\
0 & 0
\end{array}\right]\left\{\left[\begin{array}{ll}
b_{11}^{r r} & b_{12}^{r r} \\
b_{21}^{r r} & b_{22}^{r r}
\end{array}\right]\left[\begin{array}{l}
y_{1}^{r s} \\
y_{2}^{r s}
\end{array}\right]+\left[\begin{array}{ll}
b_{11}^{r t} & b_{12}^{r t} \\
b_{21}^{r t} & b_{22}^{r t}
\end{array}\right]\left[\begin{array}{l}
y_{1}^{t s} \\
y_{2}^{t s}
\end{array}\right]+\left[\begin{array}{ll}
b_{11}^{r s} & b_{12}^{r s} \\
b_{21}^{r s} & b_{22}^{r s}
\end{array}\right]\left[\begin{array}{l}
y_{1}^{s s} \\
y_{2}^{s s}
\end{array}\right]\right\}\right.
\end{aligned}
$$

With these two value-added trade measures precisely defined in mathematics, we are ready to proof following three propositions, which are summarized in four statements at the end of section 2.3 in the main text:

Proposition A: In a three or more countries world, $v a x_{-} g_{i}^{s r}$, and $v a x_{-} f_{i}^{s r}$ are not equal to each other in general except under special restrictions. $r d v_{-} g_{i}^{s r}$, and $r d v_{-} f_{i}^{s r}$ are also not equal to each other in general. In addition, the following aggregation relations (1)-(5) always hold:

$$
\begin{aligned}
& \text { (1) } v a x_{-} g_{i}^{s r} \neq v a x_{-} f_{i}^{s r}, \sum_{i=1}^{N} v a x_{-} g_{i}^{s r} \neq \sum_{i=1}^{N} v a x_{-} f_{i}^{s r}, \text { and } \sum_{r \neq s}^{G} v a x_{-} g_{i}^{s r} \neq \sum_{r \neq s}^{G} v a x_{-} f_{i}^{s r} \\
& \text { (2) } \sum_{r \neq s}^{G} \sum_{i=1}^{N} v a x_{-} f_{i}^{s r}=\sum_{r \neq s}^{G} \sum_{i=1}^{N} v a x_{-} g_{i}^{s r}(3) \sum_{i=1}^{N} r d v_{-} f_{i}^{s r}=\sum_{i=1}^{N} r d v_{-} g_{i}^{s r} \text { and } \\
& \sum_{r \neq s}^{G} \sum_{i=1}^{N} r d v_{-} f_{i}^{s r}=\sum_{r \neq s}^{G} \sum_{i=1}^{N} r d v_{-} g_{i}^{s r} \\
& \text { (4) } \sum_{r \neq s}^{G} r d v_{-} g_{i}^{s r} \neq \sum_{r \neq s}^{G} r d v_{-} f_{i}^{s r}, \sum_{i=1}^{N} d v a_{-} g_{i}^{s r} \neq \sum_{i=1}^{N} d v a_{-} f_{i}^{s r}, \text { and } \sum_{r \neq s}^{G} d v a_{-} g_{i}^{s r} \neq \sum_{r \neq s}^{G} d v a_{-} f_{i}^{s r} \\
& \text { (5) } \sum_{r \neq s}^{G} \sum_{i=1}^{N} d v a_{-} f_{i}^{s r}=\sum_{r \neq s}^{G} \sum_{i=1}^{N} d v a_{-} g_{i}^{s r}
\end{aligned}
$$


Proposition B: In a three-country or more countries world, $v a x_{-} g_{i}^{s r}$ and $d v a_{-} g_{i}^{s r}$ is always less than or equal to $e_{i}^{s r}$, the sector level gross bilateral exports. Therefore domestic value added absorbed abroad to gross exports ratio is upper-bounded at 1, i.e. $\frac{v a x_{-} g_{i}^{s r}}{e_{i}^{s r}} \leq \frac{d v a_{-} g_{i}^{s r}}{e_{i}^{s r}} \leq 1$ when $e_{i}^{s r}>0$.

Proposition C: $v a x_{-} f_{i}^{s^{*}}$ and $d v a_{-} f_{i}^{s^{*}}$ are always less than or equal to sector level value-added production, i.e. $v a x_{-} f_{i}^{s^{*}}=\sum_{r \neq s}^{G} v a x_{-} f_{i}^{s r} \leq d v a_{-} f_{i}^{s^{*}}=\sum_{r \neq s}^{G} d v a_{-} f_{i}^{s r} \leq v_{i}^{s} x_{i}^{s} \quad . \quad$ Therefore, $\frac{v a x_{-} f_{i}^{s^{*}}}{v_{i}^{s} x_{i}^{s}} \leq \frac{d v a_{-} f_{i}^{s^{*}}}{v_{i}^{s} x_{i}^{s}} \leq 1$, i.e. both $v a x_{-} f_{i}^{s^{*}}$ and $d v a_{-} f_{i}^{s^{*}}$ to GDP by industry ratio is upper-bounded at 1 .

\section{Proof:}

The difference between $v a x_{-} f_{1}^{s r}$ and $v a x_{-} g_{1}^{s r}$ is not so obvious if we compare equations (F1) and (F2) directly, so we first transform equation (F1) by using following properties of Leontief Inverse matrix:

$$
\text { From }\left[\begin{array}{ccc}
I-A^{s s} & -A^{s r} & -A^{s t} \\
-A^{r s} & I-A^{r r} & -A^{r t} \\
-A^{t s} & -A^{t r} & I-A^{t t}
\end{array}\right]\left[\begin{array}{ccc}
B^{s s} & B^{s r} & B^{s t} \\
B^{r s} & B^{r r} & B^{r t} \\
B^{t s} & B^{t r} & B^{t t}
\end{array}\right]=\left[\begin{array}{ccc}
I & 0 & 0 \\
0 & I & 0 \\
0 & 0 & I
\end{array}\right]
$$

We have:

$$
\left(I-A^{s s}\right) B^{s r}-A^{s r} B^{r r}-A^{s t} B^{t r}=0 ;\left(I-A^{s s}\right) B^{s t}-A^{s r} B^{r t}-A^{s t} B^{t t}=0
$$

Rearrange:

$$
B^{s r}=L^{s s} A^{s r} B^{r r}+L^{s s} A^{s t} B^{t r} ; B^{s t}=L^{s s} A^{s r} B^{r t}+L^{s s} A^{s t} B^{t t}
$$

Inserting equation (F5) into equation (F1) and re-arrange, we obtain:

$$
\begin{aligned}
& v a x_{-} f_{1}^{s r}=V_{1}^{s} B^{s s} Y^{s r}+V_{1}^{s} L^{s s} A^{s r} B^{r r} Y^{r r}+V_{1}^{s} L^{s s} A^{s t} B^{t r} Y^{r r}+V_{1}^{s} L^{s s} A^{s r} B^{r t} Y^{t r}+V_{1}^{s} L^{s s} A^{s t} B^{t t} Y^{t r} \\
& =\left[\begin{array}{ll}
v_{1}^{s} & 0
\end{array}\left[\begin{array}{ll}
b_{11}^{s s} & b_{12}^{s s} \\
b_{21}^{s s} & b_{22}^{s s}
\end{array}\right]\left[\begin{array}{l}
y_{1}^{s r} \\
y_{2}^{s r}
\end{array}\right]+\left[\begin{array}{ll}
v_{1}^{s} & 0
\end{array}\right]\left[\begin{array}{ll}
l_{11}^{s s} & l_{12}^{s s} \\
l_{21}^{s s} & l_{22}^{s s}
\end{array}\right]\left[\begin{array}{ll}
a_{11}^{s r} & a_{12}^{s r} \\
a_{21}^{s r} & a_{22}^{s r}
\end{array}\right]\left\{\left[\begin{array}{ll}
b_{11}^{r r} & b_{12}^{r r} \\
b_{21}^{r r} & b_{22}^{r r}
\end{array}\right]\left[\begin{array}{l}
y_{1}^{r r} \\
y_{2}^{r r}
\end{array}\right]+\left[\begin{array}{ll}
b_{11}^{r t} & b_{12}^{r t} \\
b_{21}^{r t} & b_{22}^{r t}
\end{array}\right]\left[\begin{array}{l}
y_{1}^{t r} \\
y_{2}^{t r}
\end{array}\right]\right\}\right. \\
& +\left[\begin{array}{ll}
v_{1}^{s} & 0
\end{array}\right]\left[\begin{array}{ll}
l_{11}^{s s} & l_{12}^{s s} \\
l_{21}^{s s} & l_{22}^{s s}
\end{array}\right]\left[\begin{array}{ll}
a_{11}^{s t} & a_{12}^{s t} \\
a_{21}^{s t} & a_{22}^{s t}
\end{array}\right]\left\{\left[\begin{array}{ll}
b_{11}^{t r} & b_{12}^{t r} \\
b_{21}^{t r} & b_{22}^{t r}
\end{array}\right]\left[\begin{array}{l}
y_{1}^{r r} \\
y_{2}^{r r}
\end{array}\right]+\left[\begin{array}{ll}
b_{11}^{t t} & b_{12}^{t t} \\
b_{21}^{t t} & b_{22}^{t t}
\end{array}\right]\left[\begin{array}{c}
y_{1}^{t r} \\
y_{2}^{t r}
\end{array}\right]\right\}
\end{aligned}
$$

Comparing equations (F2) and (F6), the two measures have the same BY block matrix and same block local inverse. However, Equation (F6) only include value-added from the $1^{\text {st }}$ sector of Country 
$\mathrm{s}$, including $1^{\text {st }}$ sector's value-added embodied in its $2^{\text {nd }}$ sector's final and intermediate exports, while equation (F2) only measure Country s' value-added embodied in its $1^{\text {st }}$ sector's final and intermediate goods exports to Country r, regardless the value-added come from which sectors.

The difference between $v a x_{-} g_{1}^{s r}$ and $v a x_{-} f_{1}^{s r}$ equals

$$
\begin{aligned}
& v a x_{-} g_{1}^{s r}-v a x_{-} f_{1}^{s r}=\left[\begin{array}{ll}
0 & v_{2}^{s}
\end{array}\right]\left[\begin{array}{ll}
b_{11}^{s s} & b_{12}^{s s} \\
b_{21}^{s s} & b_{22}^{s s}
\end{array}\right]\left[\begin{array}{c}
y_{1}^{s r} \\
0
\end{array}\right]-\left[\begin{array}{ll}
v_{1}^{s} & 0
\end{array}\right]\left[\begin{array}{cc}
b_{11}^{s s} & b_{12}^{s s} \\
b_{21}^{s s} & b_{22}^{s s}
\end{array}\right]\left[\begin{array}{c}
0 \\
y_{2}^{s r}
\end{array}\right] \\
& +\left[\begin{array}{ll}
0 & v_{2}^{s}
\end{array}\right]\left[\begin{array}{ll}
l_{11}^{s s} & l_{12}^{s s} \\
l_{21}^{s s} & l_{22}^{s s}
\end{array}\right]\left[\begin{array}{cc}
a_{11}^{s r} & a_{12}^{s r} \\
0 & 0
\end{array}\right]\left\{\left[\begin{array}{ll}
b_{11}^{r r} & b_{12}^{r r} \\
b_{21}^{r r} & b_{22}^{r r}
\end{array}\right]\left[\begin{array}{l}
y_{1}^{r r} \\
y_{2}^{r r}
\end{array}\right]+\left[\begin{array}{ll}
b_{11}^{r t} & b_{12}^{r t} \\
b_{21}^{r t} & b_{22}^{r t}
\end{array}\right]\left[\begin{array}{c}
y_{1}^{t r} \\
y_{2}^{t r}
\end{array}\right]\right\} \\
& -\left[\begin{array}{ll}
v_{1}^{s} & 0
\end{array}\right]\left[\begin{array}{ll}
l_{11}^{s s} & l_{12}^{s s} \\
l_{21}^{s s} & l_{22}^{s s}
\end{array}\right]\left[\begin{array}{cc}
0 & 0 \\
a_{21}^{s r} & a_{22}^{s r}
\end{array}\right]\left\{\left[\begin{array}{ll}
b_{11}^{r r} & b_{12}^{r r} \\
b_{21}^{r r} & b_{22}^{r r}
\end{array}\right]\left[\begin{array}{c}
y_{1}^{r r} \\
y_{2}^{r r}
\end{array}\right]+\left[\begin{array}{ll}
b_{11}^{r t} & b_{12}^{r t} \\
b_{21}^{r t} & b_{22}^{r t}
\end{array}\right]\left[\begin{array}{c}
y_{1}^{t r} \\
y_{2}^{t r}
\end{array}\right]\right\} \\
& +\left[\begin{array}{ll}
v_{1}^{s} & v_{2}^{s}
\end{array}\right]\left[\begin{array}{ll}
l_{11}^{s s} & l_{12}^{s s} \\
l_{21}^{s s} & l_{22}^{s s}
\end{array}\right]\left[\begin{array}{cc}
a_{11}^{s r} & a_{12}^{s r} \\
0 & 0
\end{array}\right]\left\{\left[\begin{array}{ll}
b_{11}^{r r} & b_{12}^{r r} \\
b_{21}^{r r} & b_{22}^{r r}
\end{array}\right]\left[\begin{array}{l}
y_{1}^{r t} \\
y_{2}^{r t}
\end{array}\right]+\left[\begin{array}{ll}
b_{11}^{r t} & b_{12}^{r t} \\
b_{21}^{r t} & b_{22}^{r t}
\end{array}\right]\left[\begin{array}{l}
y_{1}^{t t} \\
y_{2}^{t t}
\end{array}\right]\right\} \\
& -\left[\begin{array}{ll}
v_{1}^{s} & 0
\end{array}\right]\left[\begin{array}{ll}
l_{11}^{s s} & l_{12}^{s s} \\
l_{21}^{s s} & l_{22}^{s s}
\end{array}\right]\left[\begin{array}{ll}
a_{11}^{s t} & a_{12}^{s t} \\
a_{21}^{s t} & a_{22}^{s t}
\end{array}\right]\left\{\left[\begin{array}{ll}
b_{11}^{t r} & b_{12}^{t r} \\
b_{21}^{t r} & b_{22}^{t r}
\end{array}\right]\left[\begin{array}{l}
y_{1}^{r r} \\
y_{2}^{r r}
\end{array}\right]+\left[\begin{array}{ll}
b_{11}^{t t} & b_{12}^{t t} \\
b_{21}^{t t} & b_{22}^{t t}
\end{array}\right]\left[\begin{array}{c}
y_{1}^{t r} \\
y_{2}^{t r}
\end{array}\right]\right\}
\end{aligned}
$$

Where the first two positive terms in equation (F7) represent value added created by the $2^{\text {nd }}$ sector of Country s embodied in the $1^{\text {st }}$ sector exports from Country $\mathrm{s}$ to Country $\mathrm{r}$ and consumed in $\mathrm{r}$. The first two negative terms represent value added created by the $1^{\text {st }}$ sector of Country s embodied in the $2^{\text {nd }}$ sector exports from Country $s$ to Country $r$ and consumed in Country $r$. The final positive term represent value added created by Country s (both sectors) embodied in the $1^{\text {st }}$ sector exports from Country $\mathrm{s}$ to Country $\mathrm{r}$ and consumed in third Country t. The final negative term represent value added created by the $1^{\text {st }}$ sector of Country s embodied in exports (Doth sectors) from Country s to third Country $\mathrm{t}$ and consumed in $\mathrm{t}$. These positive and negative terms are should not equal each other except very special cases, so vax _ $g_{1}^{s r}$ and $v a x_{-} f_{1}^{s r}$ do not equal each other in general.

Similarly, the difference between $v a x_{-} g_{2}^{s r}$ and $v a x_{-} f_{2}^{s r}$ equals 


$$
\begin{aligned}
& v a x_{-} g_{2}^{s r}-v a x_{2} f_{2}^{s r}=\left[\begin{array}{ll}
v_{1}^{s} & 0
\end{array}\right]\left[\begin{array}{ll}
b_{11}^{s s} & b_{12}^{s s} \\
b_{21}^{s s} & b_{22}^{s s}
\end{array}\right]\left[\begin{array}{c}
0 \\
y_{2}^{s r}
\end{array}\right]-\left[\begin{array}{ll}
0 & v_{2}^{s}
\end{array}\right]\left[\begin{array}{ll}
b_{11}^{s s} & b_{12}^{s s} \\
b_{21}^{s s} & b_{22}^{s s}
\end{array}\right]\left[\begin{array}{c}
y_{1}^{s r} \\
0
\end{array}\right] \\
& +\left[\begin{array}{ll}
v_{1}^{s r} & 0
\end{array}\right]\left[\begin{array}{ll}
l_{11}^{s s} & l_{12}^{s s} \\
l_{21}^{s s} & l_{22}^{s s}
\end{array}\right]\left[\begin{array}{cc}
0 & 0 \\
a_{21}^{s r} & a_{22}^{s r}
\end{array}\right]\left\{\left[\begin{array}{ll}
b_{11}^{r r} & b_{12}^{r r} \\
b_{21}^{r r} & b_{22}^{r r}
\end{array}\right]\left[\begin{array}{l}
y_{1}^{r r} \\
y_{2}^{r r}
\end{array}\right]+\left[\begin{array}{ll}
b_{11}^{r t} & b_{12}^{r t} \\
b_{21}^{r t} & b_{22}^{r t}
\end{array}\right]\left[\begin{array}{l}
y_{1}^{t r} \\
y_{2}^{t r}
\end{array}\right]\right\} \\
& -\left[\begin{array}{ll}
0 & v_{2}^{s}
\end{array}\left[\begin{array}{ll}
l_{11}^{s s} & l_{12}^{s s} \\
l_{21}^{s s} & l_{22}^{s s}
\end{array}\right]\left[\begin{array}{cc}
a_{11}^{s r} & a_{12}^{s r} \\
0 & 0
\end{array}\right]\left\{\left[\begin{array}{ll}
b_{11}^{r r} & b_{12}^{r r} \\
b_{21}^{r r} & b_{22}^{r r}
\end{array}\right]\left[\begin{array}{l}
y_{1}^{r r} \\
y_{2}^{r r}
\end{array}\right]+\left[\begin{array}{ll}
b_{11}^{r t} & b_{12}^{r t} \\
b_{21}^{r t} & b_{22}^{r t}
\end{array}\right]\left[\begin{array}{l}
y_{1}^{t r} \\
y_{2}^{t r}
\end{array}\right]\right\}\right. \\
& +\left[\begin{array}{ll}
v_{1}^{s r} & v_{2}^{s}
\end{array}\left[\begin{array}{ll}
l_{11}^{s s} & l_{12}^{s s} \\
l_{21}^{s s} & l_{22}^{s s}
\end{array}\right]\left[\begin{array}{cc}
0 & 0 \\
a_{21}^{s r} & a_{22}^{s r}
\end{array}\right]\left\{\left[\begin{array}{ll}
b_{11}^{r r} & b_{12}^{r r} \\
b_{21}^{r r} & b_{22}^{r r}
\end{array}\right]\left[\begin{array}{l}
y_{1}^{r t} \\
y_{2}^{r t}
\end{array}\right]+\left[\begin{array}{ll}
b_{11}^{r t} & b_{12}^{r t} \\
b_{21}^{r t} & b_{22}^{r t}
\end{array}\right]\left[\begin{array}{l}
y_{1}^{t t} \\
y_{2}^{t t}
\end{array}\right]\right\}\right. \\
& -\left[\begin{array}{ll}
0 & v_{2}^{s}
\end{array}\right]\left[\begin{array}{ll}
l_{11}^{s s} & l_{12}^{s s} \\
l_{21}^{s s} & l_{22}^{s s}
\end{array}\right]\left[\begin{array}{ll}
a_{11}^{s t} & a_{12}^{s t} \\
a_{21}^{s t} & a_{22}^{s t}
\end{array}\right]\left\{\left[\begin{array}{ll}
b_{11}^{t r} & b_{12}^{t r} \\
b_{21}^{t r} & b_{22}^{t r}
\end{array}\right]\left[\begin{array}{l}
y_{1}^{r r} \\
y_{2}^{r r}
\end{array}\right]+\left[\begin{array}{ll}
b_{11}^{t t} & b_{12}^{t t} \\
b_{21}^{t t} & b_{22}^{t t}
\end{array}\right]\left[\begin{array}{l}
y_{1}^{t r} \\
y_{2}^{t r}
\end{array}\right]\right\}
\end{aligned}
$$

Where the first two positive terms in equation (F8) are the first two negative terms in equation (F7) exactly, and the first two negative terms in equation (F8) are the first two positive terms in equation (F7). Therefore, when we aggregate over sectors, the difference between $v a x_{-} g_{i}^{s r}$ and $v a x \_f_{i}^{s r}$ will partly cancels out.

$$
\begin{aligned}
& \left(v a x_{-} g_{1}^{s r}+v a x_{-} g_{2}^{s r}\right)-\left(v a x_{-} f_{1}^{s r}+v a x_{-} f_{2}^{s r}\right)= \\
& {\left[\begin{array}{ll}
v_{1}^{s} & v_{2}^{s}
\end{array}\right]\left[\begin{array}{ll}
l_{11}^{s s} & l_{12}^{s s} \\
l_{21}^{s s} & l_{22}^{s s}
\end{array}\right]\left[\begin{array}{ll}
a_{11}^{s r} & a_{12}^{s r} \\
a_{21}^{s r} & a_{22}^{s r}
\end{array}\right]\left\{\left[\begin{array}{ll}
b_{11}^{r r} & b_{12}^{r r} \\
b_{21}^{r r} & b_{22}^{r r}
\end{array}\right]\left[\begin{array}{c}
y_{1}^{r t} \\
y_{2}^{r t}
\end{array}\right]+\left[\begin{array}{ll}
b_{11}^{r t} & b_{12}^{r t} \\
b_{21}^{r t} & b_{22}^{r t}
\end{array}\right]\left[\begin{array}{c}
y_{1}^{t t} \\
y_{2}^{t t}
\end{array}\right]\right\}} \\
& -\left[\begin{array}{ll}
v_{1}^{s} & v_{2}^{s}
\end{array}\right]\left[\begin{array}{ll}
l_{11}^{s s} & l_{12}^{s s} \\
l_{21}^{s s} & l_{22}^{s s}
\end{array}\right]\left[\begin{array}{ll}
a_{11}^{s t} & a_{12}^{s t} \\
a_{21}^{s t} & a_{22}^{s t}
\end{array}\right]\left\{\left[\begin{array}{ll}
b_{11}^{t r} & b_{12}^{t r} \\
b_{21}^{t r} & b_{22}^{t r}
\end{array}\right]\left[\begin{array}{l}
y_{1}^{r r} \\
y_{2}^{r r}
\end{array}\right]+\left[\begin{array}{ll}
b_{11}^{t t} & b_{12}^{t t} \\
b_{21}^{t t} & b_{22}^{t t}
\end{array}\right]\left[\begin{array}{c}
y_{1}^{t r} \\
y_{2}^{t r}
\end{array}\right]\right\}
\end{aligned}
$$

Where the first term (positive) represents value added created by Country s embodied in Country s' intermediate exports to Country $r$ and absorbed in third Country t. The second term (negative) represents value added created by Country s embodied in Country s' intermediate exports to the third Country $t$ and finally consumed in $r$. These two indirect value-added exports via other countries (the positive and negative terms) should not equal each other except very special cases, so $\left(v a x_{-} g_{1}^{s r}+v a x_{-} g_{2}^{s r}\right)$ and $\left(v a x_{-} f_{1}^{s r}+v a x_{-} f_{2}^{s r}\right)$ do not equal each other in general. i.e.

$$
\sum_{i=1}^{N} v a x_{-} f_{i}^{s r} \neq \sum_{i=1}^{N} v a x_{-} g_{i}^{s r} \text { due to indirect value-added trade via third countries. }
$$

Similarly, the difference between $\left(v a x_{-} g_{1}^{s t}+v a x_{-} g_{2}^{s t}\right)$ and $\left(v a x_{-} f_{1}^{s t}+v a x_{-} f_{2}^{s t}\right)$ equals 


$$
\begin{aligned}
& \left(v a x_{-} g_{1}^{s t}+v a x_{-} g_{2}^{s t}\right)-\left(v a x_{-} f_{1}^{s t}+v a x_{-} f_{2}^{s t}\right)= \\
& {\left[\begin{array}{ll}
v_{1}^{s} & v_{2}^{s}
\end{array}\left[\begin{array}{ll}
l_{11}^{s s} & l_{12}^{s s} \\
l_{21}^{s s} & l_{22}^{s s}
\end{array}\right]\left[\begin{array}{ll}
a_{11}^{s t} & a_{12}^{s t} \\
a_{21}^{s t} & a_{22}^{s t}
\end{array}\right]\left\{\left[\begin{array}{ll}
b_{11}^{t r} & b_{12}^{t r} \\
b_{21}^{t r} & b_{22}^{t r}
\end{array}\right]\left[\begin{array}{c}
y_{1}^{r r} \\
y_{2}^{r r}
\end{array}\right]+\left[\begin{array}{ll}
b_{11}^{t t} & b_{12}^{t t} \\
b_{21}^{t t} & b_{22}^{t t}
\end{array}\right]\left[\begin{array}{c}
y_{1}^{t r} \\
y_{2}^{t r}
\end{array}\right]\right\}\right.} \\
& -\left[\begin{array}{ll}
v_{1}^{s} & v_{2}^{s}
\end{array}\right]\left[\begin{array}{ll}
l_{11}^{s s} & l_{12}^{s s} \\
l_{21}^{s s} & l_{22}^{s s}
\end{array}\right]\left[\begin{array}{ll}
a_{11}^{s r} & a_{12}^{s r} \\
a_{21}^{s r} & a_{22}^{s r}
\end{array}\right]\left\{\left[\begin{array}{ll}
b_{11}^{r r} & b_{12}^{r r} \\
b_{21}^{r r} & b_{22}^{r r}
\end{array}\right]\left[\begin{array}{l}
y_{1}^{r t} \\
y_{2}^{r t}
\end{array}\right]+\left[\begin{array}{ll}
b_{11}^{r t} & b_{12}^{r t} \\
b_{21}^{r t} & b_{22}^{r t}
\end{array}\right]\left[\begin{array}{c}
y_{1}^{t t} \\
y_{2}^{t t}
\end{array}\right]\right\}
\end{aligned}
$$

Compare equations (F9) and (F10), the difference between (vax $\left.g_{1}^{s r}+v a x \_g_{2}^{s r}\right)$ and $\left(v a x_{-} f_{1}^{s r}+v a x_{-} f_{2}^{s r}\right)$ is exactly the same as the difference between $\left(v a x_{-} f_{1}^{s t}+v a x_{-} f_{2}^{s t}\right)$ and $\left(v a x \_g_{1}^{s t}+v a x \_g_{2}^{s t}\right)$, therefore, when one aggregate the two measures over both sector and trading partners, these difference in indirect value-added trade via third countries cancel each other. i.e. $v a x_{-} g_{1}^{s r}+v a x_{-} g_{2}^{s r}+v a x_{-} g_{1}^{s t}+v a x_{-} g_{2}^{s t}$ equals $v a x_{-} f_{1}^{s r}+v a x_{-} f_{2}^{s r}+v a x_{-} f_{1}^{s t}+v a x_{-} f_{2}^{s t}$.

Similar to equation (F7), we can obtain the difference between $v a x_{-} g_{1}^{s t}$ and $v a x_{-} f_{1}^{s t}$ as

$$
\begin{aligned}
& v a x_{-} g_{1}^{s t}-v a x_{-} f_{1}^{s t}=\left[\begin{array}{ll}
0 & v_{2}^{s}
\end{array}\left[\begin{array}{ll}
b_{11}^{s s} & b_{12}^{s s} \\
b_{21}^{s s} & b_{22}^{s s}
\end{array}\right]\left[\begin{array}{c}
y_{1}^{s t} \\
0
\end{array}\right]-\left[\begin{array}{ll}
v_{1}^{s} & 0
\end{array}\right]\left[\begin{array}{cc}
b_{11}^{s s} & b_{12}^{s s} \\
b_{21}^{s s} & b_{22}^{s s}
\end{array}\right]\left[\begin{array}{c}
0 \\
y_{2}^{s t}
\end{array}\right]\right. \\
& +\left[\begin{array}{ll}
0 & v_{2}^{s}
\end{array}\right]\left[\begin{array}{cc}
l_{11}^{s s} & l_{12}^{s s} \\
l_{21}^{s s} & l_{22}^{s s}
\end{array}\right]\left[\begin{array}{cc}
a_{11}^{s t} & a_{12}^{s t} \\
0 & 0
\end{array}\right]\left\{\left[\begin{array}{ll}
b_{11}^{t r} & b_{12}^{t r} \\
b_{21}^{t r} & b_{22}^{t r}
\end{array}\right]\left[\begin{array}{l}
y_{1}^{r t} \\
y_{2}^{r t}
\end{array}\right]+\left[\begin{array}{ll}
b_{11}^{t t} & b_{12}^{t t} \\
b_{21}^{t t} & b_{22}^{t t}
\end{array}\right]\left[\begin{array}{l}
y_{1}^{t t} \\
y_{2}^{t t}
\end{array}\right]\right\} \\
& -\left[\begin{array}{ll}
v_{1}^{s} & 0
\end{array}\right]\left[\begin{array}{ll}
l_{11}^{s s} & l_{12}^{s s} \\
l_{21}^{s s} & l_{22}^{s s}
\end{array}\right]\left[\begin{array}{cc}
0 & 0 \\
a_{21}^{s t} & a_{22}^{s t}
\end{array}\right]\left\{\left[\begin{array}{ll}
b_{11}^{t r} & b_{12}^{t r} \\
b_{21}^{t r} & b_{22}^{t r}
\end{array}\right]\left[\begin{array}{l}
y_{1}^{r t} \\
y_{2}^{r t}
\end{array}\right]+\left[\begin{array}{ll}
b_{11}^{t t} & b_{12}^{t t} \\
b_{21}^{t t} & b_{22}^{t t}
\end{array}\right]\left[\begin{array}{l}
y_{1}^{t t} \\
y_{2}^{t t}
\end{array}\right]\right\} \\
& +\left[\begin{array}{ll}
v_{1}^{s} & v_{2}^{s}
\end{array}\right]\left[\begin{array}{ll}
l_{11}^{s s} & l_{12}^{s s} \\
l_{21}^{s s} & l_{22}^{s s}
\end{array}\right]\left[\begin{array}{cc}
a_{11}^{s t} & a_{12}^{s t} \\
0 & 0
\end{array}\right]\left\{\left[\begin{array}{ll}
b_{11}^{t r} & b_{12}^{t r} \\
b_{21}^{t r} & b_{22}^{t r}
\end{array}\right]\left[\begin{array}{l}
y_{1}^{r r} \\
y_{2}^{r r}
\end{array}\right]+\left[\begin{array}{ll}
b_{11}^{t t} & b_{12}^{t t} \\
b_{21}^{t t} & b_{22}^{t t}
\end{array}\right]\left[\begin{array}{c}
y_{1}^{t r} \\
y_{2}^{t r}
\end{array}\right]\right\} \\
& -\left[\begin{array}{ll}
v_{1}^{s} & 0
\end{array}\right]\left[\begin{array}{ll}
l_{11}^{s s} & l_{12}^{s s} \\
l_{21}^{s s} & l_{22}^{s s}
\end{array}\right]\left[\begin{array}{ll}
a_{11}^{s r} & a_{12}^{s r} \\
a_{21}^{s r} & a_{22}^{s r}
\end{array}\right]\left\{\left[\begin{array}{ll}
b_{11}^{r r} & b_{12}^{r r} \\
b_{21}^{r r} & b_{22}^{r r}
\end{array}\right]\left[\begin{array}{l}
y_{1}^{r t} \\
y_{2}^{r t}
\end{array}\right]+\left[\begin{array}{ll}
b_{11}^{r t} & b_{12}^{r t} \\
b_{21}^{r t} & b_{22}^{r t}
\end{array}\right]\left[\begin{array}{l}
y_{1}^{t t} \\
y_{2}^{t t}
\end{array}\right]\right\}
\end{aligned}
$$

Comparing equation (F7) and (F11), we can see that only the last terms can be partly cancelled out when aggregate $v a x_{-} g_{1}^{s u}$ and $v a x_{-} f_{1}^{s u}$ over trading partners, other terms will be fully reserved. 


$$
\begin{aligned}
& \left(v a x_{-} g_{1}^{s r}+v a x_{-} g_{1}^{s t}\right)-\left(v a x_{-} f_{1}^{s r}+v a x_{-} f_{1}^{s t}\right) \\
& =\left[\begin{array}{ll}
0 & v_{2}^{s}
\end{array}\right]\left[\begin{array}{ll}
b_{11}^{s s} & b_{12}^{s s} \\
b_{21}^{s s} & b_{22}^{s s}
\end{array}\right]\left[\begin{array}{c}
y_{1}^{s r}+y_{1}^{s t} \\
0
\end{array}\right]-\left[\begin{array}{ll}
v_{1}^{s} & 0
\end{array}\right]\left[\begin{array}{ll}
b_{11}^{s s} & b_{12}^{s s} \\
b_{21}^{s s} & b_{22}^{s s}
\end{array}\right]\left[\begin{array}{c}
0 \\
y_{2}^{s r}+y_{2}^{s t}
\end{array}\right] \\
& +\left[\begin{array}{ll}
0 & v_{2}^{s}
\end{array}\right]\left[\begin{array}{cc}
l_{11}^{s s} & l_{12}^{s s} \\
l_{21}^{s s} & l_{22}^{s s}
\end{array}\right]\left[\begin{array}{cc}
a_{11}^{s r} & a_{12}^{s r} \\
0 & 0
\end{array}\right]\left\{\left[\begin{array}{ll}
b_{11}^{r r} & b_{12}^{r r} \\
b_{21}^{r r} & b_{22}^{r r}
\end{array}\right]\left[\begin{array}{l}
y_{1}^{r r} \\
y_{2}^{r r}
\end{array}\right]+\left[\begin{array}{ll}
b_{11}^{r t} & b_{12}^{r t} \\
b_{21}^{r t} & b_{22}^{r t}
\end{array}\right]\left[\begin{array}{l}
y_{1}^{t r} \\
y_{2}^{t r}
\end{array}\right]\right\} \\
& -\left[\begin{array}{ll}
v_{1}^{s} & 0
\end{array}\right]\left[\begin{array}{ll}
l_{11}^{s s} & l_{12}^{s s} \\
l_{21}^{s s} & l_{22}^{s s}
\end{array}\right]\left[\begin{array}{cc}
0 & 0 \\
a_{21}^{s r} & a_{22}^{s r}
\end{array}\right]\left\{\left[\begin{array}{ll}
b_{11}^{r r} & b_{12}^{r r} \\
b_{21}^{r r} & b_{22}^{r r}
\end{array}\right]\left[\begin{array}{l}
y_{1}^{r r} \\
y_{2}^{r r}
\end{array}\right]+\left[\begin{array}{ll}
b_{11}^{r t} & b_{12}^{r t} \\
b_{21}^{r t} & b_{22}^{r t}
\end{array}\right]\left[\begin{array}{l}
y_{1}^{t r} \\
y_{2}^{t r}
\end{array}\right]\right\} \\
& +\left[\begin{array}{ll}
0 & v_{2}^{s}
\end{array}\right]\left[\begin{array}{cc}
l_{11}^{s s} & l_{12}^{s s} \\
l_{21}^{s s} & l_{22}^{s s}
\end{array}\right]\left[\begin{array}{cc}
a_{11}^{s t} & a_{12}^{s t} \\
0 & 0
\end{array}\right]\left\{\left[\begin{array}{ll}
b_{11}^{t r} & b_{12}^{t r} \\
b_{21}^{t r} & b_{22}^{t r}
\end{array}\right]\left[\begin{array}{l}
y_{1}^{r t} \\
y_{2}^{r t}
\end{array}\right]+\left[\begin{array}{ll}
b_{11}^{t t} & b_{12}^{t t} \\
b_{21}^{t t} & b_{22}^{t t}
\end{array}\right]\left[\begin{array}{c}
y_{1}^{t t} \\
y_{2}^{t t}
\end{array}\right]\right\} \\
& -\left[\begin{array}{ll}
v_{1}^{s} & 0
\end{array}\right]\left[\begin{array}{ll}
l_{11}^{s s} & l_{12}^{s s} \\
l_{21}^{s s} & l_{22}^{s s}
\end{array}\right]\left[\begin{array}{cc}
0 & 0 \\
a_{21}^{s t} & a_{22}^{s t}
\end{array}\right]\left\{\left[\begin{array}{ll}
b_{11}^{t r} & b_{12}^{t r} \\
b_{21}^{t r} & b_{22}^{t r}
\end{array}\right]\left[\begin{array}{l}
y_{1}^{r t} \\
y_{2}^{r t}
\end{array}\right]+\left[\begin{array}{ll}
b_{11}^{t t} & b_{12}^{t t} \\
b_{21}^{t t} & b_{22}^{t t}
\end{array}\right]\left[\begin{array}{l}
y_{1}^{t t} \\
y_{2}^{t t}
\end{array}\right]\right\} \\
& +\left[\begin{array}{ll}
0 & v_{2}^{s}
\end{array}\right]\left[\begin{array}{cc}
l_{11}^{s s} & l_{12}^{s s} \\
l_{21}^{s s} & l_{22}^{s s}
\end{array}\right]\left[\begin{array}{cc}
a_{11}^{s r} & a_{12}^{s r} \\
0 & 0
\end{array}\right]\left\{\left[\begin{array}{ll}
b_{11}^{r r} & b_{12}^{r r} \\
b_{21}^{r r} & b_{22}^{r r}
\end{array}\right]\left[\begin{array}{l}
y_{1}^{r t} \\
y_{2}^{r t}
\end{array}\right]+\left[\begin{array}{ll}
b_{11}^{r t} & b_{12}^{r t} \\
b_{21}^{r t} & b_{22}^{r t}
\end{array}\right]\left[\begin{array}{l}
y_{1}^{t t} \\
y_{2}^{t t}
\end{array}\right]\right\} \\
& -\left[\begin{array}{ll}
v_{1}^{s} & 0
\end{array}\right]\left[\begin{array}{ll}
l_{11}^{s s} & l_{12}^{s s} \\
l_{21}^{s s} & l_{22}^{s s}
\end{array}\right]\left[\begin{array}{cc}
0 & 0 \\
a_{21}^{s r} & a_{22}^{s r}
\end{array}\right]\left\{\left[\begin{array}{ll}
b_{11}^{r r} & b_{12}^{r r} \\
b_{21}^{r r} & b_{22}^{r r}
\end{array}\right]\left[\begin{array}{l}
y_{1}^{r t} \\
y_{2}^{r t}
\end{array}\right]+\left[\begin{array}{ll}
b_{11}^{r t} & b_{12}^{r t} \\
b_{21}^{r t} & b_{22}^{r t}
\end{array}\right]\left[\begin{array}{l}
y_{1}^{r t} \\
y_{2}^{t t}
\end{array}\right]\right\} \\
& +\left[\begin{array}{ll}
0 & v_{2}^{s}
\end{array}\right]\left[\begin{array}{ll}
l_{11}^{s s} & l_{12}^{s s} \\
l_{21}^{s s} & l_{22}^{s s}
\end{array}\right]\left[\begin{array}{cc}
a_{11}^{s t} & a_{12}^{s t} \\
0 & 0
\end{array}\right]\left\{\left[\begin{array}{ll}
b_{11}^{t r} & b_{12}^{t r} \\
b_{21}^{t r} & b_{22}^{t r}
\end{array}\right]\left[\begin{array}{l}
y_{1}^{r r} \\
y_{2}^{r r}
\end{array}\right]+\left[\begin{array}{ll}
b_{11}^{t t} & b_{12}^{t t} \\
b_{21}^{t t} & b_{22}^{t t}
\end{array}\right]\left[\begin{array}{l}
y_{1}^{t r} \\
y_{2}^{t r}
\end{array}\right]\right\} \\
& -\left[\begin{array}{ll}
v_{1}^{s} & 0
\end{array}\right]\left[\begin{array}{ll}
l_{11}^{s s} & l_{12}^{s s} \\
l_{21}^{s s} & l_{22}^{s s}
\end{array}\right]\left[\begin{array}{cc}
0 & 0 \\
a_{21}^{s t} & a_{22}^{s t}
\end{array}\right]\left\{\left[\begin{array}{ll}
b_{11}^{t r} & b_{12}^{t r} \\
b_{21}^{t r} & b_{22}^{t r}
\end{array}\right]\left[\begin{array}{l}
y_{1}^{r r} \\
y_{2}^{r r}
\end{array}\right]+\left[\begin{array}{ll}
b_{11}^{t t} & b_{12}^{t t} \\
b_{21}^{t t} & b_{22}^{t t}
\end{array}\right]\left[\begin{array}{l}
y_{1}^{t r} \\
y_{2}^{t r}
\end{array}\right]\right\}
\end{aligned}
$$

In the right side of equation (F12), all positive terms represent value added created by the $2^{\text {nd }}$ sector of Country s embodied in the $1^{\text {st }}$ sector exports of Country $\mathrm{s}$ and consumed abroad, all negative terms represent value added created by the $1^{\text {st }}$ sector of Country s embodied in the $2^{\text {nd }}$ sector exports of Country s and consumed at abroad. Therefore, $\sum_{r \neq s}^{G} v a x_{-} g_{i}^{s r} \neq \sum_{r \neq s}^{G} v a x_{-} f_{i}^{s r}$ except very special cases.

Similarly, aggregate $v a x_{-} g_{2}^{s u}$ and $v a x_{-} f_{2}^{s u}$ over trading partners, 


$$
\begin{aligned}
& \left(v_{a x} g_{2}^{s r}+v a x_{-} g_{2}^{s t}\right)-\left(v a x_{-} f_{2}^{s r}+v a x_{-} f_{2}^{s t}\right) \\
& =\left[\begin{array}{ll}
v_{1}^{s} & 0
\end{array}\right]\left[\begin{array}{ll}
b_{11}^{s s} & b_{12}^{s s} \\
b_{21}^{s s} & b_{22}^{s s}
\end{array}\right]\left[\begin{array}{c}
0 \\
y_{2}^{s r}+y_{2}^{s t}
\end{array}\right]-\left[\begin{array}{ll}
0 & v_{2}^{s}
\end{array}\left[\begin{array}{ll}
b_{11}^{s s} & b_{12}^{s s} \\
b_{21}^{s s} & b_{22}^{s s}
\end{array}\right]\left[\begin{array}{c}
y_{1}^{s r}+y_{1}^{s t} \\
0
\end{array}\right]\right. \\
& +\left[\begin{array}{ll}
v_{1}^{s} & 0
\end{array}\right]\left[\begin{array}{ll}
l_{11}^{s s} & l_{12}^{s s} \\
l_{21}^{s s} & l_{22}^{s s}
\end{array}\right]\left[\begin{array}{cc}
0 & 0 \\
a_{21}^{s r} & a_{22}^{s r}
\end{array}\right]\left\{\left[\begin{array}{ll}
b_{11}^{r r} & b_{12}^{r r} \\
b_{21}^{r r} & b_{22}^{r r}
\end{array}\right]\left[\begin{array}{l}
y_{1}^{r r} \\
y_{2}^{r r}
\end{array}\right]+\left[\begin{array}{ll}
b_{11}^{r t} & b_{12}^{r t} \\
b_{21}^{r t} & b_{22}^{r t}
\end{array}\right]\left[\begin{array}{l}
y_{1}^{t r} \\
y_{2}^{t r}
\end{array}\right]\right\} \\
& -\left[\begin{array}{ll}
0 & v_{2}^{s}
\end{array}\right]\left[\begin{array}{ll}
l_{11}^{s s} & l_{12}^{s s} \\
l_{21}^{s s} & l_{22}^{s s}
\end{array}\right]\left[\begin{array}{cc}
a_{11}^{s r} & a_{12}^{s r} \\
0 & 0
\end{array}\right]\left\{\left[\begin{array}{ll}
b_{11}^{r r} & b_{12}^{r r} \\
b_{21}^{r r} & b_{22}^{r r}
\end{array}\right]\left[\begin{array}{l}
y_{1}^{r r} \\
y_{2}^{r r}
\end{array}\right]+\left[\begin{array}{ll}
b_{11}^{r t} & b_{12}^{r t} \\
b_{21}^{r t} & b_{22}^{r t}
\end{array}\right]\left[\begin{array}{l}
y_{1}^{t r} \\
y_{2}^{t r}
\end{array}\right]\right\} \\
& +\left[\begin{array}{ll}
v_{1}^{s} & 0
\end{array}\right]\left[\begin{array}{ll}
l_{11}^{s s} & l_{12}^{s s} \\
l_{21}^{s s} & l_{22}^{s s}
\end{array}\right]\left[\begin{array}{cc}
0 & 0 \\
a_{21}^{s t} & a_{22}^{s t}
\end{array}\right]\left\{\left[\begin{array}{ll}
b_{11}^{t r} & b_{12}^{t r} \\
b_{21}^{t r} & b_{22}^{t r}
\end{array}\right]\left[\begin{array}{l}
y_{1}^{r t} \\
y_{2}^{r t}
\end{array}\right]+\left[\begin{array}{ll}
b_{11}^{t t} & b_{12}^{t t} \\
b_{21}^{t t} & b_{22}^{t t}
\end{array}\right]\left[\begin{array}{l}
y_{1}^{t t} \\
y_{2}^{t t}
\end{array}\right]\right\} \\
& -\left[\begin{array}{ll}
0 & v_{2}^{s}
\end{array}\right]\left[\begin{array}{ll}
l_{11}^{s s} & l_{12}^{s s} \\
l_{21}^{s s} & l_{22}^{s s}
\end{array}\right]\left[\begin{array}{cc}
a_{11}^{s t} & a_{12}^{s t} \\
0 & 0
\end{array}\right]\left\{\left[\begin{array}{ll}
b_{11}^{t r} & b_{12}^{t r} \\
b_{21}^{t r} & b_{22}^{t r}
\end{array}\right]\left[\begin{array}{l}
y_{1}^{r t} \\
y_{2}^{r t}
\end{array}\right]+\left[\begin{array}{ll}
b_{11}^{t t} & b_{12}^{t t} \\
b_{21}^{t t} & b_{22}^{t t}
\end{array}\right]\left[\begin{array}{l}
y_{1}^{t t} \\
y_{2}^{t t}
\end{array}\right]\right\} \\
& +\left[\begin{array}{ll}
v_{1}^{s} & 0
\end{array}\right]\left[\begin{array}{ll}
l_{11}^{s s} & l_{12}^{s s} \\
l_{21}^{s s} & l_{22}^{s s}
\end{array}\right]\left[\begin{array}{cc}
0 & 0 \\
a_{21}^{s r} & a_{22}^{s r}
\end{array}\right]\left\{\left[\begin{array}{ll}
b_{11}^{r r} & b_{12}^{r r} \\
b_{21}^{r r} & b_{22}^{r r}
\end{array}\right]\left[\begin{array}{l}
y_{1}^{r t} \\
y_{2}^{r t}
\end{array}\right]+\left[\begin{array}{ll}
b_{11}^{r t} & b_{12}^{r t} \\
b_{21}^{r t} & b_{22}^{r t}
\end{array}\right]\left[\begin{array}{c}
y_{1}^{t t} \\
y_{2}^{t t}
\end{array}\right]\right\} \\
& -\left[\begin{array}{ll}
0 & v_{2}^{s}
\end{array}\left[\begin{array}{ll}
l_{11}^{s s} & l_{12}^{s s} \\
l_{21}^{s s} & l_{22}^{s s}
\end{array}\right]\left[\begin{array}{cc}
a_{11}^{s r} & a_{12}^{s r} \\
0 & 0
\end{array}\right]\left\{\left[\begin{array}{ll}
b_{11}^{r r} & b_{12}^{r r} \\
b_{21}^{r r} & b_{22}^{r r}
\end{array}\right]\left[\begin{array}{l}
y_{1}^{r t} \\
y_{2}^{r t}
\end{array}\right]+\left[\begin{array}{ll}
b_{11}^{r t} & b_{12}^{r t} \\
b_{21}^{r t} & b_{22}^{r t}
\end{array}\right]\left[\begin{array}{l}
y_{1}^{t t} \\
y_{2}^{t t}
\end{array}\right]\right\}\right. \\
& +\left[\begin{array}{ll}
v_{1}^{s} & 0
\end{array}\right]\left[\begin{array}{ll}
l_{11}^{s s} & l_{12}^{s s} \\
l_{21}^{s s} & l_{22}^{s s}
\end{array}\right]\left[\begin{array}{cc}
0 & 0 \\
a_{21}^{s t} & a_{22}^{s t}
\end{array}\right]\left\{\left[\begin{array}{ll}
b_{11}^{t r} & b_{12}^{t r} \\
b_{21}^{t r} & b_{22}^{t r}
\end{array}\right]\left[\begin{array}{l}
y_{1}^{r r} \\
y_{2}^{r r}
\end{array}\right]+\left[\begin{array}{ll}
b_{11}^{t t} & b_{12}^{t t} \\
b_{21}^{t t} & b_{22}^{t t}
\end{array}\right]\left[\begin{array}{l}
y_{1}^{t r} \\
y_{2}^{t r}
\end{array}\right]\right\} \\
& -\left[\begin{array}{ll}
0 & v_{2}^{s}
\end{array}\left[\begin{array}{ll}
l_{11}^{s s} & l_{12}^{s s} \\
l_{21}^{s s} & l_{22}^{s s}
\end{array}\right]\left[\begin{array}{cc}
a_{11}^{s t} & a_{12}^{s t} \\
0 & 0
\end{array}\right]\left\{\left[\begin{array}{ll}
b_{11}^{t r} & b_{12}^{t r} \\
b_{21}^{t r} & b_{22}^{t r}
\end{array}\right]\left[\begin{array}{l}
y_{1}^{r r} \\
y_{2}^{r r}
\end{array}\right]+\left[\begin{array}{ll}
b_{11}^{t t} & b_{12}^{t t} \\
b_{21}^{t t} & b_{22}^{t t}
\end{array}\right]\left[\begin{array}{l}
y_{1}^{t r} \\
y_{2}^{t r}
\end{array}\right]\right\}\right.
\end{aligned}
$$

In the right side of equation $(\mathrm{F} 13)$, all positive terms represent value added created by the $1^{\text {st }}$ sector of Country $\mathrm{s}$ embodied in the $2^{\text {nd }}$ sector exports of Country $\mathrm{s}$ and consumed abroad, all negative terms represent value added created by the $2^{\text {nd }}$ sector of Country s embodied in the $1^{\text {st }}$ sector exports of Country s and consumed abroad. Therefore, adding up equation (F12) and (F13), the difference will be fully canceled out.

The difference between $r d v_{-} g_{1}^{s r}$ and $r d v_{-} f_{1}^{s r}$ equals 
$r d v_{-} g_{1}^{s r}-r d v_{-} f_{1}^{s r}$

$=\left[\begin{array}{ll}v_{1}^{s} & v_{2}^{s}\end{array}\right]\left[\begin{array}{ll}l_{11}^{s s} & l_{12}^{s s} \\ l_{21}^{s s} & l_{22}^{s s}\end{array}\right]\left[\begin{array}{cc}a_{11}^{s r} & a_{12}^{s r} \\ 0 & 0\end{array}\right]\left\{\left[\begin{array}{ll}b_{11}^{r r} & b_{12}^{r r} \\ b_{21}^{r r} & b_{22}^{r r}\end{array}\right]\left[\begin{array}{l}y_{1}^{r s} \\ y_{2}^{r s}\end{array}\right]+\left[\begin{array}{ll}b_{11}^{r t} & b_{12}^{r t} \\ b_{21}^{r t} & b_{22}^{r t}\end{array}\right]\left[\begin{array}{l}y_{1}^{t s} \\ y_{2}^{t s}\end{array}\right]+\left[\begin{array}{ll}b_{11}^{r s} & b_{12}^{r s} \\ b_{21}^{r s} & b_{22}^{r s}\end{array}\right]\left[\begin{array}{l}y_{1}^{s s} \\ y_{2}^{s s}\end{array}\right]\right\}$

$-\left[\begin{array}{ll}v_{1}^{s} & 0\end{array}\right]\left[\begin{array}{ll}l_{11}^{s s} & l_{12}^{s s} \\ l_{21}^{s s} & l_{22}^{s s}\end{array}\right]\left[\begin{array}{ll}a_{11}^{s r} & a_{12}^{s r} \\ a_{21}^{s r} & a_{22}^{s r}\end{array}\right]\left\{\left[\begin{array}{ll}b_{11}^{r r} & b_{12}^{r r} \\ b_{21}^{r r} & b_{22}^{r r}\end{array}\right]\left[\begin{array}{l}y_{1}^{r s} \\ y_{2}^{r s}\end{array}\right]+\left[\begin{array}{ll}b_{11}^{r t} & b_{12}^{r t} \\ b_{21}^{r t} & b_{22}^{r t}\end{array}\right]\left[\begin{array}{l}y_{1}^{t s} \\ y_{2}^{t s}\end{array}\right]+\left[\begin{array}{ll}b_{11}^{r s} & b_{12}^{r s} \\ b_{21}^{r s} & b_{22}^{r s}\end{array}\right]\left[\begin{array}{l}y_{1}^{s s} \\ y_{2}^{s s}\end{array}\right]\right\}$

$=\left[\begin{array}{ll}0 & v_{2}^{s}\end{array}\right]\left[\begin{array}{ll}l_{11}^{s s} & l_{12}^{s s} \\ l_{21}^{s s} & l_{22}^{s s}\end{array}\right]\left[\begin{array}{cc}a_{11}^{s r} & a_{12}^{s r} \\ 0 & 0\end{array}\right]\left\{\left[\begin{array}{ll}b_{11}^{r r} & b_{12}^{r r} \\ b_{21}^{r r} & b_{22}^{r r}\end{array}\right]\left[\begin{array}{l}y_{1}^{r s} \\ y_{2}^{r s}\end{array}\right]+\left[\begin{array}{ll}b_{11}^{r t} & b_{12}^{r r} \\ b_{21}^{r t} & b_{22}^{r t}\end{array}\right]\left[\begin{array}{l}y_{1}^{t s} \\ y_{2}^{t s}\end{array}\right]+\left[\begin{array}{ll}b_{11}^{r s} & b_{12}^{r s} \\ b_{21}^{r s} & b_{22}^{r s}\end{array}\right]\left[\begin{array}{l}y_{1}^{s s} \\ y_{2}^{s s}\end{array}\right]\right\}$

$-\left[\begin{array}{ll}v_{1}^{s} & 0\end{array}\right]\left[\begin{array}{cc}l_{11}^{s s} & l_{12}^{s s} \\ l_{21}^{s s} & l_{22}^{s s}\end{array}\right]\left[\begin{array}{cc}0 & 0 \\ a_{21}^{s r} & a_{22}^{s r}\end{array}\right]\left\{\left[\begin{array}{ll}b_{11}^{r r} & b_{12}^{r r} \\ b_{21}^{r r} & b_{22}^{r r}\end{array}\right]\left[\begin{array}{l}y_{1}^{r s} \\ y_{2}^{r s}\end{array}\right]+\left[\begin{array}{ll}b_{11}^{r t} & b_{12}^{r r} \\ b_{21}^{r t} & b_{22}^{r t}\end{array}\right]\left[\begin{array}{l}y_{1}^{t s} \\ y_{2}^{t s}\end{array}\right]+\left[\begin{array}{ll}b_{11}^{r s} & b_{12}^{r s} \\ b_{21}^{r s} & b_{22}^{r s}\end{array}\right]\left[\begin{array}{c}y_{1}^{s s} \\ y_{2}^{s s}\end{array}\right]\right\}$

Similarly, The difference between $r d v_{-} g_{2}^{s r}$ and $r d v_{-} f_{2}^{s r}$ equals

$$
\begin{aligned}
& r d v_{-} g_{2}^{s r}-r d v_{-} f_{2}^{s r} \\
& =\left[\begin{array}{ll}
v_{1}^{s} & 0
\end{array}\right]\left[\begin{array}{ll}
l_{11}^{s s} & l_{12}^{s s} \\
l_{21}^{s s} & l_{22}^{s s}
\end{array}\right]\left[\begin{array}{cc}
0 & 0 \\
a_{21}^{s r} & a_{22}^{s r}
\end{array}\right]\left\{\left[\begin{array}{ll}
b_{11}^{r r} & b_{12}^{r r} \\
b_{21}^{r r} & b_{22}^{r r}
\end{array}\right]\left[\begin{array}{l}
y_{1}^{r s} \\
y_{2}^{r s}
\end{array}\right]+\left[\begin{array}{ll}
b_{11}^{r t} & b_{12}^{r r} \\
b_{21}^{r t} & b_{22}^{r t}
\end{array}\right]\left[\begin{array}{l}
y_{1}^{t s} \\
y_{2}^{t s}
\end{array}\right]+\left[\begin{array}{ll}
b_{11}^{r s} & b_{12}^{r s} \\
b_{21}^{r s} & b_{22}^{r s}
\end{array}\right]\left[\begin{array}{l}
y_{1}^{s s} \\
y_{2}^{s s}
\end{array}\right]\right\} \\
& -\left[\begin{array}{ll}
0 & v_{2}^{s s}
\end{array}\left[\begin{array}{ll}
l_{11}^{s s} & l_{12}^{s s} \\
l_{21}^{s s} & l_{22}^{s s}
\end{array}\right]\left[\begin{array}{cc}
a_{11}^{s r} & a_{12}^{s r} \\
0 & 0
\end{array}\right]\left\{\left[\begin{array}{ll}
b_{11}^{r r} & b_{12}^{r r} \\
b_{21}^{r r} & b_{22}^{r r}
\end{array}\right]\left[\begin{array}{l}
y_{1}^{r s} \\
y_{2}^{r s}
\end{array}\right]+\left[\begin{array}{ll}
b_{11}^{r t} & b_{12}^{r t} \\
b_{21}^{r t} & b_{22}^{r t}
\end{array}\right]\left[\begin{array}{l}
y_{1}^{t s} \\
y_{2}^{t s}
\end{array}\right]+\left[\begin{array}{ll}
b_{11}^{r s} & b_{12}^{r s} \\
b_{21}^{r s} & b_{22}^{r s}
\end{array}\right]\left[\begin{array}{l}
y_{1}^{s s} \\
y_{2}^{s s}
\end{array}\right]\right\}\right.
\end{aligned}
$$

Compare equations (F14) and (F15), the positive terms in (F14) are exactly the same as the negative terms in (F15). Therefore, when we aggregate over sectors, the difference between $r d v_{-} g_{i}^{s r}$ and $r d v_{-} f_{i}^{s r}$ will cancels out, at bilateral aggregate level:

$$
r d v_{-} g_{1}^{s r}+r d v_{-} g_{2}^{s r}=r d v_{-} f_{1}^{s r}+r d v_{-} f_{2}^{s r} \text { or } u R D V_{-} G^{s r}=u R D V_{-} F^{s r}
$$

Similar to equation (F14), the difference between $r d v_{-} g_{1}^{s t}$ and $r d v_{-} f_{1}^{s t}$ equals

$$
\begin{aligned}
& r d v_{-} g_{1}^{s t}-r d v_{-} f_{1}^{s t} \\
& =\left[\begin{array}{ll}
0 & v_{2}^{s t}
\end{array}\right]\left[\begin{array}{ll}
l_{11}^{s s} & l_{12}^{s s} \\
l_{21}^{s s} & l_{22}^{s s}
\end{array}\right]\left[\begin{array}{cc}
a_{11}^{s t} & a_{12}^{s t} \\
0 & 0
\end{array}\right]\left\{\left[\begin{array}{ll}
b_{11}^{t r} & b_{12}^{t r} \\
b_{21}^{t r} & b_{22}^{t r}
\end{array}\right]\left[\begin{array}{l}
y_{1}^{r s} \\
y_{2}^{r s}
\end{array}\right]+\left[\begin{array}{ll}
b_{11}^{t t} & b_{12}^{t t} \\
b_{21}^{t t} & b_{22}^{t t}
\end{array}\right]\left[\begin{array}{l}
y_{1}^{t s} \\
y_{2}^{t s}
\end{array}\right]+\left[\begin{array}{ll}
b_{11}^{t s} & b_{12}^{t s} \\
b_{21}^{t s} & b_{22}^{t s}
\end{array}\right]\left[\begin{array}{l}
y_{1}^{s s} \\
y_{2}^{s s}
\end{array}\right]\right\} \\
& \left.-\left[\begin{array}{ll}
v_{1}^{s s} & 0
\end{array}\right] \begin{array}{ll}
l_{11}^{s s} & l_{12}^{s s} \\
l_{21}^{s s} & l_{22}^{s s}
\end{array}\right]\left[\begin{array}{cc}
0 & 0 \\
a_{21}^{s t} & a_{22}^{s t}
\end{array}\right]\left\{\left[\begin{array}{ll}
b_{11}^{t r} & b_{12}^{t r} \\
b_{21}^{t r} & b_{22}^{t r}
\end{array}\right]\left[\begin{array}{l}
y_{1}^{r s} \\
y_{2}^{r s}
\end{array}\right]+\left[\begin{array}{ll}
b_{11}^{t t} & b_{12}^{t t} \\
b_{21}^{t t} & b_{22}^{t t}
\end{array}\right]\left[\begin{array}{l}
y_{1}^{t s} \\
y_{2}^{t s}
\end{array}\right]+\left[\begin{array}{ll}
b_{11}^{t s} & b_{12}^{t s} \\
b_{21}^{t s} & b_{22}^{t s}
\end{array}\right]\left[\begin{array}{l}
y_{1}^{s s} \\
y_{2}^{s s}
\end{array}\right]\right\}
\end{aligned}
$$

Comparing equation (F14) and (F17), we can see that all terms are fully reserved when aggregate $r d v_{-} g_{1}^{s u}$ and $r d v_{-} f_{1}^{s u}$ over trading partners. Therefore, $R D V_{-} G^{s^{*}} \neq R D V_{-} F^{s^{*}}$, i.e $\sum_{r \neq s}^{G} r d v_{-} g_{i}^{s r} \neq \sum_{r \neq s}^{G} r d v_{-} f_{i}^{s r}$.

At country aggregate level 


$$
\begin{aligned}
& u R D V_{-} G^{s^{*}}=u R D V_{-} F^{s^{*}} \\
& =V^{s} L^{s s} \sum_{r \neq s}^{G} A^{s r} B^{r r} Y^{r s}+V^{s} L^{s s} \sum_{r \neq s}^{G} A^{s r} \sum_{t \neq s, r}^{G} B^{r t} Y^{t s}+V^{s} L^{s s} \sum_{r \neq s}^{G} A^{s r} B^{r s} Y^{s s} \\
& =V^{s} L^{s s} \sum_{r \neq s}^{G} A^{s r} \sum_{t \neq s}^{G} B^{r t} Y^{t s}+V^{s} L^{s s} \sum_{r \neq s}^{G} A^{s r} B^{r s} Y^{s s} \\
& =V^{s} \sum_{t \neq s}^{G} B^{s t} Y^{t s}+V^{s}\left(B^{s s}-L^{s s}\right) Y^{s s}=V^{s} \sum_{r \neq s}^{G} B^{s r} Y^{r s}+V^{s} \sum_{r \neq s}^{G} B^{s r} A^{r s} L^{s s} Y^{s s}
\end{aligned}
$$

At country aggregate level, $\mathrm{RDV} \mathrm{G}^{\mathrm{s}^{*}}$ and $\mathrm{RDV} \mathrm{F}^{\mathrm{s}^{*}}$ are equal to the sum of the $4^{\text {th }}$ and $5^{\text {th }}$ terms of Equation 36 in KWW.

$D V A \_G^{s r}$ equals the sum of $V A X \_G^{s r}$ and $R D V \_G^{s r}$, and $D V A \_F^{s r}$ equals the sum of $V A X{ }_{-} F^{s r}$ and $R D V \_F^{s r}$ by definition, while we already show $V A X \_G$ and $V A X \_F$ are equal only at country aggregate level and $R D V_{-} G^{s r}$ and $R D V_{-} F^{s r}$ are equal at bilateral and country aggregate level, therefore, $D V A_{-} G^{s r}$ and $D V A_{-} F^{s r}$ are equal only at country aggregate level. i.e $\sum_{r \neq s}^{G} \sum_{i=1}^{2} d v a_{-} f_{i}^{s r}=\sum_{r \neq s}^{G} \sum_{i=1}^{2} d v a_{-} g_{i}^{s r}$ holds.

By proof of proposition A above, the relationship among the two measures of trade in value-added and the two measures of domestic value-added embodied in gross exports are made clear analytically. Then, the proof of proposition B and C is straightforward.

Because $v a x_{-} g_{i}^{s r}$ is the sum of the first five terms and $d v a_{-} g_{i}^{s r}$ is the sum of the eight terms in equation (18) of the main text by definition, i. e. $v a x_{-} g_{i}^{s r}$ and $d v a_{-} g_{i}^{s r}$ are always part of $e_{i}^{s r}$ and $v a x_{-} g_{i}^{s r} \leq d v a_{-} g_{i}^{s r} \leq e_{i}^{s r}$, therefore, $\frac{v a x_{-} g_{i}^{s r}}{e_{i}^{s r}} \leq \frac{d v a_{-} g_{i}^{s r}}{e_{i}^{s r}} \leq 1$ always holds. i.e. Proposition $\mathrm{B}$ is valid.

From equation (F1), the definition of value-added exports based on forward linkage, we have

$$
\begin{aligned}
& v a x_{-} f_{i}^{s^{*}}=\sum_{u \neq s}^{G} v a x_{-} f_{i}^{s u}=v a x_{-} f_{i}^{s r}+v a x_{-} f_{i}^{s t} \\
& =V_{i}^{s} B^{s s} Y^{s r}+V_{i}^{s} B^{s r} Y^{r r}+V_{i}^{s} B^{s t} Y^{t r}+V_{i}^{s} B^{s s} Y^{s t}+V_{i}^{s} B^{s r} Y^{r t}+V_{i}^{s} B^{s t} Y^{t t} \\
& =V_{i}^{s} B^{s s}\left(Y^{s r}+Y^{s t}\right)+V_{i}^{s} B^{s r}\left(Y^{r r}+Y^{r t}\right)+V_{i}^{s} B^{s t}\left(Y^{t r}+Y^{t t}\right)
\end{aligned}
$$

Where $V_{i}^{s}=\left[\begin{array}{lllll}0 & \cdots & v_{i}^{s} & \cdots & 0\end{array}\right]$ is an $\mathrm{N}$ by 1 vector.

Based on the definition of value-added (GDP) by industry, we have 


$$
\begin{aligned}
& G D P_{i}^{s}=v_{i}^{s} x_{i}^{s}=V_{i}^{s} X^{s} \\
& =V_{i}^{s} B^{s s}\left(Y^{s s}+Y^{s r}+Y^{s t}\right)+V_{i}^{s} B^{s r}\left(Y^{r s}+Y^{r r}+Y^{r t}\right)+V_{i}^{s} B^{s t}\left(Y^{t s}+Y^{t r}+Y^{t t}\right)
\end{aligned}
$$

Subtract equation (F18) and (F18) from (F20)

$$
\begin{aligned}
& G D P_{i}^{s}-\sum_{u \neq s}^{G} v a x_{-} f_{i}^{s u}-\sum_{u \neq s}^{G} r d v_{-} f_{i}^{s u} \\
& =V_{i}^{s} B^{s s}\left(Y^{s s}+Y^{s r}+Y^{s t}\right)+V_{i}^{s} B^{s r}\left(Y^{r s}+Y^{r r}+Y^{r t}\right)+V_{i}^{s} B^{s t}\left(Y^{t s}+Y^{t r}+Y^{t t}\right) \\
& -V_{i}^{s} B^{s s}\left(Y^{s r}+Y^{s t}\right)-V_{i}^{s} B^{s r}\left(Y^{r r}+Y^{r t}+\right)-V_{i}^{s} B^{s t}\left(Y^{t r}+Y^{t t}\right)-V^{s} L^{s s} \sum_{r \neq s}^{G} A^{s r} \sum_{t}^{G} B^{r t} Y^{t s} \\
& =V_{i}^{s} L^{s s} Y^{s s} \geq 0
\end{aligned}
$$

Therefore, $v a x_{-} f_{i}^{s^{*}}=\sum_{u \neq s}^{G} v a x_{-} f_{i}^{s u} \leq \sum_{u \neq s}^{G} d v a_{-} f_{i}^{s u} \leq v_{i}^{s} x_{i}^{s}=G D P_{i}^{s}$ and $\frac{\sum_{u \neq s}^{G} v a x_{-} f_{i}^{s u}}{v_{i}^{s} x_{i}^{s}} \leq \frac{\sum_{u \neq s}^{G} d v a_{-} f_{i}^{s u}}{v_{i}^{s} x_{i}^{s}} \leq 1$ i.e.

\begin{tabular}{|c|c|c|c|c|c|c|c|c|c|c|c|}
\hline \multirow[b]{3}{*}{ Country } & \multirow{3}{*}{$\begin{array}{c}\text { Country } \\
\text { Sector }\end{array}$} & \multicolumn{6}{|c|}{ Intermediate Uses } & \multicolumn{3}{|c|}{ Final Uses } & \multirow{3}{*}{$\begin{array}{l}\text { Gross } \\
\text { outputs }\end{array}$} \\
\hline & & \multicolumn{2}{|c|}{$\mathbf{s}$} & \multicolumn{2}{|c|}{$\mathbf{R}$} & \multicolumn{2}{|c|}{ t } & \multirow{2}{*}{$\mathbf{Y}^{\mathbf{s}}$} & \multirow{2}{*}{$\mathbf{Y}^{\mathbf{r}}$} & \multirow{2}{*}{$\mathbf{Y}^{\mathbf{t}}$} & \\
\hline & & s1 & s2 & r1 & r2 & t1 & t2 & & & & \\
\hline \multirow{2}{*}{$\mathbf{S}$} & s1 & 1 & 1 & 0 & 0 & 0 & 0 & $9 / 10$ & $1 / 10$ & 0 & 3 \\
\hline & s2 & 0 & 1 & 0 & 1 & 0 & 0 & 1 & 0 & 0 & 3 \\
\hline \multirow{2}{*}{$\mathbf{R}$} & r1 & 0 & 0 & 1 & 1 & 0 & 0 & 0 & 1 & 0 & 3 \\
\hline & r2 & 0 & 0 & 1 & 1 & 0 & 0 & 0 & 1 & 1 & 4 \\
\hline \multirow{2}{*}{$\mathbf{T}$} & t1 & 1 & 0 & 0 & 0 & 1 & 0 & 1 & 0 & 0 & 3 \\
\hline & t2 & 0 & 0 & 0 & 0 & 1 & 1 & 0 & 0 & 1 & 3 \\
\hline \multicolumn{2}{|c|}{ Value-added } & 1 & 1 & 1 & 1 & 1 & 2 & & & & \\
\hline \multicolumn{2}{|c|}{ Total inputs } & 3 & 3 & 3 & 4 & 3 & 3 & & & & \\
\hline
\end{tabular}

Proposition $\mathrm{C}$ is proved.

To help reader better understand our decomposition method, we provide a numerical example below to illustrate various concepts discussed in section 2 of the main text.

Suppose a simple 3-country, 2-sector ICIO table as summarized in table F1 below:

Table F1 3-country, 2-sector numerical ICIO table

Gross exports (E) can be decomposed into gross intermediate exports (EI) and final good exports (EF) .

$$
E=E I+E F=\left[\begin{array}{ccc}
0 & 1 / 10 & 0 \\
0 & 0 & 0 \\
0 & 0 & 0 \\
0 & 0 & 1 \\
1 & 0 & 0 \\
0 & 0 & 0
\end{array}\right]+\left[\begin{array}{ccc}
0 & 0 & 0 \\
0 & 1 & 0 \\
0 & 0 & 0 \\
0 & 0 & 0 \\
1 & 0 & 0 \\
0 & 0 & 0
\end{array}\right]=\left[\begin{array}{ccc}
0 & 1 / 10 & 0 \\
0 & 1 & 0 \\
0 & 0 & 0 \\
0 & 0 & 1 \\
2 & 0 & 0 \\
0 & 0 & 0
\end{array}\right]
$$


The direct input coefficient matrix A, Global Leontief inverse Matrix B, Local Leontief inverse matrix L, and direct value-added coefficient vector $\mathrm{V}$ can be easily computed as

$$
\begin{aligned}
& A=\left[\begin{array}{cccccc}
1 / 3 & 1 / 3 & 0 & 0 & 0 & 0 \\
0 & 1 / 3 & 0 & 1 / 4 & 0 & 0 \\
0 & 0 & 1 / 3 & 1 / 4 & 0 & 0 \\
0 & 0 & 1 / 3 & 1 / 4 & 0 & 0 \\
1 / 3 & 0 & 0 & 0 & 1 / 3 & 0 \\
0 & 0 & 0 & 0 & 1 / 3 & 1 / 3
\end{array}\right] \\
& B=\left[\begin{array}{cccccc}
3 / 2 & 3 / 4 & 3 / 20 & 3 / 10 & 0 & 0 \\
0 & 3 / 2 & 3 / 10 & 3 / 5 & 0 & 0 \\
0 & 0 & 9 / 5 & 3 / 5 & 0 & 0 \\
0 & 0 & 4 / 5 & 8 / 5 & 0 & 0 \\
3 / 4 & 3 / 8 & 3 / 40 & 3 / 20 & 3 / 2 & 0 \\
3 / 8 & 3 / 16 & 3 / 80 & 3 / 40 & 3 / 4 & 3 / 2
\end{array}\right] \\
& L=\left[\begin{array}{cccccc}
3 / 2 & 3 / 4 & 0 & 0 & 0 & 0 \\
0 & 3 / 2 & 0 & 0 & 0 & 0 \\
0 & 0 & 9 / 5 & 3 / 5 & 0 & 0 \\
0 & 0 & 4 / 5 & 8 / 5 & 0 & 0 \\
0 & 0 & 0 & 0 & 3 / 2 & 0 \\
0 & 0 & 0 & 0 & 3 / 4 & 3 / 2
\end{array}\right] \\
& V=\left[\begin{array}{llllll}
1 / 3 & 1 / 3 & 1 / 3 & 1 / 4 & 1 / 3 & 2 / 3
\end{array}\right]
\end{aligned}
$$

\begin{tabular}{|c|c|c|c|c|c|c|}
\hline Name & \multicolumn{2}{|c|}{$A^{s s}$} & \multicolumn{2}{|c|}{$A^{s r}$} & \multicolumn{2}{|c|}{$A^{s t}$} \\
\hline \multirow{2}{*}{$\begin{array}{l}\text { Block } \\
\text { matrix }\end{array}$} & $1 / 3$ & $1 / 3$ & 0 & 0 & 0 & 0 \\
\hline & 0 & $1 / 3$ & 0 & $1 / 4$ & 0 & 0 \\
\hline Name & \multicolumn{2}{|c|}{$A^{r s}$} & \multicolumn{2}{|c|}{$A^{r r}$} & \multicolumn{2}{|c|}{$A^{r t}$} \\
\hline \multirow{2}{*}{$\begin{array}{l}\text { Block } \\
\text { matrix }\end{array}$} & 0 & 0 & $1 / 3$ & $1 / 4$ & 0 & 0 \\
\hline & 0 & 0 & $1 / 3$ & $1 / 4$ & 0 & 0 \\
\hline Name & \multicolumn{2}{|c|}{$A^{t s}$} & \multicolumn{2}{|c|}{$A^{t r}$} & \multicolumn{2}{|c|}{$A^{t t}$} \\
\hline Block & $1 / 3$ & 0 & 0 & 0 & $1 / 3$ & 0 \\
\hline matrix & 0 & 0 & 0 & 0 & $1 / 3$ & $1 / 3$ \\
\hline
\end{tabular}

\begin{tabular}{|c|c|c|c|c|c|c|}
\hline Name & \multicolumn{2}{|c|}{$B^{s s}$} & \multicolumn{2}{|c|}{$B^{s r}$} & \multicolumn{2}{|c|}{$B^{s t}$} \\
\hline \multirow{2}{*}{$\begin{array}{l}\text { Block } \\
\text { matrix }\end{array}$} & $3 / 2$ & $3 / 4$ & $3 / 20$ & $3 / 10$ & 0 & 0 \\
\hline & 0 & $3 / 2$ & $3 / 10$ & $3 / 5$ & 0 & 0 \\
\hline Name & \multicolumn{2}{|c|}{$B^{r S}$} & \multicolumn{2}{|c|}{$B^{r r}$} & \multicolumn{2}{|c|}{$B^{r t}$} \\
\hline \multirow{2}{*}{$\begin{array}{l}\text { Block } \\
\text { matrix }\end{array}$} & 0 & 0 & $9 / 5$ & $3 / 5$ & 0 & 0 \\
\hline & 0 & 0 & $4 / 5$ & $8 / 5$ & 0 & 0 \\
\hline Name & \multicolumn{2}{|c|}{$B^{t s}$} & \multicolumn{2}{|c|}{$B^{t r}$} & \multicolumn{2}{|c|}{$B^{t t}$} \\
\hline Block & $3 / 4$ & $3 / 8$ & $3 / 40$ & $3 / 20$ & $3 / 2$ & 0 \\
\hline matrix & $3 / 8$ & $3 / 16$ & $3 / 80$ & $3 / 40$ & $3 / 4$ & $3 / 2$ \\
\hline
\end{tabular}

The block direct input-output coefficients matrixes

The block global Leontief inverse matrixes:

The block Local Leontief inverse matrixes

\begin{tabular}{|l|c|c|c|c|c|c|}
\hline Name & \multicolumn{2}{|c|}{$L^{s s}$} & \multicolumn{2}{c|}{$L^{r r}$} & \multicolumn{2}{c|}{$L^{t t}$} \\
\hline \multirow{2}{*}{$\begin{array}{l}\text { Block } \\
\text { matrix }\end{array}$} & $3 / 2$ & $3 / 4$ & $9 / 5$ & $3 / 5$ & $3 / 2$ & 0 \\
\cline { 2 - 7 } & 0 & $3 / 2$ & $4 / 5$ & $8 / 5$ & $3 / 4$ & $3 / 2$ \\
\hline
\end{tabular}


The block Value Added Coefficients Vectors

\begin{tabular}{|c|c|c|c|c|c|c|}
\hline Name & \multicolumn{2}{|c|}{$V^{s}$} & \multicolumn{2}{c|}{$V^{r}$} & \multicolumn{2}{c|}{$V^{t}$} \\
\hline Vectors & $1 / 3$ & $1 / 3$ & $1 / 3$ & $1 / 4$ & $1 / 3$ & $2 / 3$ \\
\hline
\end{tabular}

Based on equations (15) in the main text, the total value added coefficients or value added multipliers can be computed as

\begin{tabular}{|c|c|c|c|c|c|c|c|}
\hline Name & \multicolumn{3}{|c|}{$V^{s} B^{s s}$} & \multicolumn{2}{c|}{$V^{r} B^{r r}$} & \multicolumn{3}{c|}{$V^{t} B^{t t}$} \\
\hline Vectors & $1 / 2$ & \multicolumn{2}{|c|}{$3 / 4$} & $4 / 5$ & $3 / 5$ & 1 & 1 \\
\hline Name & \multicolumn{2}{|c|}{$V^{s} L^{s s}$} & \multicolumn{2}{|c|}{$V^{r} L^{r r}$} & \multicolumn{3}{|c|}{$V^{t} L^{t t}$} \\
\hline Vectors & $1 / 2$ & $3 / 4$ & \multicolumn{2}{|c|}{$4 / 5$} & $3 / 5$ & 1 & 1 \\
\hline Name & \multicolumn{2}{|c|}{$V^{r} B^{r s}$} & \multicolumn{2}{|c|}{$V^{t} B^{t r}$} & \multicolumn{3}{|c|}{$V^{s} B^{s t}$} \\
\hline Vectors & 0 & 0 & \multicolumn{2}{|c|}{$1 / 20$} & $1 / 10$ & 0 & 0 \\
\hline Name & \multicolumn{3}{|c|}{$V^{t} B^{t s}$} & \multicolumn{2}{|c|}{$V^{s} B^{s r}$} & \multicolumn{2}{|c|}{$V^{r} B^{r t}$} \\
\hline Vectors & $1 / 2$ & $1 / 4$ & $3 / 20$ & $3 / 10$ & 0 & 0 \\
\hline
\end{tabular}

Based on equation (11) in the main text, Country s' intermediate exports to Country $r$ can be split into following 8 parts:

$$
\begin{aligned}
A^{s r} B^{r r} Y^{r r} & =\left[\begin{array}{cc}
0 & 0 \\
0 & 1 / 4
\end{array}\right]\left[\begin{array}{ll}
9 / 5 & 3 / 5 \\
4 / 5 & 8 / 5
\end{array}\right]\left[\begin{array}{l}
1 \\
1
\end{array}\right]=\left[\begin{array}{c}
0 \\
3 / 5
\end{array}\right] \\
A^{s r} B^{r t} Y^{t t} & =\left[\begin{array}{cc}
0 & 0 \\
0 & 1 / 4
\end{array}\right]\left[\begin{array}{ll}
0 & 0 \\
0 & 0
\end{array}\right]\left[\begin{array}{l}
0 \\
1
\end{array}\right]=\left[\begin{array}{l}
0 \\
0
\end{array}\right] \\
A^{s r} B^{r r} Y^{r t} & =\left[\begin{array}{cc}
0 & 0 \\
0 & 1 / 4
\end{array}\right]\left[\begin{array}{ll}
9 / 5 & 3 / 5 \\
4 / 5 & 8 / 5
\end{array}\right]\left[\begin{array}{l}
0 \\
1
\end{array}\right]=\left[\begin{array}{c}
0 \\
2 / 5
\end{array}\right] \\
A^{s r} B^{r t} Y^{t r} & =\left[\begin{array}{cc}
0 & 0 \\
0 & 1 / 4
\end{array}\right]\left[\begin{array}{cc}
0 & 0 \\
0 & 0
\end{array}\right]\left[\begin{array}{l}
0 \\
0
\end{array}\right]=\left[\begin{array}{l}
0 \\
0
\end{array}\right] \\
A^{s r} B^{r r} Y^{r s} & =\left[\begin{array}{cc}
0 & 0 \\
0 & 1 / 4
\end{array}\right]\left[\begin{array}{cc}
9 / 5 & 3 / 5 \\
4 / 5 & 8 / 5
\end{array}\right]\left[\begin{array}{l}
0 \\
0
\end{array}\right]=\left[\begin{array}{l}
0 \\
0
\end{array}\right] \\
A^{s r} B^{r t} Y^{t s} & =\left[\begin{array}{cc}
0 & 0 \\
0 & 1 / 4
\end{array}\right]\left[\begin{array}{ll}
0 & 0 \\
0 & 0
\end{array}\right]\left[\begin{array}{l}
1 \\
0
\end{array}\right]=\left[\begin{array}{l}
0 \\
0
\end{array}\right] \\
A^{s r} B^{r s} Y^{s s} & =\left[\begin{array}{cc}
0 & 0 \\
0 & 1 / 4
\end{array}\right]\left[\begin{array}{ll}
0 & 0 \\
0 & 0
\end{array}\right]\left[\begin{array}{l}
9 / 10 \\
1
\end{array}\right]=\left[\begin{array}{l}
0 \\
0
\end{array}\right] \\
A^{s r} B^{r s}\left(Y^{s r}\right. & \left.+Y^{s t}\right)=\left[\begin{array}{ll}
0 & 0 \\
0 & 1 / 4
\end{array}\right]\left[\begin{array}{ll}
0 & 0 \\
0 & 0
\end{array}\right]\left\{\left[\begin{array}{l}
1 / 10 \\
0
\end{array}\right]+\left[\begin{array}{l}
0 \\
0
\end{array}\right]\right\}=\left[\begin{array}{l}
0 \\
0
\end{array}\right]
\end{aligned}
$$


Adding up the eight $A B Y$ terms above, we obtain Country s' intermediate exports to Country r: $E I^{s r}=\left[\begin{array}{l}0 \\ 1\end{array}\right]$

Based on equation (14) in the main text, Country s' intermediate exports to Country $r$ can also be split as

$$
\begin{aligned}
A^{s r} L^{r r} Y^{r r} & =\left[\begin{array}{cc}
0 & 0 \\
0 & 1 / 4
\end{array}\right]\left[\begin{array}{ll}
9 / 5 & 3 / 5 \\
4 / 5 & 8 / 5
\end{array}\right]\left[\begin{array}{l}
1 \\
1
\end{array}\right]=\left[\begin{array}{c}
0 \\
3 / 5
\end{array}\right] \\
A^{s r} L^{r r} E^{r^{*}} & =\left[\begin{array}{cc}
0 & 0 \\
0 & 1 / 4
\end{array}\right]\left[\begin{array}{ll}
9 / 5 & 3 / 5 \\
4 / 5 & 8 / 5
\end{array}\right]\left[\begin{array}{l}
0 \\
1
\end{array}\right]=\left[\begin{array}{c}
0 \\
2 / 5
\end{array}\right]
\end{aligned}
$$

Applying decomposition equation (18), we can fully decompose each of the three countries' gross bilateral exports into the 16 value-added and double counted components as reported in table F2. Detailed computation is listed below:

$$
\begin{aligned}
& T_{1}^{s r}=\left(V^{s} B^{s s}\right)^{T} \# Y^{s r}=\left[\begin{array}{c}
1 / 2 \\
3 / 4
\end{array}\right] \#\left[\begin{array}{c}
1 / 10 \\
0
\end{array}\right]=\left[\begin{array}{c}
1 / 20 \\
0
\end{array}\right] \\
& T_{2}^{s r}=\left(V^{s} L^{s s}\right)^{T} \#\left(A^{s r} B^{r r} Y^{r r}\right)=\left[\begin{array}{l}
1 / 2 \\
3 / 4
\end{array}\right] \#\left[\begin{array}{c}
0 \\
3 / 5
\end{array}\right]=\left[\begin{array}{c}
0 \\
9 / 20
\end{array}\right] \\
& T_{3}^{s r}=\left(V^{s} L^{s s}\right)^{T} \#\left(A^{s r} B^{r t} Y^{t t}\right)=\left[\begin{array}{l}
1 / 2 \\
3 / 4
\end{array}\right] \#\left[\begin{array}{l}
0 \\
0
\end{array}\right]=\left[\begin{array}{l}
0 \\
0
\end{array}\right] \\
& T_{4}^{s r}=\left(V^{s} L^{s s}\right)^{T} \#\left(A^{s r} B^{r r} Y^{r t}\right)=\left[\begin{array}{l}
1 / 2 \\
3 / 4
\end{array}\right] \#\left[\begin{array}{l}
0 \\
2 / 5
\end{array}\right]=\left[\begin{array}{c}
0 \\
3 / 10
\end{array}\right] \\
& T_{5}^{s r}=\left(V^{s} L^{s s}\right)^{T} \#\left(A^{s r} B^{r t} Y^{t r}\right)=\left[\begin{array}{l}
1 / 2 \\
3 / 4
\end{array}\right] \#\left[\begin{array}{l}
0 \\
0
\end{array}\right]=\left[\begin{array}{l}
0 \\
0
\end{array}\right] \\
& T_{6}^{s r}=\left(V^{s} L^{s s}\right)^{T} \#\left(A^{s r} B^{r r} Y^{r s}\right)=\left[\begin{array}{l}
1 / 2 \\
3 / 4
\end{array}\right] \#\left[\begin{array}{l}
0 \\
0
\end{array}\right]=\left[\begin{array}{l}
0 \\
0
\end{array}\right] \\
& T_{9}^{s r}=\left(V^{s} L^{s s}\right)^{T} \#\left(A^{s r} B^{r s}\left(Y^{s r}+Y^{s t}\right)\right)=\left(\begin{array}{l}
1 / 2 \\
3 / 4
\end{array}\right] \#\left[\begin{array}{l}
0 \\
0
\end{array}\right]=\left[\begin{array}{l}
0 \\
0
\end{array}\right] \\
& T_{8}^{s r}=\left(V^{s} L^{s s}\right)^{T} \#\left(A^{s r} B^{r s} Y^{s s}\right)=\left[\begin{array}{l}
1 / 2 \\
3 / 4
\end{array}\right] \#\left[\begin{array}{l}
0 \\
0
\end{array}\right]=\left[\begin{array}{l}
0 \\
0
\end{array}\right]
\end{aligned}
$$




$$
\begin{aligned}
& T_{10}^{s r}=\left(V^{s} B^{s s}-V^{s} L^{s s}\right)^{T} \#\left(E I^{s r}\right)=\left\{\left[\begin{array}{l}
1 / 2 \\
3 / 4
\end{array}\right]-\left[\begin{array}{l}
1 / 2 \\
3 / 4
\end{array}\right]\right\} \#\left[\begin{array}{l}
0 \\
1
\end{array}\right]=\left[\begin{array}{l}
0 \\
0
\end{array}\right] \\
& T_{11}^{s r}=\left(V^{r} B^{r s}\right)^{T} \# Y^{s r}=\left[\begin{array}{l}
0 \\
0
\end{array}\right] \#\left[\begin{array}{c}
1 / 10 \\
0
\end{array}\right]=\left[\begin{array}{l}
0 \\
0
\end{array}\right] \\
& T_{12}^{s r}=\left(V^{r} B^{r s}\right)^{T} \#\left(A^{r s} L^{s s} Y^{s s}\right)=\left[\begin{array}{l}
0 \\
0
\end{array}\right] \#\left[\begin{array}{c}
0 \\
3 / 5
\end{array}\right]=\left[\begin{array}{l}
0 \\
0
\end{array}\right] \\
& T_{13}^{s r}=\left(V^{r} B^{r s}\right)^{T} \#\left(A^{r s} L^{s s} E^{s^{*}}\right)=\left[\begin{array}{l}
0 \\
0
\end{array}\right] \#\left[\begin{array}{c}
0 \\
2 / 5
\end{array}\right]=\left[\begin{array}{l}
0 \\
0
\end{array}\right] \\
& T_{14}^{s r}=\left(V^{t} B^{t s}\right)^{T} \# Y^{s r}=\left[\begin{array}{l}
1 / 2 \\
1 / 4
\end{array}\right] \#\left[\begin{array}{c}
1 / 10 \\
0
\end{array}\right]=\left[\begin{array}{c}
1 / 20 \\
0
\end{array}\right] \\
& T_{15}^{s r}=\left(V^{t} B^{t s}\right)^{T} \#\left(A^{r s} L^{s s} Y^{s s}\right)=\left[\begin{array}{c}
1 / 2 \\
1 / 4
\end{array}\right] \#\left[\begin{array}{c}
0 \\
3 / 5
\end{array}\right]=\left[\begin{array}{c}
0 \\
3 / 20
\end{array}\right] \\
& T_{16}^{s r}=\left(V^{t} B^{t s}\right)^{T} \#\left(A^{r s} L^{s s} E^{s^{*}}\right)=\left[\begin{array}{l}
1 / 2 \\
1 / 4
\end{array}\right] \#\left[\begin{array}{c}
0 \\
2 / 5
\end{array}\right]=\left[\begin{array}{c}
0 \\
1 / 10
\end{array}\right]
\end{aligned}
$$

Adding up the 16 components above, we can get the Country s' sectorial exports to Country r, $E^{S r}=\left\lfloor\begin{array}{c}1 / 10 \\ 1\end{array}\right\rfloor$.

Using equation 19-23, we can calculate the two measures of "domestic value added embedded in gross exports" at the bilateral-sector level in addition to the two measure of value added exports .

$$
\begin{aligned}
& V A X_{-} G^{s r}=\sum_{i=1}^{5} T_{i}^{s r}=\left\lfloor\begin{array}{c}
1 / 20 \\
3 / 4
\end{array}\right] \text { DVA } G^{s r}=\sum_{i=1}^{8} T_{i}^{s r}=\left\lfloor\begin{array}{c}
1 / 20 \\
3 / 4
\end{array}\right] \\
& V A X_{-} F^{s r}=\hat{V}^{s} B^{s s} Y^{s r}+\hat{V}^{s} B^{s r} Y^{r r}+\hat{V}^{s} \sum_{t \neq s, r}^{G} B^{s t} Y^{t r} \\
& =\left[\begin{array}{cc}
1 / 3 & 0 \\
0 & 1 / 3
\end{array}\right]\left\{\left[\begin{array}{cc}
3 / 2 & 3 / 4 \\
0 & 3 / 2
\end{array}\right]\left[\begin{array}{c}
1 / 10 \\
0
\end{array}\right]+\left[\begin{array}{cc}
3 / 20 & 3 / 10 \\
3 / 10 & 3 / 5
\end{array}\right]\left[\begin{array}{l}
1 \\
1
\end{array}\right]+\left[\begin{array}{ll}
0 & 0 \\
0 & 0
\end{array}\right]\left[\begin{array}{l}
0 \\
0
\end{array}\right]\right\} \\
& =\left[\begin{array}{cc}
1 / 3 & 0 \\
0 & 1 / 3
\end{array}\right]\left\{\left[\begin{array}{c}
3 / 20 \\
0
\end{array}\right]+\left[\begin{array}{c}
9 / 20 \\
9 / 10
\end{array}\right]\right\}=\left[\begin{array}{cc}
1 / 3 & 0 \\
0 & 1 / 3
\end{array}\right]\left[\begin{array}{c}
3 / 5 \\
9 / 10
\end{array}\right]=\left[\begin{array}{c}
1 / 5 \\
3 / 10
\end{array}\right]
\end{aligned}
$$




$$
\begin{aligned}
& D V A_{-} F^{s r}=V A X_{-} F^{s r}+\hat{V}^{s} L^{s S} A^{s r} \sum_{t}^{G} B^{r t} Y^{t s} \\
& =\left[\begin{array}{c}
1 / 5 \\
3 / 10
\end{array}\right]+\left[\begin{array}{cc}
1 / 3 & 0 \\
0 & 1 / 3
\end{array}\right]\left[\begin{array}{cc}
3 / 2 & 3 / 4 \\
0 & 3 / 2
\end{array}\right]\left[\begin{array}{ll}
9 / 5 & 3 / 5 \\
4 / 5 & 8 / 5
\end{array}\right]\left[\begin{array}{l}
0 \\
0
\end{array}\right] \\
& =\left[\begin{array}{c}
1 / 5 \\
3 / 10
\end{array}\right]
\end{aligned}
$$

In the same way, other bilateral trade flows can be fully decomposed as reported in Table F2

This example shows that one has to be careful about defining the VAX ratios at a disaggregated level. If one were to use the definition based on forward industrial linkages proposed by Johnson and Noguera (2012), 6 out of the 12 VAX ratios at the bilateral sector level would be undefined (positive value added exports, but zero gross exports, the ratio goes to infinity, shown in Column 24 of table F2). At the aggregate bilateral level, the same VAX ratio would be undefined in 2 out of the 6 cases (rows ST and TR in Table F2). While the VAX ratio based on backward industrial linkage (computed in column 19 of Table F2) we defined in this paper is always bounded between zero and $100 \%$ for all cases. Indicating it can be used as an inverse measure of double counting at any level of disaggregation. Note that at the country aggregate level, our proposed measure coincides with the other VAX ratio. 
Table F2: Gross exports decomposition results: 3-country, 2-sector numerical example

\begin{tabular}{|c|c|c|c|c|c|c|c|c|c|c|c|c|c|c|c|c|c|c|c|c|c|c|c|}
\hline & T1 & $\mathrm{T} 2$ & $\mathbf{T 3}$ & T4 & T5-T6 & T7 & T8-10 & T11 & T12-13 & T14 & T15 & T16 & $\begin{array}{c}\text { Gross } \\
\text { exports }\end{array}$ & VAX_G & $\begin{array}{c}\% \text { of } \\
\text { VAX_G }\end{array}$ & RDV_G & DVA_G & $\begin{array}{c}\% \text { of } \\
\text { DVA_G }\end{array}$ & $\begin{array}{c}\text { VAX_F } \\
\text { J\&N }\end{array}$ & $\begin{array}{c}\text { VAX_F } \\
\text { Ratio }\end{array}$ & RDV_F & DVA_F & $\begin{array}{c}\text { DVA_F } \\
\text { Ratio }\end{array}$ \\
\hline & (1) & (2) & (3) & (4) & $(5-6)$ & (7) & $(8-10)$ & (11) & $(12-13)$ & (14) & (15) & (16) & (17) & (18) & (19) & (20) & (21) & (22) & (23) & (24) & (25) & (26) & (27) \\
\hline SR1 & $1 / 20$ & 0 & 0 & 0 & 0 & 0 & 0 & 0 & 0 & $1 / 20$ & 0 & 0 & $1 / 10$ & $1 / 20$ & $50 \%$ & 0 & $1 / 20$ & $50 \%$ & $1 / 5$ & $200 \%$ & 0 & $1 / 5$ & $200 \%$ \\
\hline SR2 & 0 & $9 / 20$ & 0 & $3 / 10$ & 0 & 0 & 0 & 0 & 0 & 0 & $3 / 20$ & $1 / 10$ & 1 & $3 / 4$ & $75 \%$ & 0 & $3 / 4$ & $75 \%$ & $3 / 10$ & $30 \%$ & 0 & $3 / 10$ & $30 \%$ \\
\hline ST1 & 0 & 0 & 0 & 0 & 0 & 0 & 0 & 0 & 0 & 0 & 0 & 0 & 0 & 0 & $0 \%$ & 0 & 0 & $0 \%$ & $1 / 10$ & $\infty$ & 0 & $1 / 10$ & $\infty$ \\
\hline ST2 & 0 & 0 & 0 & 0 & 0 & 0 & 0 & 0 & 0 & 0 & 0 & 0 & 0 & 0 & $0 \%$ & 0 & 0 & $0 \%$ & $1 / 5$ & $\infty$ & 0 & $1 / 5$ & $\infty$ \\
\hline RT1 & 0 & 0 & 0 & 0 & 0 & 0 & 0 & 0 & 0 & 0 & 0 & 0 & 0 & 0 & $0 \%$ & 0 & 0 & $0 \%$ & $1 / 5$ & $\infty$ & 0 & $1 / 5$ & $\infty$ \\
\hline RT2 & $3 / 5$ & 0 & 0 & 0 & 0 & 0 & 0 & $1 / 10$ & 0 & $3 / 10$ & 0 & 0 & 1 & $3 / 5$ & $60 \%$ & 0 & $3 / 5$ & $60 \%$ & $2 / 5$ & $40 \%$ & 0 & $2 / 5$ & $40 \%$ \\
\hline RS1 & 0 & 0 & 0 & 0 & 0 & 0 & 0 & 0 & 0 & 0 & 0 & 0 & 0 & 0 & $0 \%$ & 0 & 0 & $0 \%$ & 0 & $0 \%$ & 0 & 0 & $0 \%$ \\
\hline RS2 & 0 & 0 & 0 & 0 & 0 & 0 & 0 & 0 & 0 & 0 & 0 & 0 & 0 & 0 & $0 \%$ & 0 & 0 & $0 \%$ & 0 & $0 \%$ & 0 & 0 & $0 \%$ \\
\hline TS1 & 1 & $7 / 10$ & $3 / 20$ & $1 / 20$ & 0 & $1 / 10$ & 0 & 0 & 0 & 0 & 0 & 0 & 2 & $19 / 10$ & $95 \%$ & $1 / 10$ & 2 & $100 \%$ & $17 / 20$ & $43 \%$ & $1 / 20$ & $18 / 20$ & $45 \%$ \\
\hline TS2 & 0 & 0 & 0 & 0 & 0 & 0 & 0 & 0 & 0 & 0 & 0 & 0 & 0 & 0 & $0 \%$ & 0 & 0 & $0 \%$ & $17 / 20$ & $\infty$ & $1 / 20$ & $18 / 20$ & $\infty$ \\
\hline TR1 & 0 & 0 & 0 & 0 & 0 & 0 & 0 & 0 & 0 & 0 & 0 & 0 & 0 & 0 & $0 \%$ & 0 & 0 & $0 \%$ & $1 / 10$ & $\infty$ & 0 & $1 / 10$ & $\infty$ \\
\hline TR2 & 0 & 0 & 0 & 0 & 0 & 0 & 0 & 0 & 0 & 0 & 0 & 0 & 0 & 0 & $0 \%$ & 0 & 0 & $0 \%$ & $1 / 10$ & $\infty$ & 0 & $1 / 10$ & $\infty$ \\
\hline SR & $1 / 20$ & $9 / 20$ & 0 & $3 / 10$ & 0 & 0 & 0 & 0 & 0 & $1 / 20$ & $3 / 20$ & $1 / 10$ & $11 / 10$ & $4 / 5$ & $73 \%$ & 0 & $4 / 5$ & $73 \%$ & $1 / 2$ & $45 \%$ & 0 & $1 / 2$ & $45 \%$ \\
\hline ST & 0 & 0 & 0 & 0 & 0 & 0 & 0 & 0 & 0 & 0 & 0 & 0 & 0 & 0 & $0 \%$ & 0 & 0 & $0 \%$ & $3 / 10$ & $\infty$ & 0 & $3 / 10$ & $\infty$ \\
\hline RT & $3 / 5$ & 0 & 0 & 0 & 0 & 0 & 0 & $1 / 10$ & 0 & $3 / 10$ & 0 & 0 & 1 & $3 / 5$ & $60 \%$ & 0 & $3 / 5$ & $60 \%$ & $3 / 5$ & $60 \%$ & 0 & $3 / 5$ & $60 \%$ \\
\hline RS & 0 & 0 & 0 & 0 & 0 & 0 & 0 & 0 & 0 & 0 & 0 & 0 & 0 & 0 & $0 \%$ & 0 & 0 & $0 \%$ & 0 & $0 \%$ & 0 & 0 & $0 \%$ \\
\hline TS & 1 & $7 / 10$ & $3 / 20$ & $1 / 20$ & 0 & $1 / 10$ & 0 & 0 & 0 & 0 & 0 & 0 & 2 & $19 / 10$ & $95 \%$ & $1 / 10$ & 2 & $100 \%$ & $17 / 10$ & $85 \%$ & $1 / 10$ & $18 / 10$ & $90 \%$ \\
\hline TR & 0 & 0 & 0 & 0 & 0 & 0 & 0 & 0 & 0 & 0 & 0 & 0 & 0 & 0 & $0 \%$ & 0 & 0 & $0 \%$ & $1 / 5$ & $\infty$ & 0 & $1 / 5$ & $\infty$ \\
\hline $\mathbf{S}$ & $1 / 20$ & $9 / 20$ & 0 & $3 / 10$ & 0 & 0 & 0 & 0 & 0 & $1 / 20$ & $3 / 20$ & $1 / 10$ & $11 / 10$ & $4 / 5$ & $73 \%$ & 0 & $4 / 5$ & $73 \%$ & $4 / 5$ & $73 \%$ & 0 & $4 / 5$ & $73 \%$ \\
\hline $\mathbf{R}$ & $3 / 5$ & 0 & 0 & 0 & 0 & 0 & 0 & $1 / 10$ & 0 & $3 / 10$ & 0 & 0 & 1 & $3 / 5$ & $60 \%$ & 0 & $3 / 5$ & $60 \%$ & $3 / 5$ & $60 \%$ & 0 & $3 / 5$ & $60 \%$ \\
\hline $\mathbf{T}$ & 1 & $7 / 10$ & $3 / 20$ & $1 / 20$ & 0 & $1 / 10$ & 0 & 0 & 0 & 0 & 0 & 0 & 2 & $19 / 10$ & $95 \%$ & $1 / 10$ & 2 & $100 \%$ & $19 / 10$ & $95 \%$ & $1 / 10$ & 2 & $100 \%$ \\
\hline
\end{tabular}




\section{Note: Description of Terms in Table $\mathrm{f} 2$}

\begin{tabular}{|c|c|c|}
\hline NO. & Label & Description \\
\hline $\mathrm{T} 1$ & DVA_FIN & DVA exports in final goods exports \\
\hline $\mathrm{T} 2$ & DVA_INT & DVA in intermediate exports to the direct importer and is absorbed there \\
\hline $\mathrm{T} 3$ & DVA_INTrex1 & $\begin{array}{l}\text { DVA in intermediate exports used by the direct importer to produce } \\
\text { intermediate exports for production of third countries' domestic used final } \\
\text { goods }\end{array}$ \\
\hline $\mathrm{T} 4$ & DVA_INTrex2 & $\begin{array}{l}\text { DVA in Intermediate exports used by the direct importer producing final } \\
\text { exports to third countries }\end{array}$ \\
\hline T5 & DVA_INTrex3 & $\begin{array}{l}\text { DVA in Intermediate exports used by the direct importer producing } \\
\text { intermediate exports to third countries }\end{array}$ \\
\hline T6 & RDV_FIN1 & Returned DVA in final goods imports -from the direct importer \\
\hline $\mathrm{T} 7$ & RDV_FIN2 & Returned DVA in final goods imports -via third countries \\
\hline $\mathrm{T} 8$ & RDV_INT & Returned DVA in intermediate imports \\
\hline T9 & DDC_FIN & Double counted DVA used to produce final goods exports \\
\hline $\mathrm{T} 10$ & DDC_INT & Double counted DVA used to produce intermediate exports \\
\hline T11 & MVA_FIN & Direct importer's VA in source country's final goods exports \\
\hline $\mathrm{T} 12$ & MVA_INT & Direct importer's VA in source country's intermediate goods exports \\
\hline $\mathrm{T} 13$ & OVA_FIN & Third countries' VA in final goods exports \\
\hline $\mathrm{T} 14$ & OVA_INT & Third countries' countries' VA in intermediate goods exports \\
\hline $\mathrm{T} 15$ & MDC & Direct importer's VA double counted in exports production \\
\hline \multirow[t]{7}{*}{ T16 } & ODC & Third countries' VA double counted in exports production \\
\hline & VAX_G & Value Added Exports based on backward linkage \\
\hline & RDV_G & Returned DVA based on backward linkage \\
\hline & DVA_G & DVA embodied in gross exports based on backward linkage \\
\hline & VAX_F & Value Added Exports based on forward linkage \\
\hline & RDV_F & Returned DVA based on forward linkage \\
\hline & DVA_F & DVA embodied in gross exports based on forward linkage \\
\hline
\end{tabular}

\section{Appendix G: Derivation of Equation (24) in the main text}

Based on equation (21) in the main text, VAX_F $\mathrm{F}^{\mathrm{sr}}$ can be expressed as 


$$
\begin{aligned}
& V A X_{-} F^{s r}=\hat{V}^{s} B^{s s} Y^{s r}+\hat{V}^{s} B^{s r} Y^{r r}+\hat{V}^{s} \sum_{t \neq s, r}^{G} B^{s t} Y^{t r} \\
& =\left[\hat{V}^{s} L^{s s} Y^{s r}+\hat{V}^{s} L^{s s} A^{s r} B^{r s} Y^{s r}+\hat{V}^{s} L^{s s} \sum_{t \neq s, r}^{G} A^{s t} B^{t s} Y^{s r}\right] \\
& +\left[\hat{V}^{s} L^{s s} A^{s r} B^{r r} Y^{r r}+\hat{V}^{s} L^{s s} \sum_{t \neq s, r}^{G} A^{s t} B^{t r} Y^{r r}\right] \\
& +\left[\hat{V}^{s} L^{s s} A^{s r} \sum_{t \neq s, r}^{G} B^{r t} Y^{t r}+\hat{V}^{s} L^{s s} \sum_{u \neq s, r}^{G} A^{s u} \sum_{t \neq s, r}^{G} B^{u t} Y^{t r}\right]
\end{aligned}
$$

Rearranging equation (G1)

$$
\begin{aligned}
& V A X_{-} F^{s r}=\hat{V}^{s} L^{s s} Y^{s r}+\hat{V}^{s} L^{s s} A^{s r} \sum_{t}^{G} B^{r t} Y^{t r}++\hat{V}^{s} L^{s s} \sum_{t \neq s, r}^{G} A^{s t} \sum_{u}^{G} B^{t u} Y^{u r} \\
& =\hat{V}^{s} L^{s s} Y^{s r}+\left[\hat{V}^{s} L^{s s} A^{s r} B^{r r} Y^{r r}+\hat{V}^{s} L^{s s} A^{s r} \sum_{t \neq s, r}^{G} B^{r t} Y^{t r}+\hat{V}^{s} L^{s s} A^{s r} B^{r s} Y^{s r}\right] \\
& +\left[\hat{V}^{s} L^{s s} \sum_{t \neq s, r}^{G} A^{s t} B^{t r} Y^{r r}+\hat{V}^{s} L^{s s} \sum_{t \neq s, r}^{G} A^{s t} \sum_{u \neq s, r}^{G} B^{t u} Y^{u r}+\hat{V}^{s} L^{s s} \sum_{t \neq s, r}^{G} A^{s t} B^{t s} Y^{s r}\right]
\end{aligned}
$$

Using equations (10) and (11) in the main text, we can decompose $\mathrm{V}^{\mathrm{ss}} \mathrm{L}^{\mathrm{ss}} \mathrm{E}^{\mathrm{sr}}$ based on forward industrial linkage in G-country world as follows.

$$
\begin{aligned}
& \hat{V}^{s} L^{s s} E^{s r}=\hat{V}^{s} L^{s s} Y^{s r}+\hat{V}^{s} L^{s s} A^{s r} \sum_{t}^{G} \sum_{u}^{G} B^{r u} Y^{u t} \\
& =\hat{V}^{s} L^{s s} Y^{s r}+\hat{V}^{s} L^{s s} A^{s r} \sum_{t}^{G} B^{r t} Y^{t r}+\hat{V}^{s} L^{s s} A^{s r} \sum_{t \neq s, r}^{G} \sum_{u}^{G} B^{r u} Y^{u t}+\hat{V}^{s} L^{s s} A^{s r} \sum_{t}^{G} B^{r t} Y^{t s} \\
& =\hat{V}^{s} L^{s s} Y^{s r}+\left[\hat{V}^{s} L^{s s} A^{s r} B^{r r} Y^{r r}+\hat{V}^{s} L^{s s} A^{s r} \sum_{t \neq s, r}^{G} B^{r t} Y^{t r}+\hat{V}^{s} L^{s s} A^{s r} B^{r s} Y^{s r}\right] \\
& +\left[\hat{V}^{s} L^{s s} A^{s r} B^{r r} \sum_{t \neq s, r}^{G} Y^{r t}+\hat{V}^{s} L^{s s} A^{s r} \sum_{t \neq s, r u \neq s, r}^{G} \sum^{G} B^{r u} Y^{u t}+\hat{V}^{s} L^{s s} A^{s r} B^{r s} \sum_{t \neq s, r}^{G} Y^{s t}\right] \\
& +\left[\hat{V}^{s} L^{s s} A^{s r} B^{r r} Y^{r s}+\hat{V}^{s} L^{s s} A^{s r} \sum_{t \neq s, r}^{G} B^{r t} Y^{t s}+\hat{V}^{s} L^{s s} A^{s r} B^{r s} Y^{s s}\right]
\end{aligned}
$$

The $1^{\text {st }}$ term, $\hat{V}^{s} L^{s s} Y^{s r}$, measures GDP by sector of Country s embodied in its final goods exports to Country r. The $2^{\text {nd }}-4^{\text {th }}$ terms (the $1^{\text {st }}$ bracket) measures GDP by sector of Country $\mathrm{s}$ embodied in its intermediate exports to Country $r$ and absorbed in Country $\mathrm{r}$. The $5^{\text {th }}-7^{\text {th }}$ terms 
(the $2^{\text {nd }}$ bracket) are GDP by sector of Country s embodied in its intermediate exports to Country $\mathrm{r}$ and absorbed in third countries ( $\mathrm{t}$ ). The $8^{\text {th }}-10^{\text {th }}$ terms (the $3^{\text {rd }}$ bracket) are GDP by sector of Country s embodied in its intermediate exports to Country $r$ and ultimately returned and absorbed by Country s.

Therefore,

$$
\begin{aligned}
& \hat{V}^{s} L^{s s} E^{s r}-V A X_{-} F^{s r} \\
& =\hat{V}^{s} L^{s s} A^{s r} \sum_{t}^{G} B^{r t} Y^{t s}+\hat{V}^{s} L^{s s} A^{s r} \sum_{t \neq s, r}^{G} \sum_{u}^{G} B^{r u} Y^{u t}-\hat{V}^{s} L^{s s} \sum_{t \neq s, r}^{G} A^{s t} \sum_{u}^{G} B^{t u} Y^{u r} \\
& =\left[\hat{V}^{s} L^{s s} A^{s r} B^{r r} Y^{r s}+\hat{V}^{s} L^{s s} A^{s r} \sum_{t \neq s, r}^{G} B^{r t} Y^{t s}+\hat{V}^{s} L^{s s} A^{s r} B^{r s} Y^{s s}\right] \\
& +\left[\hat{V}^{s} L^{s s} A^{s r} B^{r r} \sum_{t \neq s, r}^{G} Y^{r t}+\hat{V}^{s} L^{s s} A^{s r} \sum_{t \neq s, r}^{G} \sum_{u \neq s, r}^{G} B^{r u} Y^{u t}+\hat{V}^{s} L^{s s} A^{s r} B^{r s} \sum_{t \neq s, r}^{G} Y^{s t}\right] \\
& -\left[\hat{V}^{s} L^{s s} \sum_{t \neq s, r}^{G} A^{s t} B^{t r} Y^{r r}+\hat{V}^{s} L^{s s} \sum_{t \neq s, r}^{G} A^{s t} \sum_{u \neq s, r}^{G} B^{t u} Y^{u r}+\hat{V}^{s} L^{s s} \sum_{t \neq s, r}^{G} A^{s t} B^{t s} Y^{s r}\right]
\end{aligned}
$$

The $1^{\text {st }}$ bracket in equation (G4) is GDP by industry of Country s embodied in its intermediate exports to Country $\mathrm{r}$ and ultimately returned and absorbed home, which are Country s' returned domestic value added in its' exports to Country r, we label it as RDV_F ${ }^{\text {sr }}$.

$$
\begin{aligned}
& R D V_{-} F^{s r}=\hat{V}^{s} L^{s s} A^{s r} B^{r r} Y^{r s}+\hat{V}^{s} L^{s s} A^{s r} \sum_{t \neq s, r}^{G} B^{r t} Y^{t s}+\hat{V}^{s} L^{s s} A^{s r} B^{r s} Y^{s s} \\
& =\hat{V}^{s} L^{s s} A^{s r} \sum_{u \neq s}^{G} B^{r u} Y^{u s}+\hat{V}^{s} L^{s s} A^{s r} B^{r s} Y^{s s}=\hat{V}^{s} L^{s s} A^{s r} \sum_{u}^{G} B^{r u} Y^{u s}
\end{aligned}
$$

The $2^{\text {nd }}$ bracket in equation (G4) is GDP by industry of Country s embodied in its intermediate exports to Country $\mathrm{r}$ and absorbed by the third country ( $\mathrm{t}$. The $3^{\text {rd }}$ bracket in equation (G4) are GDP by industry of Country s embodied in its intermediate exports to the third country (t) and absorbed by Country $r$. Summing up equation (G4) over all trade partners, the terms in $2^{\text {nd }}$ bracket and the terms in $3^{\text {rd }}$ bracket will equal each other and are cancelled at country-sector level. 


$$
\begin{aligned}
& \hat{V}^{s} L^{s s} \sum_{r \neq s}^{G} E^{s r}-\sum_{r \neq s}^{G} V A X_{-} F^{s r} \\
& =\sum_{r \neq s}^{G} R D V_{-} F^{s r}+\hat{V}^{s} L^{s s} \sum_{r \neq s}^{G} A^{s r} \sum_{u}^{G} B^{r u} \sum_{t \neq s, r}^{G} Y^{u t}-\hat{V}^{s} L^{s s} \sum_{t \neq s, r}^{G} A^{s t} \sum_{u}^{G} B^{t u} \sum_{r \neq s}^{G} Y^{u r} \\
& =\sum_{r \neq s}^{G} R D V_{-} F^{s r}+\hat{V}^{s} L^{s s} \sum_{r \neq s}^{G} A^{s r} \sum_{u}^{G} B^{r u} \sum_{t \neq s, r}^{G} Y^{u t}-\hat{V}^{s} L^{s s} \sum_{t \neq s}^{G} A^{s t} \sum_{u}^{G} B^{t u} \sum_{r \neq s, t}^{G} Y^{u r} \\
& =\sum_{r \neq s}^{G} R D V_{-} F^{s r}
\end{aligned}
$$

Rearranging equation (G6)

$$
\hat{V}^{s} L^{s s} \sum_{r \neq s}^{G} E^{s r}=\sum_{r \neq s}^{G} V A X_{-} F^{s r}+\sum_{r \neq s}^{G} R D V_{-} F^{s r}=\sum_{r \neq s}^{G} D V A_{-} F^{s r}
$$

Therefore, DVA_F or VLE based on forward linkage are equal VAX_F + RDV_F at country-aggregate level.

We can also decompose $\mathrm{V}^{\mathrm{ss}} \mathrm{L}^{\mathrm{ss}} \mathrm{E}^{\mathrm{sr}}$ based on backward industrial linkage in G-country world as follows.

$$
\begin{aligned}
& \left(V^{s} L^{s s}\right)^{T} \# E^{s r}=\left(V^{s} L^{s s}\right)^{T} \# Y^{s r}+\left(V^{s} L^{s s}\right)^{T} \#\left(A^{s r} B^{r r} Y^{r r}+A^{s r} \sum_{t \neq s, r}^{G} B^{r t} Y^{t r}+A^{s r} B^{r s} Y^{s r}\right) \\
& +\left(V^{s} L^{s s}\right)^{T} \#\left(A^{s r} \sum_{u \neq s, r}^{G} B^{r u} \sum_{t \neq s, r}^{G} Y^{u t}+A^{s r} B^{r r} \sum_{t \neq s, r}^{G} Y^{r t}+A^{s r} B^{r s} \sum_{t \neq s, r}^{G} Y^{s t}\right) \\
& +\left(V^{s} L^{s s}\right)^{T} \#\left(A^{s r} B^{r r} Y^{r s}+A^{s r} \sum_{t \neq s, r}^{G} B^{r t} Y^{t s}+A^{s r} B^{r s} Y^{s s}\right) \\
& =\left(V^{s} L^{s s}\right)^{T} \# Y^{s r}+\left(V^{s} L^{s s}\right)^{T} \#\left(A^{s r} B^{r r} Y^{r r}+A^{s r} \sum_{t \neq s, r}^{G} B^{r t} Y^{t t}\right) \\
& +\left(V^{s} L^{s s}\right)^{T} \#\left(A^{s r} B^{r r} \sum_{t \neq s, r}^{G} Y^{r t}+A^{s r} \sum_{t \neq s, r}^{G} B^{r t} \sum_{u \neq s, t}^{G} Y^{t u}\right) \\
& +\left(V^{s} L^{s s}\right)^{T} \#\left(A^{s r} B^{r r} Y^{r s}+A^{s r} \sum_{t \neq s, r}^{G} B^{r t} Y^{t s}+A^{s r} B^{r s} Y^{s s}+A^{s r} \sum_{t \neq s}^{G} B^{r s} Y^{s t}\right)
\end{aligned}
$$

It shows that VLE can be decomposed into four parts: domestic value added embodied in final goods exports, and domestic value-added embodied in intermediate goods that are finally absorbed in the direct importing country r, returned to the exporting country s, and re-exported to third countries $t$, respectively. Domestic value-added in these terms not only include value-added from the exporting sectors, but also other domestic sectors that contributes to the 
production of a particular sector's gross exports.

Based on equation (19) in the main text, VAX_G ${ }^{\text {sr }}$ can be expressed as

$$
\begin{aligned}
& V A X_{-} G^{s r}=\left(V^{s} L^{s s}\right)^{T} \# Y^{s r}+\left(V^{s} L^{s s}\right)^{T} \#\left(A^{s r} B^{r r} Y^{r r}+A^{s r} \sum_{t \neq s, r}^{G} B^{r t} Y^{t t}\right) \\
& +\left(V^{s} L^{s s}\right)^{T} \#\left(A^{s r} B^{r r} \sum_{t \neq s, r}^{G} Y^{r t}+A^{s r} \sum_{t \neq s, r}^{G} B^{r t} \sum_{u \neq s, t}^{G} Y^{t u}\right)
\end{aligned}
$$

Where

$$
\begin{aligned}
& \left(V^{s} B^{s s}\right)^{T} \# Y^{s r}=\left(V^{s} L^{s s}\right)^{T} \# Y^{s r}+\left(V^{s} B^{s s}-V^{s} L^{s s}\right)^{T} \# Y^{s r} \\
& =\left(V^{s} L^{s s}\right)^{T} \# Y^{s r}+\left(V^{s} L^{s s} A^{s r} B^{r s}\right)^{T} \# Y^{s r}+\left(V^{s} L^{s s} \sum_{t \neq s, r}^{G} A^{s t} B^{t s}\right)^{T} \# Y^{s r}
\end{aligned}
$$

Inserting equation (G10) into equation (G9)

$$
\begin{aligned}
& V A X_{-} G^{s r}=\left(V^{s} L^{s s}\right)^{T} \# Y^{s r}+\left(V^{s} L^{s s} A^{s r} B^{r s}\right)^{T} \# Y^{s r}+\left(V^{s} L^{s s} \sum_{t \neq s, r}^{G} A^{s t} B^{t s}\right)^{T} \# Y^{s r} \\
& +\left(V^{s} L^{s s}\right)^{T} \#\left(A^{s r} B^{r r} Y^{r r}\right)+\left(V^{s} L^{s s}\right)^{T} \#\left(A^{s r} \sum_{t \neq s, r}^{G} B^{r t} Y^{t t}\right) \\
& +\left(V^{s} L^{s s}\right)^{T} \#\left(A^{s r} B^{r r} \sum_{t \neq s, r}^{G} Y^{r t}\right)+\left(V^{s} L^{s s}\right)^{T} \#\left(A^{s r} \sum_{t \neq s, r}^{G} B^{r t} \sum_{u \neq s, t}^{G} Y^{t u}\right)
\end{aligned}
$$

(G11)

Therefore

$$
\begin{aligned}
& \left(V^{s} L^{s s}\right)^{T} \# E^{s r}-V A X_{-} G^{s r} \\
& =\left(V^{s} L^{s s}\right)^{T} \#\left(A^{s r} B^{r r} Y^{r s}\right)+\left(V^{s} L^{s s}\right)^{T} \#\left(A^{s r} \sum_{t \neq s, r}^{G} B^{r t} Y^{t s}\right)+\left(V^{s} L^{s s}\right)^{T} \#\left(A^{s r} B^{r s} Y^{s s}\right) \\
& +\left[\left(V^{s} L^{s s}\right)^{T} \#\left(A^{s r} B^{r s} Y^{s r}\right)+\left(V^{s} L^{s s}\right)^{T} \#\left(A^{s r} \sum_{t \neq s, r}^{G} B^{r s} Y^{s t}\right)\right] \\
& -\left[\left(V^{s} L^{s s} A^{s r} B^{r s}\right)^{T} \# Y^{s r}+\left(V^{s} L^{s s} \sum_{t \neq s, r}^{G} A^{s t} B^{t s}\right)^{T} \# Y^{s r}\right]
\end{aligned}
$$

The first three terms of equation (G12) are Country s' returned value added in its' sectoral exports to Country r, are exactly the sum of the $6^{\text {th }}-8^{\text {th }}$ terms in equation (18), we named it RDV_G ${ }^{\text {sr }}$.

$$
R D V_{-} G^{s r}=\left(V^{s} L^{s s}\right)^{T} \#\left(A^{s r} B^{r r} Y^{r s}\right)+\left(V^{s} L^{s s}\right)^{T} \#\left(A^{s r} \sum_{l \neq s, r}^{G} B^{r t} Y^{t s}\right)+\left(V^{s} L^{s s}\right)^{T} \#\left(A^{s r} B^{r s} Y^{s s}\right)
$$


The $4^{\text {th }}-5^{\text {th }}$ terms (in the $1^{\text {st }}$ bracket) of equation (G12) are Country s' value added in its' sectoral intermediate exports to Country $r$ and then returned Country $s$ for production of its final exports. The $6^{\text {th }} 7^{\text {th }}$ terms (in the $2^{\text {nd }}$ bracket) of equation (G12) are Country s' value added in its' gross intermediate exports and returned Country s for production of its sectoral final exports to Country $r$.

Therefore

$$
\begin{aligned}
& \left(V^{s} L^{s s}\right)^{T} \# E^{s r}-V A X_{-} G^{s r} \\
& =R D V_{-} G^{s r}+\left(V^{s} L^{s s}\right)^{T} \#\left(A^{s r} \sum_{t \neq s}^{G} B^{r s} Y^{s t}\right)-\left(V^{s} L^{s s} \sum_{t \neq s}^{G} A^{s t} B^{t s}\right)^{T} \# Y^{s r}
\end{aligned}
$$

In 3-country and 2-sector case, the $1^{\text {st }}$ sector of equation (G14) can be expressed as

$$
\begin{aligned}
& V^{s} L^{s s} E_{1}^{s r}-v a x_{-} g_{1}^{s r}-r d v_{-} b_{1}^{s r} \\
& =\left[\begin{array}{ll}
v_{1}^{s} & v_{2}^{s r}
\end{array}\right]\left[\begin{array}{ll}
l_{11}^{s s} & l_{12}^{s s} \\
l_{21}^{s s} & l_{22}^{s s}
\end{array}\right]\left\{\left[\begin{array}{cc}
a_{11}^{s r} & a_{12}^{s r} \\
0 & 0
\end{array}\right]\left[\begin{array}{ll}
b_{11}^{r s} & b_{12}^{r s} \\
b_{21}^{r s} & b_{22}^{r s}
\end{array}\right]\left[\begin{array}{c}
y_{1}^{s r} \\
y_{2}^{s r}
\end{array}\right]+\left[\begin{array}{cc}
a_{11}^{s r} & a_{12}^{s r} \\
0 & 0
\end{array}\right]\left[\begin{array}{ll}
b_{11}^{r s} & b_{12}^{r s} \\
b_{21}^{r s} & b_{22}^{r s}
\end{array}\right]\left[\begin{array}{c}
y_{1}^{s t} \\
y_{2}^{s t}
\end{array}\right]\right\} \\
& -\left[\begin{array}{ll}
v_{1}^{s} & v_{2}^{s t}
\end{array}\right]\left[\begin{array}{ll}
l_{11}^{s s} & l_{12}^{s s} \\
l_{21}^{s s} & l_{22}^{s s}
\end{array}\right]\left\{\left[\begin{array}{ll}
a_{11}^{s r} & a_{12}^{s r} \\
a_{21}^{s r} & a_{22}^{r r}
\end{array}\right]\left[\begin{array}{ll}
b_{11}^{r s} & b_{12}^{r s} \\
b_{21}^{r s} & b_{22}^{r s}
\end{array}\right]\left[\begin{array}{c}
y_{1}^{s r} \\
0
\end{array}\right]+\left[\begin{array}{ll}
a_{11}^{s t} & a_{12}^{s t} \\
a_{21}^{s t} & a_{22}^{s t}
\end{array}\right]\left[\begin{array}{ll}
b_{11}^{t s} & b_{12}^{t s} \\
b_{21}^{t s} & b_{22}^{t s}
\end{array}\right]\left[\begin{array}{c}
y_{1}^{s r} \\
0
\end{array}\right]\right\}
\end{aligned}
$$

In equation (G15), the $1^{\text {st }}$ term is domestic value added embodied in the $1^{\text {st }}$ sector's intermediate exports from Country s to Country $r$ and returned Country s for production of its final exports from both sectors. The $2^{\text {nd }}$ term is domestic value added embodied in the Country s' gross intermediate exports and return to Country s for production of its $1^{\text {st }}$ sector's final exports to Country r. Obviously, the $1^{\text {st }}$ term and the $2^{\text {nd }}$ term are not equal each other in general.

Similarly, the $2^{\text {nd }}$ sector of equation (G15) can be expressed as

$$
\begin{aligned}
& V^{s} L^{s s} E_{2}^{s r}-\left[v a x_{-} g_{2}^{s r}+r d v_{-} g_{2}^{s r}\right] \\
& =\left[\begin{array}{ll}
v_{1}^{s} & v_{2}^{s}
\end{array}\right]\left[\begin{array}{ll}
l_{11}^{s s} & l_{12}^{s s} \\
l_{21}^{s s} & l_{22}^{s s}
\end{array}\right]\left\{\left[\begin{array}{cc}
0 & 0 \\
a_{21}^{s r} & a_{22}^{s r}
\end{array}\right]\left[\begin{array}{ll}
b_{11}^{r s} & b_{12}^{r s} \\
b_{21}^{r s} & b_{22}^{r s}
\end{array}\right]\left[\begin{array}{c}
y_{1}^{s r} \\
y_{2}^{s r}
\end{array}\right]+\left[\begin{array}{cc}
0 & 0 \\
a_{21}^{s r} & a_{22}^{s r}
\end{array}\right]\left[\begin{array}{ll}
b_{11}^{r s} & b_{12}^{r s} \\
b_{21}^{r s} & b_{22}^{r s}
\end{array}\right]\left[\begin{array}{c}
y_{1}^{s t} \\
y_{2}^{s t}
\end{array}\right]\right\} \\
& -\left[\begin{array}{ll}
v_{1}^{s s} & v_{2}^{s}
\end{array}\right]\left[\begin{array}{ll}
l_{11}^{s s} & l_{12}^{s s} \\
l_{21}^{s s} & l_{22}^{s s}
\end{array}\right]\left\{\left[\begin{array}{ll}
a_{11}^{s r} & a_{12}^{s r} \\
a_{21}^{s r} & a_{22}^{s r}
\end{array}\right]\left[\begin{array}{ll}
b_{11}^{r s} & b_{12}^{r r} \\
b_{21}^{r s} & b_{22}^{r s}
\end{array}\right]\left[\begin{array}{c}
0 \\
y_{2}^{s r}
\end{array}\right]+\left[\begin{array}{ll}
a_{11}^{s t} & a_{12}^{s t} \\
a_{21}^{s t} & a_{22}^{s t}
\end{array}\right]\left[\begin{array}{ll}
b_{11}^{t s} & b_{12}^{t s} \\
b_{21}^{t s} & b_{22}^{t s}
\end{array}\right]\left[\begin{array}{c}
0 \\
y_{2}^{s r}
\end{array}\right]\right\}
\end{aligned}
$$

Summing up equation (G15) and (16) 
$V^{s} L^{s s} E^{s r}-\left[u V A X_{-} G^{s r}+u R D V_{-} G^{s r}\right]$

$=\left[V^{s} L^{s s} E_{1}^{s r}+V^{s} L^{s s} E_{2}^{s r}\right]-\left[v a x_{-} g_{1}^{s r}+r d v_{-} b_{1}^{s r}+v a x_{-} g_{2}^{s r}+r d v_{-} b_{2}^{s r}\right]$

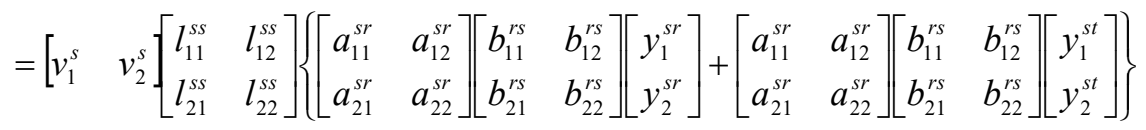

$-\left[\begin{array}{ll}v_{1}^{s} & v_{2}^{s}\end{array}\left[\begin{array}{ll}l_{11}^{s s} & l_{12}^{s s} \\ l_{21}^{s s} & l_{22}^{s s}\end{array}\right]\left\{\left[\begin{array}{ll}a_{11}^{s r} & a_{12}^{s r} \\ a_{21}^{s r} & a_{22}^{s r}\end{array}\right]\left[\begin{array}{ll}b_{11}^{r s} & b_{12}^{r s} \\ b_{21}^{r s} & b_{22}^{r s}\end{array}\right]\left[\begin{array}{l}y_{1}^{s r} \\ y_{2}^{s r}\end{array}\right]+\left[\begin{array}{ll}a_{11}^{s t} & a_{12}^{s t} \\ a_{21}^{s t} & a_{22}^{s t}\end{array}\right]\left[\begin{array}{ll}b_{11}^{t s} & b_{12}^{t s} \\ b_{21}^{t s} & b_{22}^{t s}\end{array}\right]\left[\begin{array}{l}y_{1}^{s r} \\ y_{2}^{s r}\end{array}\right]\right\}\right.$

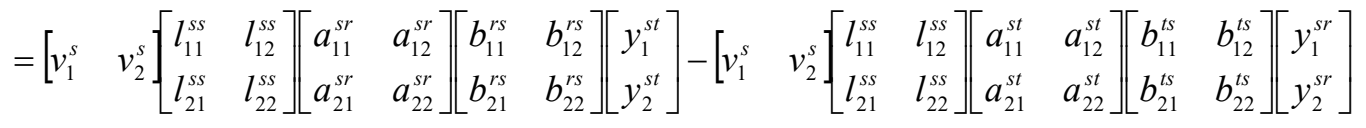

Or

$u\left(V^{s} L^{s s}\right)^{T} \# E^{s r}-u V A X_{-} G^{s r}-u R D V V_{-} G^{s r}$

$=\left[V^{s} L^{s s} A^{s r} B^{r s} Y^{s r}+V^{s} L^{s s} A^{s r} B^{r s} Y^{s t}\right]-\left[V^{s} L^{s s} A^{s r} B^{r s} Y^{s r}+V^{s} L^{s s} A^{s t} B^{t s} Y^{s r}\right]$

$=V^{s} L^{s s} A^{s r} B^{r s} Y^{s t}-V^{s} L^{s s} A^{s t} B^{t s} Y^{s r}$

$u D V A A_{-} G^{s r}$ doesn't equal to sum of $u V A X X_{-} G^{s r}$ and $u R D V{ }_{-} G^{s r}$ at bilateral aggregate level

Summing up equation D15 over all trading partners,

$\left[V^{s} L^{s s} E_{1}^{s r}+V^{s} L^{s s} E_{2}^{s r}\right]-\left[v a x_{-} g_{1}^{s r}+r d v_{-} g_{1}^{s r}+v a x_{2} g_{2}^{s r}+r d v_{-} g_{2}^{s r}\right]$

$=\left[\begin{array}{ll}v_{1}^{s} & v_{2}^{s}\end{array}\right]\left[\begin{array}{ll}l_{11}^{s s} & l_{12}^{s s} \\ l_{21}^{s s} & l_{22}^{s s}\end{array}\right]\left\{\left[\begin{array}{cc}a_{11}^{s r} & a_{12}^{s r} \\ 0 & 0\end{array}\right]\left[\begin{array}{cc}b_{11}^{r s} & b_{12}^{r s} \\ b_{21}^{r s} & b_{22}^{r s}\end{array}\right]\left[\begin{array}{l}y_{1}^{s r} \\ y_{2}^{s r}\end{array}\right]+\left[\begin{array}{cc}a_{11}^{s r} & a_{12}^{s r} \\ 0 & 0\end{array}\right]\left[\begin{array}{ll}b_{11}^{r s} & b_{12}^{r s} \\ b_{21}^{r s} & b_{22}^{r s}\end{array}\right]\left[\begin{array}{l}y_{1}^{s t} \\ y_{2}^{s t}\end{array}\right]\right\}$

$-\left[\begin{array}{ll}v_{1}^{s} & v_{2}^{s}\end{array}\right]\left[\begin{array}{ll}l_{11}^{s s} & l_{12}^{s s} \\ l_{21}^{s s} & l_{22}^{s s}\end{array}\right]\left\{\left[\begin{array}{ll}a_{11}^{s r} & a_{12}^{s r} \\ a_{21}^{s r} & a_{22}^{s r}\end{array}\right]\left[\begin{array}{ll}b_{11}^{r s} & b_{12}^{r s} \\ b_{21}^{r s} & b_{22}^{r s}\end{array}\right]\left[\begin{array}{c}y_{1}^{s r} \\ 0\end{array}\right]+\left[\begin{array}{ll}a_{11}^{s t} & a_{12}^{s t} \\ a_{21}^{s t} & a_{22}^{s t}\end{array}\right]\left[\begin{array}{ll}b_{11}^{t s} & b_{12}^{t s} \\ b_{21}^{t s} & b_{22}^{t s}\end{array}\right]\left[\begin{array}{c}y_{1}^{s r} \\ 0\end{array}\right]\right\}$

$+\left[\begin{array}{ll}v_{1}^{s} & v_{2}^{s} \\ l_{11}^{s s} & l_{12}^{s s} \\ l_{21}^{s s} & l_{22}^{s s}\end{array}\right]\left\{\left[\begin{array}{cc}a_{11}^{s t} & a_{12}^{s t} \\ 0 & 0\end{array}\right]\left[\begin{array}{cc}b_{11}^{t s} & b_{12}^{t s} \\ b_{21}^{t s} & b_{22}^{t s}\end{array}\right]\left[\begin{array}{c}y_{1}^{s t} \\ y_{2}^{s t}\end{array}\right]+\left[\begin{array}{cc}a_{11}^{s t} & a_{12}^{s t} \\ 0 & 0\end{array}\right]\left[\begin{array}{ll}b_{11}^{t s} & b_{12}^{t s} \\ b_{21}^{t s} & b_{22}^{t s}\end{array}\right]\left[\begin{array}{c}y_{1}^{s r} \\ y_{2}^{s r}\end{array}\right]\right\}$

$-\left[\begin{array}{ll}v_{1}^{s} & v_{2}^{s} \\ l_{11}^{s s} & l_{12}^{s s} \\ l_{21}^{s s} & l_{22}^{s s}\end{array}\right]\left[\left\{\left[\begin{array}{ll}a_{11}^{s t} & a_{12}^{s t} \\ a_{21}^{s t} & a_{22}^{s t}\end{array}\right]\left[\begin{array}{ll}b_{11}^{t s} & b_{12}^{t s} \\ b_{21}^{s s} & b_{22}^{t s}\end{array}\right]\left[\begin{array}{c}y_{1}^{s t} \\ 0\end{array}\right]+\left[\begin{array}{ll}a_{11}^{s r} & a_{12}^{s r} \\ a_{21}^{s r} & a_{22}^{s r}\end{array}\right]\left[\begin{array}{ll}b_{11}^{r s} & b_{12}^{r s} \\ b_{21}^{r s} & b_{22}^{r s}\end{array}\right]\left[\begin{array}{c}y_{1}^{s t} \\ 0\end{array}\right]\right\}\right.$

$=\left[\begin{array}{ll}v_{1}^{s} & v_{2}^{s}\end{array}\right]\left[\begin{array}{ll}l_{11}^{s s} & l_{12}^{s s} \\ l_{21}^{s s} & l_{22}^{s s}\end{array}\right]\left\{\left[\begin{array}{cc}a_{11}^{s r} & a_{12}^{s r} \\ 0 & 0\end{array}\right]\left[\begin{array}{cc}b_{11}^{r s} & b_{12}^{r s} \\ b_{21}^{r s} & b_{22}^{r s}\end{array}\right]\left[\begin{array}{c}y_{1}^{s r} \\ 0\end{array}\right]+\left[\begin{array}{cc}a_{11}^{s r} & a_{12}^{s r} \\ 0 & 0\end{array}\right]\left[\begin{array}{cc}b_{11}^{r s} & b_{12}^{r s} \\ b_{21}^{r s} & b_{22}^{r s}\end{array}\right]\left[\begin{array}{c}0 \\ y_{2}^{s t}\end{array}\right]\right\}$

$-\left[\begin{array}{ll}v_{1}^{s} & v_{2}^{s}\end{array}\right]\left[\begin{array}{ll}l_{11}^{s s} & l_{12}^{s s} \\ l_{21}^{s s} & l_{22}^{s s}\end{array}\right]\left\{\left[\begin{array}{cc}0 & 0 \\ a_{21}^{s r} & a_{22}^{s s}\end{array}\right]\left[\begin{array}{cc}b_{11}^{r s} & b_{12}^{r s} \\ b_{21}^{r s} & b_{22}^{r s}\end{array}\right]\left[\begin{array}{c}y_{1}^{s r} \\ 0\end{array}\right]+\left[\begin{array}{cc}0 & 0 \\ a_{21}^{s t} & a_{22}^{s t}\end{array}\right]\left[\begin{array}{ll}b_{11}^{t s} & b_{12}^{t s} \\ b_{21}^{t s} & b_{22}^{t s}\end{array}\right]\left[\begin{array}{c}y_{1}^{s r} \\ 0\end{array}\right]\right\}$

$\left.+\left[\begin{array}{ll}v_{1}^{s} & v_{2}^{s} \\ l_{21}^{s s} & l_{22}^{s s}\end{array}\right]\left[\begin{array}{cc}l_{12}^{s s} \\ l^{s s}\end{array}\right]\left[\begin{array}{cc}a_{11}^{s t} & a_{12}^{s t} \\ 0 & 0\end{array}\right]\left[\begin{array}{ll}b_{11}^{t s} & b_{12}^{t s} \\ b_{21}^{t s} & b_{22}^{t s}\end{array}\right]\left[\begin{array}{c}0 \\ y_{2}^{s t}\end{array}\right]+\left[\begin{array}{cc}a_{11}^{s t} & a_{12}^{s t} \\ 0 & 0\end{array}\right]\left[\begin{array}{cc}b_{11}^{t s} & b_{12}^{t s} \\ b_{21}^{t s} & b_{22}^{t s}\end{array}\right]\left[\begin{array}{c}0 \\ y_{2}^{s r}\end{array}\right]\right\}$

(G19)

$-\left[\begin{array}{ll}v_{1}^{s} & v_{2}^{s s}\end{array}\left[\begin{array}{ll}l_{11}^{s s} & l_{12}^{s s} \\ l_{21}^{s s} & l_{22}^{s s}\end{array}\right]\left\{\left[\begin{array}{cc}0 & 0 \\ a_{21}^{s t} & a_{22}^{s t}\end{array}\right]\left[\begin{array}{cc}b_{11}^{t s} & b_{12}^{t s} \\ b_{21}^{s} & b_{22}^{t s}\end{array}\right]\left[\begin{array}{c}y_{1}^{s t} \\ 0\end{array}\right]+\left[\begin{array}{cc}0 & 0 \\ a_{21}^{s r} & a_{22}^{s r}\end{array}\right]\left[\begin{array}{cc}b_{11}^{r s} & b_{12}^{r s} \\ b_{21}^{r s} & b_{22}^{r s}\end{array}\right]\left[\begin{array}{c}y_{1}^{s t} \\ 0\end{array}\right]\right\}\right.$ 
$\sum_{r \neq s}^{G} D V A_{-} G^{s r}$ doesn't equal to the sum of $\sum_{r \neq s}^{G} V A X_{-} G^{s r}$ and $\sum_{r \neq s}^{G} R D V V_{-} G^{s r}$ at country-sector level

Summing up the last two terms in equation D19 over all trading partners, we have:

$$
\begin{aligned}
& \sum_{s \neq r}^{G} V^{s} L^{s s} E^{s r}-\sum_{r \neq s}^{G}\left(u V A X_{-} G^{s r}+u R D V_{-} G^{s r}\right) \\
& =\left[\begin{array}{ll}
v_{1}^{s r} & v_{2}^{s}
\end{array}\right]\left[\begin{array}{ll}
l_{11}^{s s} & l_{12}^{s s} \\
l_{21}^{s s} & l_{22}^{s s}
\end{array}\right]\left[\begin{array}{ll}
a_{11}^{s r} & a_{12}^{s r} \\
a_{21}^{s r} & a_{22}^{s r}
\end{array}\right]\left[\begin{array}{ll}
b_{11}^{r s} & b_{12}^{r s} \\
b_{21}^{r s} & b_{22}^{r s}
\end{array}\right]\left[\begin{array}{l}
y_{1}^{s t} \\
y_{2}^{s t}
\end{array}\right]-\left[\begin{array}{ll}
v_{1}^{s} & v_{2}^{s}
\end{array}\right]\left[\begin{array}{ll}
l_{11}^{s s} & l_{12}^{s s} \\
l_{21}^{s s} & l_{22}^{s s}
\end{array}\right]\left[\begin{array}{ll}
a_{11}^{s t} & a_{12}^{s t} \\
a_{21}^{s t} & a_{22}^{s t}
\end{array}\right]\left[\begin{array}{ll}
b_{11}^{t s} & b_{12}^{t s} \\
b_{21}^{t s} & b_{22}^{t s}
\end{array}\right]\left[\begin{array}{l}
y_{1}^{s r} \\
y_{2}^{s r}
\end{array}\right](\mathrm{G} 20) \\
& +\left[\begin{array}{ll}
v_{1}^{s} & v_{2}^{s}
\end{array}\right]\left[\begin{array}{ll}
l_{11}^{s s} & l_{12}^{s s} \\
l_{21}^{s s} & l_{22}^{s s}
\end{array}\right]\left[\begin{array}{ll}
a_{11}^{s t} & a_{12}^{s t} \\
a_{21}^{s t} & a_{22}^{s t}
\end{array}\right]\left[\begin{array}{ll}
b_{11}^{t s} & b_{12}^{t s} \\
b_{21}^{t s} & b_{22}^{t s}
\end{array}\right]\left[\begin{array}{l}
y_{1}^{s r} \\
y_{2}^{s r}
\end{array}\right]-\left[\begin{array}{ll}
v_{1}^{s} & v_{2}^{s}
\end{array}\right]\left[\begin{array}{ll}
l_{11}^{s s} & l_{12}^{s s} \\
l_{21}^{s s} & l_{22}^{s s}
\end{array}\right]\left[\begin{array}{ll}
a_{11}^{s r} & a_{12}^{s r} \\
a_{21}^{s r} & a_{22}^{s r}
\end{array}\right]\left[\begin{array}{ll}
b_{11}^{r s} & b_{12}^{r s} \\
b_{21}^{r s} & b_{22}^{r s}
\end{array}\right]\left[\begin{array}{l}
y_{1}^{s t} \\
y_{2}^{s t}
\end{array}\right] \\
& =0
\end{aligned}
$$

Therefore.

$$
\sum_{r \neq s}^{G} \mu D V A_{-} G^{s r}=\sum_{r \neq s}^{G}\left(\mu V A X_{-} G^{s r}+\mu R D V_{-} G^{s r}\right)=\sum_{s \neq r}^{G} V^{s} L^{s s} E^{s r}
$$

\section{Table A3 WIOD Country/Region}

\begin{tabular}{|l|l|l|l|}
\hline Label & Country & Label & Country \\
\hline AUS & Australia & IRL & Ireland \\
\hline AUT & Austria & ITA & Italy \\
\hline BEL & Belgium & JPN & Japan \\
\hline BGR & Bulgaria & KOR & South Korea \\
\hline BRA & Brazil & LTU & Lithuania \\
\hline CAN & Canada & LUX & Luxembourg \\
\hline CHN & China & LVA & Latvia \\
\hline CYP & Cyprus & MEX & Mexico \\
\hline CZE & Czech Republic & MLT & Malta \\
\hline DEU & Germany & NLD & Netherlands \\
\hline DNK & Denmark & POL & Poland \\
\hline ESP & Spain & PRT & Portugal \\
\hline EST & Estonia & ROM & Romania \\
\hline FIN & Finland & RUS & Russia \\
\hline
\end{tabular}




\begin{tabular}{|l|l|l|l|} 
FRA & France & SVK & Slovak Republic \\
\hline GBR & $\begin{array}{l}\text { United } \\
\text { Kingdom }\end{array}$ & SVN & Slovenia \\
\hline GRC & Greece & SWE & Sweden \\
\hline HUN & Hungary & TUR & Turkey \\
\hline IDN & Indonesia & TWN & Taiwan \\
\hline IND & India & USA & United States \\
\hline
\end{tabular}

